\title{
Population dynamics and pathogens of the invasive yellow crazy ant (Anoplolepis gracilipes) in Arnhem Land, Australia
}

\author{
by \\ Meghan Dawn Cooling
}

\author{
A thesis submitted to \\ Victoria University of Wellington \\ in fulfillment of the requirements for the degree of \\ Doctor of Philosophy \\ in Ecology and Biodiversity
}

Victoria University of Wellington

Te Whare Wānanga o te Ūpoko o te Ika a Māui 

This thesis was conducted under the supervision of

Professor Phil J. Lester (primary supervisor)

Victoria University of Wellington

Wellington, New Zealand

and

Dr. Benjamin D. Hoffmann (secondary supervisor)

CSIRO Land and Water Flagship, Tropical Ecosystems Research Centre

Winnellie, Northern Territory, Australia 


\section{Abstract}

Though many populations of introduced species have been observed to collapse, the reasons behind these declines are seldom investigated. Anoplolepis gracilipes is considered among one of the top six most economically and ecologically damaging invasive ant species in the world. However, introduced populations of A. gracilipes have been observed to decline. My overall aims in this thesis were to document $A$. gracilipes population declines, to investigate the possibility that pathogens were playing a role in the observed population declines, and to identify putative pathogens infecting A. gracilipes as potential candidates for biocontrol agents.

I documented the observed A. gracilipes population declines that were the driving force for this project. I detailed large-scale reductions in the spatial extent of four populations with before and after survey data. I also presented data on three populations that were recorded as present, but disappeared before they could be spatially delimited. I speculated on the possible reasons for these declines and explained why I do not think other explanations are likely. I then investigated the hypothesis that a pathogen or parasite is affecting A. gracilipes queens in declining Arnhem Land populations. I did this in three ways: 1) based on preliminary findings, I looked at the effect of an artificial fungal infection on $A$. gracilipes reproduction. I compared reproductive output between control colonies and those treated with either a fungal entomopathogen (Metarhizium anisopliae) or fungicidal antibiotics. There was no correlation between either treatment and the number of eggs, larvae, pupae or males a colony produced after 70 days. I found queen number had no effect on colony reproductive output, suggesting that queens are able to adjust their egg-laying rate in the presence of other queens. I found no evidence that $M$. anisopliae affected reproductive output at the tested concentrations; 2) I explored the hypothesis that a pathogen that kills or affects the reproductive output of $A$. gracilipes queens is the mechanism or reason behind the population declines. I measured queen number per nest, egg-laying rate, fecundity and fat content and compared them between sites in different stages of decline or expansion (population types, consisting of low, medium and high-density populations). I discovered that $23 \%$ of queens had melanized 


\begin{abstract}
nodules, a cellular immune response in insects, in their ovaries or fat bodies. The presence of nodules was correlated with a $22 \%$ decrease in the number of oocytes per ovary; however, nodule presence was not associated with population type, suggesting that though there are clearly pathogens or parasites capable of penetrating the cuticle of A. gracilipes, they are unlikely to be responsible for the observed population declines; 3) I compared microbial communities (bacteria and viruses) between queens from different population types. I found viral sequences that match to the Dicistroviridae family of viruses in low and medium-density populations. I found no differences in bacterial community structure between population types. The presence of sequences similar to the entomopathogens Rhabdochlamydia and Serratia marcescens, as well as the reproductive parasite Cardinium in A.gracilipes, deserves further investigation.
\end{abstract}

Though introduced species' populations have been observed to decline, this is one of the first studies to quantitatively examine, document, and investigate a mechanism behind such a decline. Understanding the mechanisms by which an invader declines may have important implications for invasive ant management worldwide. 


\section{Acknowledgements}

First and foremost I would like to thank my supervisor Professor Dr. Phil Lester for never failing to provide good advice and be calming and reassuring when needed. Without Phil's support I never would have done a PhD.

Thank you as well to my amazing Aussie supervisor Dr. Ben Hoffmann, whose unfailing energy, motivation and organizational abilities made my field work in Nhulunbuy not only possible but a lot of fun. Also thanks for not laughing too hard at my first attempts to excavate a yellow crazy ant nest Ben.

I would also like to thank Dr. Keith Wade, one of my first biology teachers at Capilano University. Without his vast enthusiasm for all living things and incredible teaching abilities, I would never have had the confidence to go into science in the first place.

Thank you to the Dhimurru Aboriginal Corporation for providing field support in Nhulunbuy. Thank you to Dhimurru's director, Djami Marika. Most especially I am grateful to Paul Augustin for ensuring there was always a ranger to accompany me, even if it was himself via radio on a Sunday morning, as well as Lisa Roeger, Steve Roeger and Vanessa Drysdale. A special thanks to Daryl Lacey for tireless assistance looking for yellow crazy ant queens and digging pitfall traps, especially for that first field season when I didn't know what I was doing! I am grateful to the rangers Grace, Fiona, Daniel, Rakrakpuy, Anthony and Shane for field assistance. Thanks as well to Banula Marika for always being friendly and welcoming.

I am very thankful to Rio Tinto Alcan Gove for allowing me to do my fieldwork on their rehabilitation sites and letting me stay in the camp during my time in Nhulunbuy. I am very grateful to Faye Lawton for her unending efforts to ensure I had all the paperwork and equipment I needed to work on the mine site. Thanks to YBE and Tony Shultz for his ceaseless assistance and impressive ant queen catching abilities. Thank you as well to the 
YBE crewmembers who assisted me: David, Wendy and especially Leanne, Pipa and Reece.

Thank you to Conservation Volunteers Australia for providing volunteers to map yellow crazy ant infestations. A big thanks to Doug Clarke and Lauren Gleeson for coordinating crews and making the best of a difficult job. Thank you to the two crews that assisted.

Thank you to Dr. Michelle Baker, Dr. Kenneth McColl and Dr. Ivano Broz at the Australian Animal Health Laboratory, for sharing your knowledge, your kindness and above-and-beyond support when I visited.

I am grateful for the financial support provided by the Victoria Doctoral Scholarship and the Victoria Completion Scholarship, which allowed me to conduct my research.

Thank you so much to Kirsty Yule for always being there and willing to listen, this whole process would have been so much more difficult without you. Thanks to Kylee Rutland for your support and friendship (and many drives to the airport!).

Thanks to the Ant Club (I refuse to call it by any other name) for reading my countless drafts and providing helpful feedback. Thanks to Alexandra Sébastien for all those writing sessions and so many movies! Thanks to Evan Brenton-Rule for those walks to Cotton and endless entertaining discussions. Thank you to Rafael Barbareri for being awesome. Thanks to Oliver Quinn for sharing the pain and always making me laugh. Thank you to Monica Gruber for so much HPC and genomics advice. Thanks to Davide Santoro for many cups of tea. Thank you to Antoine Feldon for the late night chats. Thank you to Varun Venkatesh for always being there on the other side of the wall if I needed to talk. Thanks to Shalen Kumar for a lot of lab advice and help locating equipment as well as fun chats. Thanks to Julia Lopelt for always listening and some very fun trips. Thanks to Matt Sorola for all those nights at Meow and shooting the shit. 
Thank you as well to Lizzie Towl, for organizing the Thesis Bootcamp (as well as many other extremely helpful workshops), without which I may never have written these acknowledgements or indeed a good part of my thesis.

Thank you so much to Adrian Pike, Lesley Milicich, Sushila Pillai and Chris Thorn for always finding that much needed piece of equipment. Thank you to Kevin Buckley for all the HPC support and advice.

I am grateful to Marry Murray, Mark Stephen, Lesley Thompson, Sandra Taylor and Paul Marsden for making everything run smoothly against all odds.

I am grateful to my friend Masami Hoshino-Spafford for proofreading large parts of this thesis.

Thank you to Tim Townshend for keeping me sane (as was possible) through the final months and for being an all around wonderful human being.

And finally, thank you to my family and friends in Canada for their unwavering love and support, without which I never would have made it this far. 



\section{Contents}

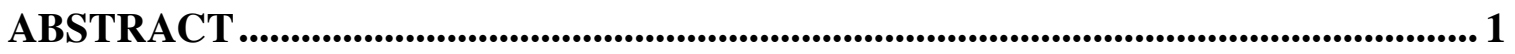

ACKNOWLEDGEMENTS .......................................................................................ii

LIST OF FIGURES ...............................................................................................................

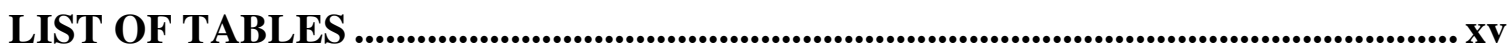

STATEMENT OF AUTHORSHIP .................................................................................... xvii

CHAPTER 1: GENERAL INTRODUCTION .................................................................... 1

1.1. Invasive species................................................................................................................................ 1

1.2. Study system: The yellow crazy ant in Arnhem Land, Australia............................2

1.3. Invasive species population collapses ................................................................................... 3

1.4. Pathogens in ants..................................................................................................................... 5

1.5. Importance of biological control........................................................................................ 8

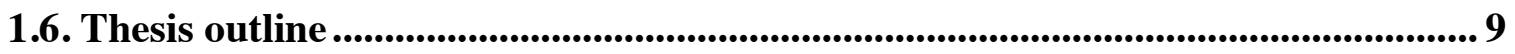

CHAPTER 2: HERE TODAY, GONE TOMORROW- DECLINES AND LOCAL EXTINCTIONS OF INVASIVE ANT POPULATIONS IN THE ABSENCE OF

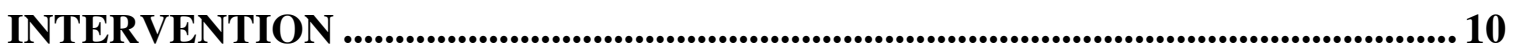

2.1. Abstract ......................................................................................................................................... 10

2.2. Introduction ..................................................................................................................................... 10

2.3. Methods............................................................................................................................................... 11

2.4. Results ................................................................................................................................. 13

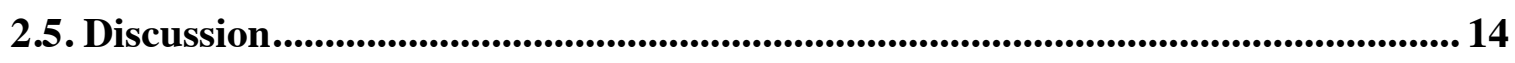




\section{CHAPTER 3: AN EXPERIMENTAL FUNGAL PATHOGEN INFECTION DID} NOT AFFECT ANOPLOLEPIS GRACILIPES REPRODUCTION...........................20

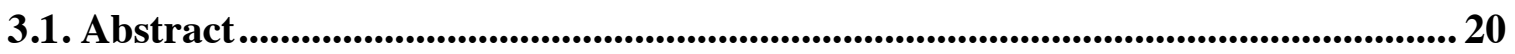

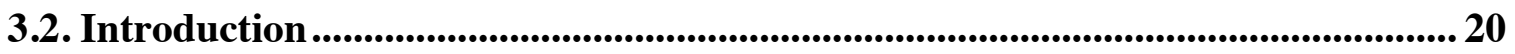

3.3. Methods................................................................................................................................... 23

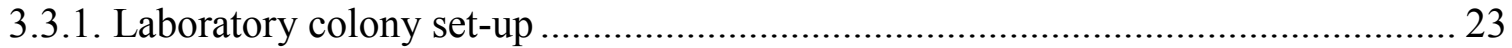

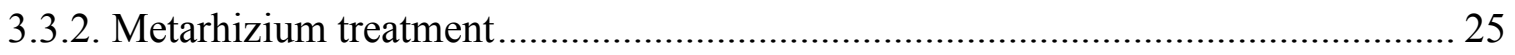

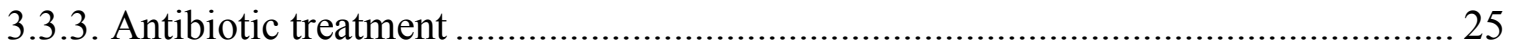

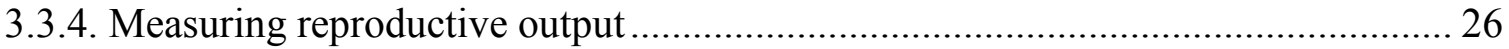

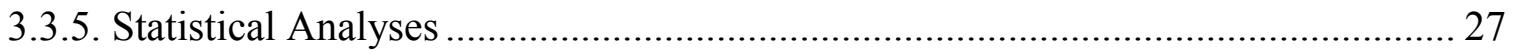

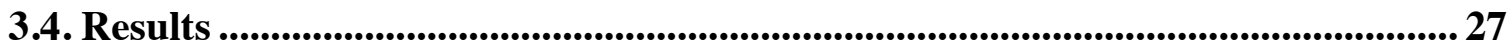

3.5. Discussion................................................................................................................................... 29

3.6. In Retrospect... ….............................................................................................................35

CHAPTER 4: PATHOGEN-RELATED REDUCED OOCYTE PRODUCTION IN ANOPLOLEPIS GRACILIPES QUEENS IN ARNHEM LAND, AUSTRALIA ...... 36

4.1. Abstract ....................................................................................................................................36

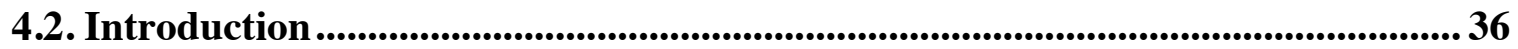

4.3. Experimental Methods ....................................................................................................... 39

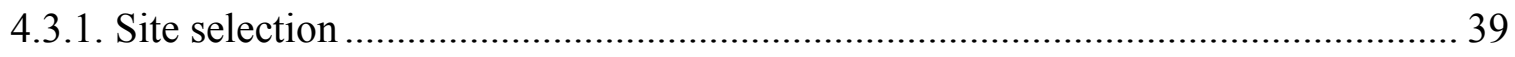

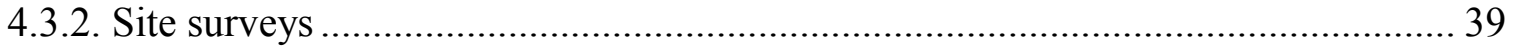

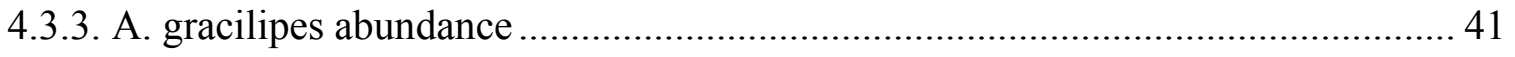

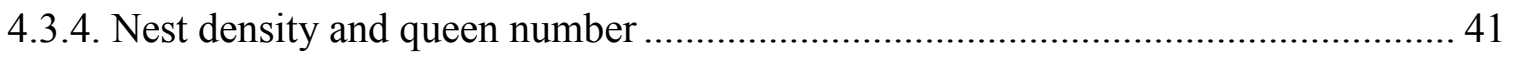

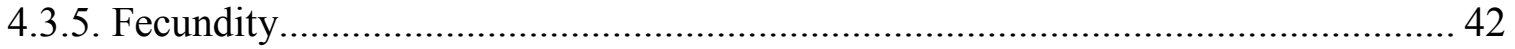

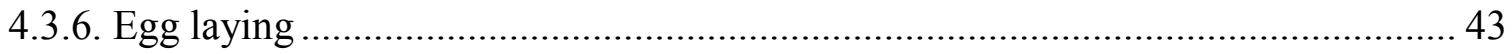

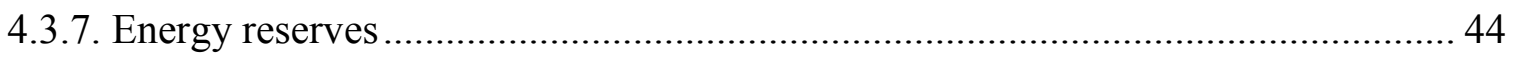




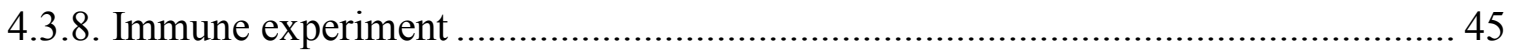

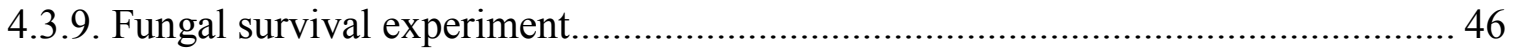

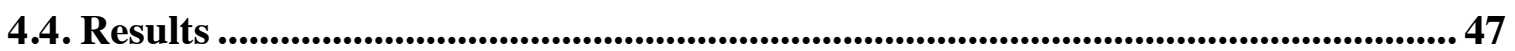

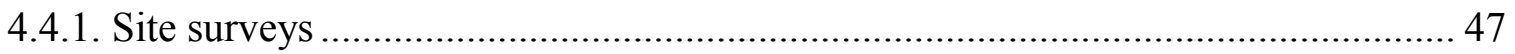

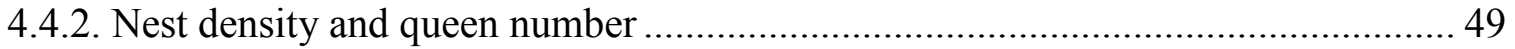

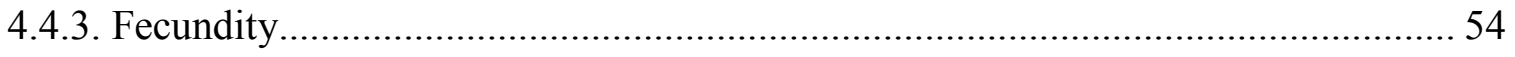

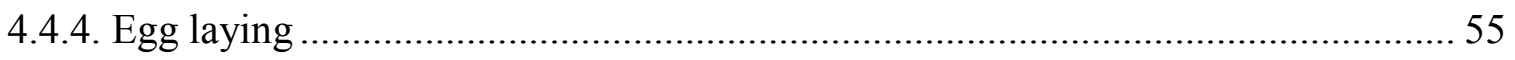

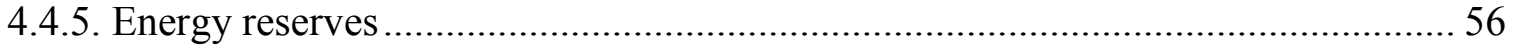

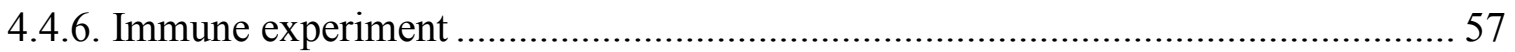

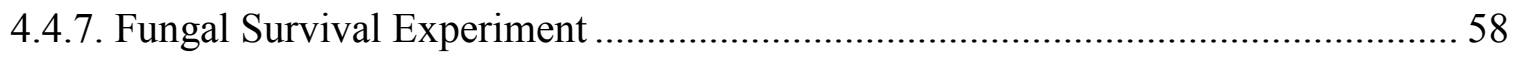

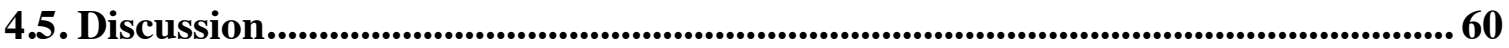

CHAPTER 5: A METATRANSCRIPTOMIC SURVEY OF ANOPLOLEPIS

GRACILIPES IDENTIFIES SEVERAL POTENTIAL PATHOGENS .................... 64

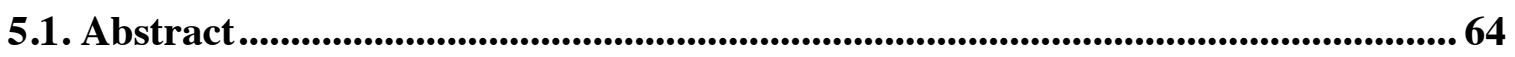

5.2. Introduction ................................................................................................................................. 64

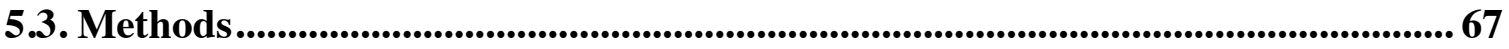

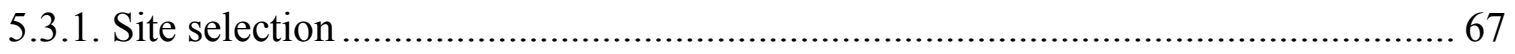

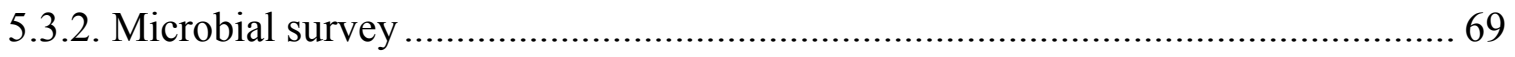

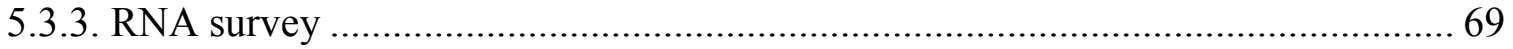

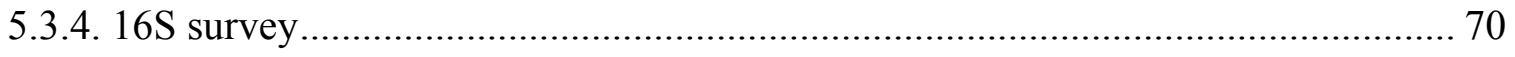

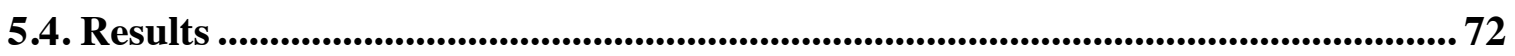

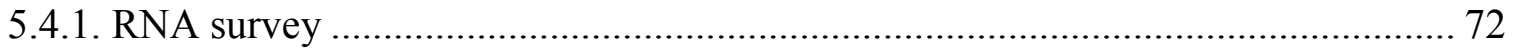

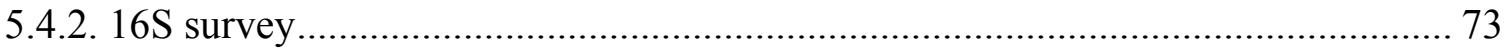

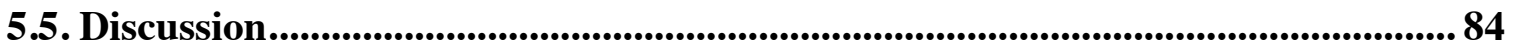


CHAPTER 6: GENERAL DISCUSSION ....................................................................90

6.1. Summary .......................................................................................................................................90

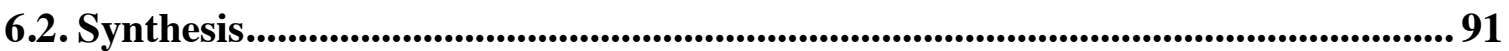

6.3. Constraints and future research .................................................................................95

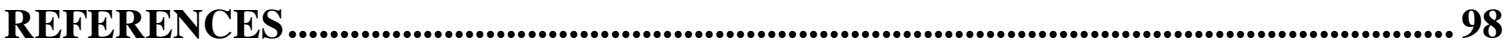

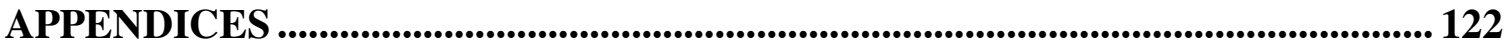




\section{List of Figures}

Figure 2.1. Inset of Australia and map of Arnhem Land showing locations where $A$. gracilipes has been detected since 2003 (black circles), and the locations of the populations detailed here (triangles).

Figure 2.2. Site A, showing the distribution of a continuous A. gracilipes population surveyed in 2003 (polygons), and absence points recorded when the site was resurveyed in 2013 (triangles).. 15

Figure 2.3. Site E showing the A. gracilipes population as mapped in 2008 and $2013 \ldots 16$

Figure 2.4. Site G, showing the A. gracilipes population as mapped in 2007, 2012, 2013 and 2014 . 17

Figure 3.1. (A) Plaster nest with five chambers (B) Experimental set-up ...................... 24

Figure 3.2. Survivorship curves for queens, with data divided by treatment. ................ 28

Figure 3.3. Boxplots of the reproductive output (eggs, larvae and pupae) of colonies after 70 days under four different treatments ( $\mathrm{n}=10$ per treatment). Graph $\mathrm{F}$ shows reproductive output (measured as number of oocytes in each queen) for uninfected (white bars) and infected (black bars) queens within each treatment 32

Figure 4.1. Inset of Australia and map of Arnhem Land showing study site locations (red squares) and town of Nhulunbuy

Figure 4.2. Ovaries from an infected queen. The ovary on the right contains melanized nodules (circled in red), the ovary on the left does not.

Figure 4.3 Medium-density site 1 (M1) (right) and medium-density site (M2) (left)

showing the A. gracilipes population as mapped in 2009, 2013 and 2014 48

Figure 4.4. Low-density site 1 (L1) showing the A. gracilipes population as mapped in 2012, 2013 and 2014

Figure 4.5. Low density site 2 (L2) showing the A. gracilipes population as mapped in 2007, 2012, 2013 and 2014.

Figure 4.6. Mean number of $A$. gracilipes workers \pm SD in one plot $(n=4 /$ site) at each of the two low-density (light grey bars), medium-density (dark grey bars) and highdensity (black bars) sites. Anoplolepis gracilipes abundances are shown for two sampling years at each site, 2013 (solid colour bars) and 2014 (speckled bars) ...... 51 


\section{List of Figures}

Figure 4.7. Box plot showing the median number of oocytes found in uninfected and infected queens. Uninfected queens have significantly more oocytes than infected $(p<0.0001$, see results). Black X's indicate the mean $(n=213$ uninfected queens; 65 infected queens)

Figure 4.8. Boxplot showing the median number of eggs laid by queens from low-density (light grey), medium-density (dark grey) and high-density (black) sites in the laboratory over a 24 period. There were no differences in number of eggs laid between the different population types 56

Figure 4.9. Box plot showing the median weight of fat found in uninfected and infected queens at the three site types. There were no differences in fat content between queens from different population type.....

Figure 4.10. Fat bodies of dissected queens from the four treatments A) sham, B) PBS, C) LPS and D) fungal

Figure 4.11. Boxplot showing the median number of nodules found in each queen after 24 hours

Figure 4.12. Survivorship curves for queens in the control group (solid black line) and Metarhizium treatment (dashed line)..... 59

Figure 5.1. Inset of Australia and map of Arnhem Land showing study site locations (red squares) and town of Nhulunbuy 68

Figure 5.2. Alpha rarefaction curves for the six 16S samples. 72

Figure 5.3. Metagenomic data summary from BLASTn results of RNA data showing taxonomic assignment of individual reads for all samples combined

Figure 5.4. Maximum-likelihood phylogenetic trees (1000 bootstrap replicates) showing the relationship of found sequence (A) TR44839 from the medium-density site M2 (B) TR80102 from the low-density site L2 and (C) TR17983 from the low-density site L2.

Figure 5.5. Principal coordinates analysis comparing bacterial communities among samples from low, medium and high-density populations. PCoA based on BrayCurtis distance values computed for A.gracilipes microbial communities at the order level

Figure 5.6. Relative abundance of OTUs (97\%) at the genus level for each sample site. 77 


\section{List of Figures}

Figure 5.7. Relative abundance of OTUs (97\%) at the phylum level for each sample sit 78 Figure 5.8. Relative abundance of OTUs $(97 \%)$ at the order level for each sample site.

The phylum each order belongs to is indicated on the right ................................ 80

Figure S.1. PCoA based on Bray-Curtis distance values computed for local ant communities between A) population type, B) year and C) site

Figure S.2. Relationship between A. gracilipes abundance (total number of ants per plot) and the abundance of resident ant species by functional group (total number of ants in each functional group per plot) 



\section{List of Tables}

Table 2.1. Details of initial surveys and reassessments of seven A. gracilipes populations conducted between 2003 and 2014. Sites ordered from declining to extinct $A$. gracilipes populations 14

Table 3.1. Results of a multivariate general linear model testing the effect of treatment and the number of queens remaining at the end of treatment on the number of eggs, larvae and pupae ( $\mathrm{n}=10$ colonies per treatment). Results of a generalized linear model examining the effect of treatment and the number of queens remaining at the end of treatment on the number of male pupae.

Table 3.2. Results of a multivariate general linear model testing the effect of treatment, status and their interaction on the number of oocytes, eggs, larvae and pupae. Results of a generalized linear model examining the effect of treatment and queen number on the number of male pupae.

Table 4.1. Site location (WGS84 decimal degrees), size of site and number of GPS points taken each year

Table 4.2. Bonferonni-corrected Tukey test pairwise comparisons of A. gracilipes abundance between sites.

Table 4.3. Population type, number of queens dissected with the percentage of infected queens in brackets, total number of nests excavated and nest density per site. 52

Table 4.4. A) Results of a generalized mixed effect models testing the effect of population type, canopy cover, litter depth and cover, Acacia number and Eucalyptus number on nest presence and number of queens per nest. B) Results of a generalized mixed effect model testing the effect of population type, nodulation status (status), the interaction between population type and nodulation status, gaster width, head width, queen number per nest (queen number), ovariole number and longest basal oocyte on oocyte number and fat content.

Table 5.1. The 10 closest matches for each viral sequence of interest on GenBank using BLASTn against the nt database. Results are ordered by the highest max score for each sequence of interest. 
Table 5.2. Top 10 most prevalent bacterial orders (out of 40 total) across all samples, and samples from low, medium and high-density sites........................................... 79

Table 5.3. SIMPER results showing which bacterial orders contributed to approximately $50 \%$ of the dissimilarity between population types.

Table 5.4. Ten bacterial orders that had significantly different (log-likelihood ratio test) mean number of reads between population types.

Table 5.5. Bacterial genera that were significantly (log-likelihood ratio test) more prevalent in site M2 than the other study sites. Serratia marcescens is one of the few OTUs identified to species. Candidates for contents of the melanized nodules found in Chapter 4.

Table S.1. Results of generalized linear model of functional group abundance as a function of population type, site and year. The Dominant Dolichoderine were significantly negatively affected by population type, and the generalized Myrmicinae were positively affected. 


\section{Statement of Authorship}

I hereby declare that this thesis is my own work and that all sources quoted, paraphrased or otherwise referred to, have been properly acknowledged in the references at the end of each respective chapter. To the best of my knowledge, this thesis neither contains material previously published or written by another person, nor material which to a substantial extent has been accepted for the award of any other degree or diploma of the university or other institutes of higher learning, except where due to acknowledgement it has been made clear in the text.

Chapters 2, 3, 4 and 5 have been written as individual research papers, so there is inevitable repetition between the introductions and discussions of these chapters. As all chapters contain contributions from collaborators, they are written in first person plural tense. In all cases I wrote the manuscripts. Professor Phil Lester and Dr. Ben Hoffmann provided advice throughout and contributed to editing of the manuscripts, and are therefore co-authors on all manuscripts, expect Chapter 2. The contributions of other coauthors are outlined below, indicated by author initials ${ }^{1}$.

Chapter 2 is published in Biological Invasions (see Appendices). Author contributions: $\mathrm{MC}$ and $\mathrm{BH}$ designed the research and formulated the research questions. $\mathrm{MC}$ and $\mathrm{BH}$ did the surveys and collected the data. BH provided data from earlier work. MC made the figures, analyzed the data, and interpreted the results.

Chapter 3 author contributions: MC, BH and PL formulated the research questions and designed the experiment. $\mathrm{MC}$ built the required equipment. $\mathrm{MC}$ and $\mathrm{BH}$ collected the ants. MC conducted the experiment, collected the data, analyzed the data, and interpreted the results. 


\section{Statement of Authorship}

Chapter 4 author contributions: $\mathrm{MC}, \mathrm{BH}$ and PL formulated the research questions. MC designed the research. MC conducted the field surveys and experiments, dissections, analyzed the data, and interpreted the results.

Chapter 5 author contributions: MC, MG and PL designed the research. MC and $\mathrm{BH}$ collected the data. $\mathrm{MC}$ conducted the laboratory work. $\mathrm{MC}$ and $\mathrm{BH}$ did the ant identifications. MC and MG analyzed the data. MC interpreted the results.

\footnotetext{
${ }^{1}$ Author initials and names: BH Ben Hoffmann; MC Meghan Cooling; MG Monica Gruber; PL Phil Lester
} 
1. General Introduction

\section{Chapter 1: General Introduction}

\subsection{Invasive species}

Invasive species are non-native and potentially harmful organisms that are major drivers of global environmental change (Vitousek et al. 1997). These species threaten native species and ecosystem functioning all over the world, as well as having significant economic impacts in their new regions (Lockwood et al. 2009). Invasive species may change ecosystem functioning by displacing other species through predation or competition (Christian 2001; O'Dowd et al. 2003). However, the vast majority of introduced species do not become invasive. Most fail to establish, and of those that do, many may become innocuous members of their new community (Lockwood et al. 2009). Only a small minority of introduced species go on to become invasive. In this thesis when I refer to an "invasive" species I refer to a species that has fulfilled all of the following three criteria (Lockwood et al. 2009): 1) the species has been transported by human means (either purposefully or accidentally) from it's native range to a new geographic location where it does not naturally occur; 2) it has established a viable, self-sustaining population and become widespread and abundant in this new range; 3 ) it has demonstrably caused extensive ecological and or economic harm.

Introduced ant species are often particularly successful invaders (Holway et al. 2002), as exemplified by the presence of five species of ant on the " 100 of the world's worst invasive alien species list" (Lowe et al. 2000). The most widely-established, ecologically and economically damaging invasive ant species share a number of characteristics that are thought to aid in their success. They are often polygynous, with multiple queens per colony, which increases reproductive output and leads to larger colony size (Tsutsui and Suarez 2003). Colony reproduction often occurs by budding, where queens do not participate in mating flights; instead they walk away from their natal nest with a small group of workers and establish new colonies nearby. Furthermore, invasive ants are often closely associated with anthropogenic disturbance, enabling dispersal by humans rapidly and easily (Passera 1994; Holway et al. 2002). Polygyny and budding both increase the chances of these ants being spread to new locations by humans because colony fragments 
are more likely to have an impregnated queen in them (Tsutsui and Suarez 2003). Perhaps most important to the success of invasive ants is that they are usually unicolonial, meaning there is no intraspecific aggression between workers of different colonies. Thus, energy that would have been spent defending territorial boundaries can be used for foraging and reproduction (Thomas et al. 2006). These traits often lead to invasive ants forming massive supercolonies (a polydomous colony with high nest density and an expansive spatial scale such that worker exchange between all parts of the colony is unlikely), with enormous numbers of workers. This supercolonial behaviour has been observed in the Argentine ant (Linepithema humile), the little fire ant (Wasmannia auropunctata), the big-headed ant (Pheidole megacephala) and the yellow crazy ant (Anoplolepis gracilipes), to name a few (Errard et al. 2005; Holway et al. 2002; Tsutsui and Suarez 2003). However, declines of invasive ant populations have been recorded (Cooling et al. 2012; Cooling and Hoffmann 2015; Gruber et al. 2012a; Haines and Haines 1978).

\subsection{Study system: The yellow crazy ant in Arnhem Land, Australia}

The yellow crazy ant, Anoplolepis gracilipes, is considered one of the world's worst invasive species due to the ecological and economic harm it has done where it occurs (Lowe et al. 2000; Haines and Haines 1978; Hill et al. 2003; Holway et al. 2002; O'Dowd et al. 2003). Though its native range is unknown, it has been long established in the Pacific where it was first recorded in 1870, and has since spread widely around this region (Greenslade 1972). It is also established in Australia, east Africa, and Asia (Wetterer 2005). Like many other invasive ant species it is polygynous and unicolonial, and can reach extraordinarily high population densities (Holway et al. 2002). On Christmas Island, for example, populations of this ant reach such high densities, aided by an invasive scale insect (Abbott and Green 2007), that they extirpate the endemic red land crab, that is the primary consumer on the forest floor. The loss of the crab severely disrupts the rainforest ecosystem, facilitating secondary invasions by other exotic species, coining the term "invasional meltdown" (Simberloff and Van Holle 1999; O'Dowd et al. 2003; Abbott and Green 2007; Green et al.2011). Most of the studies done on $A$. gracilipes have focused on its impact in its invaded environment (Bos et al. 2008; Hill et 
al. 2003; Hoffmann and Saul 2010; Mezger and Pfeiffer 2003; Gillespie and Reimer 1993; Braby 2010; Davis et al. 2008, 2009; Gerlach 2004; Suwabe et al.2009) or supercolonial structure (Abbott 2005; Drescher et al. 2007, 2010). Surprisingly, there has only been one study investigating possible microorganisms carried by A. gracilipes, Sébastien et al. (2011) investigated the prevalence of several bacterial endosymbionts in A. gracilipes populations in the Pacific region, including populations from my study sites in Arnhem Land, Australia.

Anoplolepis gracilipes was first detected in northeast Arnhem Land on rehabilitated bauxite mine sites in 1982 (Majer 1984), but had probably been established for several decades before this initial observation (Young et al. 2001). By 2009 it was patchily distributed across 25000 ha (Hoffmann and Saul 2010). A recent study investigating population genetic structure showed that all A. gracilipes populations in Arnhem Land are descended from the introduction of a single population (Gruber et al. 2012b). These ants have mostly invaded undisturbed savanna woodland where they form discrete patches of populations (Hoffmann and Saul 2010). Here, they attain high densities where they exclude other dominant native ant species such as Oecophylla smaragdina and Iridomyrmex spp. (Gruber et al.2012c). Anoplolepis gracilipes populations have been observed to fluctuate strongly (Gruber et al. 2012a; Haines and Haines 1978; O'Dowd et al.2003). In Arnhem Land, populations of these ants fluctuate spatially and temporally and sometimes disappear altogether (Chapter 2).

\subsection{Invasive species population collapses}

Though not common, established, widespread populations of invasive species have been known to collapse or decline suddenly (Simberloff and Gibbons 2004). Unfortunately most of these cases, though verified, are anecdotal. There are very few studies that document declines quantitatively as they occur (but see Chapter 2). This absence of documented collapses is likely because interest in invasive species occurs only so long as they are perceived as a problem, probably resulting in a publication bias. However, interest in this phenomenon is growing (Cooling et al. 2012; Cooling and Hoffmann 2015; Sandström et al. 2014). For example, Sandström et al. (2014) found that 41\% of 
introduced signal crayfish populations in Swedish lakes had collapsed. A number of other such examples are reviewed by Simberloff and Gibbons (2004), such as the case of the waterweed, Elodea canadensis, which is well known for its boom and bust cycles, in both its native and introduced ranges, though the mechanism behind these extreme fluctuations are not understood (Simberloff and Gibbons 2004). In some cases invaders may be outcompeted by new invaders, such as the apparent displacement of the yellow fever mosquito, Aedes aegypti, with the subsequently introduced Asian tiger mosquito, $A$. albopictus, in Spain and Florida (Simberloff and Gibbons 2004). Or invaders may overexploit local resources, as has been recorded for introduced deer populations (Scheffer 1951). Pathogens may also play a role in such declines. For example, introductions of the giant African land snail on Pacific islands have been characterized by population explosions, followed by precipitous population declines apparently caused by a bacterial pathogen (Simberloff and Gibbons 2004).

This sudden disappearance of populations has also been observed in several species of invasive ants (Cooling et al. 2012; Haines et al. 1994; Wetterer 2006). Pheidole megacephala populations have been observed to go through boom and bust phases throughout their introduced range (Wetterer 2012). Wasmannia auropunctata populations in New Caledonia and L. humile populations in New Zealand periodically collapse (Le Breton, per comm; Cooling et al. 2012). In $17^{\text {th }}$ and $19^{\text {th }}$ century Bermuda, the capital town was overrun with an unidentified species of ant that was described as being in plague proportions. This ant has since disappeared completely, leaving its identity a mystery (Wetterer 2006). Haines and Haines (1978) noted the decline and disappearance of local populations of A. gracilipes on the Seychelles. Abbott (2006) also noticed local declines in some populations of this species on Christmas Island, though overall populations of $A$. gracilipes have been increasing on that island. Instead of being the ultimate cause of the collapse, pathogens and overexploitation of resources may simply be mechanisms by which a population is reduced to a low enough level that it becomes vulnerable to Allee effects or stochastic processes (Taylor and Hastings 2005). Most often there is no immediately obvious reason for such declines, though pathogens and overexploitation of resources are the most commonly invoked explanations, but evidence 
to support these claims is rarely given (Simberloff and Gibbons 2004). For example, Gruber et al. (2012a) suggested pathogens as a potential reason behind the decline in abundance of invasive ant A. gracilipes populations on Tokelau, but supporting evidence has yet to be found.

The possibility of pathogens as an agent of decline is of particular interest in the case of invasive species population declines because of the potential that such pathogens could be used as biocontrol agents. For some invasive species, particularly those that are very widespread, eradication is no longer a viable option (Oi and Valles 2009). Such is the case for $S$. invicta in the southern United States. Since this invader's introduction to Mobile, Alabama in 1933, it has spread over 129.5 million hectares, across more than 20 states (Oi and Valles 2009). Eradication is no longer considered an option for this species, and widespread chemical control is economically unfeasible for both economical and environmental reasons. One of the chief advantages of biocontrol is that once the biocontrol agent is released and establishes a self-sustaining population, it does the work of suppressing the target population itself. Unlike a poison, it does not need to be reapplied. It can also be used for those invaders that inhabit vulnerable or valuable ecosystems, where application of poison as a means of control may not be feasible.

\subsection{Pathogens in ants}

Insects are host to a suite of microbes, which may have substantial impacts on the host's development, physiology and longevity, both positive and negative (Dunn et al. 2012; Russell et al. 2009). The influence endosymbiotic bacteria have on host ecology and evolution is a growing field of study, with more relationships being elucidated every day (Brownlie and Johnson 2009 and references therein; Kaltenpoth 2009; Sharon et al. 2013). Mutualistic bacteria have been found to provide essential nutrients lacking in the host's diet, mediate host thermal tolerance, enhance reproduction and increase resistance to parasites and pathogens (Ceja-Navarro et al. 2015; Panteleev et al. 2007; Russell and Moran 2006; Russell et al. 2009). Alternatively, many microbial pathogens have been found to negatively affect reproduction in insects (Calleri et al. 2006; Dunn et al. 2012). Bacterial, fungal and viral entomopathogens can cause extensive declines of insect pest 
populations, as seen for various species of sawflies, with viruses in the family

Baculoviridae in Europe and eastern North America (Arif et al. 2011; Lacey et al. 2001).

The microbial community living within an insect may have complex relationships with their hosts.

Social insects also have a rich microbiota, and may be host to a multitude of mutualists, commensals and pathogens (Cox-Foster et al. 2007; Russell et al. 2009; Vasquez et al. 2012). The microbiome of Apis mellifera, the honey bee, is particularly well-studied. These hymenopterans may carry many pathogens, including, but not limited to, bacteria, such as Paenibacillus larvae (American foulbrood), microsporidia, such as Nosema, and a number of viruses in the Dicistroviridae and Iflaviridae families (Evans and Schwarz 2011). All of these pathogens have been associated with significant declines of $A$. mellifera populations (Evans and Schwarz 2011; Schroeder and Martin 2012). Alternatively, mutualistic bacteria may provide protection against some of these pathogens. For example, the lactic acid bacterium genus, Lactobacillus, has been shown to inhibit the growth of $P$. larvae in A. mellifera brood (Forsgren et al. 2009; Vasquez et al.2012). Lactobacillus was also found to dominate the microbiome of the leaf-cutting ant, Mycocepurus smithii, where it was hypothesized to play a defensive role against pathogenic fungi (Kellner et al. 2015). Other mutualistic bacteria in social insects supplement nutrient poor diets. For example, obligate Blochmannia endosymbionts in Camponotini ants provide essential amino acids to the host (Feldhaar et al. 2007). Sébastien et al. (2011) discovered a number of bacterial endosymbionts infecting the invasive ant, A. gracilipes, some of which (Wolbachia and Arsenophonus) were proposed as potential biocontrol agents. In fact, social insects are hypothesized to be especially prone to pathogens, through living in dense groups of intermixing individuals, compared to solitary insects (Schmid-Hempel 1998). Microbes are hypothesized to play an important role in the success or failure of biological invasions, including those of ants (Ishak et al. 2011a; Sébastien et al. 2011). Invasive species are thought to be particularly vulnerable to disease due to low genetic diversity. 
Introduced species tend to have low genetic diversity because small populations of colonists often impose a genetic bottleneck, due to small founding population size, resulting in significantly reduced genetic diversity compared to that of the parent population (Allendorf and Lundquist 2003). Inbreeding depression can limit population growth, and reduce the likelihood of population persistence (Sakai et al. 2001). Low genetic diversity also interferes with a species' ability to adapt to its new environment (Allendorf and Lundquist 2003). Due to these factors, invasive species may be prone to population crashes (Sakai et al. 2001). For example, low genetic diversity may interfere with workers' ability to detect and respond to pathogens, leaving the colony vulnerable to infection (Ugelvig et al. 2010). Invasive ant species, such as A. gracilipes, may be especially at risk for three reasons: (1) their unique unicolonial colony structure allows no gene flow from other newly introduced populations, thus forming a closed genetic unit, and retaining what was already potentially very low genetic diversity (Ugelvig and Cremer 2012), and (2) their polygynous nature results in high levels of intermixing individuals, and may result in higher transmission rates. For example, Valles et al. (2010) found that the unicolonial polygyne form of $S$. invicta was both more likely to be infected with pathogens than the monogyne form, and also had an increased chance of harbouring multiple pathogens at one time. The initial population bottleneck at introduction may also deprive introduced species of beneficial microbial mutualists, further decreasing their resistance to infection.

The vast majority of studies investigating pathogens in ants have looked at S. invicta, which is arguably the most well studied invasive ant (Holway et al. 2002; Yang et al. 2010). The impetus behind such investigations has been to identify potential biocontrol agents, as this ant is a severe economic and ecological pest in the United States and is estimated to cost the US economy over $\$ 6$ billion annually (Pereira et al. 2003). Surveys for natural enemies have been done both in this ant's native range, South America, and in the United States (Allen and Buren 1974; Jouvenaz and Kimbrough 1991; Briano et al. 1995a; Valles et al. 2004; Oi et al. 2012 and references therein). These studies have uncovered a number of pathogenic microbes infecting these ants, including fungi, microsporidia, bacteria and viruses. The effects of these microbial taxa on S. invicta 
populations are varied. Though some, such as the microsporidian Kneallhazia solenopsae and the RNA virus Solenopsis invicta virus-3 can exert a strong influence where present and even lead to colony collapse (Williams et al. 1998; Valles 2012).

\subsection{Importance of biological control}

Invasive species may carry their own microorganisms into their new environment (Sébastien et al. 2011) or pick up novel ones in their introduced range (Barton 1997; Espadaler et al. 2011). Solenopsis invicta brought several of its own pathogens with it from South America, and over two dozen more have been found by surveying its native range (Allen and Buren 1979; Oi et al. 2012). As the native range of A. gracilipes is unknown, surveying for potential pathogens there is impossible. However, by investigating unusual behaviour, such as unexplained population declines, which may indicate unhealthy populations and the presence of pathogens, the discovery of potential biocontrol agents becomes more likely (Valles et al. 2012).

Biocontrol is defined as the control of a specific undesirable species population by a natural enemy. A biocontrol agent may be a predator, parasite or pathogen. Originally predators, either vertebrate or insect, were commonly used as biocontrol agents. However they had a tendency to do more damage than the species they were meant to control. In the past several decades, microbes have been heavily researched as potential biocontrol agents due to their higher host specificity (Porter et al. 2013). Biocontrol can be thought of as a last resort due to the potentially catastrophic consequences a rogue biological control agent can have (Simberloff 2008). The rosy wolf snail, Euglandina rosea, in the Pacific and the cane toad, Bufo marinus, in Australia are classic examples of biocontrol agents that ended up being much worse than the species they were originally meant to control (Civeyrel and Simberloff 1996; Simberloff and Gibbons 2004). However, A. gracilipes on Christmas Island may be a case where there is no other viable option. Currently, A. gracilipes populations are controlled by fipronil applications, a poison bait (Simberloff 2008). However, poison bait use for ant control is just a stop-gap measure. As red land crabs and robber crabs are vulnerable to the bait, it is only possible to bait $A$. gracilipes populations that are at such high densities the land crabs have been eliminated 
already. After baiting, the ant population is reduced to almost zero and the red land crab can recolonize the area. Nevertheless, once A. gracilipes populations recover, the whole cycle starts over (Boland et al. 2011). Regardless, this method is the best option available at present and it is preventing even more drastic declines in the red land crab population (Simberloff 2008). However, the introduction of an epizootic that regulated A. gracilipes populations and was specific only to the ants could potentially keep A. gracilipes populations at low densities so the red land crab and ants could co-exist.

Declining A. gracilipes populations in Arnhem Land represent a unique and tractable opportunity to investigate mechanisms by which a globally significant invader declines. Identifying the drivers and mechanisms behind such declines could have important applications for invasive species management worldwide.

\subsection{Thesis outline}

In this thesis I investigate the relationship between pathogens and bacterial endosymbionts and observed population declines in A. gracilipes in Arnhem Land, Australia. My overall goal was threefold: to document population declines in $A$. gracilipes, to investigate if microbes potentially play a role in the observed declines and to identify pathogens infecting A. gracilipes as potential candidates for biocontrol agents. In Chapter 2, I document previous population declines in A. gracilipes. Chapter 3 investigates the effect artificial infection by the entomopathogenic fungus, Metarhizium anisopliae, has on reproductive output in laboratory colonies of $A$. gracilipes.

In Chapter 4, I investigate the hypothesis that a pathogen is affecting queen health in field populations of A. gracilipes. I do so by comparing queen number and queen health between populations that are in various stages of decline or expansion.

Chapter 5 examines differences in microbial load between populations of A. gracilipes in various stages of decline. I also suggest several candidates for potential biocontrol agents and future study.

Chapter 6 summarizes and synthesizes the main findings of my thesis, outlines encountered restraints and explores avenues for further research. 


\section{Chapter 2: Here today, gone tomorrow- declines and local extinctions of invasive ant populations in the absence of intervention}

\subsection{Abstract}

Invasive species are known to exhibit boom and bust cycles. We report population declines of one of the world's most serious ant invaders, Anoplolepis gracilipes (Smith) (yellow crazy ant) in Arnhem Land, Australia. Anoplolepis gracilipes populations are known to fluctuate, both spatially and temporally, but this is the first instance of quantitative monitoring of spatial declines of entire populations. We present before and after survey data on seven populations that have either declined substantially or disappeared completely without human intervention. Sites ranged in size from 1.8 ha to 15 ha. Although the mechanistic cause of these declines remains unknown, A. gracilipes populations in Arnhem Land represent a unique opportunity to investigate mechanisms by which a globally significant invader declines, which could have important implications for invasive species management worldwide.

\subsection{Introduction}

Population declines of an exotic species following an initial population "explosion" are a well recognized, but rarely investigated, syndrome of invasions (Simberloff and Gibbons 2004; Gruber et al. 2012a; Sandström et al. 2014). In most instances, the mechanisms driving the declines are unclear (Cooling et al. 2012; Sandström et al. 2014). Similarly, data quantifying the declines as they occur are extremely rare because they most often happen quickly and unexpectedly, and because interest in invasions is reduced after a decline has taken place, which results in a publication bias (Simberloff and Gibbons 2004).

The yellow crazy ant, Anoplolepis gracilipes (Smith), is considered one of the world's most widespread, ecologically and economically damaging invasive ant species (Holway 
et al. 2002), and like many other invasive ant species it can reach extraordinarily high population densities and substantially modify ecosystems (O’Dowd et al. 2003). Populations of this ant are also known to fluctuate strongly, both spatially and temporally (Haines et al. 1994; Abbott 2005; Gruber et al. 2012a, b). Anoplolepis gracilipes was first detected in northeast Arnhem Land in Australia's Northern Territory in 1982 (Majer 1984), though it had probably been established for several decades prior (Young et al. 2001). The ant is patchily distributed throughout 25,000 ha, inhabiting mostly undisturbed savanna woodland, where it forms spatially discrete populations probably as a result of accidental dispersal by people (Hoffmann and Saul 2010; Figure 2.1).

Some populations of A. gracilipes were found to decline or disappear, in the absence of intervention, during delimiting surveys, that were part of management operations against this ant that have been ongoing in northeast Arnhem Land since 2004. The declines occurred either between the time that they were found and then accurately delimited, between multiple delimitations when treatments were delayed, or while they were being observed for other experimental work (Hoffmann 2014, 2015). Here we detail large-scale reductions in the spatial extent of four populations of this highly invasive species, including one population (site $G$ ) that we monitored for three years. We also present data on three populations that were recorded as present, but disappeared before they were spatially delimited.

\subsection{Methods}

We monitored and quantified the change in spatial extent of four populations and recorded the collapse of three others (Figure 2.1). Unfortunately ideal baseline data was not obtained for most populations due to this work not being anticipated when they were first found or mapped. Four populations were mapped using the standard visual assessments used by the eradication program (detailed below), but GPS data were not collected at sites A and F for each visual assessment, rather only the boundary of each population was recorded as a polygon, thereby giving only an area, not an indication of $A$. gracilipes continuity through the area. However, pre-decline nest density at site A was known from prior research (Hoffmann 2015). Three populations (B, C, D) were not 
mapped prior to their decline and so their baseline data are only a single GPS point indicating that they existed, and thus their original extents are unknown.

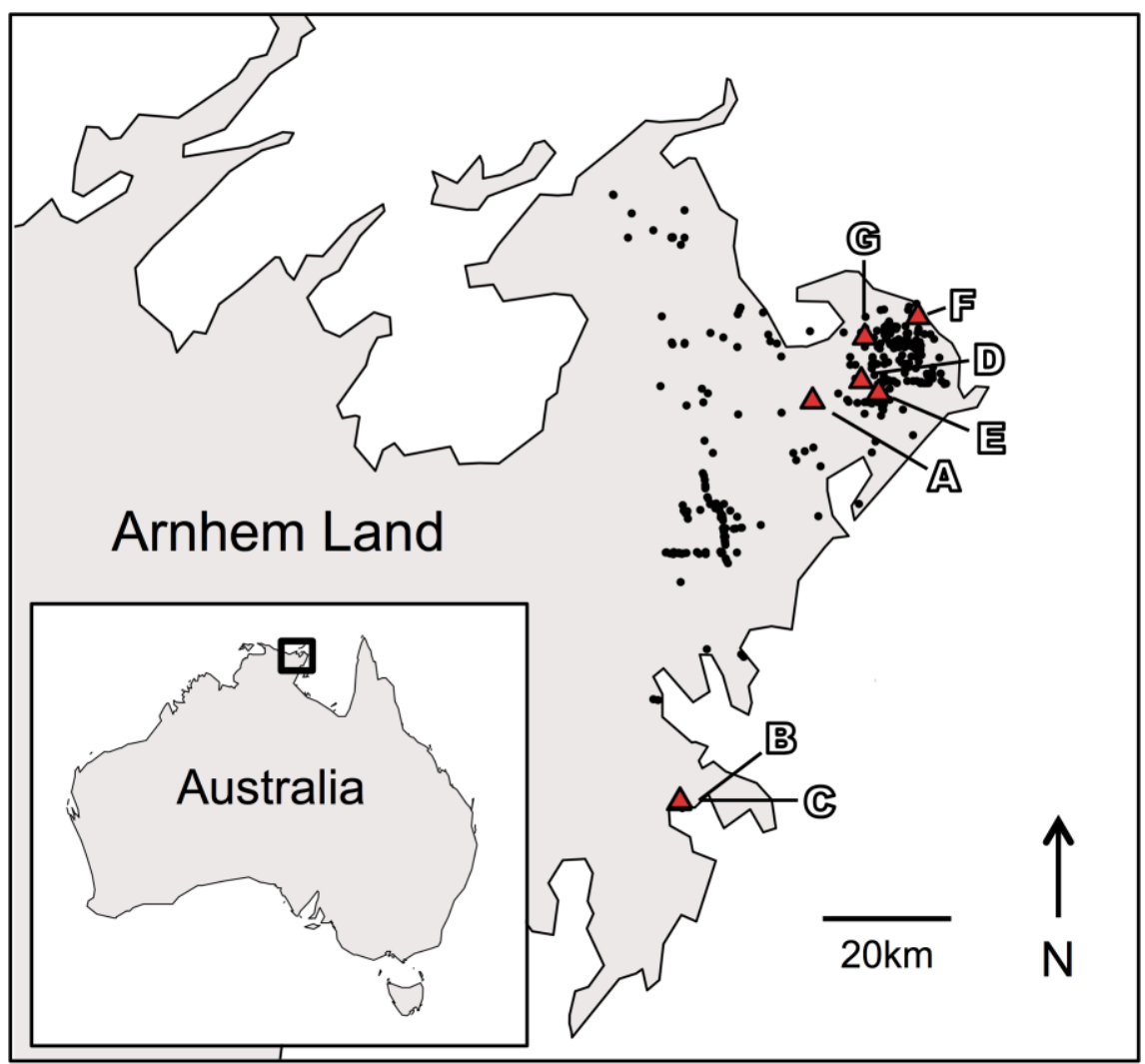

Figure 2.1. Inset of Australia and map of Arnhem Land showing locations where A. gracilipes has been detected since 2003 (black circles), and the locations of the populations detailed here (triangles). Sites $B$ and $C$ appear as one site on this map because they are $<500 \mathrm{~m}$ apart. Note that most of these detections (black circles) represent spatially discrete populations, and most have not been resurveyed since their initial detection, so it is unknown how many others have undergone spatial collapse since their detection.

Mapping and subsequent re-surveys of populations were conducted by visual assessments of the presence/absence of A. gracilipes workers. Assessments were conducted between 0600-0930 and 1530-1830, when temperatures do not greatly hinder A. gracilipes activity $\left(15-30^{\circ} \mathrm{C}\right)($ Hoffmann 2015). Assessments were conducted by teams of people walking in parallel, commencing in any direction from an A. gracilipes detection point. Assessments were conducted haphazardly, approximately one per every $2 \mathrm{~m}$. Early work conducted prior to 2007 did not collect point-level GPS data, rather only the boundary of populations was recorded as a polygon. When point-level GPS data were collected, $A$. gracilipes was recorded as present or absent. The boundary of the population was deemed 
to have been determined when no detections had been made for at least $100 \mathrm{~m}$ in all directions from the peripheral detections. The accuracy of visual assessments in determining A. gracilipes presence/absence was verified in a previous pilot study, where visual assessments accurately detected the full extent of multiple small and isolated clusters of nests previously delineated using attractive food lures (data not presented). Visual assessments are the standard technique used by the management program for detection and mapping A. gracilipes populations. This visual method did not attempt to detect nests, as this would be an impossible task to complete accurately at the scale of multiple hectares. Therefore data presented here focus on population distribution, not abundance.

In subsequent assessments to quantify decline, the entire area of small populations $(<9$ ha; populations A-E) was re-surveyed, but for the two larger populations ( $F$ and $G$ ) only two areas of 2.3 and 8.6 ha respectively that originally had a high density of detections were re-surveyed. Finally, to assess if the populations had merely shifted their distribution to a new area, we also conducted a search up to $400 \mathrm{~m}$ in all directions around the original distribution of population $\mathrm{G}$, and for three other populations $(A, B, C)$ searches in some peripheral locations also extended well past the $100 \mathrm{~m}$ search limit.

\subsection{Results}

Of the seven populations, five (sites A, B, C, D, E) appear to have disappeared completely from when they were first found or mapped to when they were resurveyed (Table 2.1, Figure 2.2, 2.3). These populations ranged in size from single point detections with unknown extent to 3.6 ha. The populations at sites F and G, which had the largest original infestations covering 15 and 8.6 ha respectively, declined substantially. Average nest density at site F was known to be one nest per $6.3 \mathrm{~m}^{2}$ in 2006 (Hoffmann 2015), which declined to only a single nest being found throughout 2.3 ha in 2012 and no other detections being made throughout a greater area in other informal searches (data not presented). No A. gracilipes were found in the areas searched on the eastern half and far western side of site $\mathrm{G}$ in 2012, and there was a clear continual decline in detections, including their spatial distribution, throughout the permanent re-survey zone throughout 
2. Declines and local extinctions of invasive ant populations

Table 2.1. Details of initial surveys and reassessments of seven $A$. gracilipes populations conducted between 2003 and 2014. Sites ordered from declining to extinct $A$. gracilipes populations

\begin{tabular}{|c|c|c|c|c|c|}
\hline Site & Year & Mapping method & $\begin{array}{l}\text { Area surveyed } \\
\text { (ha) }\end{array}$ & $\begin{array}{l}\text { Presence } \\
\text { points }\end{array}$ & $\begin{array}{l}\text { Absence } \\
\text { points }\end{array}$ \\
\hline \multirow[t]{2}{*}{$\mathrm{F}$} & 2006 & boundary mapped $^{1}$ & 14.97 & $\mathrm{n} / \mathrm{a}$ & $\mathrm{n} / \mathrm{a}$ \\
\hline & 2012 & point-level GPS data ${ }^{2}$ & 2.3 & 1 & 700 \\
\hline \multirow[t]{4}{*}{$\mathrm{G}^{\mathrm{a}}$} & 2007 & point-level GPS data & 8.62 & 154 & 6192 \\
\hline & 2012 & point-level GPS data & 8.62 & 17 & $3317^{\mathrm{b}}$ \\
\hline & 2013 & point-level GPS data & 8.62 & 35 & 4102 \\
\hline & 2014 & point-level GPS data & 8.62 & 14 & 3380 \\
\hline \multirow[t]{2}{*}{ A } & 2003 & boundary mapped & 3.64 & $\mathrm{n} / \mathrm{a}$ & $\mathrm{n} / \mathrm{a}$ \\
\hline & 2013 & point-level GPS data & 10.29 & 0 & 3980 \\
\hline \multirow[t]{2}{*}{$\mathrm{E}$} & 2008 & point-level GPS data & 6.53 & 16 & 5072 \\
\hline & 2013 & point-level GPS data & 3.47 & 0 & 1586 \\
\hline \multirow[t]{3}{*}{ B } & 2003 & presence detected $^{3}$ & not delimited & $\mathrm{n} / \mathrm{a}$ & $\mathrm{n} / \mathrm{a}$ \\
\hline & 2005 & visual assessment ${ }^{4}$ & not delimited & $\mathrm{n} / \mathrm{a}$ & $\mathrm{n} / \mathrm{a}$ \\
\hline & 2009 & point-level GPS data & 1.80 & 0 & 156 \\
\hline \multirow[t]{3}{*}{$\mathrm{C}$} & 2003 & presence detected & not delimited & $\mathrm{n} / \mathrm{a}$ & $\mathrm{n} / \mathrm{a}$ \\
\hline & 2005 & visual assessment & not delimited & $\mathrm{n} / \mathrm{a}$ & $\mathrm{n} / \mathrm{a}$ \\
\hline & 2009 & point-level GPS data & 2.06 & 0 & 261 \\
\hline \multirow[t]{2}{*}{$\mathrm{D}$} & 2004 & presence detected & not delimited & $\mathrm{n} / \mathrm{a}$ & $\mathrm{n} / \mathrm{a}$ \\
\hline & 2008 & point-level GPS data & 2.3 & 0 & 1461 \\
\hline
\end{tabular}

Mapping methodologies are: 1) no point level GPS data were recorded of A. gracilipes presence/absence, only the boundary of the population was determined; 2) point level GPS data recorded of A. gracilipes presence/absence throughout the population; 3) Rapid visual reassessment of A. gracilipes presence/absence only, no GPS data recorded; 4) single GPS detection point only collected to record the location of a broad and unmapped $A$. gracilipes population.

a the area and number of presence/absence points for all four years, refers to the re-surveyed area delimited by the polygon in Figure 2.4

${ }^{\mathrm{b}}$ indicates that approximately half of the absence points were inadvertently lost and are not reported here

all years (Figure 2.4). No detections were made up to $400 \mathrm{~m}$ surrounding site $\mathrm{G}$ in 2012 , or at sites A-C where searches sometimes exceeded far more than $100 \mathrm{~m}$ past a detection point, making it unlikely that the populations had just moved to a new location.

\subsection{Discussion}

Populations of $A$. gracilipes have previously been reported to fluctuate (Haines et al. 1994; Abbott 2005; Gruber et al. 2012a) but their decline over several years has rarely been monitored. We quantified the spatial decline of four A. gracilipes populations, and documented the extinction of three others. On the Seychelles, very abundant local populations of A. gracilipes declined and disappeared over extensive areas within five years (Haines et al. 1994). A supercolony on Christmas Island was observed to decline 


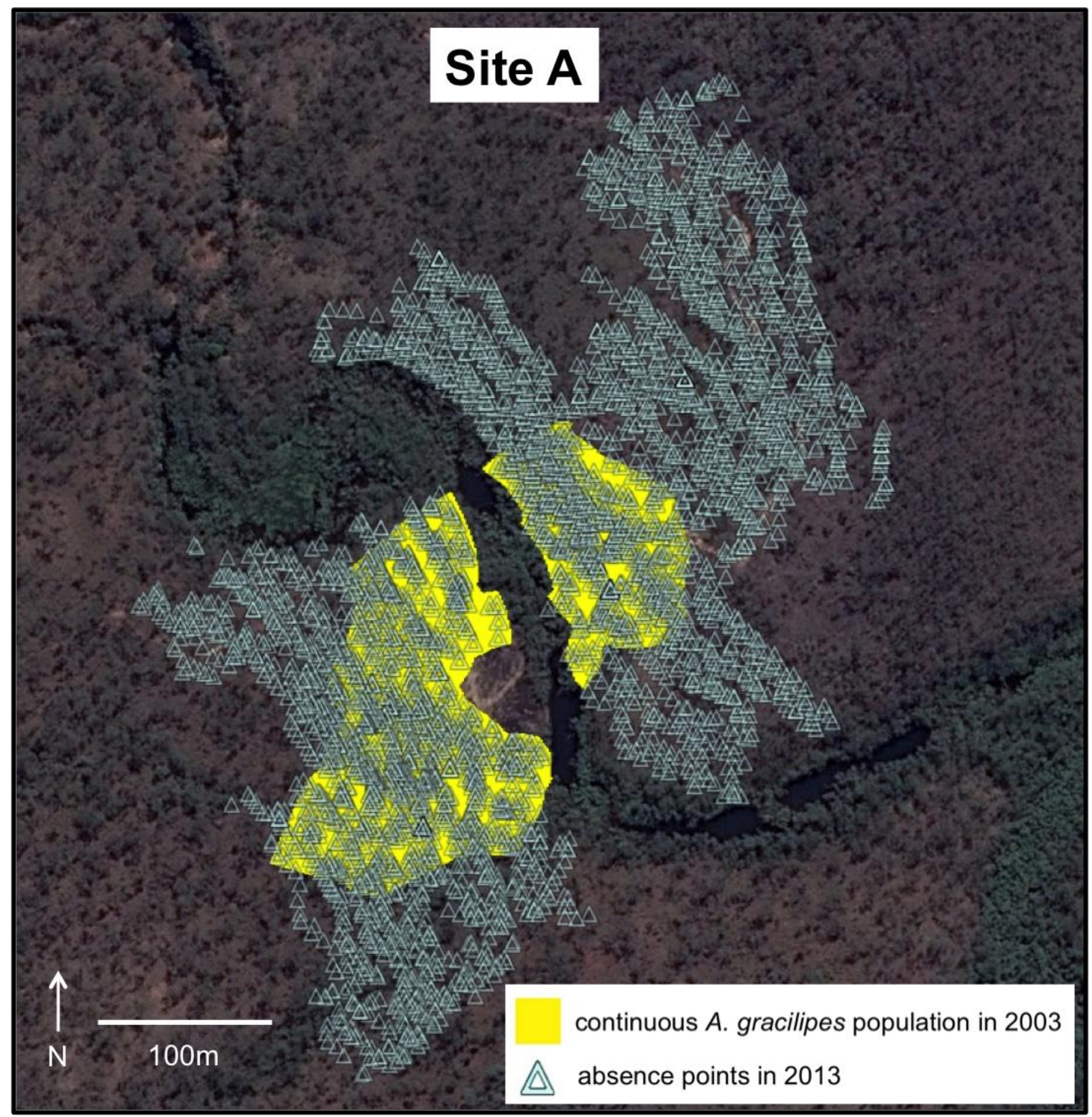

Figure 2.2. Site A, showing the distribution of a continuous $A$. gracilipes population surveyed in 2003 (polygons), and absence points recorded when the site was resurveyed in 2013 (triangles). No $A$. gracilipes were observed in the 2013 sampling. Note that the central data gap is an inaccessible flooded creek and bare rock face.

rapidly in abundance over an 18 month period, to the point that red land crabs, which are completely excluded by high-densities of A. gracilipes, were able to recolonize the area (Abbott 2005; Abbott et al. 2014). Though uncommon, other established and widespread invasive species have been known to collapse or decline suddenly (Simberloff and Gibbons 2004; Sandström et al. 2014). For example, invasive giant African land snail populations on islands periodically crash, apparently due to a bacterial pathogen 
(Simberloff and Gibbons 2004). Introduced deer are well known for initial population explosions followed by catastrophic collapse, caused by overexploitation of resources (Simberloff and Gibbons 2004). The highly invasive signal crayfish has been known to suffer unexplained population declines, Sandström et al. (2014) found that $41 \%$ of surveyed signal crayfish populations in Swedish lakes had collapsed. This sudden disappearance of populations has also been observed in several species of invasive ants (Wetterer 2006, 2012). Pheidole megacephala populations have been observed to go

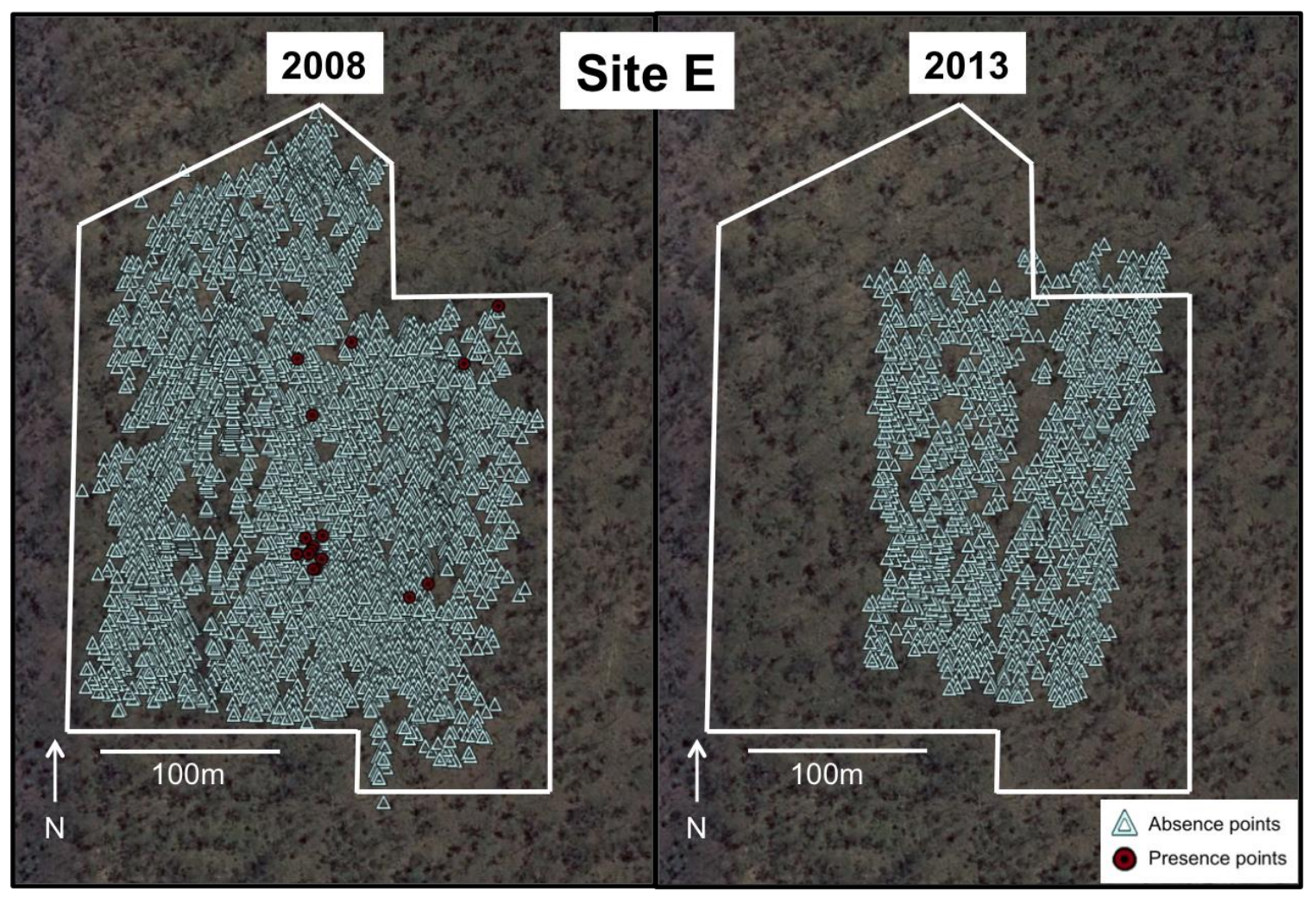

Figure 2.3. Site E showing the $A$. gracilipes population as mapped in 2008 and 2013. The white polygon indicates the same area on both maps.

through boom and bust phases throughout their introduced range (Wetterer 2012) and local populations of Linepithema humile in New Zealand periodically collapse (Cooling et al. 2012). Mechanisms such as pathogens and overexploitation of resources may not cause the disappearance of a population, but simply reduce the population to low-enough levels that it becomes vulnerable to Allee effects or stochastic processes (Taylor and Hastings 2005). 
Invasive species are thought to be vulnerable to population decline due to low genetic diversity resulting in inbreeding depression and the inability to adapt to local environments (Vogel et al. 2010). A recent study investigating population genetic

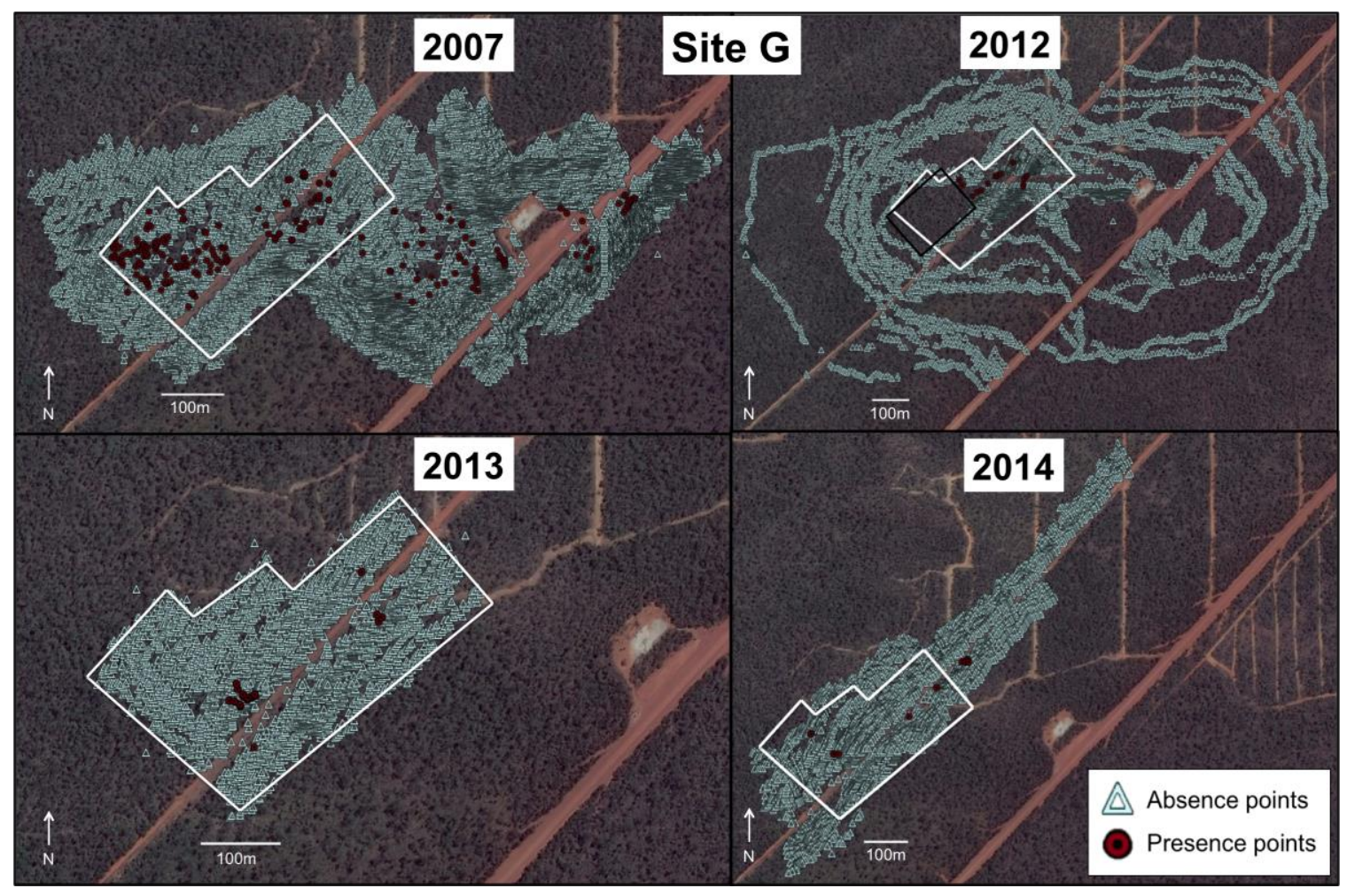

Figure 2.4. Site $\mathrm{G}$, showing the $A$. gracilipes population as mapped in 2007, 2012, 2013 and 2014. The white polygon indicates the same area on all maps. The black rectangle on the 2012 map indicates where GPS data of $\boldsymbol{A}$. gracilipes absence points were lost.

structure showed that all A. gracilipes populations in Arnhem Land are likely to be descended from the introduction of a single population (Gruber et al. 2012a).

Due to the nature of the surveys done, we do not know when A. gracilipes became established in our study sites, nor in most cases how long it took populations to collapse. However, we do know that populations at sites B and C disappeared completely in under two years, so swift declines are possible. Declines of smaller infestations such as observed at site E may be explained by stochastic events that all small populations are vulnerable to, but collapses of larger infestations such as observed at sites A and G are less easily explained. There are several hypotheses to explain these results and patterns, 
which include fire, pesticides, migration, resource overexploitation and pathogens or parasites. Bush fires are commonplace in the savanna woodland where these declines occurred, with up to half or more of some regions being burnt each year (Russell-Smith et al. 1997) and most sites in this study burning at least every two years (B. Hoffmann, personal observation). Considering the high frequency of burning, it seems very unlikely that A. gracilipes would have been able to persist in this region for over 30 years (and probably much longer) if populations could not tolerate fire. These populations have not been treated with poison baits, nor do they appear to have moved. Though individual nests may move up to several meters, it is extremely unlikely for an entire population covering multiple hectares and consisting of hundreds of individual nests to move hundreds of meters away as one and we found no evidence for this. Overexploitation of resources is also an unconvincing argument in this case. Like many other invasive ant species, A. gracilipes populations are largely driven by carbohydrates (Holway et al. 2002; O'Dowd et al. 2003) and the savanna woodland in Arnhem Land consists predominantly of Acacia, which has carbohydrate-producing extra-floral nectaries (Lach and Hoffmann 2011). Previous studies in this region have found no association between Acacia or invertebrate abundances in high-density vs low-density A. gracilipes populations (Hoffmann and Saul 2010; Gruber et al. 2012b). Five arthropod nest symbionts and one ecto-parasitic mite have been found in association with A. gracilipes in Arnhem Land (Hoffmann 2015), but they are unlikely to have such an important influence as they have been rarely encountered.

Pathogens are a final factor that may cause localized extinctions, and work is currently being undertaken to determine what role, if any, pathogens may play in these declines. Invasive species can carry their own microorganisms and pathogens into their new environment (Oi and Valles 2009), or pick up novel ones in their introduced range (Espadaler et al. 2011). For example, it is now well known that Solenopsis invicta brought several pathogens with it to North America from its native range in South America, and many more have been found by surveying its native range (Oi and Valles 2009). Some of these pathogens, such as Kneallhazia solenopsae, are now being used as biocontrol agents against $S$. invicta (Oi and Valles 2009). As the native range of $A$. 
gracilipes is unknown, we are unable to survey for potential co-evolved pathogens, but we do know that $A$. gracilipes harbours potentially pathogenic fauna throughout its range (Gruber 2012). It remains unclear, however, exactly which associated fauna is pathogenic or not, and what is from the native range or has been transmitted to the ant within the exotic range. Unexplained population declines such as these are key research arenas because the declines may indicate unhealthy populations and the presence of pathogens (Valles et al. 2012). Declining A. gracilipes populations in Arnhem Land represent a unique opportunity to investigate mechanisms by which a globally significant invader declines. Identifying the drivers and mechanisms behind such declines could have important applications for invasive species management worldwide. 


\section{Chapter 3: An experimental fungal pathogen infection did not affect Anoplolepis gracilipes reproduction}

\subsection{Abstract}

Pathogens may have a deleterious impact on the reproduction and survival of their hosts. In preliminary studies, I documented a significant negative correlation between fecundity and infection by a potential fungal pathogen in queens of the invasive ant, Anoplolepis gracilipes. Here, I investigated the effect of inoculation with a fungal entomopathogen or fungicidal antibiotics on the reproductive output of A. gracilipes. Neither treatment significantly affected the number of eggs, larvae, worker pupae or male pupae produced after 70 days in laboratory colonies. As in the following chapter, infection by a potential fungal pathogen was negatively correlated with oocyte number; however, egg, larvae and pupae number present in the nests were not associated with infection status. Queen number also had no effect on colony reproductive output, suggesting that queens adjust their egg-laying rate in the presence of other queens. In this laboratory trial, I found no evidence that the fungus Metarhizium anisopliae is able to affect the reproductive output of A. gracilipes at the tested concentrations, though different fungal pathogens may have different effects.

\subsection{Introduction}

The microbial community living within an insect may have both positive and negative effects on its health and reproduction (Dunn et al.2012; Russell et al. 2009). Many bacterial pathogens have been found to negatively affect reproduction in insects (Dunn $e t$ al.2012; Wenseleers et al. 1998), while bacterial symbionts in the gut may help insects obtain the nutrients they need to live and reproduce (Dillon and Dillon 2004; Russell et al. 2009). Bacterial and fungal entomopathogens can be responsible for significant declines of insect pest populations, such as with the gypsy moth, Lymantria dispar dispar, infected by the fungus, Entomophaga maimaiga, in eastern North America (Lacey et al. 2001). Similarly, the South American bumble bee, Bombis dahlbomii, is disappearing across its native range, which has been hypothesized to be due to a 
3. No effect of a fungal pathogen on A. gracilipes reproduction

protozoan parasite spread by the introduced bumble bee, B. terrestris (Schmid-Hempel et al. 2013). Cooling et al. (2012) hypothesized that pathogens were responsible for unexplained declines in populations of the Argentine ant, Linepithema humile, in New Zealand and multiple viral infections have been observed in these ants (Sébastien et al. 2015)

The impact of disease and parasites may be especially high in social animals, due to increased transmission rates (Hughes and Boomsma 2004). Within ant species, Valles et al. (2010) found that the unicolonial polygne form of Solenopsis invicta was more likely to be infected with pathogens than the monocolonial monogyne form, probably due to the high levels of intermixing individuals found in unicolonial colonies. Low genetic diversity may result in lowered resistance to disease and reduced anti-pathogen response in ants (Ugelvig et al. 2010). Introduced unicolonial populations of ants are hypothesized to be especially susceptible to pathogens and parasites because their unique colony structure prevents gene flow from other newly introduced populations, thus maintaining what may be very low genetic diversity (Ugelvig and Cremer 2012). Genetic diversity has been found to increase colony resistance to parasitic infection in leaf-cutting ants (Hughes and Boomsma 2004). The polygynous colony structure of the invasive ant, Anoplolepis gracilipes, could make it particularly vulnerable to disease. In support of this hypothesis, Gruber et al. (2012c) found that genetic diversity had a strong positive relationship with A. gracilipes abundance in Arnhem Land.

Pathogens are ubiquitous in nature and may influence the population dynamics of a species by affecting birth and/or death rates (Tompkins et al.2011). For example, polygyne $S$. invicta queens experienced decreased weight, survival and egg-laying rates when they were infected with the microsporidian, Kneallhazia solenopsae (Williams et al. 1998). There can also be tradeoffs between investment in immune response and other physiological processes, such as reproduction (Calleri et al. 2006; Tompkins et al. 2011). For example, Contreras-Garduño et al. (2014) found that immune priming, the enhanced protection by the immune system due to past experience with the same pathogen, resulted in reduction in the reproductive output of the mosquito, Anopheles albimanus, when 
3. No effect of a fungal pathogen on A. gracilipes reproduction

infected with Plasmodium berghei. Though there was no difference in egg-laying rates between immune primed females and control females, the eggs of primed females were less likely to hatch, and primed females were less likely to lay eggs. Calleri et al. (2006) observed that founding pairs of the termite, Zootermopsis angusticollis, had a lower reproductive output (laid fewer eggs) in the first 70 days after serial exposure to the entomopathogenic fungus Metarhizium anisopliae, though this effect diminished over time and was insignificant by 300 days.

Ants are hosts to a suite of pathogens (Allen and Buren 1974; Boer 2008; Briano et al. 1995a; Espadaler and Santamaria 2012; Poinar 2012; Schmid-Hempel 1998; Valles et al. 2010; Yang et al.2010). The effect many of these fungi have on ant worker mortality has been well documented (Hughes et al. 2002; Hu et al. 2011; Reber and Chapuisat 2012). The effect of such pathogens on queens and their reproduction, however, is less well known. Metarhizium anisopliae is a common fungal pathogen of ants and has been shown to affect egg-laying rate in other social insects (Jaccoud et al. 1999; Calleri et al. 2006; Okuno et al.2012). It is often used as an experimental pathogen of ants and termites (Hughes and Boomsma 2004; Calleri et al. 2006; Konrad et al. 2012; Reber and Chapuisat 2012).

In Arnhem Land, Australia, populations of A. gracilipes have been known to dramatically decline in abundance and sometimes disappear completely (Chapter 2). In this chapter, I hypothesized that a fungal pathogen was able to reduce queen reproductive output to the point that populations would decline. Preliminary studies show that queens with an unidentified infection, likely fungal in nature (hereafter referred to as infected queens), have significantly fewer oocytes in their ovaries than uninfected queens (preliminary results for Chapter 4). Here, I experimentally investigated the impact of a fungal pathogen on reproduction in A. gracilipes, by (1) inoculating queens with the common entomopathogen $M$. anisopliae and (2) treating queens that are likely to be infected with an unidentified fungal pathogen with fungicidal antibiotics. I compared reproductive output among the different treatments. I expected a decrease in reproductive output in the 
3. No effect of a fungal pathogen on A. gracilipes reproduction

colonies treated with fungus, and an increase in reproduction in colonies treated with antibiotics.

\subsection{Methods}

\subsubsection{Laboratory colony set-up}

Queens and workers for laboratory colonies were collected on August $7^{\text {th }}, 9^{\text {th }}$ and $11^{\text {th }}$ 2013 from site H1 (Nhulunbuy, Australia, 12 17' 11.51"S 136 52' 11.53"E; see Chapter 4 for additional site details). This site was selected as a collection site because it was one of only two sites ( $\mathrm{H} 1$ and $\mathrm{H} 2)$ that had high enough population abundances to collect the necessary number of queens and workers, and also had the highest infection rate of queens ( $17 \%$ versus $4.5 \%$ at $\mathrm{H} 2$, Chapter 4$)$ between these two sites. Queens were collected by turning over large rocks and carefully gathering visible queens by hand. Infection status of queens was unknown at this time. Workers were collected from the same sites by placing gloved hands flat on the ground and allowing workers to run over them. Workers were then shaken into a bucket with a $10 \mathrm{~cm}$ barrier of Insect-A-Slip (BioQuip Products, CA USA) around the top. More than 160 queens and over 16000 workers were collected from approximately 60 different nests over a 10 ha area.

Queens and workers were randomly assigned to one of four treatments: Metarhizium treatment, Metarhizium control, antibiotic treatment and antibiotic control. There were 10 replicate colonies per treatment. Experimental colonies consisted of four queens and 400 workers. Each colony was placed in a nest box consisting of a plaster nest in a plastic container ( $21.4 \mathrm{~cm}$ long $\times 14.2 \mathrm{~cm}$ wide $\times 5.1 \mathrm{~cm}$ high) connected with a plastic tube to a foraging area (23.1 cm long x $15.3 \mathrm{~cm}$ wide $\times 10.2 \mathrm{~cm}$ high) (Figure 3.1; see appendices for nest design). The plaster nests contained a sponge within the plaster that could be wetted periodically to provide the ants with necessary moisture. The queens were added to colonies with workers already present. All eggs and pupae that were being carried by the workers from their old nests were removed, to ensure that there were no eggs, larvae or pupae present at the beginning of the experiment. Colonies were maintained at approximately $26 \pm 2^{\circ} \mathrm{C}$ under a $12 \mathrm{~h}$ day/night cycle. Water $(30 \mathrm{~mL})$ was added to the hydrating sponge of each nest every 5 days in order to keep the plaster nest moist. 
3.

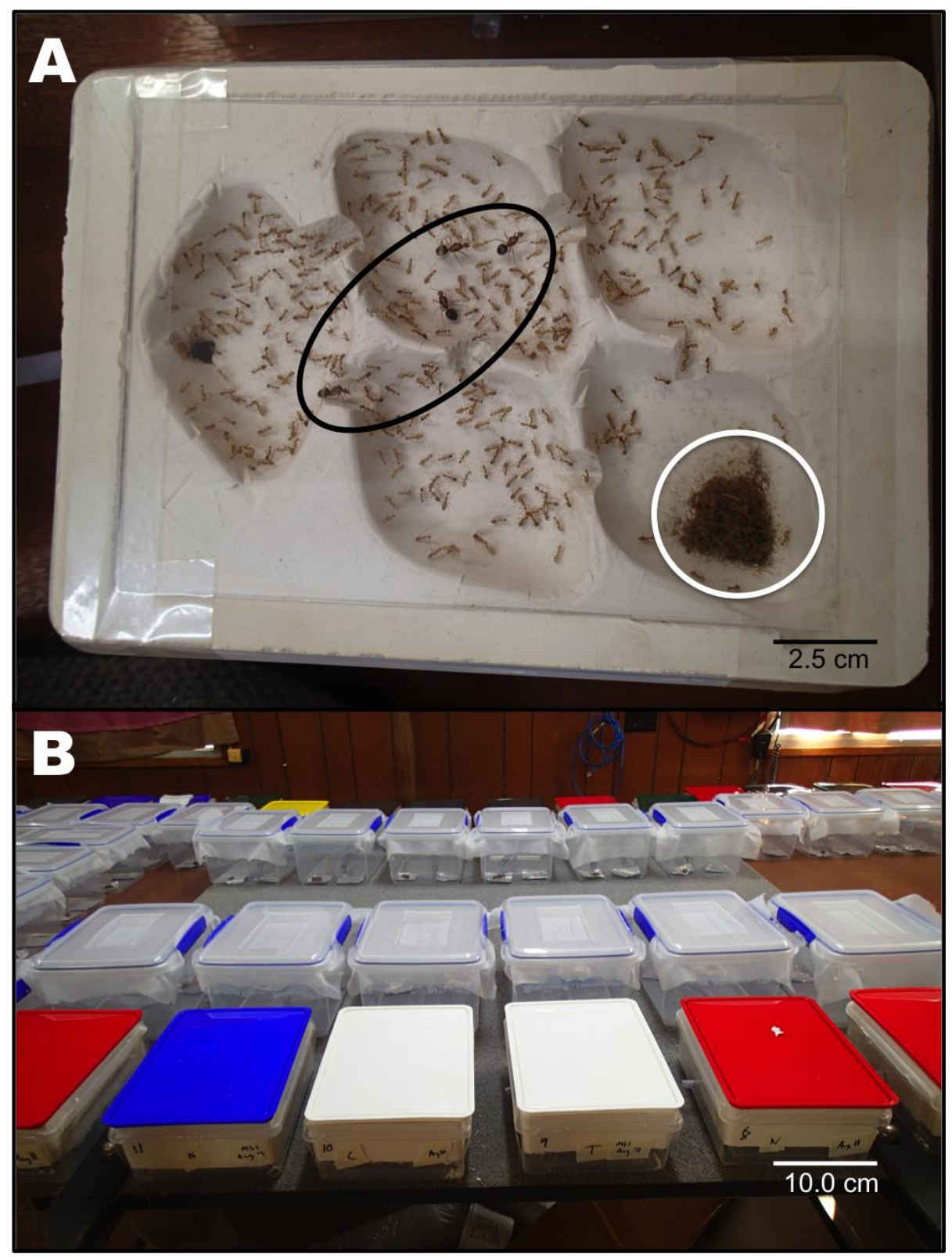

Figure 3.1. (A) Plaster nest with five chambers, the chambers are covered with perspex and usually shielded with an additional lid (see B). The four queens are circled in black among the much smaller workers, the midden (composed of dead workers and other debris) is circled in white. (B) Experimental set-up. The nest boxes seen in the foreground are each attached by a tube to a feeding arena.

Initially, colonies were fed one gram of cat food (Whiskas ocean fish platter, loaf style, Mars Australia Pty Ltd) and $1 \mathrm{ml}$ of $20 \%$ sugar water (Woolworths Homebrand, Australian white sugar) every three days. After the experiment had begun I observed worker foraging to be very low under this feeding regime, so after two weeks it was changed to feeding every five days. 
3. No effect of a fungal pathogen on A. gracilipes reproduction

\subsubsection{Metarhizium treatment}

Active M. anisopliae spores were procured from Becker Underwood, Australia (Biocane ${ }^{\mathrm{TM}}$ Granules, 2000 million spores M. anisopliae/g). The spores were mixed with sterile $0.05 \%$ Tween 20 to produce a solution with a final concentration of $10^{5}$ spores $^{-1}$ which represents a sublethal dose that was chosen to challenge the queens' immune system, but not to induce mortality (Calleri et al. 2006). This spore concentration was quantified using a haemocytometer. The spore solution was used to infect queens in the Metarhizium treatment. Queens were chilled for half an hour at $4^{\circ} \mathrm{C}$ before being inoculated with either a sublethal dose of $3 \mu \mathrm{L}$ of $10^{5}$ spore solution (Metarhizium treatment) or $3 \mu 10.05 \%$ Tween 20 (control). The solutions were applied directly to the gaster of each queen using a pipette. The inoculation was performed on a frozen freezer block to prevent queens from regaining consciousness during the process. After inoculation queens were placed in plastic isolation cups $(10.2 \mathrm{~cm}$ high $\times 8.6 \mathrm{~cm}$ in diameter) alone for 24 hours to prevent workers from removing spores before they could germinate. Self-grooming is not considered an effective defense against fungi (Okuno et al. 2012). A damp plaster block ( $3.5 \mathrm{~cm}$ long $\mathrm{x} 1.0 \mathrm{~cm}$ wide $\mathrm{x} 1.5 \mathrm{~cm}$ high) was also placed in each cup to prevent dehydration and the translucent lid was covered in red cellophane to simulate darkness. Queens were re-inoculated using the same methods two weeks after the beginning of the experiment. This second inoculation provided a further challenge to the A. gracilipes queens' immune systems, to ensure the highest probability of M. anisopliae infection (Calleri et al. 2006).

\subsubsection{Antibiotic treatment}

I wanted to investigate if eliminating any potential fungal infection affecting $15 \%$ of queens would positively affect their reproductive output. I chose to test this by treating queens with fungicidal antibiotics. Antibiotics may cause mortality in insects (Wilkinson 1998). In order to choose an appropriate antibiotic dosage that would not affect ant mortality I performed preliminary trials with three different antibiotic dosages $(2.5 \mathrm{mg} / \mathrm{g}$, $5 \mathrm{mg} / \mathrm{g}$ and $7.5 \mathrm{mg} / \mathrm{g}$ ) and a control $(0 \mathrm{mg} / \mathrm{g}$ ) (A. Sébastien, unpublished data). These doses were chosen to take into account the extremely small portions A. gracilipes eats (personal observation). I chose two antibiotics known to have fungicidal properties (Scheibel et al. 
3. No effect of a fungal pathogen on A. gracilipes reproduction

1979; Inouye et al. 2006): tetraethylthiuram disulfide (Aldrich Chemistry, 86720-50G) (referred to hereafter as disulfiram) and tetrachloro-1,4-benzoquinone (Aldrich Chemistry, 232017-25G) (referred to hereafter as chloranil). All doses were four parts chloranil and one part disulfiram, due to the higher toxicity of disulfiram (Manufacturer's instructions). Each treatment consisted of 10 mini colonies with 10 workers each. Antibiotics were fed to the workers instead of the queens because, like most ants, $A$. grailipes queens do not feed themselves but are instead fed by trophallaxis from the workers. Other methods such as injecting the queens directly with antibiotics (Wilkinson 1998) were considered too invasive, as I did not want to put the queens at risk.

Workers were starved for five days before beginning the treatment to make uptake of the antibiotic treated food more likely. They were then given one gram of cat food with the specified dose of antibiotics mixed in every day for five days. Workers were observed for one hour after feeding to ensure they were eating. The number of dead ants was counted each day and the bodies removed. A log rank test showed there was no significant difference in the survival distribution of workers between the different treatments $\left(\chi^{2}=\right.$ $6.478, p=0.091$ ). However, I chose to use the $5 \mathrm{mg} / \mathrm{g}$ dose because twice as many workers died in the $7.5 \mathrm{mg} / \mathrm{g}$ treatment as in the other treatments.

In the experimental treatments, the colonies were starved for five days prior to administering the antibiotics. Similarly, colonies in the antibiotic treatment were given one gram of cat food treated with the $5 \mathrm{mg} / \mathrm{g}$ antibiotic mixture once a day for seven days. Colonies in the control group were starved and then fed untreated cat food during this time period. After being fed, I confirmed that workers were consuming the cat food with antibiotics, by observing the colonies for one hour. After the seven days, colonies in the antibiotic treatment and antibiotic control were put on the same feeding regime as the Metarhizium treatment and Metarhizium control colonies.

\subsubsection{Measuring reproductive output}

Queen survival was assessed every two weeks for a period of 70 days. After this time period each entire colony was frozen and eggs, larvae, pupae, newly eclosed workers, 
3. No effect of a fungal pathogen on A. gracilipes reproduction

workers, queens and males were removed and counted. Male pupae were determined and counted by visual inspection of each pupa with a dissecting microscope. Queens were preserved in RNAlater ${ }^{\circledR}$ Stabilization Solution (Life Technologies, Auckland, New Zealand) until they could be dissected and their infection status and the number of oocytes in their ovaries assessed. RNAlater ${ }^{\circledR}$ was used as a preservative to enable future RNA extraction. The ovaries of queens were dissected and the number of oocytes in their ovaries counted under a Nikon SMZ1500 dissecting scope (30X magnification). The presence or absence of melanized nodules was also recorded.

\subsubsection{Statistical Analyses}

A Kaplan-Meier survival curve and logrank statistic were used to estimate queen survival over the course of the experiment and compare mortality between the four treatment groups. A multivariate general linear model was used to compare reproductive output between the treatments. The dependent variables were number of eggs, larvae and pupae. The independent variables were treatment and queen number at the end of the experiment. Data was not transformed. A generalized linear model with a Poisson distribution was used to determine the effect of treatment on the number of male pupae. I used a second multivariate general linear model to test if infection status and treatment affected oocyte number and reproductive output in individual queens. A Pearson's chisquare test was used to see if there was a relationship between infection status and treatment. All data analyses were performed using IBM SPSS Statistics v. 22.0.0.0 (IBM Corp. 2013). Figures were created using R v.3.0.2 (R Core Team 2013).

\subsection{Results}

Overall, I observed no significant $(p>0.05)$ effects of the pathogen or antibiotic inoculation treatments on A. gracilipes in these experimental trials. A log rank test showed there was no difference in the survival distribution of queens between the different treatments $\left(\chi^{2}{ }_{3}=0.90, p=0.821\right.$, Figure 3.2). Queen mortality during the experiment averaged $8 \%$, with at least one queen dying in 11 out of 40 colonies. Of the 11 colonies that lost queens, nine lost one queen and two lost two queens. Half of queen deaths occurred during the first 10 days of the experiment. Neither final queen number 
3. No effect of a fungal pathogen on A. gracilipes reproduction

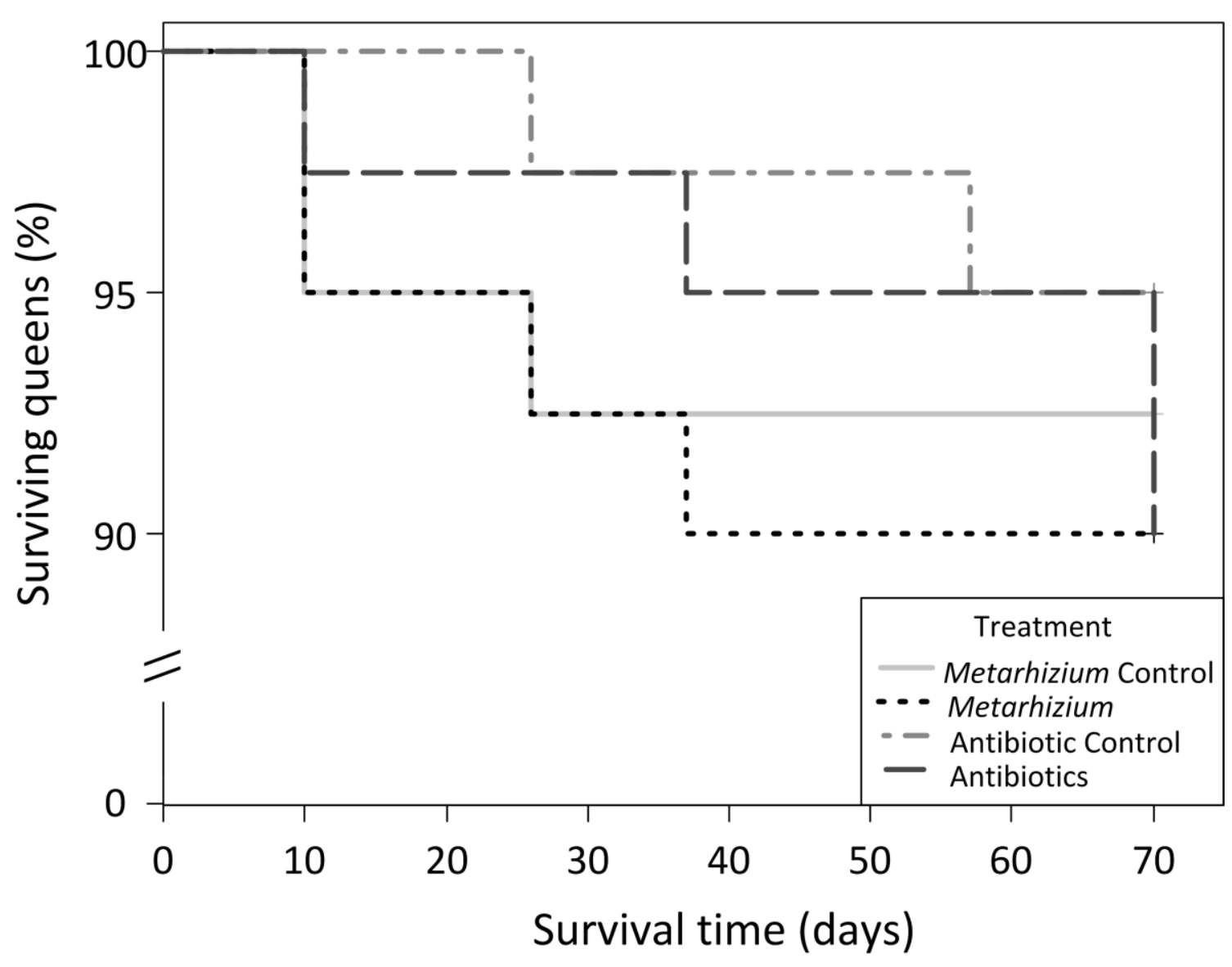

Figure 3.2. Survivorship curves for queens, with data divided by treatment. Queen survival time did not differ significantly between treatments. The $y$-axis has been split to allow a closer view of the survivorship curves.

$\left(F_{4,32}=1.71, p=0.173 ;\right.$ Wilks' $\left.\Lambda=0.82\right)$, nor treatment had a statistically significant effect on reproductive output $\left(F_{12,85}=1.13, p=0.348\right.$; Wilks' $\left.\Lambda=0.676\right)$ (measured as the number of eggs, larvae and pupae) (Table 3.1, Figure 3.3). Male pupae production was also not significantly affected by treatment (Wald $\chi^{2}{ }_{3}=0.68, p=0.881$ ). Fifty-five percent of colonies produced a mean of $2.591 \pm 0.387$ male pupae $( \pm \mathrm{SE})$, but no queen pupae were seen in any treatment.

Queen dissections revealed that twenty percent of queens in this experiment were infected with a potential fungal pathogen (see Chapter 4). Putative infection status was not associated with variation in reproductive output (Table 3.2, Figure 3.3F) $\left(F_{4,46}=1.74\right.$, $p=0.158$; Wilks' $\Lambda=0.87)$, but was negatively associated with oocyte number $\left(F_{1}=4.28\right.$, 
3. No effect of a fungal pathogen on A. gracilipes reproduction

$p=0.041 ; \mathrm{MS}=120.25)$. The interaction between treatment and status was also not significantly associated with reproductive output $\left(F_{12,122}=1.50, p=0.134\right.$; Wilks' $\Lambda=$ 0.70 ). I found no significant association between infection status and treatment (Pearson $\chi^{2}=4.32, p=0.231$ ).

\subsection{Discussion}

Research elsewhere has found that fungal pathogens can have significant negative effects on hymenopterans (Aronstein and Holloway 2013; Briano 2005; Oi and Williams 2003; Schmid-Hempel 1998), however I found no such effect. I found no evidence that $M$. anisopliae affects reproductive output in A. gracilipes. The number of eggs, larvae, pupae and male pupae observed in the Metarhizium treatment and the control did not differ statistically in the time interval examined. However, it is possible that the spores applied to the queens never germinated and/or crossed the cuticle, and thus failed to trigger an immune response. Unfortunately, in an oversight, I did not check to see if this infection had occurred. In addition, despite the precaution of isolating the queens for 24 hours after inoculation, workers may have removed the spores before they could penetrate. The $M$. anisopliae strain procured from Biocane ${ }^{\mathrm{TM}}$ has been shown to kill A. gracilipes queens at higher dosages than used in this experiment (see Chapter 4), so this strain is capable of penetrating the cuticle of this ant species.

My results in this experiment indicate that there appears to have been no trade-off between immune response and reproduction. Immune priming, which is increased protection against a pathogen that an organism has previously been exposed to, has been demonstrated in many insect species (Contreras-Garduño et al. 2014; Pham et al. 2007; Reaney and Knell 2010; Schmid-Hempel 2003), including social insects (Calleri et al. 2006; Galvez and Chapuisat 2014). However, the presence of immune priming seems to be variable across groups and species (ter Braak et al. 2013; Gonzalez-Tokman et al. 2010). For example, Reber and Chapuisat (2012) found no evidence for immune priming in the ant Formica selysi, in response to the entomopathogenic fungus Beauvaria bassiana. Further, Galvez and Chapuisat (2014) demonstrated immune priming in mated 
Table 3.1. Results of a multivariate general linear model testing the effect of treatment and the number of queens remaining at the end of treatment on the number of eggs, larvae and pupae ( $n=10$ colonies per treatment). Results of a generalized linear model examining the effect of treatment and the number of queens remaining at the end of treatment on the number of male pupae.

General linear model

\begin{tabular}{|c|c|c|c|c|c|c|c|c|}
\hline & $F$ & df & Wilks’ $\Lambda$ & & & & & \\
\hline Treatment & 1.13 & 12,85 & 0.68 & 0.348 & & & & \\
\hline Queen number & 1.71 & 4,32 & 0.82 & 0.173 & & & & \\
\hline & \multicolumn{4}{|c|}{ Treatment } & \multicolumn{4}{|c|}{ Queen number } \\
\hline Dependent variable & $F$ & $\mathrm{df}$ & MS & $p$ & $F$ & $\mathrm{df}$ & MS & $p$ \\
\hline Eggs & 1.21 & 3 & 37480.62 & 0.321 & 0.75 & 1 & 23256.20 & 0.392 \\
\hline Larvae & 0.40 & 3 & 46.91 & 0.754 & 0.79 & 1 & 92.45 & 0.381 \\
\hline Pupae & 1.21 & 3 & 969.03 & 0.319 & 0.42 & 1 & 334.15 & 0.522 \\
\hline \multicolumn{9}{|c|}{ Generalized linear model } \\
\hline & & $\mathrm{df}$ & Wald $\chi^{2}$ & $p$ & & $\mathrm{df}$ & Wald $\chi^{2}$ & $P$ \\
\hline Male pupae & & 3 & 0.68 & 0.881 & & 1 & 2.53 & 0.114 \\
\hline
\end{tabular}


Table 3.2. Results of a multivariate general linear model testing the effect of treatment, status and their interaction on the number of oocytes, eggs, larvae and pupae. Results of a generalized linear model examining the effect of treatment and queen number on the number of male pupae.

General linear model

\begin{tabular}{|c|c|c|c|c|c|c|c|c|c|c|c|c|}
\hline & $F$ & df & Wilks' $\Lambda$ & $p$ & & & & & & & & \\
\hline Treatment & 1.54 & 12,122 & 0.69 & 0.117 & & & & & & & & \\
\hline Status & 1.74 & 4,46 & 0.87 & 0.158 & & & & & & & & \\
\hline Treatment*Status & 1.50 & 12,122 & 0.70 & 0.134 & & & & & & & & \\
\hline Dependent variable & $F$ & $\mathrm{df}$ & MS & $p$ & $F$ & df & MS & $p$ & $F$ & $\mathrm{df}$ & MS & $p$ \\
\hline Oocytes & 1.59 & 3 & 44.64 & 0.198 & 4.28 & 1 & 120.25 & 0.041 & 0.30 & 3 & 8.38 & 0.833 \\
\hline Eggs & 1.58 & 3 & 52915.35 & 0.202 & 0.21 & 1 & 6927.28 & 0.652 & 0.57 & 3 & 19081.93 & 0.641 \\
\hline \multicolumn{13}{|c|}{ Generalized linear model } \\
\hline & & df & Wald $\chi^{2}$ & $p$ & & df & Wald $\chi^{2}$ & $p$ & & df & Wald $\chi^{2}$ & $p$ \\
\hline Male pupae & & 3 & 8.82 & 0.083 & & 1 & 0.43 & 0.510 & & 3 & 5.32 & 0.154 \\
\hline
\end{tabular}


3. No effect of a fungal pathogen on A. gracilipes reproduction
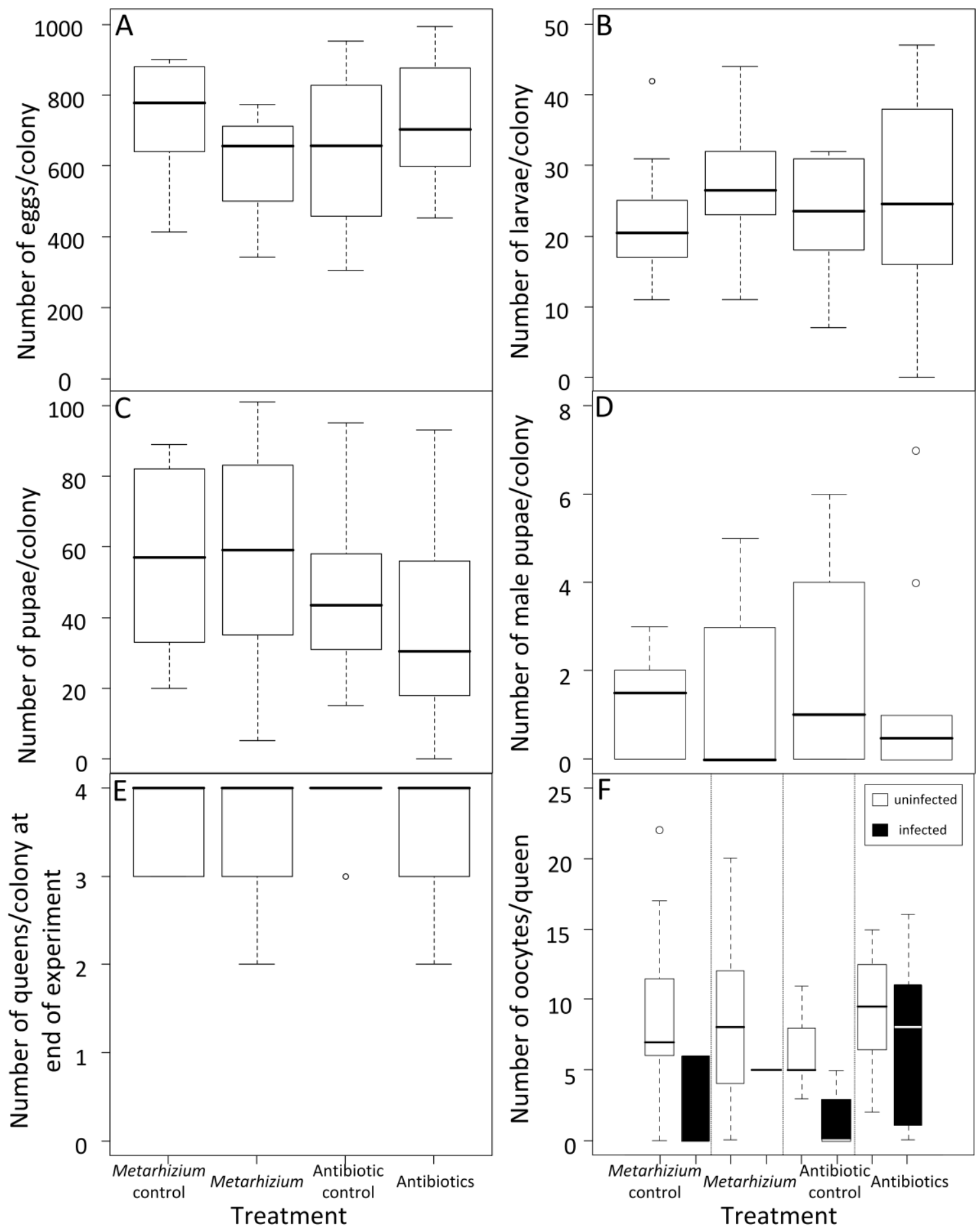

Figure 3.3. Boxplots of the reproductive output (eggs, larvae and pupae) of colonies after 70 days under four different treatments $(n=10$ per treatment). Graph $F$ shows reproductive output (measured as number of oocytes in each queen) for uninfected (white bars) and infected (black bars) queens within each treatment. Boxes show median with upper and lower quartiles, the whiskers show minimum and maximum values, outliers are more than $3 / 2$ times of upper quartile. 
3. No effect of a fungal pathogen on A. gracilipes reproduction

queens of the ant Lasius niger, but not in mated queens of the closely related species Formica selysi. It is possible A. gracilipes does not experience immune priming, or that A. gracilipes does not experience it in response to M. anisopliae specifically, as immune priming can be specific to certain pathogen species or even strains (Roth et al. 2009; Reber and Chapuisat 2012). Though M. anosopliae is cosmopolitan and a common entomopathogen of leaf-cutting ants in Central and South America (Hughes et al. 2002; Hughes and Boomsma 2004; Jaccoud et al. 1999), it is unknown whether A. gracilipes would encounter this fungus naturally in Australia or in its native range.

Treatment with antibiotics also had no effect on reproductive output, which may be attributed to one of three explanations. First, perhaps too few queens from the sample population were originally infected to observe a difference in reproductive output. Second, it is possible that the putative infection identified in Chapter 4 is not fungal. (This is, in fact, the case. The "black spots" are in fact melanized nodules, an innate cellular immune response in insects. Though a fungus could have caused the melanized nodules, they do not confirm an active infection.) The antibiotics chosen for this experiment are efficacious against fungi, but not bacteria or other pathogens (Inouye $e t$ $a l$.2006). Finally, it is also possible that the antibiotics may not have been ingested by the queens. Like the majority of ant species, A. gracilipes queens do not forage for themselves, but are instead fed by the workers, so though workers were observed feeding on the treated food, they may not have passed it on to the queens.

It is interesting that the reproductive output of colonies that suffered queen mortality did not differ from colonies with a full complement of queens. This result suggests that queens do not share in reproduction equally, or that queens adjust their egg-laying rate in the presence of other queens (Heinze and Keller 2000; Holldobler and Wilson 1990; Ruppell et al. 2002). The latter explanation is more likely, as examination of queen ovaries did not suggest a dominant female. This ability to adjust reproductive output depending on the number of co-habiting queens has been found in other ant species (Holldobler and Wilson 1990; Schrempf et al. 2011); however, it has never been demonstrated for A. gracilipes. 
I found the same negative relationship between infection status and oocyte number that I have documented elsewhere (see Chapter 4), but there was no relationship between infection status and overall colony reproductive output. This result is perhaps unsurprising considering only $20 \%$ of dissected queens in this experiment were infected by the putative pathogen. Additionally, I was not able to measure the reproductive output of each individual queen: only the colony's total output. This result supports the idea that uninfected queens can compensate for low reproductive rates in nest-mates. Originally, I had planned to have a second treatment level, with colonies from populations with high and low levels of infection. Unfortunately, it proved impossible to collect enough queens from the highly infected population to do this. Though the antibiotic treatment may have had an effect had a higher number of infected queens been present, it is also possible that the majority of queens would have had to have been infected for this to be the case. The ability for queens to adjust their reproductive output in response to other queens may mask effects of pathogens in polygynous colonies. This result is supported by the fact that a very high density site like $\mathrm{H} 1$ can have $15 \%$ of queens infected and still be expanding. It is possible that a difference in net reproductive output would not be seen unless the infection rate among queens was exceedingly high.

These experiments do not rule out the possibility of the presence of a fungal pathogen affecting queen reproductive output in A. gracilipes. It is possible that a negative effect would only be seen if the queens were both infected and otherwise stressed. The susceptibility of insects to pathogens is often significantly affected by stressors such as temperature, poor nutrition and starvation (Ben-Ami et al.2010; Donegan and Lighthart 1989; Jouvenaz and Kimbrough 1991; Lord 2010). Solenopsis invcta virus-1 is asymptomatic under ideal conditions, but causes significant mortality when the host is stressed (Oi and Valles 2009). Briano and Williams (1997) found that starved colonies of Solenopsis richteri that were infected with the microsporidian Kneallhazia solenopsae succumbed faster than starved uninfected colonies. The effect of the microsporidian was significantly faster when colonies were maintained at $28^{\circ} \mathrm{C}$ versus $21^{\circ} \mathrm{C}$. In my experiment, A. gracilipes colonies were held between $24^{\circ} \mathrm{C}$ and $26^{\circ} \mathrm{C}$, which is considered the ideal daytime temperature range for this species (Hoffmann 2014). 
3. No effect of a fungal pathogen on A. gracilipes reproduction

Perhaps the treatments would have had a different effect had the ants been held at different temperatures, been fed less, or been affected by some other form of stress.

\subsection{In Retrospect...}

If I were able to do this experiment again, I would do several things differently. In the absence of colonies from a highly infected population, I would forego the antibiotic treatment altogether and instead have a treatment that artificially stresses the colonies, such as starvation or altered temperatures. Queens would have been isolated for 48 hours instead of 24 hours, to decrease the odds of spores being removed by the workers. I chose 24 hours because $A$. gracilipes queens stop laying eggs permanently when deprived of the company of workers for too long (B. Hoffmann, personal communication). Each colony would have had a single queen so compensation would not have been an issue.

Additionally, I would have counted the number of larvae and pupae (eggs are too small to count with the naked eye) bimonthly to investigate if there was an early temporary effect of either treatment, such as was found by Calleri et al. (2006). Finally, the viability of the Metarhizium spores would have been tested by inoculating additional queens with a higher concentration of spore solution and monitoring survival, as I do in Chapter 4. 


\section{Chapter 4: Pathogen-related reduced oocyte production in Anoplolepis gracilipes queens in Arnhem Land, Australia}

\subsection{Abstract}

Anoplolepis gracilipes has been classified as one of the six most widespread and abundant invasive ant species. Populations of this invader in Arnhem Land, Australia have been observed to decline, but the reasons behind these declines are not known. In the interest of finding a potential mechanism or reason for these declines I investigated if there is evidence for a pathogen that could be responsible for killing ant queens or affecting their reproductive output. I measured queen number per nest, fecundity and fat content of queens from sites classified as low, medium and high-density A. gracilipes infestation areas. I found no statistically significant difference in any of these variables between site categories. However, $23 \%$ of queens were found to have melanized nodules, a cellular immune response, in their ovaries and fat bodies. Nodule presence was not related to ant population dynamics at each site (declined, declining or expanding). However, queens with nodules had $22 \%$ fewer oocytes in their ovaries on average. Triggers of nodule production in A. gracilipes queens were experimentally tested by injecting queens with fungal spores, bacterial lipopolysaccharides, or saline solution. Melanized nodules were only produced in response to fungal spores. The melanized nodules found in dissected queens are highly likely to indicate the presence of pathogens or parasites capable of infecting A. gracilipes. Though this microorganism is as yet unidentified, this is the first recorded incidence of a pathogen or parasite of the invasive ant A. gracilipes.

\subsection{Introduction}

Insects are host to diverse microbial communities (Dillon and Dillon 2004; Anderson $e t$ al. 2011). These microbes may be mutualistic, such as lactic acid bacteria in Apis mellifera, which appear to aid in host defense against pathogens (Vasquez et al. 2012; Koch et al. 2012). The microbial community may also be pathogenic (Schmid-Hempel 1998). Pathogens can negatively affect reproduction in insects (Calleri et al. 2006; Dunn 
et al. 2012), with symptoms including low energy reserves, and reduced fertility. Low fat content alone can impact survival; for example, ants with a lower fat content have been found to be less able to survive physiologically stressful conditions (Elmes et al. 1999). The fat content of an adult insect is an indicator of general health (Fellous and Lazzaro 2010). The size of the fat body, which can be estimated by measuring fat content, is also linked to immunity (Fellous and Lazzaro 2010).

Pathogens can affect colony health via the queen, either by killing the queen directly, or negatively affecting her reproduction. The microsporidian, Kneallhazia solenopsae, has been shown to cause a reduction in colony size in fire ants, potentially by destroying the fat bodies of queens, thereby reducing their fertility (Briano et al. 1995b). In A. mellifera colonies in Australia, the most common cause of death of larval queens is the Black queen cell virus (BQCV) (Nguyen et al. 2011) and Valles et al. (2013) found Solenopsis invicta queens infected with Solenopsis invicta virus-3 (SINV-3) had fewer eggs in their ovaries than uninfected queens.

In many social insects, the queen is the sole reproducing female in the colony. She alone produces workers, which are responsible for all the other tasks essential for colony functioning such as brood care, colony defense, and foraging (Alaux et al. 2011). In polygynous ant species population size and spread is usually positively correlated with queen number (Ingram 2002). Therefore low queen numbers could constrain colony growth and expansion (Nonacs 1991). Low queen numbers may be due to queen mortality or low queen production (old queens are not replaced). Greenburg et al. (1985) found that the number of queens in S. invicta colonies correlated negatively with the number of eggs laid per queen, but correlated positively with total number of eggs produced per colony.

Social insects, like other social animals, are thought to be particularly vulnerable to disease because of their extremely close living conditions and increased pathogen transmission rates (Schmid-Hempel 1998). Colonies may host diverse pathogen communities. These pathogen communities are especially well studied in A. mellifera, 
with colony collapse disorder and the myriad of pathogens associated with it as the classic example (Cox-Foster et al. 2007; Oldroyd 2007; vanEngelsdorp et al. 2009). Other hymenopteran species may also harbour many pathogens and parasites that affect their population dynamics (Briano et al. 1995c, 2002; Cameron et al. 2011). Pathogens of invasive species are of particular interest because of their potential role in biocontrol (Oi and Valles 2009; Valles et al. 2012; Lester et al. 2015; Sébastien et al. 2015). The most well-studied invasive ant species, $S$. invicta, has over 40 identified pathogens and parasites (Oi and Valles 2009). Most of these pathogens were discovered by exploring the native range (Allen and Burne 1974; Oi et al. 2015). The native range of an invasive species, however, is not always known. For example, Anoplolepis gracilipes (another invasive ant species, prevalent in the Pacific region) is hypothesized to come from Southeast Asia, but this has not been confirmed (Wetterer 2005; Drescher et al. 2011). Some preliminary studies have been done to identify the microorganisms this ant harbours (Sébastien et al. 2011; Gruber 2012) but no pathogens or parasites for this invasive ant have so far been described.

Here, I investigated observed population declines in the invasive ant A. gracilipes in Arnhem Land, Australia. The nature of these observed population declines, the lack of worker symptoms and the slow rate of decline, led to the hypothesis that if a pathogen was involved, it was affecting the queens, either through direct mortality, and/or reducing their reproductive output (Cooling and Hoffmann 2015). To investigate this hypothesis, I first selected three types of populations (low, medium and high-density) for study based on a combination of spatial surveys, population abundance and historical observation. This classification of population type will be used for the comparison of several factors in this chapter and Chapter 5. I then compared: 1) queen number, 2) fecundity, and 3) fat content between nests and queens from the three types of populations. I hypothesized that low and medium-density populations would have significantly fewer queens per nest, and those queens would have a lower reproductive output and reduced energy reserves than queens from high-density populations. 
4. Pathogen-related reduced oocyte production in A. gracilipes

\subsection{Experimental Methods}

\subsubsection{Site selection}

Site selection was determined by two factors: the present density of $A$. gracilipes populations at each site, and each site's history of A. gracilipes population decline or expansion (B. Hoffmann, personal observation; Cooling and Hoffmann 2015). Density was determined using a combination of surveying to determine the spatial extent of each population and pitfall trapping to examine A. gracilipes abundance. I selected six study sites that had A. gracilipes populations in various stages of decline and had never had ant management, such as with the use of toxic baits (Figure 4.1). The low-density populations $(\mathrm{L} 1, \mathrm{~L} 2)$ were all that remained of much larger populations that had declined substantially in the past 5 years (B. Hoffmann, personal communication). The mediumdensity populations (M1, M2) covered a much wider area than the low, and had higher abundances. These populations appeared to be stable, but also once belonged to larger populations in which some decline had been observed. The high-density populations (H1, H2) were expanding, and covered a large area with abundances that were several order of magnitudes higher than the low and medium density populations. Though sites M1 and M2 and $\mathrm{H} 1$ and $\mathrm{H} 2$ are very close together they can still be considered independent from each other, because the maximum foraging range of an A. gracilipes worker is $35 \mathrm{~m}$ (B. Hoffmann, unpublished data). The above populations are separated by $400 \mathrm{~m}$ and $450 \mathrm{~m}$ respectively, so there is almost certainly no mixing of workers between sites. Likewise, in Arnhem Land, A. gracilipes queens do not partake in nuptial flights. Instead, they appear to mate inside their natal nest and either stay there or walk a maximum of a couple dozen metres away to form new nests nearby (Hoffmann 2015). Therefore, there is no genetic input from geographically separated populations either.

\subsubsection{Site surveys}

In late July of 2013 and 2014, I and a crew of five to eight trained volunteers (Conservation Volunteers Australia) mapped four different A. gracilipes populations (Figure 4.1). Mapping and subsequent re-surveys of populations were conducted by visual assessments of the presence/absence of $A$. gracilipes workers. These assessments 


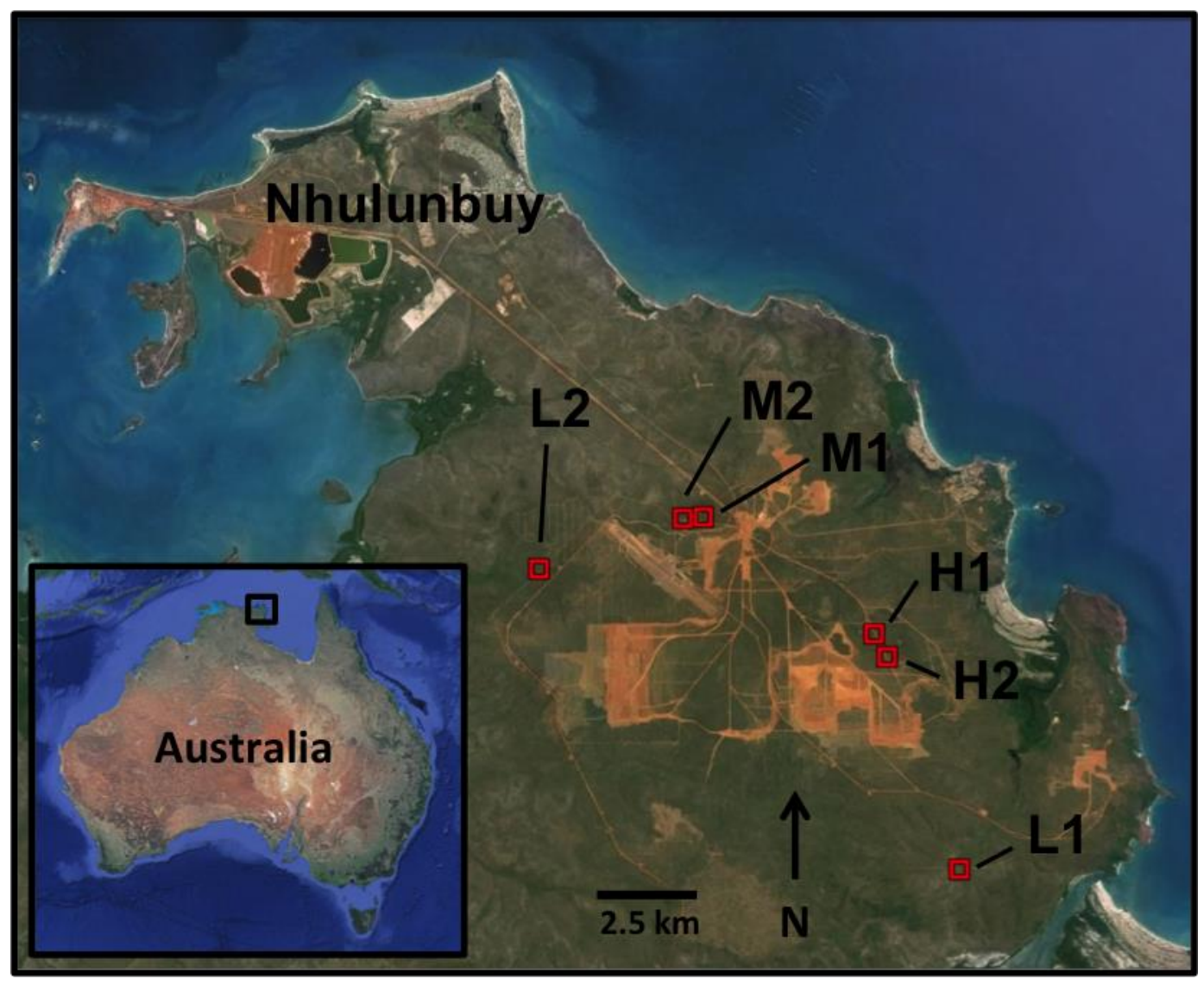

Figure 4.1. Inset of Australia and map of Arnhem Land showing study site locations (red squares) and town of Nhulunbuy. $L$ denotes low-density populations, $M$ medium-density and $H$ high-density. Sites M1 and M2 are $450 \mathrm{~m}$ apart and $\mathrm{H1}$ and $\mathrm{H2} 400 \mathrm{~m}$ apart and are distinct populations.

were conducted between 0600-0930 and 1530-1830, when high temperatures do not greatly hinder A. gracilipes activity in these areas (Hoffmann 2015). Assessments were conducted by teams of people walking in parallel, commencing in any direction from the original A. gracilipes detection point. Assessments were conducted haphazardly, approximately one per every $2 \mathrm{~m}$. Point-level GPS data were collected at each assessment point, A. gracilipes was recorded as present or absent. Two study sites (H1, H2) were not mapped because 1) these sites have very abundant, dense A. gracilipes populations and every point taken would be a "present" point, and 2) these sites were on the Rio Tinto minesite, which made surveying unfeasible. At sites where the A.gracilipes population was very widespread and therefore too time-consuming to map in its entirety, a subsection of the population (200 m x $100 \mathrm{~m}$ ) was mapped in the area where I had previously sampled (see white polygons in Figure 4.3). 
4. Pathogen-related reduced oocyte production in A. gracilipes

\subsubsection{A. gracilipes abundance}

In addition to mapping distribution, I also measured abundance at all six sites using pitfall traps. Traps were placed at each site on August $19^{\text {th }} 2013$ and July $24^{\text {th }}$ and $25^{\text {th }}$ 2014 and left for 48 hours. There were four plots in each site, separated by at least $10 \mathrm{~m}$. Plots were placed in areas where crazy ants were seen to be present. Within each plot, five pitfall traps were placed one metre apart and arranged in a cross shape. A mixture of 1:1 ethylene glycol and water was used as a preservative, and each trap was filled $2 / 3$ full. Pitfall traps were $5.5 \mathrm{~cm}$ high and $4.5 \mathrm{~cm}$ across. After collection A. gracilipes were removed and counted. All other ant species were removed, stored in 70\% ethanol and taken to the CSIRO Tropical Ecosystems Research Laboratory where they were identified to species and functional group (Andersen 1995; see appendices for results on local ant communities). Pitfall traps were pooled for each plot (Krushelnycky and Gillespie 2008). A univariate general linear model was used to compare A. gracilipes abundance between sites and years. Anoplolepis gracilipes abundance was log transformed to meet assumptions of normality before analysis. The univariate general linear model was run in the program IBM SPSS Statistics v 22.0.0.0.

\subsubsection{Nest density and queen number}

Queens were collected in February 2013 and 2015. Each year, three $30 \mathrm{~m}$ transects spaced a minimum of $30 \mathrm{~m}$ apart were randomly placed at each site. I searched a $1 \mathrm{~m}^{2}$ area along the entire transect length by scraping away litter with a trowel and moving rocks and logs. I excavated every A. gracilipes nest I found and counted and collected the queens. A nest was defined as having workers and eggs, larvae or pupae present. A congregation of workers without the presence of eggs, larvae or pupae was not considered a nest. I considered a nest completely excavated when the flow of workers exiting the nest had stopped and no queens had been found for at least 10 minutes. To control for the effect of environmental differences between sites, at each nest and every 5 $\mathrm{m}$ mark, starting at $0 \mathrm{~m}$ along a transect, I measured the canopy cover (\%), litter cover (\%), number of Acacia plants over $0.5 \mathrm{~m}$ tall, number of Eucalyptus plants over $0.5 \mathrm{~m}$ tall, rock cover (\%), deadwood cover (\%) and litter depth (average of 3 measurements) in a $1 \mathrm{~m}^{2}$ area with the nest at the centre. In sites where no, or very few, nests were found 
along transects, the surrounding area was searched intensively to locate additional nests. Environmental factors for these nests were measured in the same manner as described above. All queens were collected and stored in RNAlater ${ }^{\circledR}$ Stabilization Solution (Life Technologies, Auckland, New Zealand) for later dissection and pathogen testing. All ants were first chilled in a fridge at $4^{\circ} \mathrm{C}$ for 1.5 hours, then placed into RNAlater ${ }^{\circledR}$ alive for optimal preservation (RNAlater Handbook 2006). The vials of RNAlater ${ }^{\circledR}$ were left at room temperature for 24 hours before being placed in the fridge or freezer to allow the liquid to permeate the tissue. An additional 16 queens were randomly collected in February 2014 ( 8 from L1, 8 from M2). These queens were included in the fecundity analysis only.

Generalized mixed effect models with Poisson distributions were used to test if any of the environmental variables affected queen number per nest and nest presence. Site, transect and year were random effects, with transect nested within site. Population type (whether the nests came from a low, medium or high-density population), canopy cover, litter depth, litter cover, number of Acacia present and number of Eucalyptus present were random effects.

\subsubsection{Fecundity}

To investigate reproductive output, I dissected 278 queens (74 from low density; 103 from medium density; 101 from high density; 143 from 2013; 16 from 2014; 119 from 2015) and counted ovariole number, the number of mature oocytes and length of longest basal oocyte (to the nearest $10 \mu \mathrm{m}$ ). These variables are indicators of egg laying rates in ants (Dalecky et al. 2005). The rest of the gaster contents were placed in water and frozen for the fat content analysis. Before dissection, I measured head width and gaster width to the nearest $0.05 \mathrm{~mm}$ with an ocular micrometer mounted on a dissecting scope. Head width is a standard and accurate measure of overall body size (Holldobler and Wilson 1990; Kaspari 1993) and gaster width is a measure of egg-laying capacity in ants (Dalecky et al. 2005). While dissecting, I discovered that some queens had melanized nodules in their ovaries and fat bodies (Figure 4.2). A Poisson generalized mixed effect model was used to test which variables affected oocyte number. Site, nest, and year were 


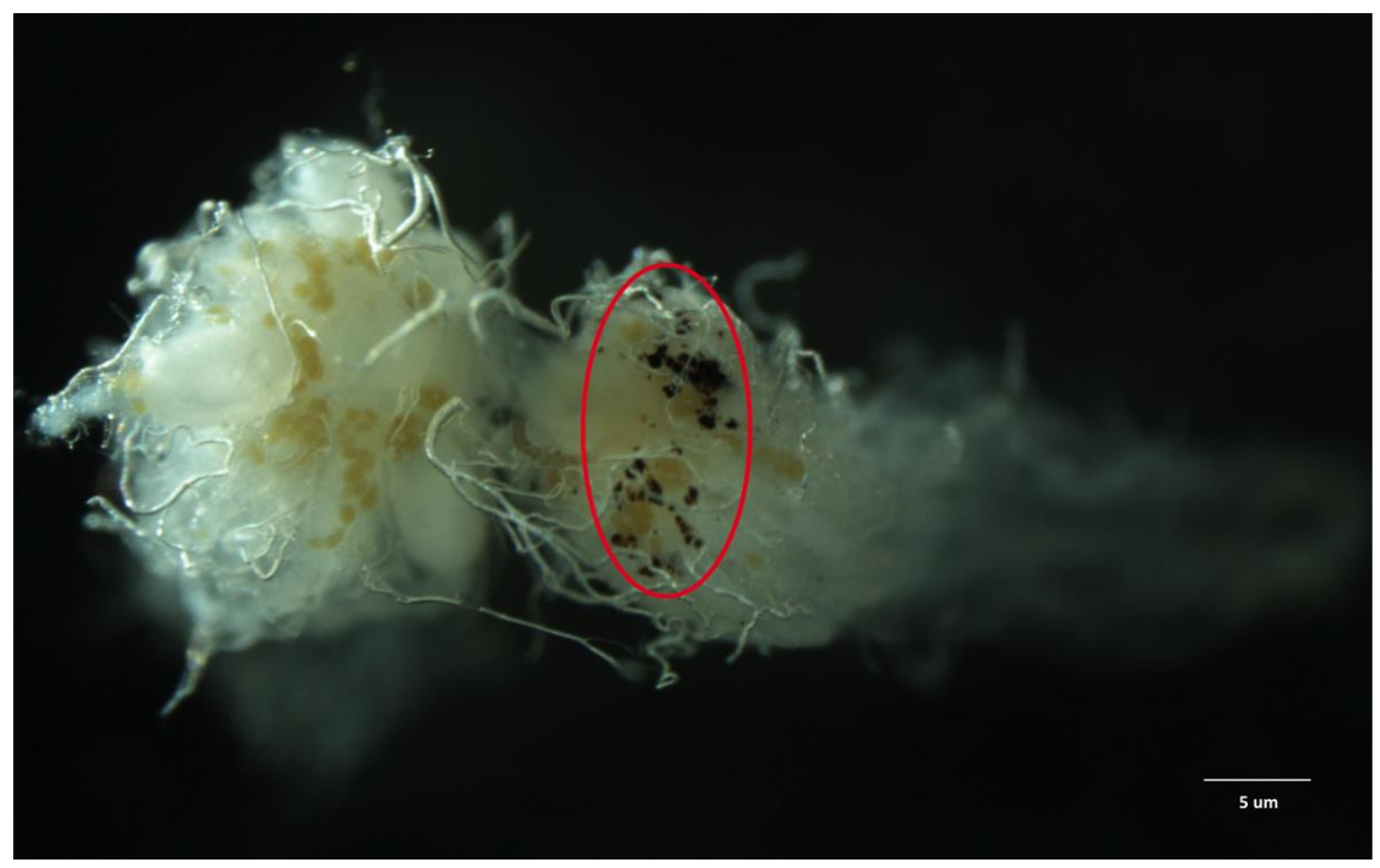

Figure 4.2. Ovaries from a queen with nodules. The ovary on the right contains melanized nodules (circled in red), the ovary on the left does not.

random effects, with nest nested within site. Nodulation status (whether or not a queen had nodules), population type, queen number (how many queens were present in the original nest), head width, gaster width, ovariole number and length of longest basal oocyte were fixed effects.

\subsubsection{Egg laying}

I hypothesized queens from high-density sites would have higher egg laying rates than queens from medium and low-density sites. To test this hypothesis I experimentally compared egg laying rates between queens from the different sites. Egg laying was measured in February 2013. Twenty queens from all six sites were tested. Only ten and seven queens were found from each low-density site respectively. Unfortunately, three of the seven queens from L2 were attacked and killed while in the laboratory by the tiny invasive ant Monomorium floricola during testing. M. floricola was able to enter the collection jars, from which A. gracilipes could not escape. The egg laying rate was measured in queens by placing one queen and three workers in a collection jar $(5.5 \mathrm{~cm}$ high and $4.5 \mathrm{~cm}$ across) containing a $1 \mathrm{~cm}$ thick layer of damp plaster. The jar sides were 
coated in Insect-A-Slip (Bioequip Products, USA) to prevent ants escaping, and the outside of the jar wrapped in white paper. Ants were maintained at approximately $25^{\circ} \mathrm{C} \pm$ $2^{\circ} \mathrm{C}$, and kept in constant darkness to simulate conditions inside the nest. Ants were put in the jar within 3 hours of collection. After 24 hours the ants were removed and eggs counted. The ants were not fed during this time. Preliminary tests showed that worker presence was critical for egg laying to occur and that 24 hours was a reasonable amount of time to observe egg laying. To compare the number of eggs laid between queens from the three different site classifications, I used a Kruskal-Wallis H test, as the data was not normally distributed.

\subsubsection{Energy reserves}

I measured fat content of queens collected in February 2015 using a petroleum ether extraction following the methods of Richards and Packer (1994). During queen dissections (discussed above), the fat bodies were isolated from the queen, collected in water and frozen at $-20^{\circ} \mathrm{C}$ until processing. The fat samples were then placed in a drying oven at approximately $65^{\circ} \mathrm{C}$ for 10 days until their weight stabilized. The samples were weighed on a Kern ABT 220-4M analytical balance to the nearest ten thousandth of a gram four times over 2 days. After that, $2 \mathrm{~mL}$ of petroleum ether was added to each sample. Samples were left for 5 days, at which point the fat had dissolved into the petroleum ether. The remaining petroleum ether was carefully decanted from each sample into another container to remove the dissolved fat. Samples were then placed in a drying oven at $65^{\circ} \mathrm{C}$ for a further 10 days. Samples were then reweighed, with the difference between the initial and final weight taken to be the amount of fat each queen possessed. A generalized mixed effect model with a Gamma distribution and log-link function was used to test which variables affected fat content. Site and nest were random effects, with nest nested within site. Nodulation status, population type, their interaction term, queen number (how many queens were present in the original nest), and head width were fixed effects. 
4. Pathogen-related reduced oocyte production in A. gracilipes

\subsubsection{Immune experiment}

In order to have supporting evidence that the black spots were indeed a cellular immune response, I injected ants with various substances to test if they formed similar nodules. On February $14^{\text {th }} 2015,60$ queens were collected from high-density site 1 (H1). This area was selected as a collection site because it was one of only two sites (H1 and H2) that had high enough population abundances to collect the necessary number of queens. Queens were collected by turning over large rocks and carefully gathering visible queens by hand. Sixty queens were collected and injected one day, then two days later another 40 were collected and injected.

Within 5 hours of collection, queens were placed in a plastic container and chilled in a fridge at $4{ }^{\circ} \mathrm{C}$ for 90 minutes. There were four treatments in this experiment: sham (queens were handled, but not injected with anything), injection with phosphate buffered saline solution (PBS), lipopolysaccharides (LPS), or spores of the entomopathogenic fungus, Metarhizium anisopliae (Biocane ${ }^{\mathrm{TM}}$ Granules, Becker Underwood, Australia) (hereafter referred to as the fungal treatment). LPS is a significant outer surface membrane component of Gram-negative bacteria and is known to induce an immune response in many eukaryotic organisms including insects and humans (Aubert and Richard 2008). The LPS treatment consisted of a $500 \mathrm{ug} \mathrm{ml}^{-1}$ LPS solution (from Escherichia coli serotype 055:B5, Sigma). This dose was chosen based on previous literature. Korner and Schmid-Hempel (2004) challenged the immune system of Bombus terrestris by injecting bees with LPS; while Aubert and Richard (2008) injected LPS into the similarly sized ant, Formica polyctena. Queens were randomly assigned to a treatment (sham, saline, LPS or fungus). Metarhizium anisopliae is a common fungal pathogen of insects, and often used as an experimental pathogen of ants and termites (Chapter 3; Hughes and Boomsma 2004; Calleri et al. 2006; Konrad et al. 2012; Reber and Chapuisat 2012). The fungal treatment was made up of M. anisopliae spores mixed with PBS to get a final concentration of $10^{6}$ spores $\mathrm{ml}^{-1}$. This concentration was chosen based on similar studies in the literature and adjusted appropriately for the size of $A$. gracilipes queens (Dean et al. 2002; Mullen and Goldsworthy 2006). The spore concentration was quantified using a haemocytometer. The volume of the injection was $1.5 \mu \mathrm{L}$ for all treatments; I measured $1.5 \mu \mathrm{L}$ of the appropriate mixture out with a pipette. 
This volume was pippetted onto a glass slide, then taken up using a $1 \mathrm{~mL}$ syringe with a 27-gauge needle. Under a dissecting scope (10X), 1.5 $\mu \mathrm{L}$ of PBS, LPS or fungus was injected into the abdominal cavity by slipping the needle in between the $2^{\text {nd }}$ and $3^{\text {rd }}$ gastral tergite into the abdominal cavity of the queens. After being injected, the queen was moved to a holding chamber that contained one small moist plaster block to provide humidity. After 24 hours, the queen was removed, chilled at $4{ }^{\circ} \mathrm{C}$ for 90 minutes then placed alive into $2 \mathrm{ml}$ of RNAlater (Mullen and Goldsworthy 2006). Vials were kept at room temperature for 36 hours to allow the RNAlater to permeate the ants' tissue, and then refrigerated at $4^{\circ} \mathrm{C}$. Twenty-five queens were used for each of the four treatments. Queens were dissected under a high-powered dissecting scope to check for the presence of nodules.

A Kruskal-Wallis test was used to test the difference in nodule formation between treatment groups. Statistical significance was assumed at $p<0.05$.

\subsubsection{Fungal survival experiment}

To test the viability of the M. anisopliae spores used in the immune experiment, I inoculated queens and measured queen survival time between different treatments. Metarhizium anisopliae spores (Biocane ${ }^{\mathrm{TM}}$ Granules, Becker Underwood, Australia) were mixed with sterile $0.05 \%$ Tween 20 to produce a solution with a final concentration of $10^{9}$ spores $\mathrm{ml}^{-1}$. Spore concentration was quantified using a haemocytometer. This dose was chosen as a lethal dose based on the literature (Konrad et al. 2012), and adjusted to be appropriate for the size of A. gracilipes queens. On Feb $14^{\text {th }} 201518$

queens were inoculated, 8 with $3 \mu \mathrm{L}$ of $10^{9}$ spore solution and 10 with $3 \mu \mathrm{L}$ of $0.05 \%$ Tween 20. Thirty additional queens were collected from the same area on Feb $17^{\text {th }}$ and 15 assigned to each treatment group. Solutions were applied topically directly to the gaster and ants were dried by blotting carefully with a kimwipe to prevent queens from becoming stuck to the container surface via surface tension. Queens were placed in a clear plastic container with a damp plaster block and survival was checked and recorded every 24 hours for 9 days. Queens may survive for several weeks in the absence of food and workers so long as humidity is maintained (B. Hoffmann, unpublished data). 
A Kaplan-Meier Survival Curve and Log Rank statistic were used to estimate survival and compare it between the two treatments.

All generalized mixed effect models were run using the package lme4 (Bates et al. 2015). All statistical analyses were done in R v.3.0.2 (R Core Team 2013).

\subsection{Results}

\subsubsection{Site surveys}

Anoplolepis gracilipes abundance and density varied greatly between sites of the three population types. The number of "presence" points recorded at the low-density sites was an order of magnitude greater than at the medium-density sites (Table 4.1, Figure 4.3, 4.4. 4.5).

Table 4.1. Site location (WGS84 decimal degrees), size of site and number of GPS points taken each year. $\mathrm{H}$ denotes high-density sites, $M$ medium-density sites and $\mathrm{L}$ low-density sites.

\begin{tabular}{llllllll}
\hline Site & Latitude & Longitude & $\begin{array}{l}\text { Area } \\
\left(\mathrm{m}^{2}\right)\end{array}$ & $\begin{array}{l}\text { "Absent" } \\
\text { points } \\
\end{array}$ & & & $\begin{array}{l}\text { "Present" "Absent" "Present" } \\
\text { points } \\
\text { points } \\
\text { points }\end{array}$ \\
\hline H1 & -12.286531 & 136.869870 & 20000 & - & - & - & - \\
H2 & -12.291767 & 136.872887 & 20000 & - & - & - & - \\
M1 & -12.260974 & 136.833686 & 20000 & 609 & 460 & 864 & 109 \\
M2 & -12.259746 & 136.825716 & 20000 & 246 & 591 & 419 & 317 \\
L1 & -12.339775 & 136.889406 & 34150 & 1454 & 34 & 1425 & 6 \\
L2 & -12.270554 & 136.793249 & 88320 & 3776 & 35 & 3402 & 7 \\
\hline
\end{tabular}

The total number of $A$. gracilipes collected in pitfall traps across all sites and years was 34 656. Ninety-six percent of these were from the two high-density sites, while the medium-density sites accounted of $3 \%$ of total collected $A$. gracilipes workers and the low-density sites 1\% (Figure 4.6). Anoplolepis gracilipes abundance was significantly different between sites overall $(F=87.851, p<0.001)$; however, sites with the same population type did not differ from each other (Table 4.2 for pairwise comparisons). Site L1 did not differ significantly in A. gracilipes abundance from sites M1 or M2 (Tukey test, $p>0.05$ ); however, as sites M1 and M2 both had approximately $1300 \%$ more presence points than site L1, I believe the different classifications are still applicable. 
Abundance of $A$. gracilipes did not differ significantly between years $(F=0.052, p=$ $0.426)$.

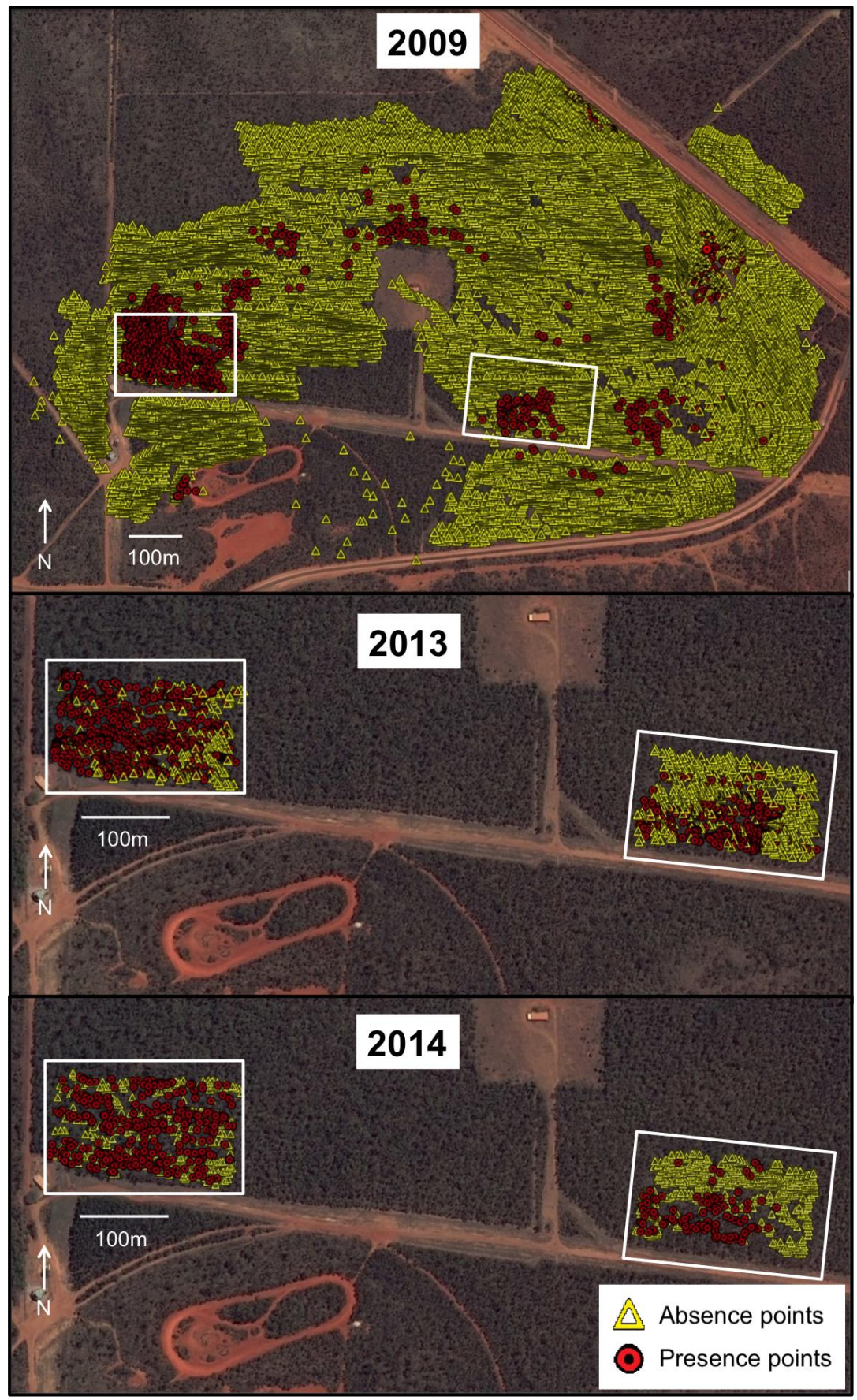

Figure 4.3 Medium-density site 1 (M1) (right) and medium-density site (M2) (left) showing the $A$. gracilipes population as mapped in 2009,2013 and 2014 . The white polygon indicates the same area on all three maps, as well as the location of the $200 \mathrm{~m} \times 100 \mathrm{~m}$ sub-sampled area of my study sites on all three maps. 


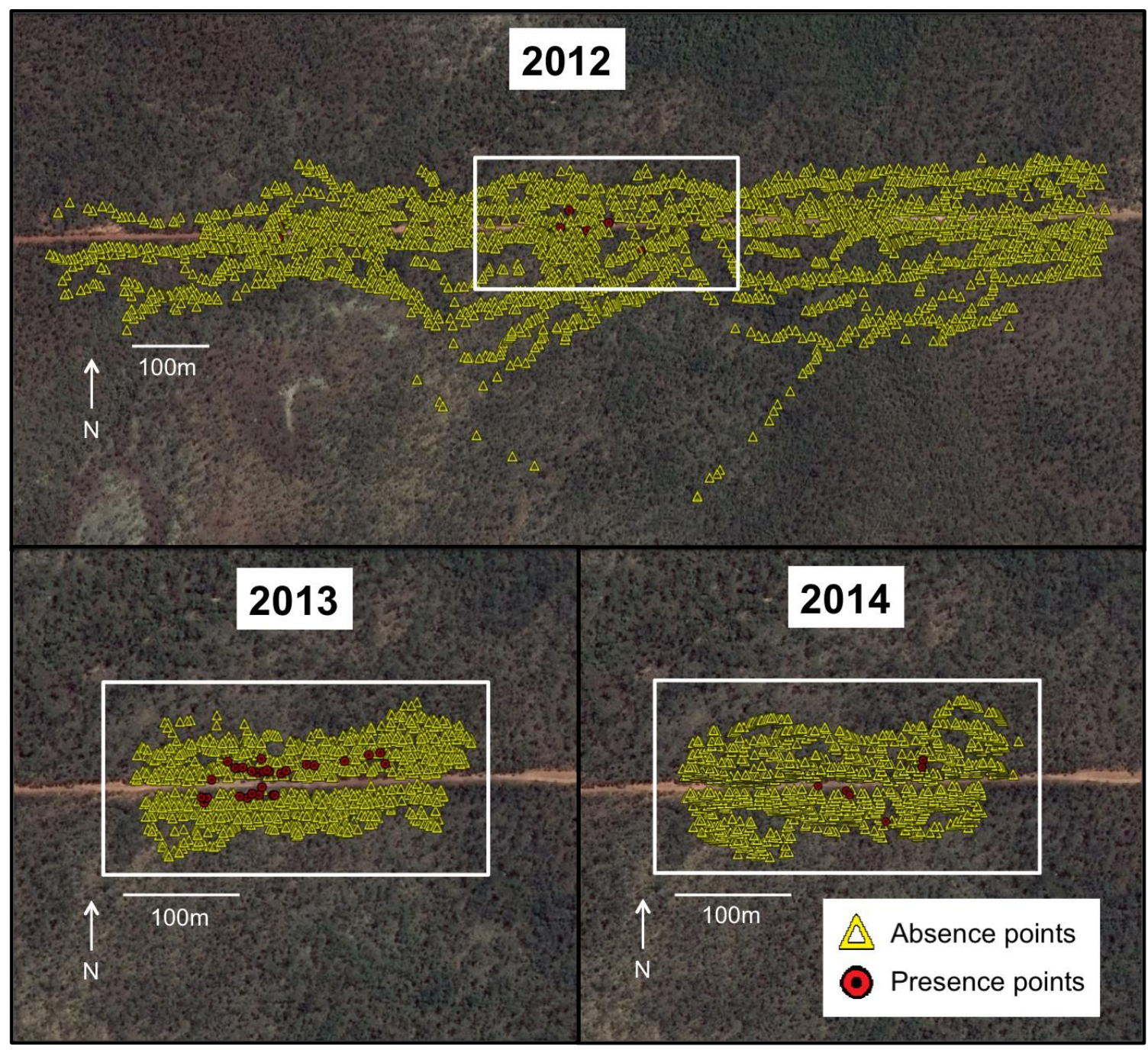

Figure 4.4. Low-density site 1 (L1) showing the $A$. gracilipes population as mapped in 2012,2013 and 2014. The white polygon indicates the same area and the location of my study sites on all three maps.

\subsubsection{Nest density and queen number}

A total of 171 nests were excavated (Table 4.3). Of these, $61 \%$ had queens present, that I collected, and of these, $50 \%$ had fewer than 4 queens. There was a significant positive correlation between population type and nest presence $(\mathrm{z}=3.071 p=0.002)$, with highdensity sites having the most nests and low-density sites having the fewest (Table 4.4). 


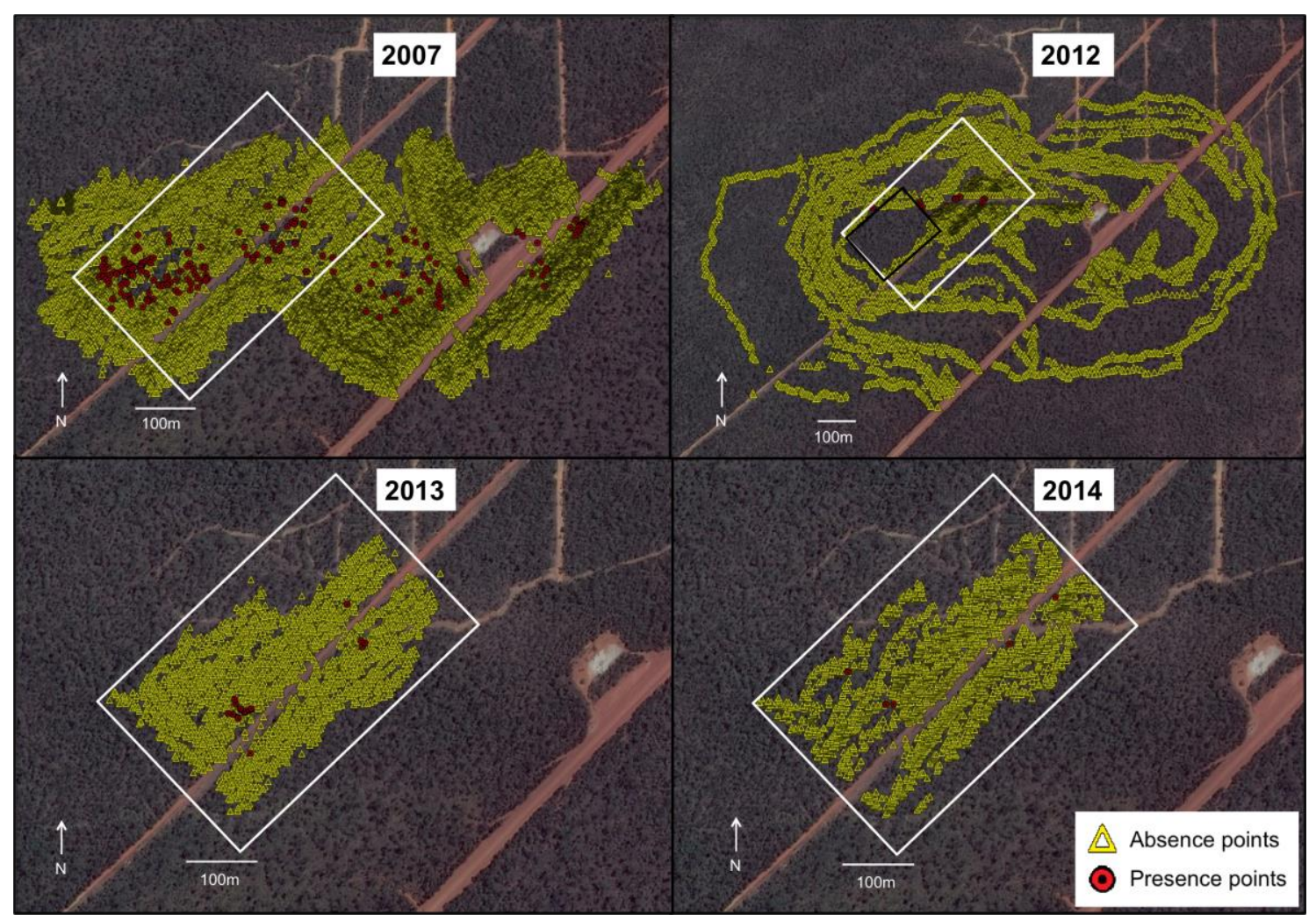

Figure 4.5. Low density site 2 (L2) showing the $A$. gracilipes population as mapped in 2007, 2012, 2013 and 2014. The white polygon indicates the same area and the location of my study sites on all three maps. The black rectangle on the 2012 map indicates where GPS data was lost; all lost data were $A$. gracilipes absence points.

Factors not significantly correlated with nest presence were canopy cover $(\mathrm{z}=0.549 p=$ $0.583)$, litter depth $(\mathrm{z}=1.610, p=0.107)$ and litter $\operatorname{cover}(\mathrm{z}=-0.061, p=0.951)$

Significantly positive correlations were found for the number of Acacia $(\mathrm{z}=2.850, p=$ $0.004)$ and number of Eucalyptus $(\mathrm{z}=1.967, p=0.049)$. Sixty-eight percent of checked areas with three or more Acacia present had at least one A. gracilipes nest present, while only $41 \%$ sampling locations that had two or fewer Acacia had A. gracilipes nests. Fiftythree percent of checked areas with three or more Eucalyptus present had A. gracilipes nests, while $42 \%$ of checked areas with two or fewer Eucalyptus present had A. gracilipes nests. 


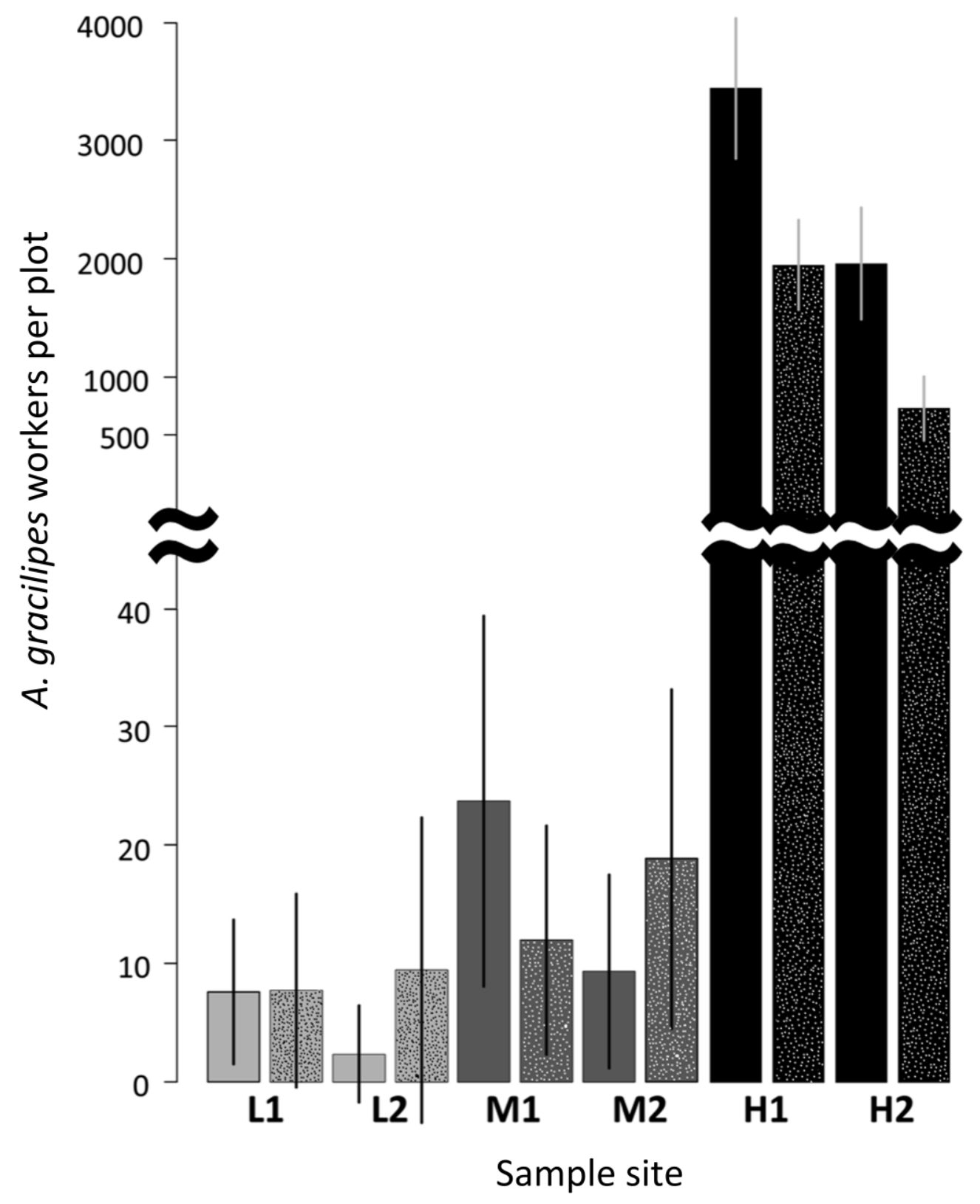

Figure 4.6. Mean number of $A$. gracilipes workers \pm SD in one plot $(n=4 /$ site) at each of the two lowdensity (light grey bars), medium-density (dark grey bars) and high-density (black bars) sites. Anoplolepis gracilipes abundances are shown for two sampling years at each site, 2013 (solid colour bars) and 2014 (speckled bars). The $y$-axis has been split to accommodate the number of $A$. gracilipes workers collected in high-density sites, whose abundances were two orders of magnitude higher per plot than in medium and low-density sites. 
4. Pathogen-related reduced oocyte production in A. gracilipes

Table 4.2. Bonferonni-corrected Tukey test pairwise comparisons of $A$. gracilipes abundance between sites.

\begin{tabular}{|c|c|c|c|c|c|c|}
\hline \multirow[t]{2}{*}{ Site1 } & \multirow[t]{2}{*}{ Site2 } & \multirow{2}{*}{$\begin{array}{l}\text { Mean diff. } \\
\text { (site1-site2) }\end{array}$} & \multirow{2}{*}{ Std. Error } & \multirow{2}{*}{$p$} & \multicolumn{2}{|c|}{$95 \% \mathrm{CI}$} \\
\hline & & & & & Lower & Upper \\
\hline \multirow[t]{5}{*}{ H1 } & $\mathrm{H} 2$ & 0.330 & 0.141 & 0.379 & -0.114 & 0.774 \\
\hline & M1 & 1.621 & 0.141 & $<0.0001$ & 1.177 & 2.065 \\
\hline & M2 & 1.709 & 0.141 & $<0.0001$ & 1.265 & 2.153 \\
\hline & L1 & 1.943 & 0.141 & $<0.0001$ & 1.499 & 2.388 \\
\hline & L2 & 2.334 & 0.141 & $<0.0001$ & 1.890 & 2.778 \\
\hline \multirow[t]{5}{*}{$\mathrm{H} 2$} & H1 & -0.330 & 0.141 & 0.379 & -0.774 & 0.114 \\
\hline & M1 & 1.291 & 0.141 & $<0.0001$ & 0.847 & 1.735 \\
\hline & M2 & 1.379 & 0.141 & $<0.0001$ & 0.935 & 1.823 \\
\hline & L1 & 1.614 & 0.141 & $<0.0001$ & 1.170 & 2.058 \\
\hline & L2 & 2.004 & 0.141 & $<0.0001$ & 1.560 & 2.448 \\
\hline \multirow[t]{5}{*}{ M1 } & H1 & -1.621 & 0.141 & $<0.0001$ & -2.065 & -1.177 \\
\hline & $\mathrm{H} 2$ & -1.291 & 0.141 & $<0.0001$ & -1.735 & -0.847 \\
\hline & M2 & 0.088 & 0.141 & 1.000 & -0.356 & 0.532 \\
\hline & L1 & 0.323 & 0.141 & 0.424 & -0.121 & 0.767 \\
\hline & L2 & 0.713 & 0.141 & $<0.0001$ & 0.269 & 1.157 \\
\hline \multirow[t]{5}{*}{ M2 } & H1 & -1.709 & 0.141 & $<0.0001$ & -2.153 & -1.265 \\
\hline & $\mathrm{H} 2$ & -1.379 & 0.141 & $<0.0001$ & -1.823 & -0.935 \\
\hline & M1 & -0.088 & 0.141 & 1.000 & -0.532 & 0.356 \\
\hline & L1 & 0.235 & 0.141 & 1.000 & -0.209 & 0.679 \\
\hline & L2 & 0.625 & 0.141 & $<0.0001$ & 0.181 & 1.069 \\
\hline \multirow[t]{5}{*}{ L1 } & H1 & -1.943 & 0.141 & $<0.0001$ & -2.388 & -1.499 \\
\hline & $\mathrm{H} 2$ & -1.614 & 0.141 & $<0.0001$ & -2.058 & -1.170 \\
\hline & M1 & -0.323 & 0.141 & 0.424 & -0.767 & 0.121 \\
\hline & M2 & -0.235 & 0.141 & 1.000 & -0.679 & 0.209 \\
\hline & L2 & 0.390 & 0.141 & 0.134 & -0.054 & 0.834 \\
\hline \multirow[t]{5}{*}{ L2 } & H1 & -2.334 & 0.141 & $<0.0001$ & -2.778 & -1.890 \\
\hline & $\mathrm{H} 2$ & -2.004 & 0.141 & $<0.0001$ & -2.448 & -1.560 \\
\hline & M1 & -0.713 & 0.141 & $<0.0001$ & -1.1572 & -.2692 \\
\hline & M2 & -0.625 & 0.141 & 0.001 & -1.069 & -0.181 \\
\hline & L1 & -0.390 & 0.141 & 0.134 & -0.834 & 0.054 \\
\hline
\end{tabular}

Table 4.3. Population type, number of queens dissected with the percentage of queens with nodules in brackets, total number of nests excavated and nest density per site

\begin{tabular}{lllll}
\hline Site & Population type & $\begin{array}{l}\text { \% queens with } \\
\text { nodules } \\
\text { (Queens dissected) }\end{array}$ & $\begin{array}{l}\text { Total nests } \\
\text { excavated }\end{array}$ & Nests/10m $\mathrm{m}^{2} \pm \mathrm{SD}$ \\
\hline L1 & Low-density & $18(34)$ & 13 & $<0.01^{\mathrm{a}}$ \\
L2 & Low-density & $5(40)$ & 14 & $<0.01^{\mathrm{a}}$ \\
M1 & Medium-density & $3(30)$ & 21 & $0.9 \pm 0.9$ \\
M2 & Medium-density & $47(73)$ & 33 & $1.0 \pm 0.8$ \\
H1 & High-density & $23(57)$ & 43 & $2.6 \pm 1.1$ \\
H2 & High-density & $20(44)$ & 47 & $2.4 \pm 0.8$ \\
\hline
\end{tabular}

${ }^{a}$ Nest density could not be accurately calculated due to paucity of nests 
Table 4.4. A) Results of a generalized mixed effect models testing the effect of population type, canopy cover, litter depth and cover, Acacia number and Eucalyptus number on nest presence and number of queens per nest. Random effects were site, year and transect. B) Results of a generalized mixed

effect model testing the effect of population type, nodulation status (status), the interaction between population type and nodulation status, gaster width, head width, queen number per nest (queen number), ovariole number and longest basal oocyte on oocyte number and fat content. Random effects were site, year and nest. Please note that due to size constraints, the results for the fixed effects ovariole number and longest basal oocyte are on the last three lines.

\begin{tabular}{|c|c|c|c|c|c|c|c|c|c|c|c|c|c|c|c|c|}
\hline \multirow[t]{2}{*}{ A } & \multicolumn{3}{|c|}{ Population type } & \multicolumn{2}{|c|}{ Canopy cover } & \multicolumn{2}{|c|}{ Litter depth } & \multicolumn{3}{|c|}{ Litter cover } & \multicolumn{3}{|c|}{ Acacia \# } & \multicolumn{3}{|c|}{ Eucalyptus \# } \\
\hline & B & $\mathrm{SE}$ & $p^{\mathrm{a}}$ & B & SE & $p \quad \beta$ & SE & $p \quad \beta$ & $\mathrm{SE}$ & $p$ & B & SE & $p$ & B & SE & $p$ \\
\hline Nest presence & 0.436 & 0.141 & $* *$ & 0.002 & 0.003 & NS 0.039 & 0.025 & NS -0.0002 & 0.003 & NS & 0.111 & 0.039 & $* *$ & 0.088 & 0.045 & $*$ \\
\hline Queen number & -0.510 & 0.199 & $*$ & 0.007 & 0.003 & * 0.013 & 0.029 & NS 0.006 & 0.004 & NS & 0.077 & 0.032 & $*$ & -0.014 & 0.052 & NS \\
\hline $\begin{array}{c}\mathrm{B} \\
\end{array}$ & \multicolumn{3}{|c|}{ Population type } & \multicolumn{4}{|c|}{ Pop type*status } & \multicolumn{3}{|c|}{ Gaster width } & \multicolumn{3}{|c|}{ Head width } & \multicolumn{3}{|c|}{ Queen number } \\
\hline & B & $\mathrm{SE}$ & $p$ & $\beta$ & SE & $p \quad \beta$ & SE & $\begin{array}{ll}p & \beta\end{array}$ & $\mathrm{SE}$ & $p$ & B & $\mathrm{SE}$ & $p$ & B & SE & $p$ \\
\hline Oocyte number & -0.113 & 0.180 & ** & -0.513 & 0.106 & $* * * 0.165$ & 0.055 & $* * 0.006$ & 0.014 & NS & -0.164 & 0.045 & $* * *$ & 0.003 & 0.018 & NS \\
\hline Fat & 14.437 & 715.600 & NS & -19.814 & 85.740 & NS 7.164 & 33.478 & NS -5.873 & 6.258 & NS & -13.81 & 542.411 & NS & -0.061 & 2.535 & NS \\
\hline & & Dvariole & & Longest & basal oc & cyte & & & & & & & & & & \\
\hline Oocyte number & $\begin{array}{l}\beta \\
0.019\end{array}$ & $\begin{array}{l}\text { SE } \\
0.003\end{array}$ & $\begin{array}{l}p \\
* * *\end{array}$ & $\begin{array}{l}\beta \\
0.175\end{array}$ & $\begin{array}{l}\text { SE } \\
0.013\end{array}$ & $\begin{array}{l}p \\
* * *\end{array}$ & & & & & & & & & & \\
\hline
\end{tabular}

${ }^{a}$ Asterisks indicate a significant effect. ${ }^{*}, p<0.05 ;{ }^{* *}, p<0.01 ; * * *, p<0.001$ 
Population type had a significant effect on queen number $(\mathrm{z}=-2.560 p=0.011)$, with lowdensity sites having more nests with higher numbers of queens. Nineteen percent of nests that had queens in low-density sites had five or more queens, while medium-density sites had $13 \%$ and high-density sites had only $7 \%$. Other factors significantly associated with queen number were canopy cover $(\mathrm{z}=2.384 p=0.017)$ and number of Acacia $(\mathrm{z}=2.415$, $p=0.016$ ). Nests with $50 \%$ or more canopy cover had $29 \%$ more queens on average than nests with less than 50\% canopy cover (mean \pm SE: $3.32 \pm 0.06 ; 2.40 \pm 0.05$ ). Nests within $1 \mathrm{~m}$ of at least one Acacia had the same likelihood of having queens present as those that were not (a $61 \%$ chance), but on average nests in close proximity to an Acacia had $34 \%$ more queens than nests that were not (mean $\pm \mathrm{SE}: 2.19 \pm 0.44$ vs $1.51 \pm 0.20$ ). Factors not significantly associated with queen number were litter depth $(\mathrm{z}=0.438, p=$ $0.661)$, litter cover $(\mathrm{z}=1.652, p=0.099)$ and number of Eucalyptus $(\mathrm{z}=-0.272, p=0.786)$.

\subsubsection{Fecundity}

A total of 278 queens were dissected, $23 \%$ of which had melanized nodules (Table 4.3). More than half the queens with nodules were from site M2 (34/65), a medium-density site. Oocyte number was significantly associated with nodulation status $(\mathrm{z}=-4.856, p<$ 0.0001 ) (with queens without nodules having more oocytes in their ovaries) (Figure 4.7), head width $(\mathrm{z}=-3.647 p=0.0003)$, number of ovarioles $(\mathrm{z}=6.233, p<0.0001)$ and largest basal oocyte $(\mathrm{z}=12.991, p<0.0001)$. Across all sites, queens without nodules had on average $22 \%$ more oocytes in their ovaries than queens with nodules (mean \pm standard error: $30.73 \pm 1.43 ; 23.97 \pm 2.36)$. Oocyte number was not significantly correlated with population type $(\mathrm{z}=-0.627, p=0.530)$, queen number $(\mathrm{z}=0.190, p=0.849)$ or gaster width $(\mathrm{z}=0.442, p=0.658)$. However, there was a highly significant correlation between the interaction of population type and nodulation status $(\mathrm{z}=3.031, p=0.002)$, with the effect of nodulation status being most strongly correlated with declining populations. 
4. Pathogen-related reduced oocyte production in A.gracilipes

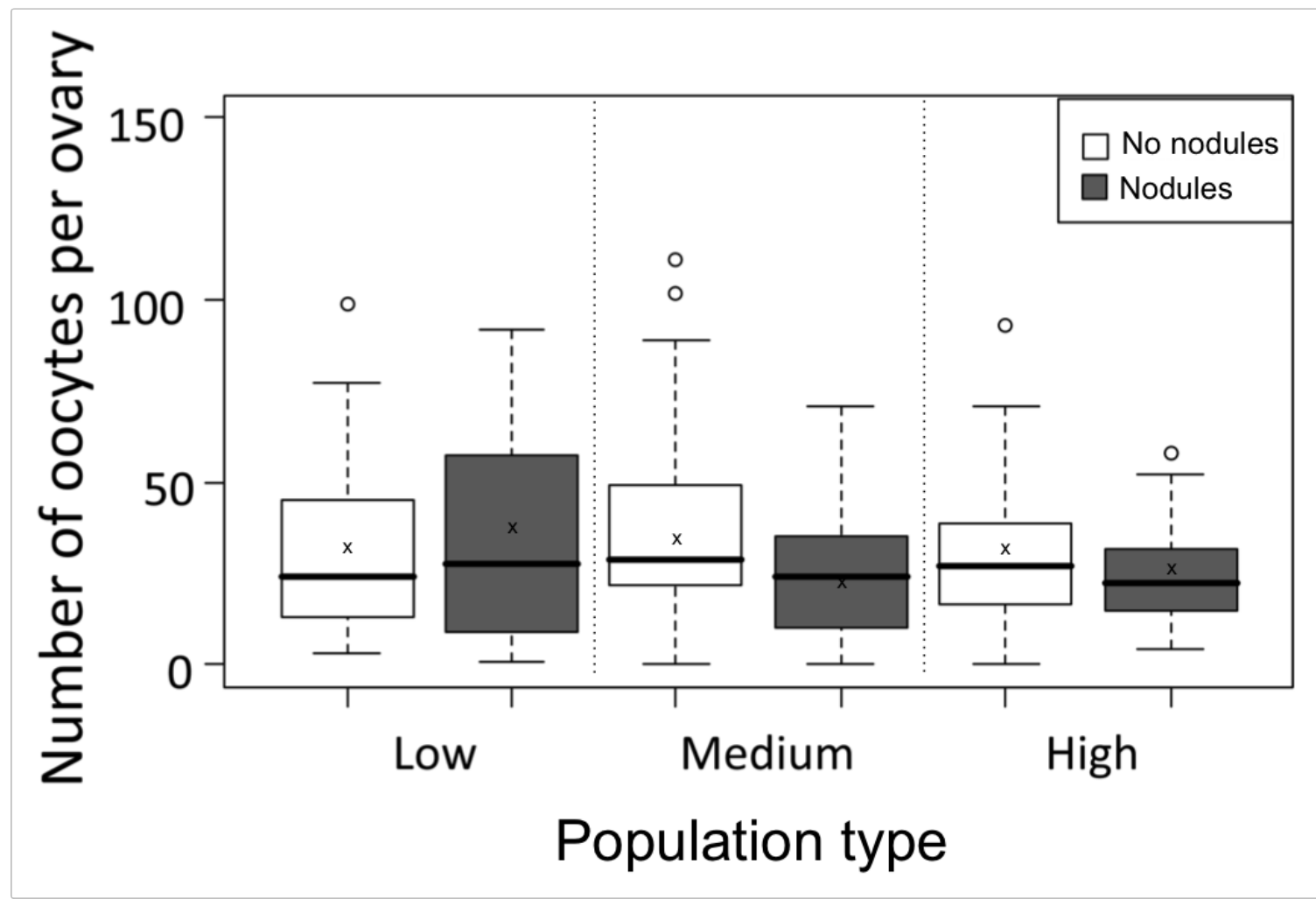

Figure 4.7. Box plot showing the median number of oocytes found in queens without nodules and queens with nodules at the three site types. Queens without nodules have significantly more oocytes than those with nodules $(p<0.0001$, see results). Black $X$ 's indicate the mean. Boxes show median with upper and lower quartiles, the whiskers show minimum and maximum values, outliers are more than $3 / 2$ times of upper quartile.

On average, queens without nodules from medium-density sites had 38\% more oocytes in their ovaries than queens with nodules (mean \pm SE: $32.48 \pm 2.69 ; 20.94 \pm 2.85$ ). Queens without nodules from high-density populations had on average $17 \%$ more oocytes in their ovaries than queens with nodules (mean $\pm \mathrm{SE}: 29.81 \pm 2.05 ; 24.73 \pm 3.10$ ), while queens without nodules from low-density populations had on average $17 \%$ fewer oocytes in their ovaries than queens with nodules (mean $\pm \mathrm{SE}: 30.03 \pm 2.80 ; 35.13 \pm 11.80$ ).

\subsubsection{Egg laying}

There were no differences in egg laying rates among queens from different sites. A Kruskal-Wallis H test showed no significant differences between the number of eggs laid by queens from low, medium or high-density sites $\left(\mathrm{X}^{2}{ }_{2}=0.272, p=0.873\right.$; Figure 4.8). Only 35\% of the 92 queens tested laid any eggs. A Kruskal-Wallis H test excluding queens that laid no eggs also found no difference between number of eggs laid between 


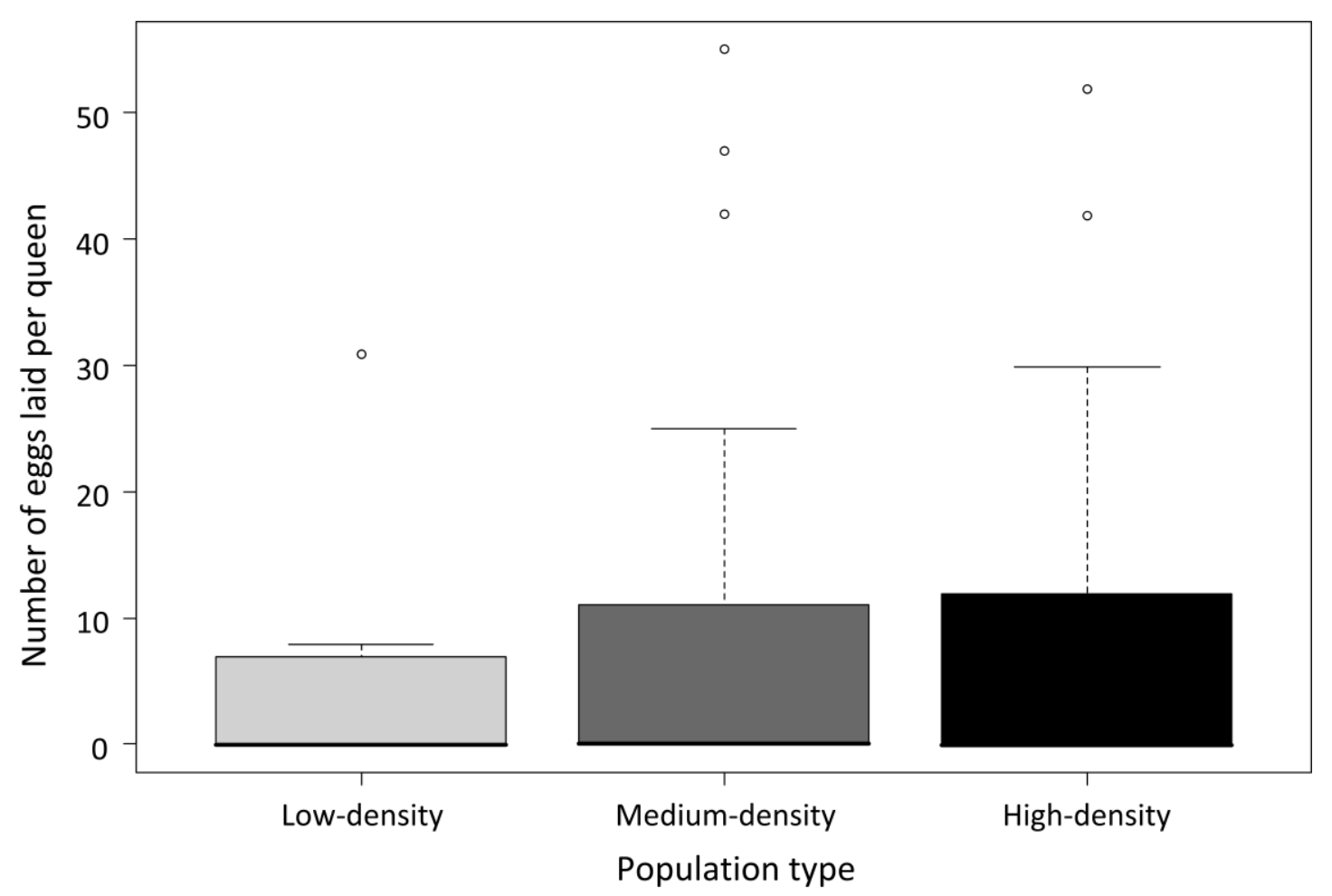

Figure 4.8. Boxplot showing the median number of eggs laid by queens from low-density (light grey), medium-density (dark grey) and high-density (black) sites in the laboratory over a 24 period. There were no differences in number of eggs laid between the different population types. Boxes show median with upper and lower quartiles, the whiskers show minimum and maximum values, outliers are more than $3 / 2$ times of upper quartile.

queens of the three different population types $\left(\mathrm{X}^{2}{ }_{2}=1.005, p=0.605\right)$. A Mann-Whitney $\mathrm{U}$ test showed no differences in number of eggs laid between queens with nodules and queens without nodules $(U=549.500, p=0.246)$.

\subsubsection{Energy reserves}

Queens had a mean fat content of $3.55 \times 10^{-3} \pm 1.33 \times 10^{-4}$ (mean $\pm \mathrm{SE}$ ). Fat content was not significantly correlated with nodulation status $(\mathrm{z}=-0.231 p=0.817)$ (Figure 4.9), nor with population type $(\mathrm{z}=0.926 p=0.355)$, head width $(\beta=-13.815, \mathrm{z}=-0.326 p=0.745)$, gaster width $(\mathrm{z}=-0.938 p=0.348)$, or queen number $(\mathrm{z}=-024, p=0.981)$. The interaction between nodulation status and population type was also not statistically significant $(\mathrm{z}=$ $0.214, p=0.831)$. 


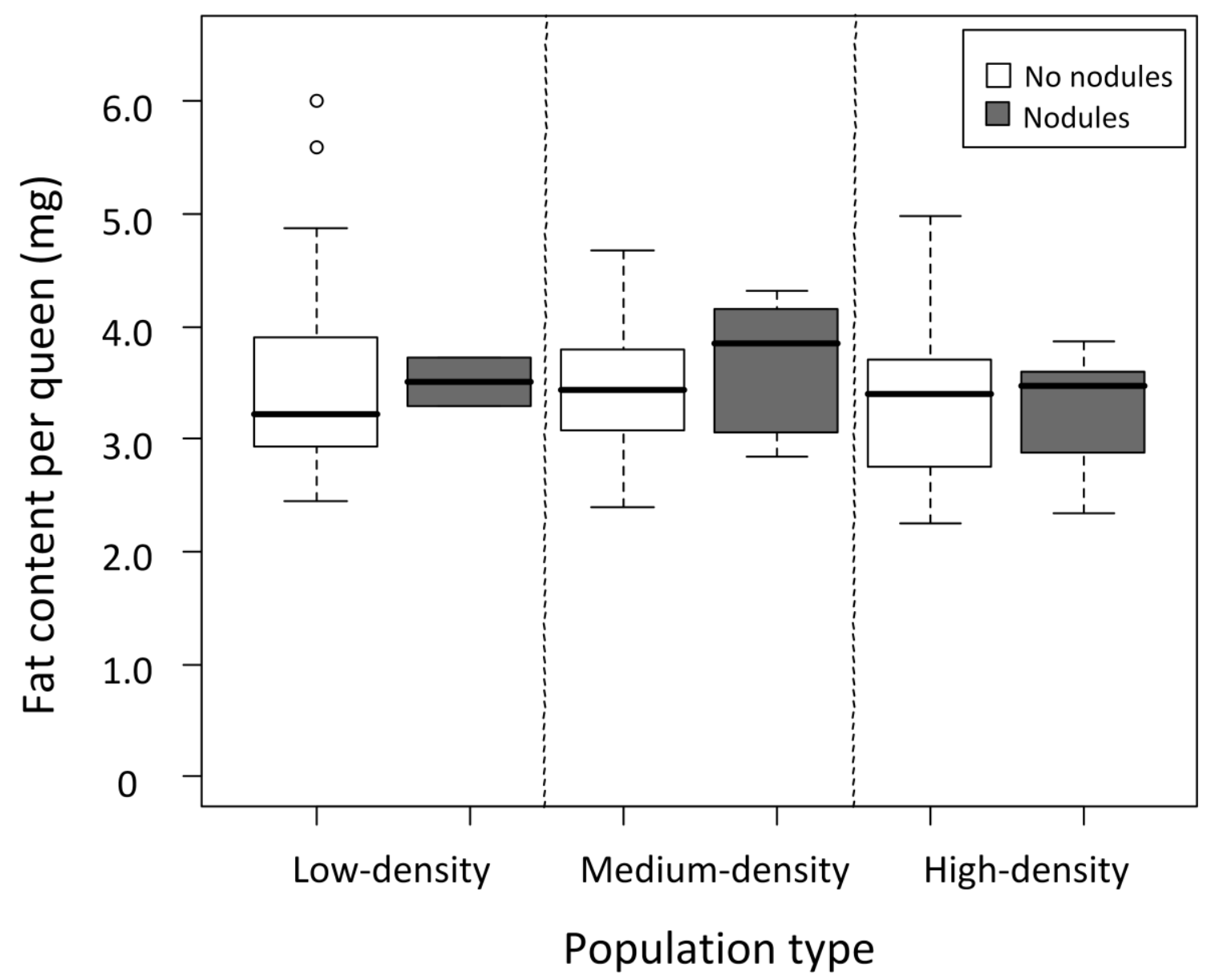

Figure 4.9. Box plot showing the median weight of fat found in queens without and with nodules at the three site types. There were no differences in fat content between queens from different population type. Boxes show median with upper and lower quartiles, the whiskers show minimum and maximum values, outliers are more than 3/2 times of upper quartile.

\subsubsection{Immune experiment}

Queens in the fungal treatment had 15\% more nodules than queens from the LPS and PBS treatments, and 60\% more than the sham treatment $\left(\mathrm{H}_{3}=50.736, p<0.001\right)$ (Figure $4.10,4.11$ ). Queens from the fungal treatment had $60.04 \pm 11.63$ (mean $\pm \mathrm{SE}$ ) nodules; while queens from the LPS, PBS and sham treatments had $3.96 \pm 1.59,3.86 \pm 1.37$ and $0.96 \pm 0.39$ nodules, respectively. One hundred percent of queens from the fungal treatment had at least 5 nodules, while $46 \%$ of the LPS treatment had two or more, and $59 \%$ of the PBS and $40 \%$ of the sham had at least one. 


\subsubsection{Fungal Survival Experiment}

The queens in the Metarhizium treatment had a mean survival time of 4.68 days (3.855.51 days; $95 \% \mathrm{CI}$ ), while the control group queens had a mean survival time of 8.760 days $(7.69-9.83 ; 95 \% \mathrm{CI})$. A log rank test showed the mean survival time of queens in the Metarhizium treatment was significantly less than those in the control group $\left(\chi^{2}{ }_{1}=\right.$ 19.989, $p<0.0001$, Figure 4.12).

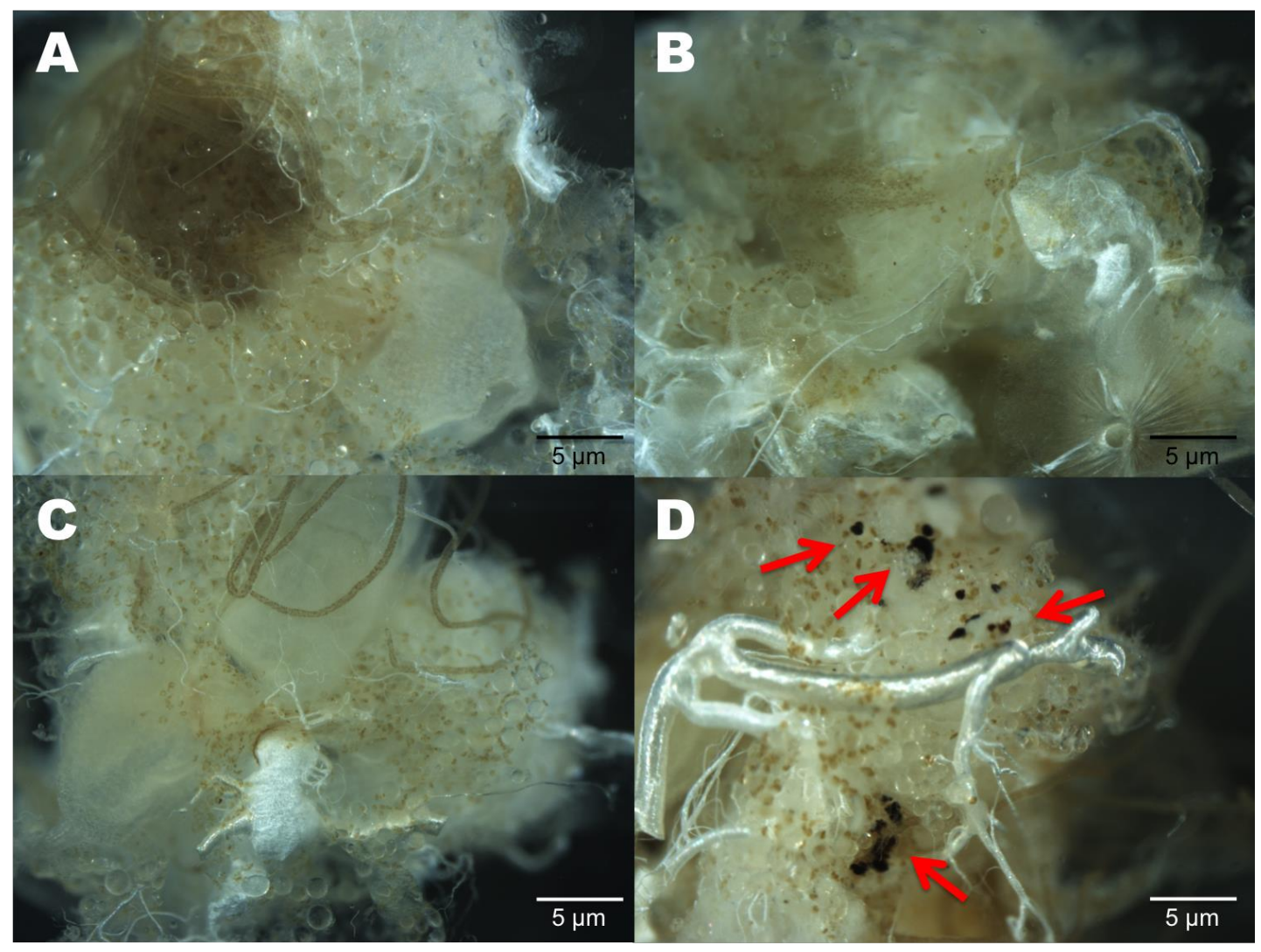

Figure 4.10. Fat bodies of dissected queens from the four treatments A) sham, B) PBS, C) LPS and D) fungal. The red arrows in photograph $D$ are pointing to melanized nodules. 
4. Pathogen-related reduced oocyte production in A. gracilipes

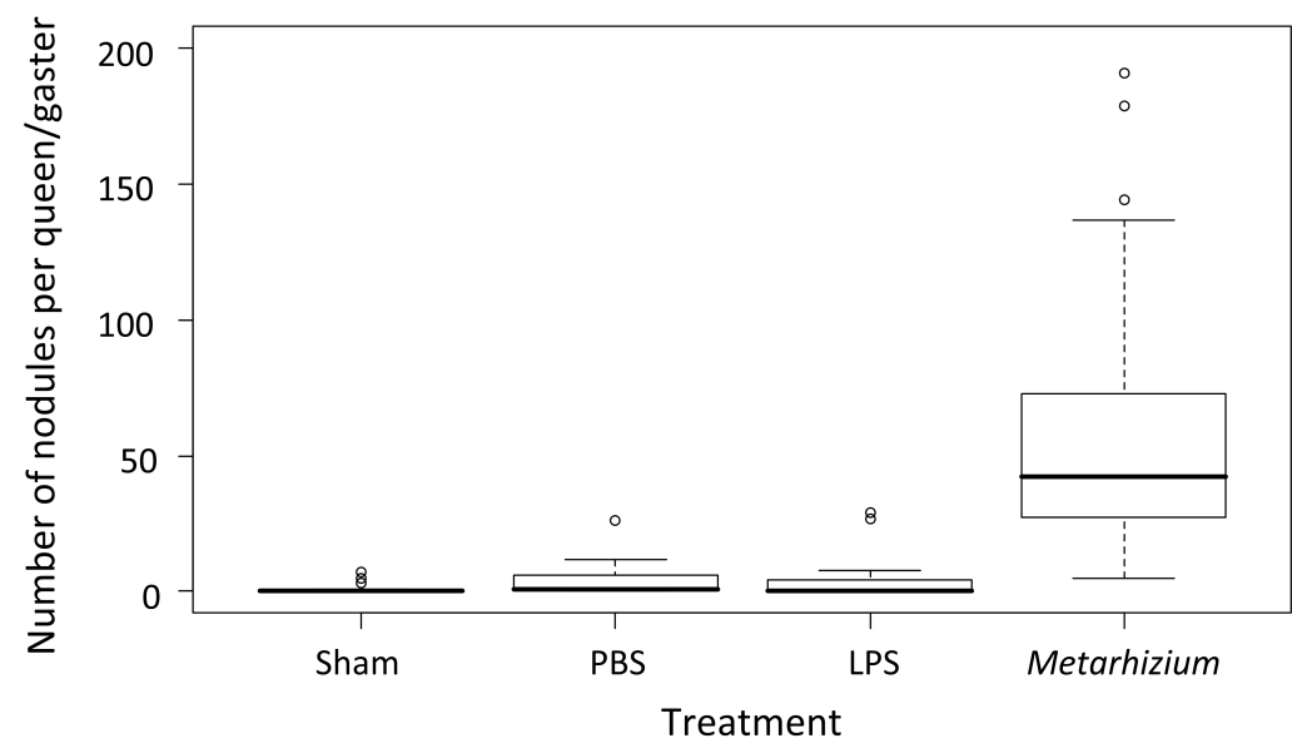

Figure 4.11. Boxplot showing the median number of nodules found in each queen after 24 hours. Boxes show median with upper and lower quartiles, the whiskers show minimum and maximum values, outliers are more than $3 / 2$ times of upper quartile.

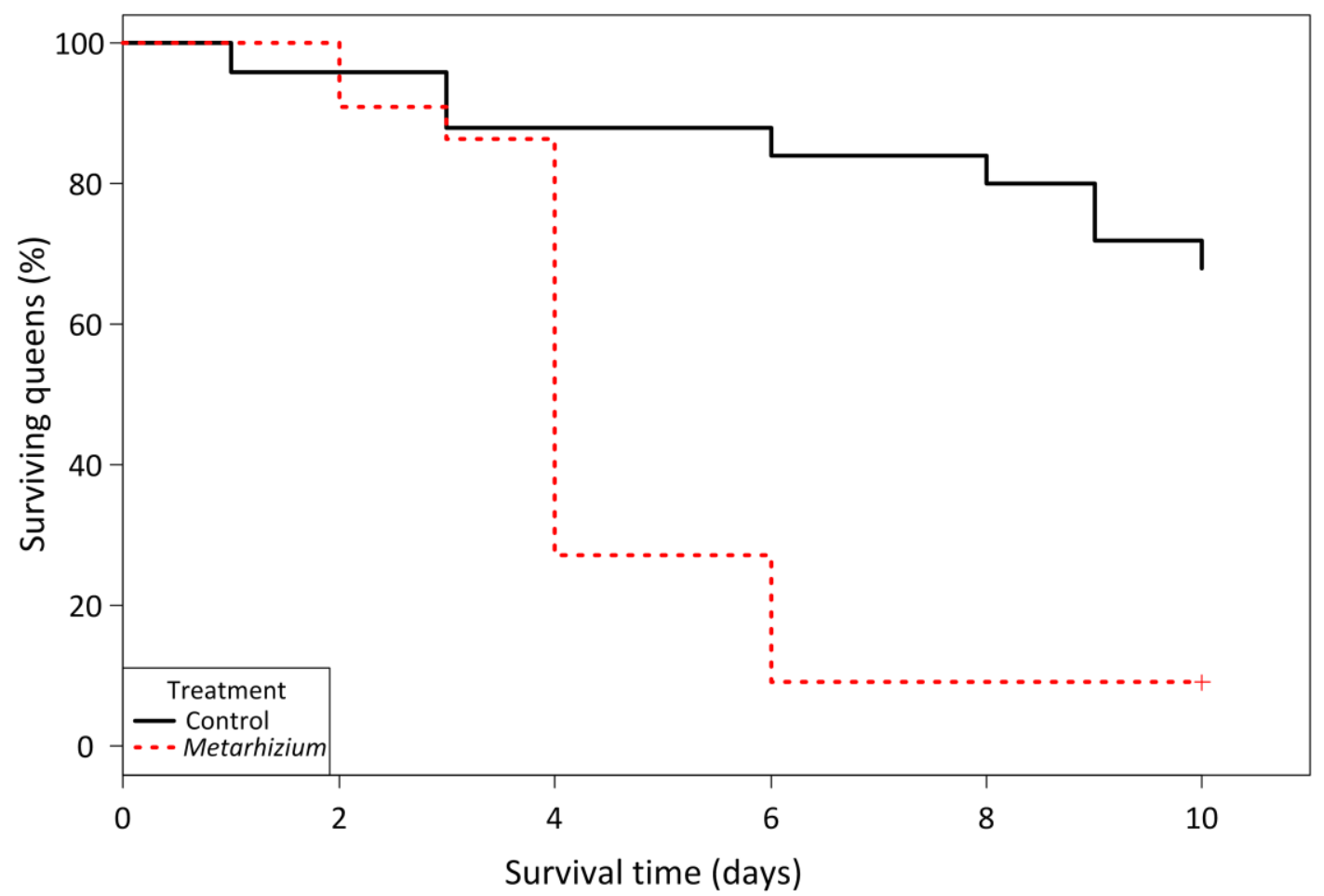

Figure 4.12. Survivorship curves for queens in the control group (solid black line) and Metarhizium treatment (dashed line). Queens in the Metarhizium treatment died significantly faster than those in the control group $(p<0.0001$, see results). 


\subsection{Discussion}

This is the first study to show that A. gracilipes queens can be significantly affected by pathogens. Twenty-three percent of queens had melanized nodules in their ovaries or fat bodies, which was significantly associated with reduced oocyte number. It is unclear if the observed reduction in oocyte number was a direct affect of the invading pathogen, or a trade-off in immune response. Though a queen's immune system may have dealt effectively with the invader, such an immune function is biologically expensive and can result in physiological trade-offs, at both the individual and colony level (Rolff and SivaJothy 2003; Siva-Jothy et al. 2005). For example, A. mellifera colonies whose members mounted a strong immune response to pathogens produced significantly fewer larvae than those that didn't (Evans and Pettis 2005). Mosquitos that have encapsulated micro-filarial parasites also have reduced and delayed egg laying (Ferdig et al. 1993).

The production of melanized nodules, or nodulation, is an innate cellular immune response in insects (Stanley et al. 2012). When an invading pathogen or parasite enters the hemocoel and is not phagocytized by a single hemocyte (the equivalent of white blood cells in insects), aggregations of hemocytes will surround the invader, smother it, and melanize (Rolff and Siva-Jothy 2003; Stanley et al. 2012). The resulting nodule is attached to an organ or the inner body wall where it typically remains for the remainder of the insect's life (Stanley et al. 2012). This response may be induced by bacteria, fungus, parasitoid eggs and, in some cases, viruses (Carton et al. 2002; Mullen and Goldsworthy 2006; Durmus et al. 2008; Gatschenberger et al. 2013). Bacteria have been the most commonly studied pathogen in relation to nodulation response (Stanley et al. 2012; Gatschenberger et al. 2013). The nodulation response by hosts to viral challenge has been mixed. Azzami et al. (2012) found that injecting A. mellifera larvae and adults with Acute bee paralysis virus did not elicit a cellular immune response, though subjects did respond to Escherichia coli injection. However, larvae of the endoparasitoid wasp, Pimpla turionellae, produced nodules in response to an injection of the Bovine Herpes Simplex virus-1 (Durmus et al. 2008). 
At this time, I do not know what type or types of pathogens attacked the queens in this study. In the laboratory experiment I found that $A$. gracilipes queens developed nodules in response to spores of the cosmopolitan fungal entomopathogen M. anisopliae, but not to LPS. As mentioned in the previous paragraph Azzami et al. (2012) found that another hymenopteran, A. mellifera, produce melanized nodules in response to E. coli, which is the same species from which the LPS used in this experiment came from. I am however, unaware of any similar studies which have used ants as their test subjects. This lack of nodulation in response to LPS does not rule out the possibility the invader was a bacterium, as Gram-positive bacteria have a different cell wall component (peptidoglycan) and elicit an immune response using a different molecular pathway than that for Gram-negative bacteria (Gillespie et al. 1997). A top priority is to discover the identity of this pathogen or pathogens. This is one of the goals of my next chapter (Chapter 5).

I observed no difference in fat content of queens between sites. It is possible that this pathogen or the observed immune response does not affect fat content in A. gracilipes queens. Alternatively, it has been shown that Nosema ceranae can cause fat reduction in overwintering bees (Baily and Ball 1991). However, Alaux et al. (2011) found that $N$. ceranae infected A. mellifera queens did not differ from uninfected queens in fat content. These authors suggested that as workers feed the queen, the queen might be able to compensate for the nutritional stress of $N$. ceranae infection by increasing her food demand from the workers. This mechanism may also be the case in A. gracilipes queens, which are also fed by workers. Ants are known to store fat during times of high resource abundance (Hahn 2006; Lease and Wolf 2011). I collected queens during February, which is the peak of the wet season, when resources are at their highest (Hoffmann and Saul 2010). It is possible that if queens had been collected in the dry season, when resources are scarce and queens may be more likely to be stressed, there may have been a noticeable difference in fat content between sites. However, February is one of the few months when queens are relatively shallow in the soil (due to increased moisture). It is extremely difficult to collect them at other times of the year when they seem to move deeper underground (personal observation; B. Hoffmann, unpublished data). 
There was a significant correlation between population type and queen number per nest. Surprisingly, low-density sites had the highest numbers of queens per nest, while highdensity sites had the lowest. This result does not support the hypothesis that queens are dying disproportionately at low and medium-density sites compared to high-density sites. Low-density sites had much lower densities of nests compared to medium and highdensity sites. Perhaps the population must reach a critical mass before queens colonize new nests, as A. gracilipes queens require the attendance of workers to survive (Holldobler and Wilson 1990). However, this is the opposite pattern as to what was found by Ingram (2002) who found a significant positive correlation between Linepithema humile queen number per nest and nest density. It is extremely difficult to document queen death in the field because workers frequently dismember and dispose of dead queens immediately after death (personal observation). The replacement of dead queens by newly produced queens may also mask the depletion of queens. In Arnhem Land, however, new queens are only produced at one time of the year: after the wet season around September (Hoffmann 2015). The timing of this production means that in February, new queens should not be present to obscure functional queen numbers and I saw no evidence of this as very few alates were observed.

I found an association between nest presence and queen number, and Acacia presence. Anoplolepis gracilipes is known to utilize this plant for its extra-floral nectaries, an important source of carbohydrates for this high-energy ant species (Lach and Hoffmann 2011). Perhaps the close proximity of this food source allows more queens, which have high nutritional demands, to be supported. No association between Acacia and A. gracilipes abundance was found by Gruber et al. (2012c) in this region. A key difference between my work and that of Gruber et al. (2012c) however, was that their study was examining worker abundances, not nest presence or queen number.

Like other organisms, insects are constantly exposed to microbial pathogens and other parasites; however, few of these encounters result in infection. In this chapter I have documented an immune response in A. gracilipes queens to an unknown pathogen or parasite. While this work suggests there may be a tradeoff between immune response and 
oocyte production in A. gracilipes queens, I do not know if the pathogen that caused the immune response is still present in the population, or if the queens' immune system was capable of destroying it upon its initial invasion of the hemocoel. If it is still present in the population, it is also possible that the pathogen or pathogens are asymptomatic, like some Picornavirales RNA viruses which are commonly present as low-level chronic infections in hymenopterans like S. invicta and A. mellifera (de Miranda et al.2010). These viruses, such as Solenopsis invicta virus-1 (SINV-1), usually appear to have no effect on colony health, though periods of high stress, or other, unknown causes, may trigger them to enter an acute-lethal stage (Bailey 1967; de Miranda et al. 2010; Porter et al.2013).

Though I discovered that pathogens or parasites do attack A. gracilipes queens in Arnhem Land, it is unclear whether these pathogens are responsible for the observed population declines. Nodulation rate was not associated with population type, and the two highdensity sites had the second and third highest nodulation rates after site M2 (23\% and $20 \%$ respectively). It would be interesting to monitor the population at the site with the most nodulation, site M2 (47\% with nodules) in future, to see if it declines. In addition, further analyses are needed to determine the nature of the microorganisms contained in the nodules. Once potential candidates are identified, Koch's postulates, as modified for microbial pathogenicity, would need to be applied to establish a causative relationship between the infection and reduced oocyte production (Fredricks and Relman 1996; Koch 1876). In the next chapter I suggest possible microbial candidates for organisms within the nodules. 


\section{Chapter 5: A metatranscriptomic survey of Anoplolepis gracilipes identifies several potential pathogens}

\subsection{Abstract}

Populations of invasive species have been observed to decline, though the mechanisms behind such declines are rarely elucidated. The microbial community living within insects can have significant impacts on their health and population dynamics. Here I use Illumina sequencing to compare the bacterial communities and investigate the presence of viruses in queens of the invasive ant, Anoplolepis gracilipes, from populations in various stages of decline or expansion in Australia. Sequences with homology to the Dicistroviridae were present in the data from low and medium-density populations. This is the first such instance of a likely virus discovery in A. gracilipes. Though overall bacterial communities were not statistically different between the population types, several putative pathogens were discovered and are suggested for further study. The potential pathogen, Candidatus Rhabdochlamydia, was only found in expanding populations. The entomopathogen, Serratia marcescens, was found in significantly higher abundance in queens with melanized nodules, making it an excellent candidate for the identity of the contents of the nodules found in Chapter 4. The reproductive parasite, Candidatus Cardinium, was also found predominantly at one medium-density site. This survey has identified several candidates for future study to identify potential microbial control agents, and which may be responsible for population declines of this invasive ant.

\subsection{Introduction}

Invasive species are one of the greatest threats to biodiversity in the modern era (Vitousek et al. 1997). However, invasive species may be vulnerable to disease: both diseases they have carried with them from their native range and those they have acquired in their new range (Oi and Valles 2015). For example, Solenopsis invicta brought several pathogens with it from South America when it invaded North America, such as the microsporidian, Kneallhazia solenopsae, which appears to play a role in controlling population size of these ants in South America (Briano et al. 1995b, 2005). Alternatively, 
5. A metatranscriptomic survey of A. gracilipes

introduced species may acquire novel pathogens in their new range (Espalader et al. 2011). For example, Flory and Clay (2013) found that the number of pathogens infecting invasive plants was positively correlated to the length of time the plants had been established in a region, suggesting these pathogens were obtained in the new range.

The microbiota of an insect can have both positive and negative affects on its health, reproduction and longevity (Cox-Foster et al. 2007; Russell et al. 2009; Vasquez et al. 2012). Mutualistic bacteria have been shown to play a myriad of roles in host physiology, such as providing essential nutrients that are lacking in the host's diet, mediating host thermal tolerance, or enhancing pathogen and parasitoid resistance (Brumin et al. 2011; Feldhaar 2011; Kaltenpoth et al. 2005; Russell et al. 2009). Beneficial taxa include lactic acid bacteria that have been implicated in honey bee health, inhibiting the bacterial brood pathogen, Paenibacillus larva (Forsgren et al. 2009; Vasquez et al. 2012). Certain microbes, such as Wolbachia, may affect various host species differently (Brownlie and Johnson 2009; Wenseleers et al. 1998, 2002). In some cases Wolbachia can cause cytoplasmic incompatibility in insects, in which a mating between a Wolbachia-infected male and uninfected female is infertile, to the detriment of its host's population (Tagami et al. 2006; Vasquez et al. 2011). Wolbachia, however, may also provide protection against viruses. Hedges et al. (2008) found Drosophila melanogaster infected with Wolbachia survived for longer when also infected with a range of RNA viruses, than flies that harboured no Wolbachia co-infection. Pathogenic microorganisms may also negatively affect host population dynamics (Arif et al. 2011; Lacey et al. 2001). Such is the case with the bacterial pathogen, Aeromonas hydrophila, which appears to play a role in periodic collapses of invasive giant African land snail populations (Simberloff and Gibbons 2004).

Though seldom quantitatively monitored, other collapses of invasive species' populations have been recorded (Simberloff and Gibbons 2004). The highly invasive signal crayfish, Pacifastacus leniusculus, was found to have collapsed in $41 \%$ of surveyed Swedish lakes (Sandström et al. 2014). This phenomenon has also been documented in a number of invasive ant species including Linepithema humile (Cooling et al. 2012), Pheidole 
megacephala (Wetterer 2012), and Anoplolepis gracilipes (Cooling and Hoffmann 2015; Gruber et al. 2012a; Haines et al. 1994). In most of these cases the mechanisms behind the population declines are not understood, but pathogens have been suggested.

Recently, six dicistroviruses have been found in the red imported fire ant, S. invicta (Valles 2007; Valles et al. 2009, 2014). Before the discovery of the first virus, SINV-1, there were no viruses known to infect ants (Valles 2012), though suspected viral particles had been noted (Allen and Buren 1974). However, since that initial discovery several viruses have been identified in the invasive Argentine ant, Linepithema humile, and other ant species (Johansson et al. 2013; Sébastien et al. 2015; Valles et al. 2012). So far it appears that many of these viruses are asymptomatic, at least under normal, non-stressful conditions, other viruses may be strongly pathogenic (de Miranda et al. 2010; Porter $e t$ al.2013; Valles et al. 2013). It seems likely there are many viruses infecting ant species, but before the advent of next-generation sequencing (NGS) they were simply too difficult to identify (Valles et al., 2004, 2012).

NGS techniques, such as 454 pyrosequencing and Illumina sequencing have revolutionized metagenomic studies and the discovery of microbes such as viruses (Caporaso et al.2011, 2012; Liu et al. 2011). Amplification and NGS sequencing of the universal $16 \mathrm{~S}$ rRNA gene in bacteria has brought new appreciation for the complexity of the bacterial community within organisms (Bartram et al. 2011; Fadrosh et al. 2014). This technology enables high throughput, swift, relatively inexpensive sequencing for the discovery of microorganisms (Johansson et al.2013). One such use is the identification of potential biocontrol agents for invasive pests (Valles et al.2012; Liu et al. 2011). Traditionally, surveys for natural enemies of an invasive species have been done in their native range, as an invader may leave many of its parasites and predators behind when it is introduced to a new area (Allen and Buren 1974; Keane and Crawely 2002; Oi and Valles 2015; Torchin et al. 2003). For example extensive surveys of the native and introduced ranges of the invasive ant, $S$. invicta, have uncovered over 35 natural enemies in its native range and only 7 in its introduced range (Oi and Valles 2015). However, in cases where the native range of an invader isn't known, it may be useful to investigate 
unusual behaviour or patterns, such as population declines, which may indicate unhealthy populations and presence of pathogens (Valles et al. 2012).

Anoplolepis gracilipes is considered among the most ecologically and economically damaging invasive ant species (Holway et al. 2002). In Chapter 2, I documented the decline of several A. gracilipes populations. In Chapter 4, I discovered the presence of unidentified pathogens capable of penetrating the cuticle of queen A. gracilipes, and causing melanized nodules. In this chapter, I compare microbial fauna between queens from sites classified as having low, medium and high-density populations of $A$. gracilipes, all of which appear to be in different stages of decline or expansion. These population types were chosen based on the hypothesis that the pathogens are contributing to the decline of populations, but might be absent from populations that are expanding. Here, I investigate 1) if pathogens and mutualists are present in A. gracilipes, 2) if there is any evidence that population types differ in their bacterial and viral communities, and 3 ) if there is any evidence that queens with melanized nodules have any distinctive microbes compared to queens without.

\subsection{Methods}

\subsubsection{Site selection}

Site selection was determined by two factors: the history of $A$. gracilipes population decline or expansion at each site (B. Hoffmann, personal observation; Cooling and Hoffmann 2015), and the present density of their A. gracilipes populations (see Chapter 4 for density data). I selected six study sites that had A. gracilipes populations in various stages of decline and had never had ant management, such as with the use of toxic baits (Figure 5.1).

The low-density populations (L1, L2) were all that remained of much larger populations that had declined substantially in the past 5 years. The medium-density populations (M1, M2) covered a much wider area than the low, and had higher abundances. These populations appeared to be stable, but also once belonged to larger populations. The high- 


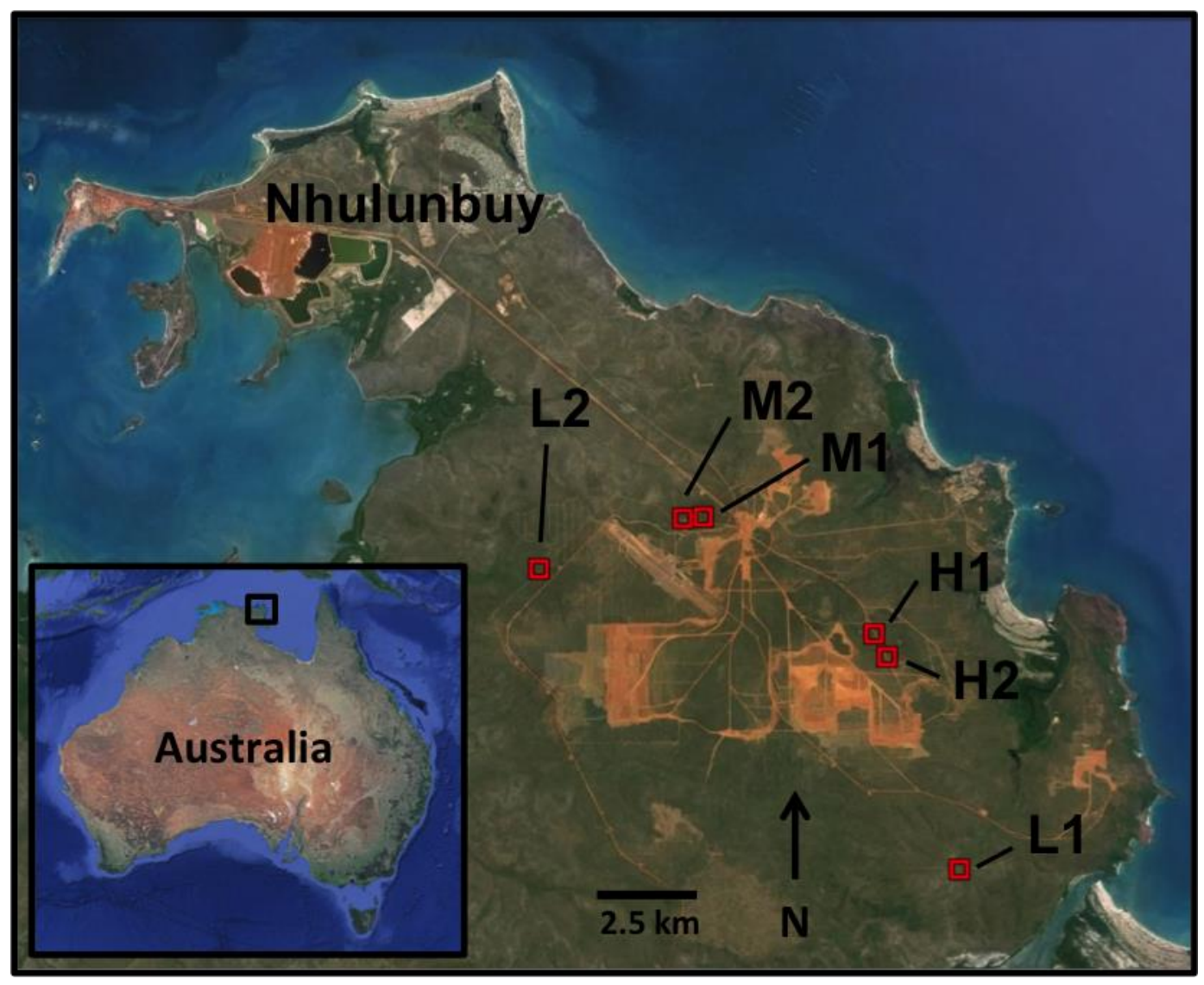

Figure 5.1. Inset of Australia and map of Arnhem Land showing study site locations (red squares) and town of Nhulunbuy. $L$ denotes low-density populations, $M$ medium-density and $H$ high-density. Sites $\mathrm{M1}$ and $\mathrm{M} 2$ are $450 \mathrm{~m}$ apart and $\mathrm{H1}$ and $\mathrm{H} 2400 \mathrm{~m}$ apart and are distinct populations.

density populations $(\mathrm{H} 1, \mathrm{H} 2)$ were expanding, and covered a large area with abundances that were several order of magnitudes higher than the low and medium-density populations (Chapter 4). Though sites M1 and M2 and $\mathrm{H} 1$ and $\mathrm{H} 2$ are very close together they can still be considered independent from each other. This is because the maximum foraging range of an A. gracilipes worker is $35 \mathrm{~m}$ (B. Hoffmann, unpublished data) and the above populations are separated by $400 \mathrm{~m}$ and $450 \mathrm{~m}$ respectively, so there is unlikely to be any mixing of workers between populations. Likewise, in Arnhem Land, A. gracilipes queens do not partake in nuptial flights. Instead they appear to mate inside their natal nest and either stay there or walk away to form new nests nearby (Hoffmann 2015). Therefore there is unlikely to be genetic input from geographically separated populations either. 


\subsubsection{Microbial survey}

Samples of queens were collected from each site in February 2013 (Chapter 4). See Chapter 4 methods for details on queen collection. On October $16^{\text {th }}$ and $20^{\text {th }} 2014$, DNA and RNA extractions were done for Illumina sequencing using Qiagen's DNeasy Blood and Tissue, and RNeasy kits following the manufacturer's protocol. There were two samples from each of the three population types, high-density (H1, H2), medium-density (M1, M2) and low-density (L1, L2). Each sample consisted of five queens from as many different nests as possible from that population. These queens had been previously dissected as part of a previous experiment and were preserved in RNAlater ${ }^{\circledR}$ Stabilization Solution (Life Technologies, Auckland, New Zealand) (Chapter 4). Queens from each site were pooled together before extraction. A Qiagen TissueRuptor was used to homogenize the tissue. In order to identify microorganisms that may be contained within the melanized nodules discovered in Chapter 4, all queens used in both RNA and DNA extractions from site M1 contained melanized nodules. Queens from all other sites contained no nodules.

\subsubsection{RNA survey}

RNA quality was determined by the presence of an $18 \mathrm{~S}$ rRNA peak using an Agilent 2100 Bioanalyzer. The TruSeq stranded total RNA libraries were constructed for each sample by New Zealand Genomics Limited (NZGL; University of Auckland, NZ). Sequencing of the libraries was conducted by NZGL (University of Otago Genomics and Bioinformatics Facility) using a single lane of Illumina HiSeq 2500 (2 X100bp PE).

The Illumina HiSeq sequencing returned just over 65 million reads (65 080 176), with an average of $10846696 \pm 1897369$ reads per sample (mean \pm SD). These were high quality reads, as they had an average of $94.6 \%$ over a Phred score of Q30. The RNA sequences were adapter trimmed and quality trimmed at a probability of 0.01 (Phred score of Q20) using the program FastQC 0.11.3 (Andrews 2015). To reduce the chance of erroneous sequences overinflating diversity estimates, all reads smaller than 50 bps were discarded, as were singletons (reads that had no paired read) with the program SolexaQA 3.0 (Cox et al.2010; Lindahl et al.2013). Transcriptome de novo assembly of paired-end 
reads was performed with the software Trinity (Grabherr et al. 2013). Reads were normalized during the process. After assembly, there were a total of 837259 reads with a mean length of $960 \pm 24 \mathrm{bp}$ (mean $\pm \mathrm{SD}$ ). These reads were compared against the NCBI nt database using BLASTn with a minimum evalue of 0.0001 . Taxonomic assignment of the BLAST output was done in MEGAN v. 4.7 using the conservative threshold of Min Score $=120$ and Top Percent $=10$ (Mitra et al. 2011). This filtering process resulted in taxonomy being assigned to 425022 reads.

Assigned viral sequences with a bit score greater than 100 were then extracted and searched with BLASTx against the nr database with the conservative search parameters of a minimum evalue of 0.0001 , Best Hit algorithm overhang value of 0.25 , and Best Hit algorithm score edge value of 0.05 (Camacho et al. 2008). Taxonomy was assigned in MEGAN using the same conservative threshold as discussed above.

Phylogenetic analyses of the three viral sequences observed from the above analysis (TR44839, TR80102, TR17983) were conducted in MEGA v. 6.06 (Tamura et al. 2013) after alignment with ClustalW (Larkin et al. 2007). Maximum-likelihood trees with 1000 bootstrap replicates were generated using the Tamura 3-parameter model for TR44839 (T92; $\operatorname{lnL}$-1126.878) and TR17983 (T92; lnL -1398.077), and the Tamura 3-parameter model with a gamma distribution (T92 + G(0.95); $\operatorname{lnL}-1409.281)$ for TR80102 (Tamura 2002).

\subsubsection{S survey}

DNA quantity was checked using a Nanodrop, DNA was run on a $1 \%$ agarose gel to test quality. PCR amplification of the V3-V4 hypervariable region of the16S rRNA gene was achieved using Nextera adapter primers provided by NZGL (forward primer 5'TCGTCGGCAGCGTCAGATGTGTATAAGAGACAGCCTACGGGNGGCWGCAG3') and reverse (5'-

GTCTCGTGGGCTCGGAGATGTGTATAAGAGACAGGACTACHVGGGTATCT AATCC-3') (Klindworth et al. 2013). The PCR reactions contained $2.5 \mathrm{uL}$ of template DNA, $12.5 \mathrm{uL}$ of 2x KAPA HiFi HotStart Ready Mix and $5 \mathrm{uL}$ of each the forward and reverse primers $(1 \mathrm{uM})$ for a total volume of $25 \mathrm{uL}$. The PCRs were cycled 25 times at 
$95^{\circ} \mathrm{C}$ for $30 \mathrm{~s}$, annealing temperature of $55^{\circ} \mathrm{C}$ for $30 \mathrm{~s}$ and $72^{\circ} \mathrm{C}$ for $30 \mathrm{~s}$, with a final elongation at $72^{\circ} \mathrm{C}$ for $5 \mathrm{~min}$. The PCR poducts were then sequenced on a 600 cycle Illumina MiSeq (2 X 300bp PE) (MiSeq Reference Guide 2013).

Primers and adaptors were trimmed and paired-end reads joined using PANDAseq, $\mathrm{v} 2.8$, which also performs error correction during assembly (Masella et al. 2012). Of the total reads, $94.5 \%$ were assembled. The final sequence length after primer removal and joining was $418 \pm 4$ bp (mean \pm SD), with an average of $43668 \pm 41723$ reads (mean \pm SD) per sample. The remaining 262009 sequences after joining were further processed and analyzed using the program Quantitative Insights Into Microbial Ecology (QIIME, v 1.9.0). First, de novo chimeric sequences were removed ( 919 sequences, $0.35 \%$ of total sequences) after detection with QIIME's implementation of USEARCH, v 6.1.544 (Edgar 2010). Sequence reads were clustered into operational taxonomic units (OTUs) at 97\% sequence similarity with the de novo method using USEARCH. A representative sequence was then picked for each OTU using the Greengenes 13.8 rep set, and taxonomy was assigned, using Greengenes 13.8 taxonomy (McDonald et al. 2012). Sequences were aligned against the Greengenes database using PYNAST, v 1.2.2, and filtered using the Greengenes lanemask. OTUs with a number of sequences less than $0.005 \%$ of the total number of sequences were discarded (Bokulich et al. 2013). Before analyses, bacterial sequence libraries from individual sites were rarified in QIIME to 2767 reads, which was the size of the smallest sequence library (site M1) (Figure 5.2).

The variation in bacterial diversity at the order level between samples of different population types was calculated using an Analysis of Similarity (ANOSIM, with 9999 permutations). The resemblance matrix was derived using the Bray-Curtis similarity index (Clarke 1993). All community data was square root transformed prior to analysis to decrease the influence of very abundant species. Differences between samples were visualized for the Bray-Curtis analysis using a PCoA plot. The contribution of each bacterial order to differences between population types was assessed using SIMPER 


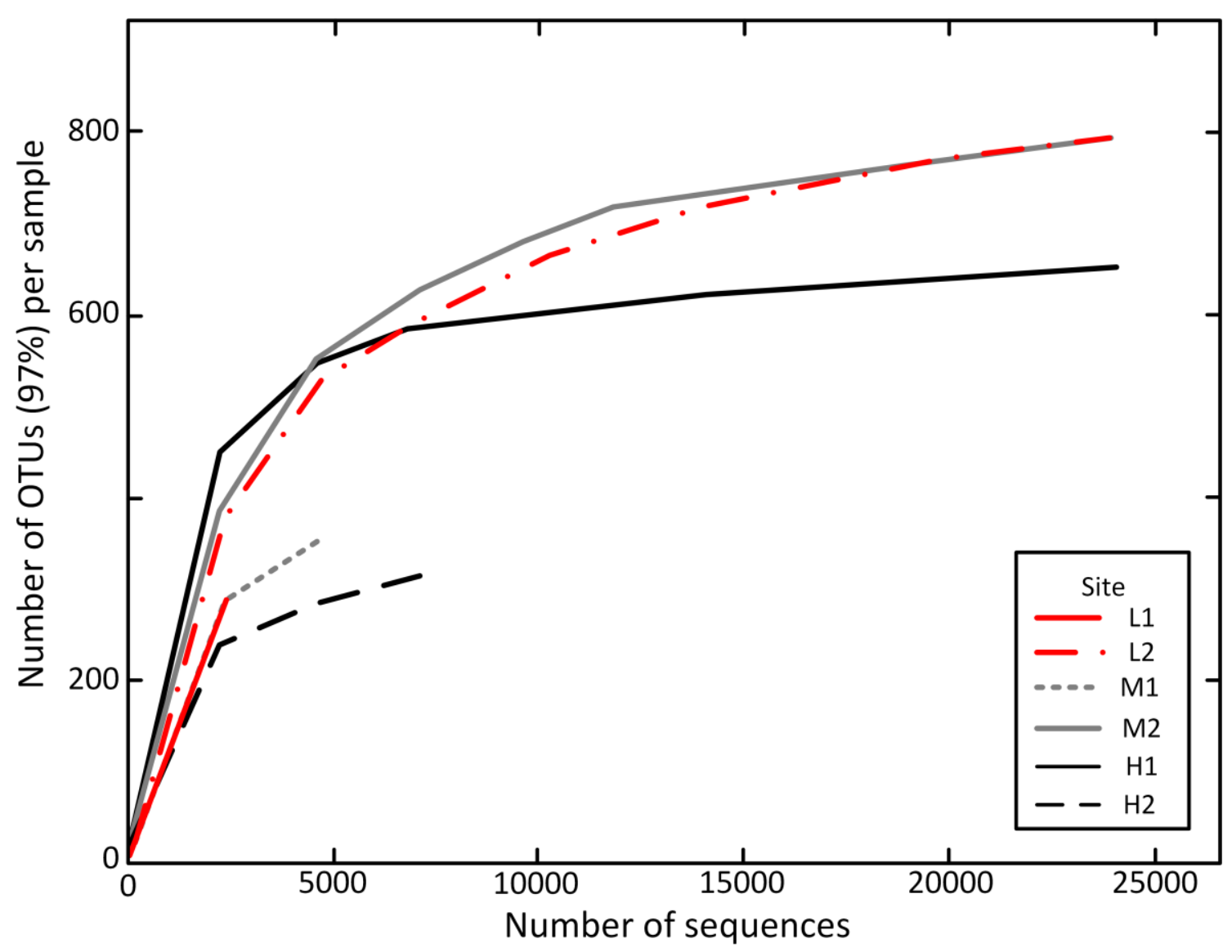

Figure 5.2. Alpha rarefaction curves for the six $16 \mathrm{~S}$ samples. Red lines represent low-density sites (L1, L2), dark grey lines represent medium-density sites (M1, M2) and black lines represent highdensity sites (H1, H2).

analysis. The ANOSIM, PCoA and SIMPER were run in Primer-E v 6.1.13 \& PERMANOVA + v 1.0.3 (Clarke and Gorley 2006). Log-likelihood ratio tests, using the Bonferroni procedure to correct for multiple comparisons, were used in QIIME to identify which bacterial groups differed between population types, and between site M2 and other sites, for order and genus (Rice 1989).

\subsection{Results}

\subsubsection{RNA survey}

Ninety-five percent of RNA reads came from eukaryotes, and likely originated from the ant host (Figure 5.3). Only $0.004 \%$ of 425,022 total reads were of viral origin. Three candidate viral sequences were found from two sites, one from the medium-density site M2 and two from the low-density site L2. The sequence, TR44839 (220 bp in length), 


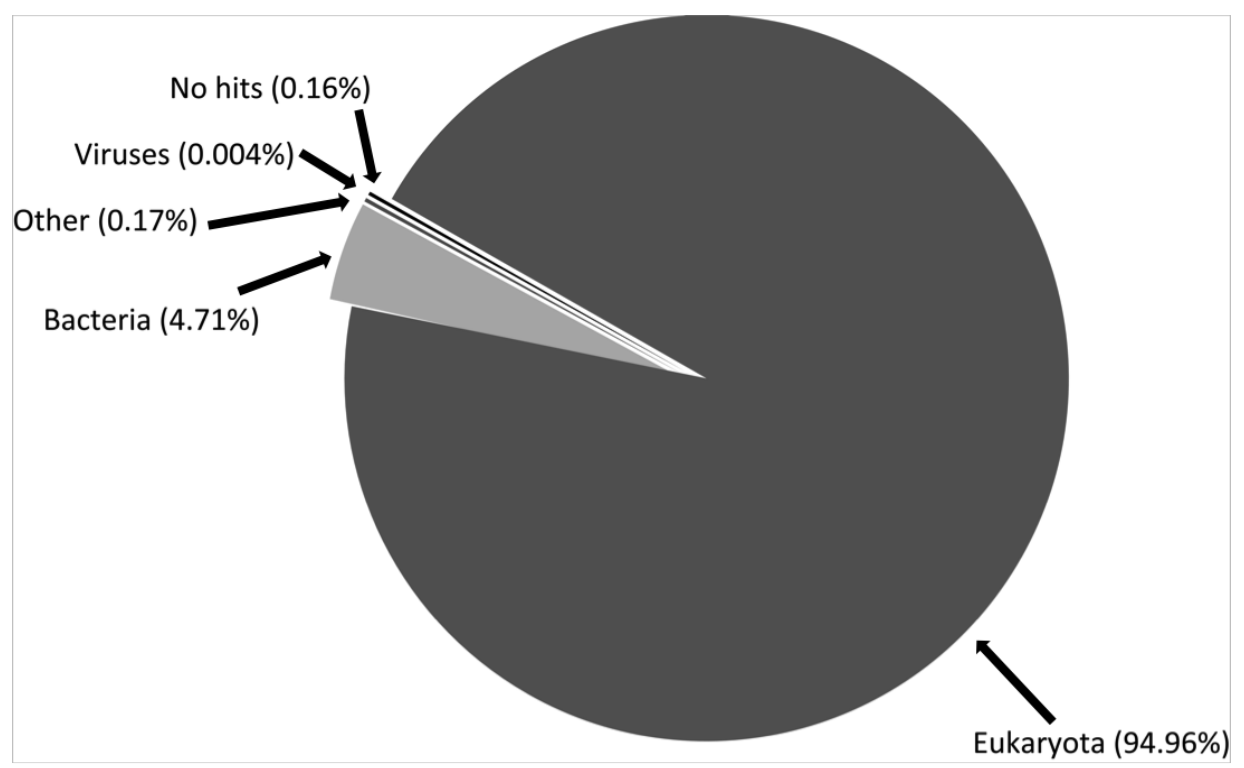

Figure 5.3. Metagenomic data summary from BLASTn results of RNA data showing taxonomic assignment of individual reads for all samples combined. Summary is based on a total of 425022 reads.

from M2 (10 hits) matched most closely to helicase of Israeli acute paralysis virus (Table 5.1). The two sequences from L2, TR17983 (240 bp in length) and TR80102 (282 bp in length) (9 hits total), matched most closely to RNA polymerase of Black queen cell virus and RNA polymerase of Kashmir bee virus, respectively (Table 5.1). Phylogenetic analysis grouped all three viral sequences with the Dicistroviridae family of viruses (Figure 5.4).

\subsubsection{S survey}

Bacterial communities from 30 A. gracilipes queens from 6 sites ( $\mathrm{n}=5$ queens per site) were characterized using Illumina sequencing (261 039 chimera-checked, quality controlled sequences; $n=7707-103350$ per library). An ANOSIM analysis found that at the order level, bacterial communities were not significantly different between low, medium and high-density populations $(\mathrm{R}=-0.056, p=0.533$; Figure 5.5$)$. An $\mathrm{R}$ value of less than zero suggests that dissimilarities are greater within groups than between groups (Warwick et al. 1990). Due to the low sample size, these results should be considered preliminary. 
Table 5.1. The 10 closest matches for each viral sequence of interest on GenBank using BLASTn against the nt database. Results are ordered by the highest max score for each sequence of interest. Site refers to the sample site the viral sequence was found in.

\begin{tabular}{|c|c|c|c|c|c|c|c|c|c|}
\hline Seq ID & Site & Closest match name $^{\mathrm{a}}$ & Max score & Total score & $\begin{array}{l}\% \text { query } \\
\text { coverage }\end{array}$ & E-value & $\begin{array}{l}\% \text { query } \\
\text { identity }\end{array}$ & Accession \# & Taxa or description of match \\
\hline \multirow[t]{9}{*}{ TR44839 } & M2 & IAPV & 171 & 171 & 91 & $4 \mathrm{e} 39$ & 80 & EU224280.1 & Honey bee (A. mellifera) virus \\
\hline & & IAPV & 166 & 166 & 91 & $2 \mathrm{e}-37$ & 80 & JX045857.1 & Honey bee (A. mellifera) virus \\
\hline & & IAPV & 160 & 160 & 91 & $1 \mathrm{e}-35$ & 79 & EU436498.1 & Honey bee (A. mellifera) virus \\
\hline & & IAPV & 160 & 160 & 91 & $1 e-35$ & 79 & EU436481.1 & Honey bee (A. mellifera) virus \\
\hline & & IAPV & 160 & 160 & 91 & $1 \mathrm{e}-35$ & 79 & EU436479.1 & Honey bee (A. mellifera) virus \\
\hline & & IAPV & 160 & 160 & 91 & $1 \mathrm{e}-35$ & 79 & EU436478.1 & Honey bee (A. mellifera) virus \\
\hline & & IAPV & 160 & 160 & 91 & $1 \mathrm{e}-35$ & 79 & EU436473.1 & Honey bee (A. mellifera) virus \\
\hline & & IAPV & 156 & 156 & 77 & $2 \mathrm{e}-34$ & 81 & EU436489.1 & Honey bee (A. mellifera) virus \\
\hline & & IAPV & 154 & 154 & 91 & $7 e-34$ & 79 & EU436423.1 & Honey bee (A. mellifera) virus \\
\hline \multirow[t]{10}{*}{ TR17983 } & L2 & KBV & 431 & 431 & 100 & $3 e-117$ & 97 & KF956377.1 & Honey bee (A. mellifera) virus \\
\hline & & KBV & 431 & 431 & 100 & $3 e-117$ & 97 & HM228889.1 & Honey bee (A. mellifera) virus \\
\hline & & KBV & 419 & 419 & 100 & $1 \mathrm{e}-113$ & 96 & AY275710.1 & Honey bee (A. mellifera) virus \\
\hline & & ABPV & 62.2 & 62.2 & 26 & $4 \mathrm{e} 06$ & 83 & AF486073.2 & Honey bee (A. mellifera) virus \\
\hline & & FEV -1 & 52.6 & 52.6 & 24 & 0.003 & 82 & KF500001 & Ant (Formica exsecta) virus \\
\hline & & Anabaena variabilis & 48.8 & 48.8 & 16 & 0.050 & 88 & СР000117.1 & Bacteria genome \\
\hline & & Alligator sinensis & 44.9 & 44.9 & 10 & 0.72 & 96 & XM_006034715.2 & Alligator genome \\
\hline & & Strongyloides stercoralis & 44.9 & 44.9 & 9 & 0.72 & 100 & L̄'999049.1 & Roundworm genome \\
\hline & & Homo sapiens & 44.9 & 44.9 & 12 & 0.72 & 91 & AC095056.3 & Human genome \\
\hline & & Oryzias latipes & 43.0 & 43.0 & 11 & 2.7 & 93 & HG313992.1 & Fish genome \\
\hline \multirow[t]{10}{*}{ TR80102 } & L2 & $\mathrm{KBV}$ & 500 & 500 & 100 & $5 \mathrm{E}-138$ & 98 & AF192404.1 & Honey bee (A. mellifera) virus \\
\hline & & KBV & 500 & 500 & 100 & $5 \mathrm{E}-138$ & 98 & AF 177935.1 & Honey bee (A. mellifera) virus \\
\hline & & KBV & 489 & 489 & 100 & $2 \mathrm{e}-134$ & 97 & AF117308.1 & Honey bee (A. mellifera) virus \\
\hline & & KBV & 471 & 471 & 100 & $3 e-129$ & 96 & AY275710.1 & Honey bee (A. mellifera) virus \\
\hline & & KBV & 339 & 339 & 98 & $2 \mathrm{e}-89$ & 88 & KF956377.1 & Honey bee (A. mellifera) virus \\
\hline & & FEV-1 & 325 & 325 & 98 & $3 e-85$ & 87 & KF500001.1 & Ant (Formica exsecta) virus \\
\hline & & KBV & 314 & 314 & 61 & $8 e-82$ & 98 & AF232007.1 & Honey bee (A. mellifera) virus \\
\hline & & KBV & 308 & 308 & 61 & $4 e-80$ & 98 & AF233366.1 & Honey bee (A. mellifera) virus \\
\hline & & Cloudy wing virus & 308 & 308 & 61 & $4 e-80$ & 98 & AF034543.2 & Honey bee (A. mellifera) virus \\
\hline & & KBV & 302 & 302 & 61 & $2 \mathrm{e}-78$ & 97 & AF135854.1 & Honey bee (A. mellifera) virus \\
\hline
\end{tabular}


A

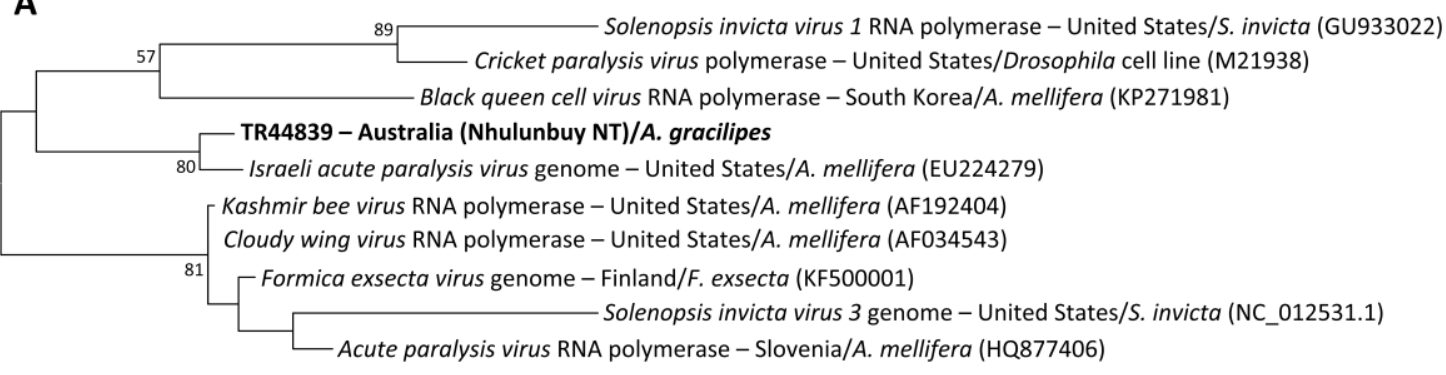

B

0.2

Taura syndrome virus genome - United States/Penaeus vannamei (JF966384)

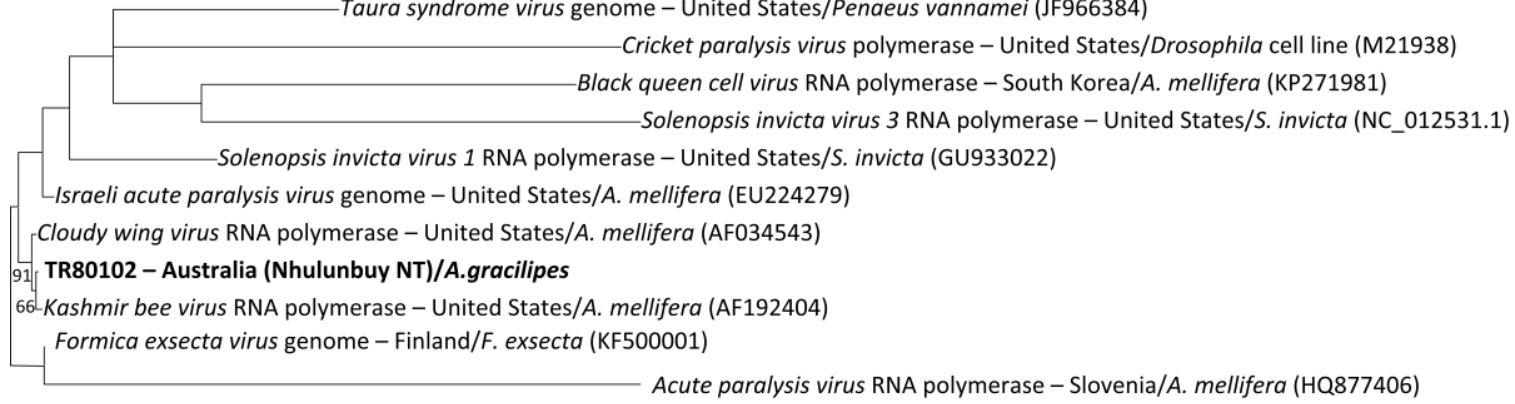

0.2

C $94-$ Kashmir bee virus RNA polymerase - United States/A. mellifera (AF192404)

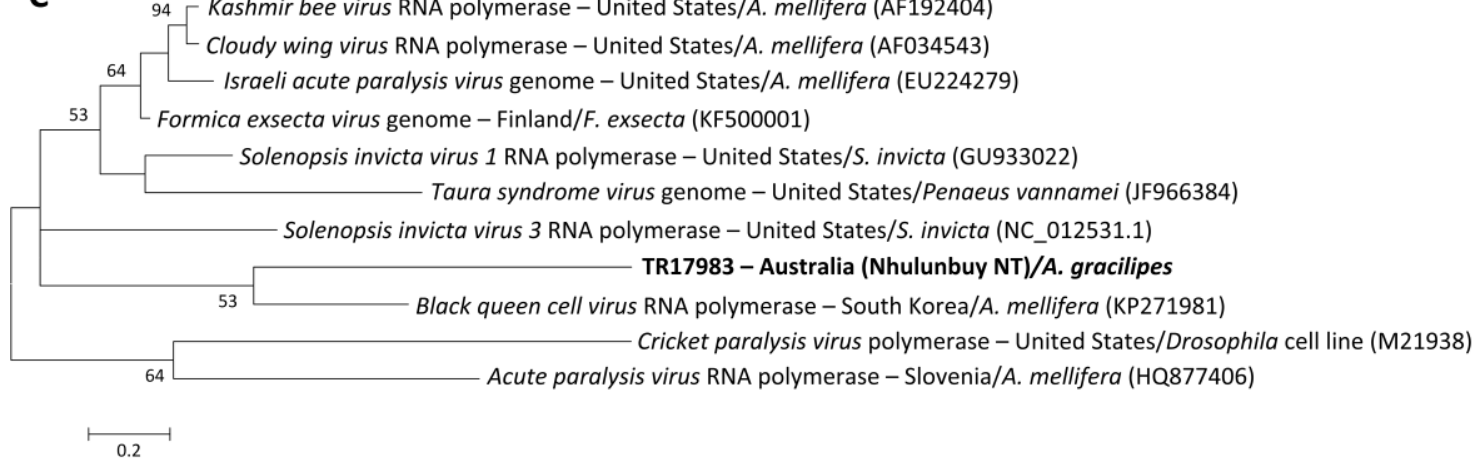

Figure 5.4. Maximum-likelihood phylogenetic trees ( 1000 bootstrap replicates) showing the relationship of found sequence (A) TR44839 from the medium-density site M2 (B) TR80102 from the low-density site L2 and (C) TR17983 from the low-density site L2. Bar in bottom left of each tree shows 0.02 changes per nucleotide. The GenBank accession number for each sequence is shown in brackets.

One hundred and seventy six unique OTUs (97\% sequence similarity), at the genus level (Figure 5.6 genus level OTUs), were found across the studied queens (96-155 OTUs per sample). In terms of number of sequences, $58 \%$ of total sequences came from the phylum Proteobacteria (110 372 sequences) (Figure 5.7). The next most prevalent phyla were Firmicutes (25 552 sequences), Cyanobacteria (19 372 sequences) and Chlamydiae (11 802 sequences). For samples from low and medium-density sites, the top 10 most 


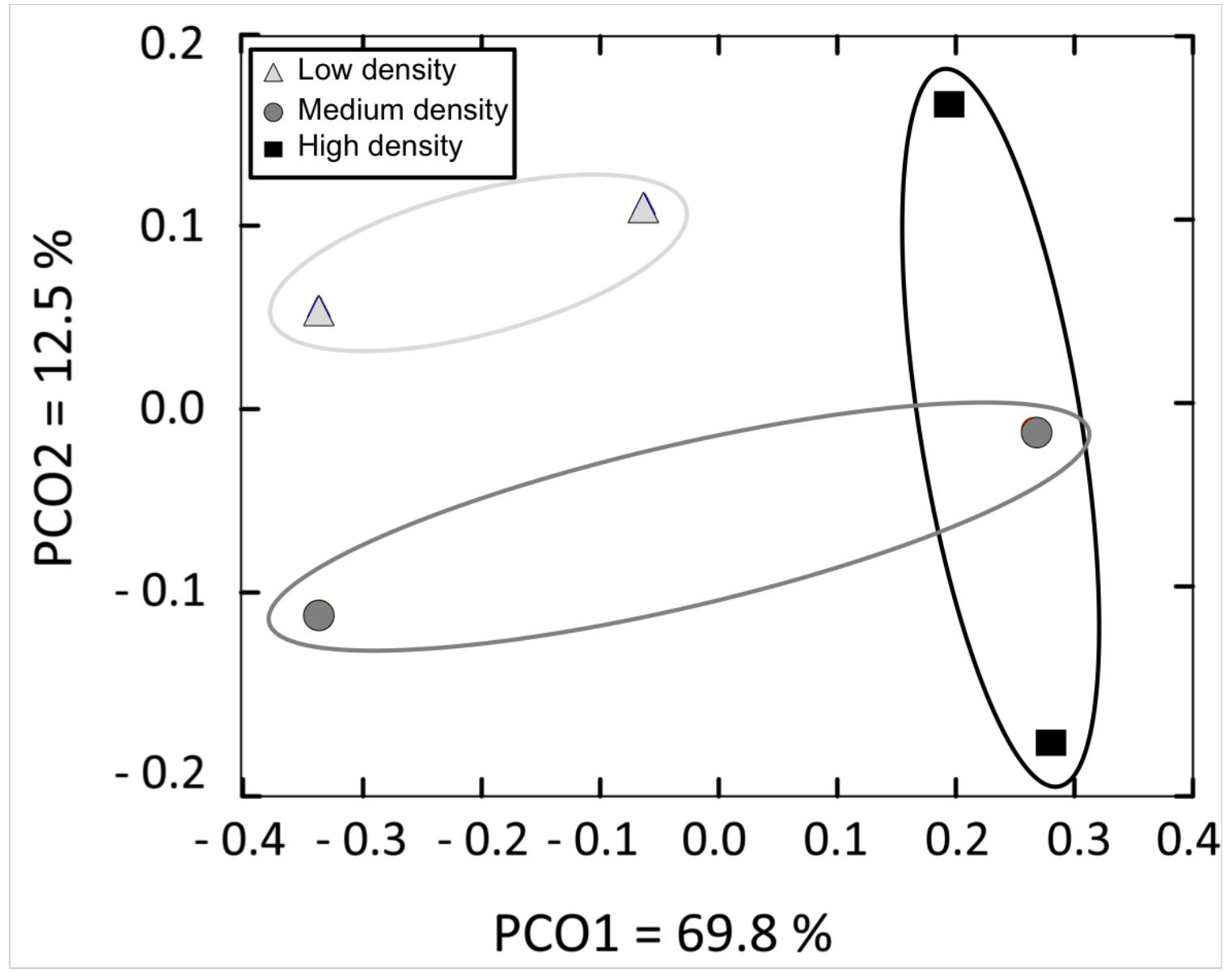

Figure 5.5. Principal coordinates analysis comparing bacterial communities among samples from low, medium and high-density populations. PCoA based on Bray-Curtis distance values computed for $A$. gracilipes microbial communities at the order level. Ovals are used to enclose all individual communities from the same population type. The first and second PCoA axes are shown, and the percent of Bray-Curtis distance variation explained by each axis is listed next to the axis labels.

prevalent orders across all samples accounted for over $92.6 \%$ of sequences (Table 5.2). For high-density sites, however, these 10 orders accounted for only $63.4 \%$ of sequences. Sequences came from 40 different bacterial orders (Figure 5.8, order level OTUs), all of which were found in samples from high-density populations, including 13 orders that were only found in high-density populations, such as Chlamydiales which was the most prevalent order at expanding sites ( $24.5 \%$ of sequences). Conversely, the top two most prevalent orders across all sites, Neisseriales and Pasteurellales, together made up 37.2\% and $68.3 \%$ of sequences in low and medium-density populations, respectively, but only $0.07 \%$ of sequences in high-density populations. 


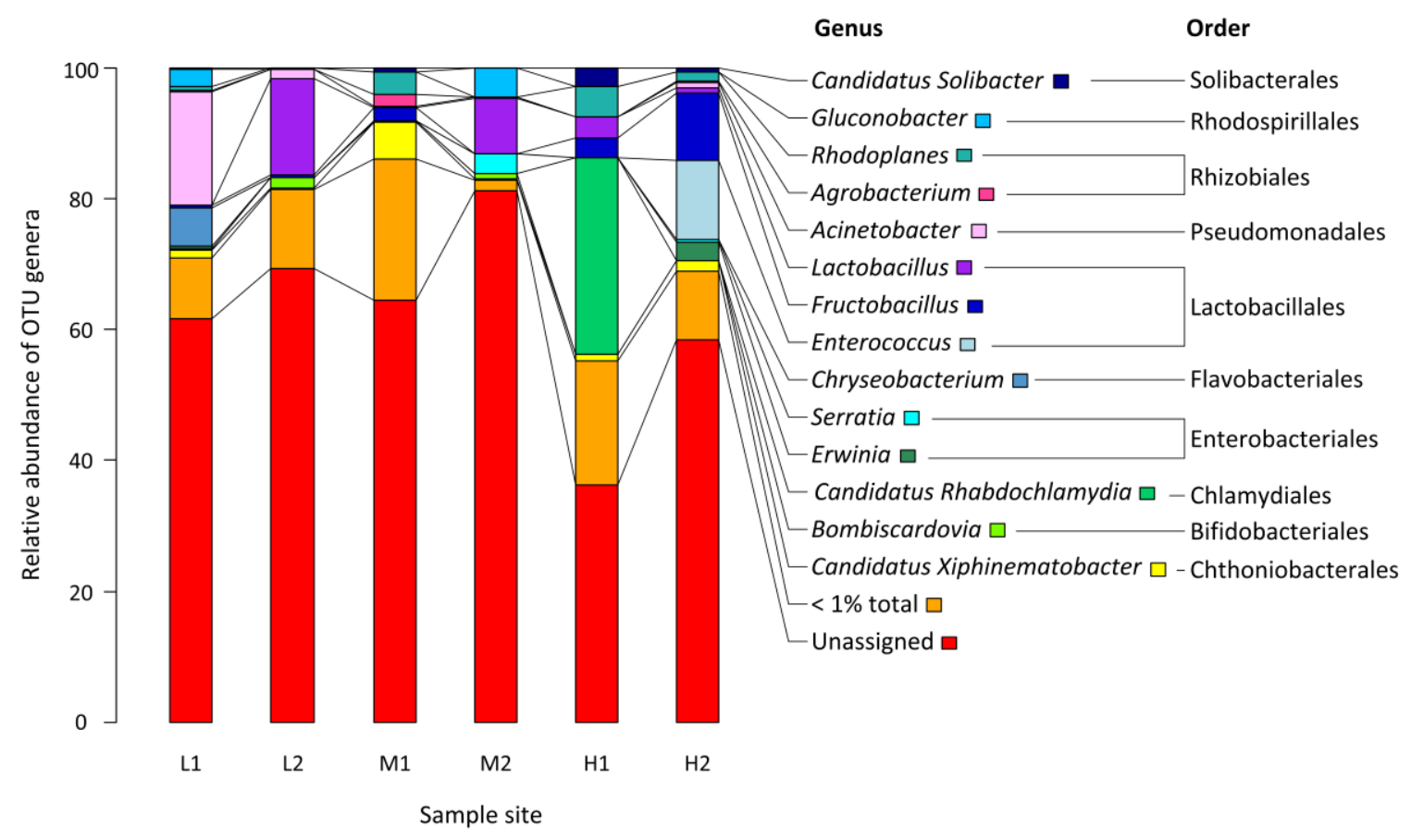

Figure 5.6. Relative abundance of OTUs $(97 \%)$ at the genus level for each sample site. Values are based on rarefied samples. The order each genus belongs to is indicated on the right. The orange bars indicate genera that made up less than $1 \%$ of the total sample and the red bars are those OTUs that were not assigned to any genera. Note the high levels of variation between replicates of the same population types.

The SIMPER analysis showed that $90 \%$ of dissimilarity between high and low-density sites was attributed to 45 bacterial orders, while $50 \%$ of the dissimilarity was attributed to 10 bacterial orders (Table 5.3). Forty-nine bacterial orders accounted for $90 \%$ of the dissimilarity between high and medium-density sites, with $50 \%$ of that dissimilarity was attributed to 13 bacterial orders. Similar numbers were found for medium and lowdensity sites, with $90 \%$ of the dissimilarity accounted for by 38 bacterial orders, and $50 \%$ of the dissimilarity by 10 bacterial orders.

Genera previously found by Gruber (2012) to differ between sites of low A. gracilipes abundance and high, Arsenophonus, Actinomyces, Bacillus, Streptomyces and Wolbachia, were not found in the $16 \mathrm{~S}$ samples (except Wolbachia, which was represented by 6 reads). However, Wolbachia was found in the RNA samples, where it was relatively evenly distributed among site types (low-density sites: 3322 sequences; medium-density sites: 2892 sequences; high-density sites: 3504 sequences). 


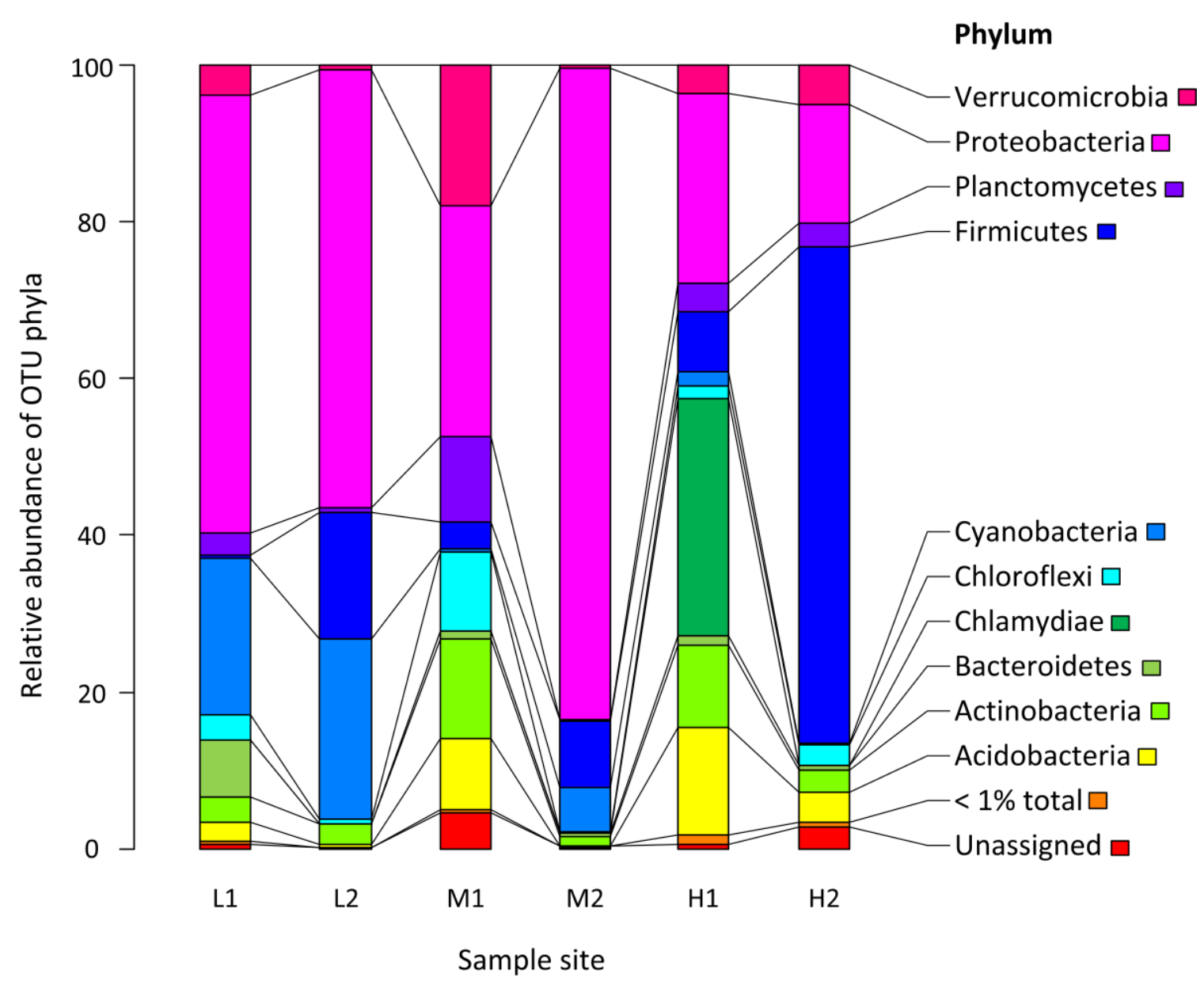

Figure 5.7. Relative abundance of OTUs $(97 \%)$ at the phylum level for each sample site. Values are based on rarefied samples. The orange bars indicate phyla that made up less than $1 \%$ of the total sample and the red bars are those OTUs that were not assigned to any phyla.

There were significant differences between population types for ten bacterial orders, representative of 13 OTUs, seven of which were identified to the genus level (Table 5.4). The pathogen, Candidatus Rhabdochlamydia (Candidatus refers to the fact this taxon has not been successfully maintained in culture; hereafter referred to as Rhabdochlamydia) was only present in the expanding populations. The order Rhizobales, which contains putative nutritional mutualists of ants was significantly less common in the declined populations. Four bacteria genera were identified as candidates as the contents of the melanized nodules detected in queen fat bodies and ovaries in Chapter 4 , as all were significantly more abundant in site M2 than the other five sites (Table 5.5). The genus Kingella was only found in queens from site M2. The entomopathogen, Serratia marcescens, was one of three OTUs identified to species. 
Table 5.2. Top 10 most prevalent bacterial orders (out of 40 total) across all samples, and samples from low, medium and high-density sites. Values are based on the raw reads, before rarefaction. The last row shows what percentage the above orders account for in each group.

\begin{tabular}{|c|c|c|c|c|c|}
\hline Phylum & Order & $\begin{array}{l}\text { Low-density } \\
\text { total reads \% (\#) }\end{array}$ & $\begin{array}{l}\text { Medium-density } \\
\text { total reads \% (\#) }\end{array}$ & $\begin{array}{l}\text { High-density } \\
\text { total reads \% (\#) }\end{array}$ & $\begin{array}{l}\text { All libraries } \\
\text { total reads \% (\#) }\end{array}$ \\
\hline \multirow[t]{2}{*}{ Proteobacteria } & Neisseriales & $12.5 \%(7799)$ & $40.1 \%(32$ 187) & $0.05 \%(25)$ & $21.0 \%(40011)$ \\
\hline & Pasteurellales & $24.7 \%(15452)$ & $28.2 \%(22639)$ & $0.02 \%(10)$ & $20.0 \%(38101)$ \\
\hline Firmicutes & Lactobacillales & $15.2 \%(9529)$ & $8.8 \%(7094)$ & $17.7 \%(8547)$ & $13.2 \%(25170)$ \\
\hline Cyanobacteria & Streptophyta & $22.7 \%(14152)$ & $5.6 \%(4484)$ & $1.5 \%(736)$ & $10.1 \%(19372)$ \\
\hline Chlamydiae & Chlamydiales & 0 & 0 & $24.5 \%\left(\begin{array}{ll}11 & 802\end{array}\right)$ & $6.2 \%(11802)$ \\
\hline \multirow[t]{4}{*}{ Proteobacteria } & Pseudomonadales & $11.9 \%(7446)$ & $0.3 \%(246)$ & $0.5 \%(238)$ & $4.1 \%(7930)$ \\
\hline & Rhodospirillales & $0.5 \%(318)$ & $4.3 \%(3456)$ & $5.4 \%(2595)$ & $3.3 \%(6369)$ \\
\hline & Rickettsiales & $3.7 \%(2324)$ & $4.0 \%(3213)$ & $0.2 \%(109)$ & $3.0 \%(5646)$ \\
\hline & Rhizobiales & $1.0 \%(649)$ & $0.9 \%(718)$ & $7.9 \%(3822)$ & $2.7 \%(5189)$ \\
\hline \multirow[t]{2}{*}{ Actinobacteria } & Actinomycetales & $0.4 \%(227)$ & $0.3 \%(224)$ & $5.6 \%(2677)$ & $1.6 \%(2064)$ \\
\hline & Total & $92.6 \%(57896)$ & $92.5 \%(74261)$ & $63.4 \%(30561)$ & $85.2 \%$ \\
\hline
\end{tabular}




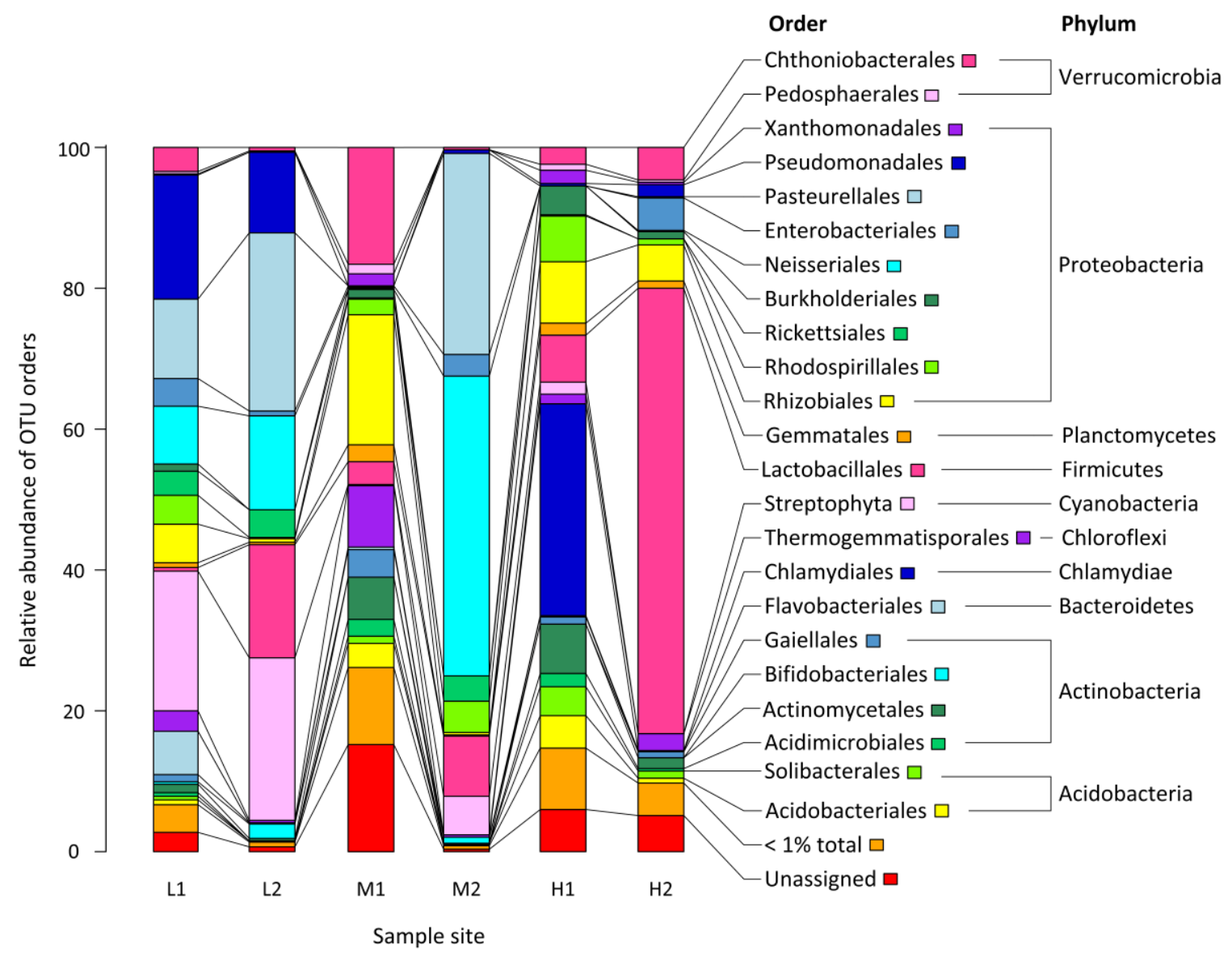

Figure 5.8. Relative abundance of OTUs (97\%) at the order level for each sample site. The phylum each order belongs to is indicated on the right. Values are based on rarefied samples. The orange bars indicate orders that made up less than $1 \%$ of the total sample and the red bars are those OTUs that were not assigned to any order. Note the high levels of variation between replicates of the same population types. 
1 Table 5.3. SIMPER results showing which bacterial orders contributed to approximately $50 \%$ of the dissimilarity between low, medium and high-

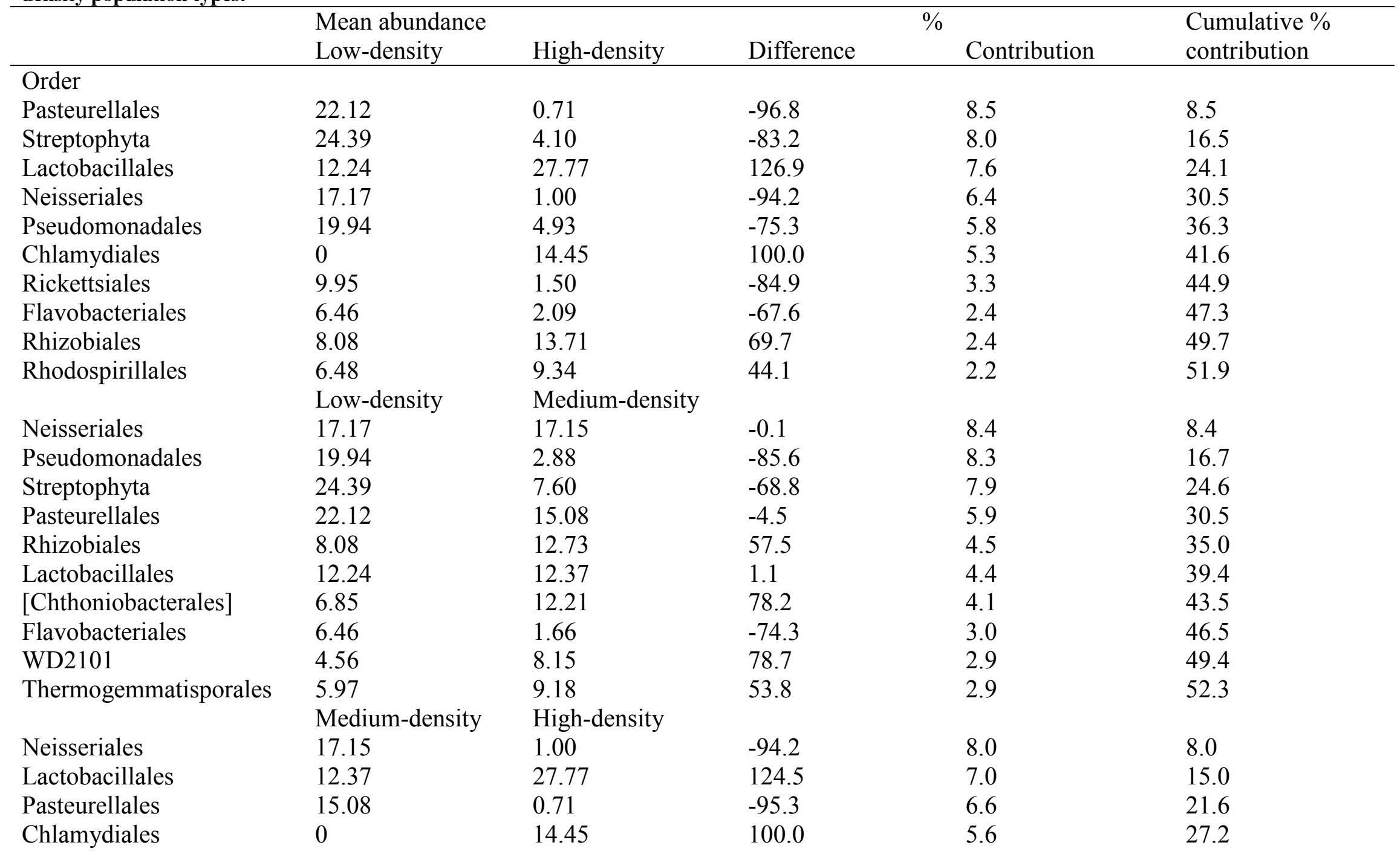


5. A metatranscriptomic survey of A. gracilipes

Rhizobiales $\quad 12.73$

$\begin{array}{ll}\text { [Chthoniobacterales] } & 12.21 \\ \text { Actinomycetales } & 7.29\end{array}$

Actinomycetales

WD2101

Thermogemmatisporales

Streptophyta

Burkholderiales

Ellin6513

Enterobacteriales
8.15

9.18

7.60

2.87

4.50

5.93

13.71
9.68
10.2
6.52
7.08
4.10
7.82
7.74
6.22

13.71

9.68

6.52

7.08

4.10

7.82

6.22

7.7
-20.7
39.9
-20.0
-22.9
-13.2
172.5
72.0
4.9

7.7

$-20.7$

$-20.0$

$-22.9$

$-13.2$

172.5

4.9

$\begin{array}{ll}4.1 & 31.3 \\ 3.7 & 35.0 \\ 2.6 & 37.6 \\ 2.6 & 40.2 \\ 2.5 & 42.7 \\ 2.5 & 45.2 \\ 2.3 & 47.5 \\ 2.2 & 49.7 \\ 2.2 & 51.9\end{array}$

31.3

35.0

40.2

42.7

45.2

49.7

51.9
3

\begin{tabular}{|c|c|c|c|c|c|c|c|}
\hline Phylum & Order & Genus & $\mathrm{LR}^{a}$ & $p^{b}$ & $\begin{array}{l}\text { Low-density } \\
\text { mean } \pm \mathrm{SE}\end{array}$ & $\begin{array}{l}\text { Medium-density } \\
\text { mean } \pm \text { SE }\end{array}$ & $\begin{array}{l}\text { High-density } \\
\text { mean } \pm \mathrm{SE}\end{array}$ \\
\hline Bacteroidetes & Flavobacteriales & Chryseobacterium & 179.818 & $<0.0001$ & $82.5 \pm 82.5$ & 0 & 0 \\
\hline Chlamydiae & Chlamydiales & Rhabdochlamydia & 915.879 & $<0.0001$ & 0 & 0 & $417.5 \pm 417.5$ \\
\hline Cyanobacteria & Streptophyta & & 834.583 & $<0.0001$ & $595.5 \pm 43.5$ & $80.5 \pm 72.5$ & $24.0 \pm 22.0$ \\
\hline \multirow[t]{4}{*}{ Firmicutes } & Lactobacillales & Enterococcus & 358.695 & $<0.0001$ & 0 & $0.5 \pm 0.5$ & $166.5 \pm 166.5$ \\
\hline & & Fructobacillus & 242.675 & $<0.0001$ & $10.5 \pm 0.5$ & $27.5 \pm 27.5$ & $186.0 \pm 102.0$ \\
\hline & & Lactobacillus & 93.596 & $<0.0001$ & $204.5 \pm 204.5$ & $121 \pm 115.0$ & $54.0 \pm 32.0$ \\
\hline & & Other & 1062.613 & $<0.0001$ & 0 & $13.0 \pm 13.0$ & $527.0 \pm 527.0$ \\
\hline \multirow[t]{6}{*}{ Proteobacteria } & Pseudomonadales & Actinetobacter & 496.000 & $<0.0001$ & $259.0 \pm 222.0$ & $0.5 \pm 0.5$ & $10.5 \pm 10.5$ \\
\hline & Rhodospirillales & Gluconobacter & 85.039 & $<0.0001$ & $35.0 \pm 33.0$ & $61.5 \pm 61.5$ & 0 \\
\hline & Rhizobales & Rhodoplanes & 97.256 & $<0.0001$ & $83.0 \pm 45.0$ & $260.0 \pm 9.5$ & $191.5 \pm 45.5$ \\
\hline & Neisseriales & & 791.301 & $<0.0001$ & $299.0 \pm 71.0$ & $588.0 \pm 586.0$ & 0 \\
\hline & Pasteurellales & & 734.923 & $<0.0001$ & $508.5 \pm 265.0$ & $398.5 \pm 394.5$ & $1.0 \pm 1.0$ \\
\hline & Rickettsiales 1 & & 116.743 & $<0.0001$ & $99.0 \pm 6.5$ & $51.0 \pm 49.5$ & $2.5 \pm 2.0$ \\
\hline
\end{tabular}

6 a Likelihood ratio from log likelihood-ratio test

$7 \quad{ }^{\mathrm{b}} p$ values have been corrected for multiple comparisons using the Bonferroni procedure 
Table 5.5. Bacterial genera that were significantly (log-likelihood ratio test) more prevalent in site M2 than the other study sites. Serratia marcescens is one of the few OTUs identified to species. Candidates for contents of the melanized nodules found in Chapter 4. Sequence values are unrarified raw data.

\begin{tabular}{|c|c|c|c|c|c|c|c|c|c|c|}
\hline Phylum & Order & Genus & $\mathrm{LR}^{a}$ & $p^{b}$ & M2 & M1 & L1 & L2 & H1 & $\mathrm{H} 2$ \\
\hline \multirow[t]{3}{*}{ Proteobacteria } & Rhodospirillales & Gluconobacter & 10616.497 & $<0.0001$ & 3239 & 0 & 122 & 57 & 0 & 0 \\
\hline & Neisseriales & Kingella & 304.058 & $<0.0001$ & 86 & 0 & 0 & 0 & 0 & 0 \\
\hline & Enterobacteriales & $\begin{array}{l}\text { Serratia } \\
\text { marcescens }\end{array}$ & 6784.528 & $<0.0001$ & 1979 & 0 & 0 & 10 & 1 & 29 \\
\hline Bacteroidetes & Cytophagales & Cardinium & 803.368 & $<0.0001$ & 269 & 0 & 41 & 13 & 0 & 0 \\
\hline
\end{tabular}


5. A metatranscriptomic survey of A. gracilipes

\subsection{Discussion}

This is the first study to record the presence of viral sequences in A. gracilipes. It is as yet unclear if this virus, or viruses, plays a role in the observed population declines of $A$. gracilipes. Viral sequences were only found in one low and one medium-density site; however, more surveys are needed to establish the full extent of this infection. The three unique viral sequences found coded for homologous genes encoding conserved replication function among viruses (helicase, RNA polymerase), making it possible to build phylogenetic trees, which grouped these sequences with the Dicistroviridae and specifically KBV, IAPV and BQCV. Members of this family of single-stranded RNA viruses have been implicated in colony collapse disorder in A. mellifera (Cox-Foster et al. 2007; de Miranda et al. 2010; Schroeder and Martin 2012), as well as colony decline in S. invicta (Valles 2012; Valles et al. 2014). Several dicistroviruses affecting S. invicta are being investigated as candidates for biocontrol in that species (Valles 2012), as viruses often have high host specificity and high pathogenicity, making them ideal biocontrol agents (Arif et al. 2012; Porter et al. 2013; Schroeder and Martin 2012).

Though the viral sequences found have a very high percentage identity to KBV and IAPV, it should be kept in mind that close sequence identity matches in GenBank do not guarantee positive identification of taxon, only that similar sequences were found. Sequence databases are limited to the data contained within them. Misidentification is a particular hazard when the observed sequences are short, as is the case with these viral sequences (220-282 bp). In order to positively identity these viruses, additional sequences would need to be found and assembled. Additionally, in the absence of evidence of replication it is unclear if these viruses are parasitizing A. gracilipes, or were simply ingested by the ant from the environment (Singh et al. 2010; Valles 2012). It is also possible that such viruses may be benign, as many insect viruses are asymptomatic (Liu et al. 2011; de Miranda et al. 2010; Valles 2012). In rare cases, viruses may even be beneficial in insects, such as the densovirus, Helicoverpa armigera densovirus-1, which appears to enhance host resistance to a baculovirus, and the bacterium Bacillus thuringiensis, as well as increasing fecundity in its host (Xu et al. 2014). The next step will be to conduct RT-PCR assays with known viral primers to 1) identify these viruses; 2) determine virus abundance and infection rates; and 3) ascertain replication within $A$. 
gracilipes by looking for the presence of negative-strand RNA. Future work is also need to understand the effects of these viruses on A. gracilipes.

Though metagenomic surveys such as this one shed light on the identity of the bacteria that make up the microbiota of a given host, such studies can only speculate on what effect these bacteria have on host fitness. Even within bacterial species of a single genus, bacteria may play diverse roles in host physiology, and can be mutualistic, commensal or pathogenic. It is thus difficult to know the effects different bacterial groups may have on a host, particularly as little is known about the function of most of the bacterial groups making up the microbiome of ants. Here I suggest several candidates for future study, and briefly review what is known about these bacteria and their associations with other arthropod hosts. Though several potentially pathogenic and mutualistic bacteria were observed, there were no obvious patterns suggesting such bacteria played a role in the observed population declines of $A$. gracilipes. This lack of pattern may in part be due to low sample sizes, which may increase the possibility of type II error (acceptance of a false null hypothesis), which should be kept in mind when interpreting these results.

A potential bacterial pathogen, Rhabdochlamydia, was found in one of the high-density sites. Members of the order Chlamydiales are often pathogenic (Corsaro and Venditti 2004). Rhabdochlamydia crassificans is known to be pathogenic in cockroaches, where it can cause swelling of the abdomen and infects the ovaries and fat bodies, however, the fitness consequences of this swelling, if any, are not known (Corsaro et al. 2007). Drobne et al. (1999) examined the effect of the closely related bacterium, Rhabdochlamydia porcellionis, on feeding rates in the isopod, Porcellio scaber (Kostanjsek et al. 2004), though the bacterium damaged host cells, they found no significant difference between feeding rates of infected and uninfected individuals. No tissue swelling was apparent in the A. gracilipes queens dissected from the infected site. To my knowledge, this bacterial genus has never before been isolated in ants, so its effects are unknown.

The genera Lactobacillus, Enterococcus and Fructobacillus belong to the lactic acid bacteria (LAB), which have been found to be mutualistic in A. mellifera. Enterococcus 
5. A metatranscriptomic survey of A. gracilipes

and Lactobacillus can protect their host from microbial pathogens such as the bacterial brood pathogen, Paenibacillus larvae (American foulbrood) (Forsgren et al. 2009; Vasquez et al. 2012; Yoshiyama et al. 2012); while Fructobacillus may produce byproducts that promote the growth of core members of the gut microbiome in $A$. mellifera (Rokop et al. 2015). Enterococcus and Fructobacillus were both significantly more prevalent at high-density sites; however, Lactobacillus was at significantly lower prevalence at high-density sites compared to low and medium-density. Thus it appears that all site types had at least one type of LAB in high prevalence, making it unlikely that the absence of these mutualists is responsible for the differing densities observed among A. gracilipes populations. However, an interactive effect between different LAB taxa is possible (Rokop et al. 2015), so the possibility cannot be discounted.

Of particular interest is the finding that the entomopathogen Serratia marcescens was in much greater abundance in queens with melanized nodules. Serratia marcescens is known to be pathogenic in a suite of insects, including the wild apple maggot fly, Rhagoletis pomonella and A. mellifera (Lauzon et al. 2003 and references therein). This bacterium is also known to induce a nodulation reaction in Drosophila melanogaster, when injected into the hemocoel (Lazzaro et al.2006; Chandler et al. 2011). It is also a common scourge of laboratory-kept insect populations, where it can be an epizootic (Sikorowski et al. 1993). However, a match to a specific taxon does not confirm its presence, only that similar sequences were found (this is the case for all identifications in this chapter). Therefore it is possible that this sequence actually represents a closely related taxon, such as $S$. symbiotica, and not $S$. marcescens. Serratia symbiotica is a secondary endosymbiont of aphids where it provides protection from a parasitoid wasp, and mediates heat shock in its host (Brownlie and Johnson 2009). It has also been isolated from the guts of the ants, Camponotus japonica and Formica cinerea, which possibly acquired it from feeding on honeydew excreted from aphids (He et al. 2011; Sirvio and Pamilo 2010). Anoplolepis gracilipes is also known to feed on honeydew (Holway et al. 2002; Lach and Hoffmann 2011) and could possibly have acquired this bacterial taxon that way. Further investigation into the identity and effect of this species is needed. 
5. A metatranscriptomic survey of A. gracilipes

Candidatus Cardinium (hereafter referred to as Cardinium) is a recently discovered reproductive parasite in arthropods (Hunter et al.2003). It is known to manipulate host reproduction, including by inducing cytoplasmic incompatibility (Hunter et al. 2003; Gotoh et al.2003; Perlman et al. 2008). Cardinium has been found in at least one other species of ant (Sirvio and Pamilo 2010) but may not be common in this hymenopteran family (Martínez-Rodriguez et al. 2013; Russell et al. 2012; Zchori-Fein and Perlman 2004), unlike other reproductive parasites such as Wolbachia, which has been found in one third of ant species examined (Russell 2012). Like Wolbachia, any impacts on fitness that Cardinium has on its ant hosts, negative or positive, have yet to be demonstrated (Russell 2012; Sirvio and Pamilo 2010). As this taxon appears to be vertically transmitted, it is very unlikely it is responsible for the observed melanized nodules observed in queens. Its role as a potential reproductive parasite, however, deserves further investigation.

Gluconobacter is a suspected mutualist in Diptera, Hemiptera and Hymenptera with high sugar diets (Chandler et al.2011; Crotti et al. 2010; Jeyaprakash et al. 2003; Martinson et al.2011), however, it can be pathogenic in some Drosophila spp., where it causes apoptosis (programmed cell death) and death of the host (Ryu et al.2008). Very little is known about the role played by Kingella in insect host physiology, if any, though this taxon has been isolated from the guts of $A$. mellifera and bumble bees (Kwong and Moran 2013).

Acinetobacter has been reported in many insect groups, such as Diptera, Coleoptera, Lepidoptera, Hemiptera and Hymenoptera, including ants (Andersen et al. 2013; CejaNavarro et al.2015; Ishak et al. 2011a; Liberti et al. 2015; Paulson et al. 2014; Priya et al. 2012; Secil et al. 2012; Singh et al. 2012). The roles it plays in most of these groups has not been elucidated, though it was found to be important for complete development of Stomoxys calcitrans (Diptera: Muscidae) (Lysyk et al. 1999), but did not influence female fitness parameters in a female wasp (Srinatha et al. 2015). 
This study examined the microbiome of queens from a single point in time, but other potential pathogens or mutualists may be found by examining other castes besides queens, such as the workers or brood (Ishak et al. 2011b). Likewise, other studies have found the presence of specific pathogens to vary throughout the year, likely due to differences in temperature and or rainfall. For example, SINV-1 has been found to be much more prevalent in spring and summer than at other times of year (Valles et al. 2010). It is suspected this difference is due to the inability of SINV-1 to replicate at cooler temperatures. Arnhem Land has consistently high temperatures throughout the year, so changing temperatures may not be an issue, but has a distinct wet season with most rain falling between December and July (Hoffmann and Saul 2010). Rainfall may also change prevalence of pathogens. Briano (2005) and Milks et al. (2008), found a significant correlation between infection of Solenopsis fire ants with the microsporidian Kneallhazia solenopsae and rainfall.

Gruber (2012) found some evidence that low abundance A. gracilipes populations in Arnhem Land had lower bacterial diversity at the genus and order levels. I found no such relationship. The five queens per sample that I used, however, may be insufficient to elucidate differences among sites. I was limited in the number of queens I could include by the lowest sample size. I was only able to collect 10 queens from site L2 in 2013, and thus was constrained to five queens for the RNA and DNA extractions for each sample, respectively, as I wanted to be able to directly compare samples from different sites. The expense of Illumina sequencing also limits the number of samples it is possible to run. Queens seem to have a very high individual bacterial diversity as evidenced by high variation among bacterial taxon in the six samples.

Viral and bacterial microbes have been successfully utilized for biocontrol programmes. For example, a baculovirus in the genus Gammabaculovirus was introduced from Europe to eastern North America where it successfully controls the invasive spruce sawfly, Diprion hercyniae, with no need for further applications (Arif et al. 2011; Bird and Burk 1961; Szewczyk et al. 2006). Likewise, the bacterium Bacillus thuringiensis is the most commonly utilized microbe worldwide for the control of agricultural pests, due to the 
insecticidal properties of this bacterium (Brar et al. 2006; Cannon 1993; Porcar and Caballero 2000). Though it is too early to say if the viruses found in A. gracilipes play a role in the observed population declines, the presence of such viruses offers a rich area for future research, and may be promising biocontrol candidates. I have also suggested several bacterial candidates for further study, including the entomopathogens Rhabdochlamydia and Serratia marcescens, and the reproductive parasite, Cardinium. 
6. General Discussion

\section{Chapter 6: General Discussion}

\subsection{Summary}

Though many populations of introduced species have been observed to collapse, the reasons behind these declines are seldom investigated (Simberloff and Gibbons 2004). My overall aims were to document $A$. gracilipes population declines, to investigate the possibility that pathogens were playing a role in the observed population declines, and to identify putative pathogens infecting A. gracilipes as potential candidates for biocontrol agents. After documenting several A. gracilipes population declines, I investigated the possibility that pathogens were involved in three ways: 1) I directly tested the effect of treatment with fungicidal antibiotics or inoculation with a fungal entomopathogen upon A. gracilipes reproductive output; 2) I investigated if there were fewer queens per nest, and if egg-laying rate, fecundity and fat content of queens was different between populations in different stages of decline or expansion (population types); 3) I compared microbial communities between population types.

In Chapter 2, I presented before and after survey data on seven A. gracilipes populations that either declined substantially or disappeared altogether. I also speculated on the possible reasons for these declines, and explained why I thought other explanations were less likely. Using the working hypothesis that a fungal pathogen had negative effects on queen reproductive output, I treated laboratory colonies of A. gracilipes with either fungicidal antibiotics, or inoculated queens with the fungal entomopathogen, Metarhizium anisopliae, then monitored colony reproductive output (Chapter 3). Neither treatment had a significant effect on the number of eggs, larvae, worker pupae or male pupae produced after 70 days. I found queen number had no effect on colony reproductive output, suggesting that queens are able to adjust their egg laying rate in the presence of other queens. I found no evidence that $M$. anisopliae is able to affect the reproductive output of $A$. gracilipes at the tested concentrations. In Chapter 4, I explored the hypothesis that a pathogen that kills or affects the reproductive output of A. gracilipes queens is the mechanism or reason behind the observed population declines in my study area. I measured queen number per nest, egg laying rate, fecundity and fat content and 
compared them between sites in three different stages of decline or expansion (low, medium and high-density). There was no significant difference between egg laying rates, fecundity or fat content between queens of different population types; however, lowdensity sites did have significantly more queens per nest than other population types. I also discovered that $23 \%$ of dissected queens had melanized nodules, a cellular immune response in insects, in their ovaries or fat bodies. The presence of nodules was significantly correlated with a $22 \%$ decrease in the number of oocytes per ovary. Nodule presence was not, however, associated with population type, suggesting that though there are clearly pathogens or parasites capable of penetrating the cuticle of A.gracilipes, such microbes are unlikely to be responsible for the observed population declines. Injecting the gaster of queens with fungal spores, bacterial lipopolysaccharides or saline solution revealed that queens only produced nodules in response to fungal spores.

In Chapter 5, I compared microbial communities (bacteria and viruses) between queens from the three population types discussed above. I uncovered viral sequences that group with the Dicistroviridae family of viruses in low and medium-density populations. Members of this family of viruses have been associated with colony-collapse disorder in Apis mellifera (Cox-Foster et al. 2007; Evans and Schwarz 2011; Schroeder and Martin 2012), and colony decline in the invasive ant, Solenopsis invicta (Valles 2012; Valles et al. 2014). However, I found no differences in bacterial community structure between population types. The presence of sequences similar to dicistroviruses and the entomopathogens Rhabdochlamydia and Serratia marcescens, as well as the reproductive parasite Cardinium in A. gracilipes, deserves further investigation.

\subsection{Synthesis}

Populations of $A$. gracilipes have been observed to fluctuate, and in some cases decline, across this invader's range (Chapter 2; Abbott 2005; Gruber et al. 2012a; Haines and Haines 1974). Declines to local extinction have been documented in A. gracilipes populations on the Seychelles and in Arnhem Land, Australia (Chapter 2; Haines et al. 1994), and lesser declines have been observed on Christmas Island and Tokelau (Abbott 2005; Gruber et al. 2012a). Sandström et al. (2014) documented a similar phenomenon for the invasive signal crayfish, Pacifastacus leniusculus, which they observed to have 
collapsed in $41 \%$ of surveyed Swedish lakes. Aside from the present study, the study of Sandström et al. (2014) is one of the only ones to my knowledge that not only systematically documented declines (instead of noting them as an aside or observation), but also investigated the mechanism behind said declines. The authors were not able to draw firm conclusions about the mechanisms behind these signal crayfish declines, though they investigated a number of possibilities, including infection by the crayfish plague, Aphanomyces astaci, a water mold. Similar population declines have also been seen in a number of other invasive ant species, such as L. humile in New Zealand (Cooling et al. 2012), W. auropunctata in New Caledonia (Le Breton, personal communication) and P. megacephala across its introduced range (Wetterer 2012). These and other observed declines of introduced species are often attributed to infection by pathogens, though this hypothesis is seldom investigated (Cooling et al. 2012; Gruber et al. 2012a; Simberloff and Gibbons 2004).

Is there evidence that pathogens are present in A. gracilipes in Arnhem Land, or that they are responsible for the observed population declines?

This is the first study to document the presence of pathogens in this ant species. Pathogens are present in A. gracilipes queens in Arnhem Land (Chapter 4, 5). The presence of melanized nodules in queen ovaries and fat bodies indicates there are parasites or pathogens capable of successfully penetrating the cuticle, and entering the hemocoel (Chapter 3, 4). It remains an important, but yet to be answered question, whether or not the documented association between the melanized nodules and the observed reduction in oocyte number (Chapter 3,4$)$ is due to a pathogenic infection (caused by microbes that eluded the ant's immune system), or is the result of a physiological tradeoff between reproduction and the cellular immune system in the host. An example of a pathogen that can affect ant queen fecundity is the microsporidian, Kneallhazia solenopsae, which can be found in Solenopsis spp. queen ovaries, causes a reduction in queen reproductive capacity and has led to colony collapse (Williams et al. 1998). The bacterial pathogen, Rhabdochlamydia, found in A. gracilipes queens in this study (Chapter 5), was also found specifically in the ovaries and fat bodies of the 
cockroach, Blatta orientalis (Corsaro et al. 2007), which may indicate this bacterium is capable of affecting host reproduction, though this has yet to be tested in cockroaches.

I have identified several other potential microbial control agents for A. gracilipes. The bacterial entomopathogen, Serratia marcescens, is a well-known killer of laboratory populations of various insects (Sikorowski et al. 1993), and is known to be pathogenic in some species of Hymenoptera, Diptera, Coleoptera and Lepidoptera (Lauzon et al. 2003; Lazzaro et al. 2006). This bacterium is also a key candidate for the pathogen that caused the melanized nodules found in some queens, as it was much substantially more prevalent in sequenced queens that had melanized nodules. The reproductive parasite, Cardinium, which was recently discovered in arthropods (Hunter et al. 2003) is known to induce cytoplasmic incompatibility in parasitic wasps and spider mites (Hunter et al. 2003; Gotoh et al.2003; Perlman et al. 2008). This reproductive parasite has been found in at least one other ant species (Sirvio and Pamilo 2010), but its effects on ants, if any, are not yet known.

The finding of viral sequences that group with the Dicistroviridae family in A. gracilipes is particularly exciting, as members in this group of viruses have been associated with colony-collapse disorder in A. mellifera (Evans and Schwarz 2011), and colony decline in the invasive ant $S$. invicta (Valles 2012). This is the first time viral sequences have been found in A. gracilipes. These sequences matched most closely to Kashmir bee virus, Israeli acute paralysis virus and black queen cell virus, all of which can have severe negative impacts on A. mellifera (Evans and Schwarz 2011; de Miranda et al. 2010). However, given the high probability of misidentification when sequences are short, as these ones are, it is just as likely these viral sequences belong to new viruses, which have not yet been identified. Such was the case in a recent study that discovered viruses, including a novel virus, in the invasive ant, Linepithema humile (Sébastien et al.2015). Work is currently being undertaken to establish the identity of these viruses, determine how widespread they are in these study populations and confirm their replication in $A$. gracilipes. These viruses are also potential candidates for the cause of the melanized nodules found in A. gracilipes queens (Chapter 3, 4), as viruses have been documented to 
induce a nodulation response in insects (Durmas et al. 2008). Once the identity of these viruses is established, it may be possible to test if these viruses are capable of inducing nodules in A. gracilipes, by injecting viral particles into the hemocoel.

Anoplplepis gracilipes may have brought these pathogens with it from its native range, such as S. invicta and several of its pathogens and L. humile and the virus $L H U V-1$ (Sébastien et al. 2015; Valles 2012). Alternatively, these pathogens may have been acquired in its new introduced range, which has also been seen in ants (Espadaler et al. 2011). As the native range of A. gracilipes is unknown, it cannot be surveyed for pathogens. However, an interesting question worthy of further investigation is if some of these pathogens were introduced with A. gracilipes, do they facilitate this ant's invasion by utilizing native ants as new hosts (Vilcinskas et al.2013)? Such seems to be the case in South America, where a protozoan parasite, co-introduced with the common bumblebee, Bombus terrestris, has spilled over into native populations of B. dahlbomii, causing heavy loses in this native species and thereby potentially speeding the spread of the invader, B. terrestris (Schmid-Hempel et al. 2013).

Though A. gracilipes is host to a multitude of microbes (Chapter 5; Gruber 2012), many which have been found to be mutualistic and pathogenic in other arthropods (Corsaro et al. 2007; Crotti et al. 2010; Drobne et al. 1999; Ishak et al.2011a; Lauzon et al. 2003; de Miranda et al. 2010; Perlman et al. 2008; Rokop et al. 2015; Vasquez et al. 2012), I found little evidence to suggest any of these play a role in the observed population declines, nor that premature queen death or reduced reproduction in queens are causing the declines (Chapters 2-5). I found no indication that queens were dying disproportionately at low and medium-density sites compared to high-density sites (Chapter 4). In fact, low-density sites had significantly more queens per nest on average, than medium and high-density sites. This unexpected result may be due to a densitydependent factor, whereby queens need a minimum number of workers present to spread to new nests, or an artifact due a lower sample size of nests in low-density sites. There was also no difference in fecundity or fat content (a measure of general health in insects; Fellous and Lazzaro 2010) between different population types (Chapter 4). 
Though I found an association between the presence of melanized nodules (infected queens) and a reduction in reproduction (Chapter 3, 4), I was unable to reproduce this effect with the fungal entomopathogen M. anisopliae in experimental laboratory colonies (Chapter 3), suggesting that a different pathogen caused the melanized nodules. Also, the proportion of infected queens between sites of different densities did not suggest that the reduction in queen reproductive output was a mechanism behind the population declines. This conclusion was supported by the finding that A. gracilipes queens may be able to adjust their reproductive output in response to other queens (Chapter 3). There was also no obvious pattern of bacterial pathogen presence, or bacterial endosymbiont absence that was related to population type (Chapter 5), though the discovery of viral sequences in low and medium-density populations and not in high-density warrants further investigation. There remain many questions to be answered in relation to A. gracilipes population declines.

\subsection{Constraints and future research}

The mechanisms behind the declines in A. gracilipes have yet to be elucidated. I encountered several constraints during the course of my study, which prevented me from investigating certain questions, and has left open future research avenues. A major constraint was finding appropriate sample sites. Ideally, I would have had a minimum of three sites per population type, to reduce the amount of intra-site variation; however, after a decade of control the majority of high and medium-density sites had already been eradicated. Originally, I had aimed to have five replicate low-density sites, but one site's A. gracilipes population declined to undetectable levels between when I began my field work in October 2012 and when I came back to measure queen density in February 2013. When I went to survey the two additional sites where A. gracilipes were known to have declined, it was discovered that the A. gracilipes populations at both those sites had also declined to undetectable levels, and were likely extinct at those sites. However, these declines did support the observation that A. gracilipes populations do sometimes go locally extinct in Arnhem Land (Chapter 2). 
The queens examined in this study, though from two different years, only represent a single season, February (wet season). This sampling time was necessary because this is one of the few times of year that it is possible to accurately count and collect queens, because they are relatively shallow in the soil, due to sufficient moisture (B. Hoffmann, unpublished data; personal observation). However, because I sampled at only one time, I may have missed a critical time that pathogens may have had an effect. For example, many pathogens are asymptomatic except for in times of stress (Briano and Williams 1997; Jouvenaz and Kimbrough 1991; Lord 2010; de Miranda et al. 2010; Oi and Valles 2009). Hence, sampling queens in the dry season (August to November; Hoffmann and Saul 2010), when resources are scarcer and environmental conditions are harsher, may reveal pathogens that would be missed in the less stressful wet season. Thus, my study represents a snapshot of queen health and microbial diversity, both of which may vary in response to temperature and rainfall (Elmes et al. 1999; Hahn 2006; Lease and Wolf 2011; Valles et al. 2010). I also only examined queens for pathogens, hence may have missed a pathogen affecting only the workers. However, for the majority of ant pathogens I am aware of, both the workers and queens tend to be infected, so missing pathogens by not surveying workers may be unlikely (Allen and Buren 1974; Briano and Williams 1997; Tufts and Bextine 2009; Sébastien et al. 2015; Valles 2012; Valles et al. 2013, 2014; Wenseleers et al. 2002).

My original intent was to also examine eukaryotic pathogens and parasites, such as microsporidia, fungi and nematodes in Chapter 5. However, due to a substantial delay in providing results by the sequencing facility, New Zealand Genomics Ltd., I did not have sufficient time to properly process and analyze this data (they were 8 months late delivering my results). I intend to do this analysis in the near future. For the same reason, I was unable to further investigate the identity and possible replication of the viral sequences found in Chapter 5. RT-PCR using viral specific primers (for example Kashmir bee virus, Israeli acute paralysis virus and black queen cell virus) to identify which viruses are present, and at what levels and to determine if the viruses are replicating (and hence parasitizing) within A. gracilipes are the next steps in this work. A time-series (taking multiple samples from different populations per year, over several 
years) following the presence and load of these viral pathogens would also be useful, as viral load can vary greatly depending on time of year (Valles 2012; Valles et al. 2010).

Investigating if other A. gracilipes populations carry similar pathogens, such as those on Christmas Island and Tokelau would also be informative. I would also suggest laboratory trials inoculating $A$. gracilipes colonies with some of the detected entomopathogens such as Serratia marcescens to assess their effect on A.gracilipes reproduction and population dynamics. As Rhabdochlamydia, and the reproductive parasite Cardinium have not yet been successfully maintained in culture, inoculating ants with these taxa is probably not yet feasible, but they could be potential biopesticides if these taxa are pathogens. Treatment with antibiotics to test the effect of bacterial symbionts would also be useful, since if a large number of endosymbiotic bacteria are mutualistic then treatment with antibiotics may result in colony declines (Wilkinson 1998).

I would especially encourage the quantitative documentation and study of other invasive ant declines, as understanding these declines may assist in the development of effective management techniques for these economically and ecologically damaging pests.

Though it is generally acknowledged that introduced species' populations can and do decline (Simberloff and Gibbons 2004), this is one of the first studies to quantitatively examine, document, and investigate the mechanisms behind an invasive species population decline. Understanding the mechanisms by which an invader declines may have important implications for invasive ant species management worldwide. 


\section{References}

Abbott K (2005) Supercolonies of the invasive yellow crazy ant, Anoplolepis gracilipes, on an oceanic island: Forager activity patterns, density and biomass. Insectes Sociaux 52:266-273

Abbott K (2006) Spatial dynamics of supercolonies of the invasive yellow crazy ant, Anoplolepis gracilipes, on Christmas Island, Indian Ocean. Diversity and Distributions, 12: 101-110.

Abbott K, Green P (2007) Collapse of an ant-scale mutualism in rainforest on Christmas Island. Oikos 116:1238-1246

Abbott K, Green P, O’Dowd D (2014) Seasonal shifts in macronutrient preferences in supercolonies of the invasive yellow crazy ant Anoplolepis gracilipes (Smith, 1857) (Hymenoptera: Formicidae) on Christmas Island, Indian Ocean. Australian Journal of Entomology 53(3):337-346

Alaux C, Folschweiller M, McDonnell C, Beslay D, Cousin M, Dussaubat C, Brunet J, Le Conte Y (2011) Pathological effects of the microsporidian Nosema ceranae on honey bee queen physiology (Apis mellifera). Journal of Invertebrate Pathology 106:380-385

Allen G, Buren W (1974) Microsporidian and fungal diseases of Solenopsis invicta Buren in Brazil. Journal of the New York Entomological Society 82(2):125-130

Allendorf, F, Lundquist L (2003) Introduction: population biology, evolution, and control of invasive species. Conservation Biology 17(1), 24-30

Andersen A (1995) A classification of Australian ant communities, based on functional groups which parallel plant life-forms in relation to stress and disturbance. Journal of Biogeography 22(1):15-29

Andersen A (1997) Using ants as bioindicators: multiscale issues in ant community ecology. Conservation Ecology 1(1):8

Andersen A, Majer J (2004) Ants show the way down under: invertebrates as bioindicators in land management. Frontiers in Ecology and the Environment 2(6):291-298 


\section{References}

Andersen S, Hansen L, Sapountzis P, Sørensen S, Boomsma J (2013) Specificity and stability of the Acromyrmex-Pseudonocardia symbiosis. Molecular Ecology $22: 4307-4321$

Anderson K, Sheehan T, Eckholm B, Mott B, DeGrandi-Hoffman G (2011) An emerging paradigm of colony health: microbial balance of the honey bee and hive (Apis mellifera). Insectes sociaux 58:431-444

Andrews S (2015) FastQC v 0.11.3 Babraham Bioinformatics. Available from http://www.bioinformatics.bbsrc.ac.uk/projects/fastqc/

Arif B, Escasa S, Pavlik L (2011) Biology and genomics of viruses within the genus Gammabaculovirus. Viruses 3:2214-2222

Aronstein K, Holloway B (2013) Honey bee fungal pathogen, Ascosphaera apis; current understanding of host-pathogen interactions and host mechanisms of resistance. In: Mendez-Vilas (ed) The battle against microbial pathogens and strategies for combating them: science, technology and education. Formatex, Badajoz pp 402410

Aubert A, Richard F (2008) Social management of LPS-induced inflammation in Formica polyctena ants. Brain, Behavior and Immunity 22:833-837

Azzami K, Ritter W, Tautz J, Beier H (2012) Infection of honey bees with acute bee paralysis virus does not trigger humoral or cellular immune responses. Archives of Virology doi:10.1007/s00705-012-1223-0

Bailey L (1967) The incidence of viral diseases in the honey bee. Annals of Applied Biology 60(1):43-48

Baily L, Ball B (1991) Honey bee pathology. $2^{\text {nd }}$ ed. Academic Press, London Barton D (1997) Introduced animals and their parasites: the cane toad, Bufo marinus, in Australia. Australian Journal of Ecology 22:316-324

Bartram A, Lynch M, Stearns J, Moreno-Hagelsieb G, Neufeld J (2011) Generation of multimillion-sequence $16 \mathrm{~S}$ rRNA gene libraries from complex microbial communities by assembling paired-end Illumina reads. Applied and Environmental Microbiology 77(11):3846-3852

Bates D, Maechler M, Bolker B, Walker S (2015). lme4: Linear mixed-effects models using Eigen and S4. R package version 1.1-8 


\section{References}

Ben-Ami F, Ebert D, Regoes R (2010) Pathogen dose infectivity curves as a method to analyze the distribution of host susceptibility: a quantitative assessment of maternal effects after food stress and pathogen exposure. The American Naturalist 175(1):106-115

Bird F, Burk J (1961) Artificial disseminated virus as a factor controlling the European spruce sawfly, Diprion hercyniae (Htg) in the absence of introduced parasites. Canadian Entomology 9:228-238

Boer P (2008) Observations of summit disease in Formica rufa LINNAEUS, 1761 (Hymenoptera: Formicidae). Myrmecological News 11:63-66

Bokulich N, Subramanian S, Faith J, Gevers D, Gordon J, Knight R, Mills D, Caporaso G (2013) Quality-filtering vastly improves diversity estimates from Illumina amplicon sequencing. Nature Methods 10(1): 57-59

Boland C, Smith M, Maple D, Tiernan B, Barr R, Napier F (2011) Heli-baiting using low concentration fipronil to control invasive yellow crazy ant supercolonies on Christmas Island, Indian Ocean. In: Veitch C, Clout M, Towns, D (eds) Island invasives: eradication and management. IUCN, Gland pp. 152-156

Bos M, Tylianakis J, Steffan-Dewenter I, Tscharntke T (2008) The invasive yellow crazy ant and the decline of forest ant diversity in Indonesian cacao agroforests. Biological Invasions 10:1399-1409

ter Braak B, Laughton A, Altincicek B, Parker B, Gerardo N (2013) Exposure to bacterial signals does not alter pea aphids' survival upon a second challenge or investment in production of winged offspring. PLoS ONE 8(8):e73600

Braby M (2010) Conservation status and management of the Gove Crow Euploea alcathoe enastri (Lepidoptera: Nymphalidae), a threatened tropical butterfly from indigenous Aboriginal lands of north-eastern Arnhem Land, Australia. Journal of Insect Conservation 14:535-554

Brar S, Tyagi V, Valero J (2006) Recent advances in downstream processing and formulations of Bacillus thuringiensis based biopesticides. Process Biochemistry $41: 323-342$ 


\section{References}

Briano J (2005) Long-term studies of the red imported fire ant, Solenopsis invicta, infected with the microsporidia Vairimorpha invictae and Thelohania solenopsae in Argentina. Environmental Entomology 34(1):124-132

Briano J, Wojcik D, Cordo H, Patterson R (1995a) Protozoan and fungal diseases in Solenopsis richteri and S. quinquecuspis (Hymenoptera: Formicidae) in Buenos Aires province, Argentina. Florida Entomologist 78(3):531-537

Briano J, Patterson R, Cordo H (1995b) Long-term studies of the black imported fire ant (Hymenoptera: Formicidae) infected with a microsporidium. Environmental Entomology 24:1328-1332

Briano J, Patterson R, Cordo H (1995c) Relationship between colony size of Solenopsis richteri and infection with Thelohania solenopsae (Microsporidia: Thelohaniidae) in Argentina. Journal of Economic Entomology 88(5):1233-1237

Briano J, Williams F (1997) Effect of the microsporidian Thelohania solenopsae (Microsporidia: Thelohaniidae) on the longevity and survival of Solenopsis richteri (Hymenoptera: Formicidae) in the laboratory. Florida Entomologist 80(3):366-376

Brownlie J, Johnson K (2009) Symbiont-mediated protection in insect hosts. Trends in Microbiology 17:348-354

Brumin M, Kontsedalov S, Ghanim M (2011) Rickettsia influences thermotolerance in the whitefly Bemisia tabaci B biotype. Insect Science 18:57-66

Calleri D, Rosengaus R, Traniello J (2006) Disease and colony establishment in the dampwood termite Zootermopsis angusticollis: survival and fitness consequences of infection in primary reproductive. Insectes Sociaux 53:204-211

Camacho C, Madden T, Ma N, Tao T, Agarwala R, Morgulis A (2008) BLAST ${ }^{\circledR}$ command line applications user manual. National Center for Biotechnology Information, Bethesda, MD

Cameron S, Lozier J, Strange J, Koch J, Cordes N, Solter L, Griswold T (2011) Patterns of widespread decline in North American bumble bees. PNAS 108(2):662-667

Cannon R (1993) Prospects and progress for Bacillus thuringiensis based pesticides. Pesticide Management Science 37:331-335 
Caporaso J, Lauber C, Walters W, Berg-Lyons D, Lozupone C, Turnbaugh P, Fierer N, Knight R (2011) Global patterns of 16S rRNA diversity at a depth of millions of sequences per sample. PNAS 108:4516-4522

Caporaso J, Lauber C, Walters W, Berg-Lyons D, Huntley J, Fierer N, Owens S, Betley J, Fraser L, Bauer M, Gormley N, Gilbert J, Smith G, Knight R (2012) Ultra-highthroughput microbial community analysis on the Illumina HiSeq and MiSeq platforms. ISME Journal 6:1621-1624

Carton Y, Frey F, Stanley D, Vass E, Nappi A (2002) Dexamethasone inhibition of the cellular immune response of Drosophila melanogaster against a parasitoid. Journal of Parasitology 88(2):405-407

Ceja-Navarro J, Vega F, Karaoz U, Hao Z, Jenkins S, Lim H, Kosina P, Infante F, Northen T, Brodie E (2015) Gut microbiota mediate caffeine detoxification in the primary insect pest of coffee. Nature Communications 6:7618

Chandler J, Lang J, Bhatnager S, Eisen J, Kopp A (2011) Bacterial communities of diverse Drosophila species: ecological context of a host-microbe model system. PLoS Genetics 7(9):e1002272

Christian C (2001) Consequences of a biological invasion reveal the importance of mutualism for plant communities. Nature 413:635-639

Civeyrel L, Simberloff D (1996) A tale of two snails: is the cure worse than the disease? Biodiversity and Conservation 5:1231-1252

Clarke K (1993) Non-parametric multivariate analyses of changes in community structure. Austral Ecology 18:117-143

Clarke K, Gorley R (2006) PRIMER v 6.1.11: User manual and tutorial. PRIMER-E, Plymouth

Contreras-Garduño J, Rodriquez M, Alvarado-Delgado A, Lanz-Mendoza H (2014) Cost of immune priming within generations: trade-off between infection and reproduction. Microbes and Infection 16(3):261-267

Cooling M, Hartley S, Sim D, Lester P (2012) The widespread collapse of an invasive species: Argentine ants (Linepithema humile) in New Zealand. Biology Letters 8(3):430-433 


\section{References}

Cooling M, Hoffmann B (2015) Here today, gone tomorrow: declines and local extinctions of invasive ant populations in the absence of intervention. Biological Invasions DOI: 10.1007/s10530-015-0963-7

Corsaro D, Venditti D (2004) Emerging Chlamydial infections. Critical Reviews in Microbiology 30:75-106

Corsaro D, Thomas V, Goy G, Venditti D, Radek R, Greub G (2007) 'Candidatus Rhabdochlamydia crassificans', an intracellular bacterial pathogen of the cockroach Blatta orientalis (Insecta: Blattodea). Systematic and Applied Microbiology 30:221-228

Cox M, Peterson D, Biggs P (2010) SolexaQA: At-a-glance quality assessment of Illumina second-generation sequencing data. BMC Bioinformatics 11:485

Cox-Foster D, Conlan S, Holmes E, Palacios G, Evans J, Moran N, Quan P, Briese T, Hornig M, Geiser D, Martinson V, vanEngelsdorp D, Kalkstein A, Drysdale A, Hui J, Zhai J, Cui L, Hutchison S, Simons J, Egholm M, Pettis J, Lipkin W (2007) A metagenomic survey of microbes in honey bee colony collapse disorder. Science 318:283-287

Crotti E, Rizzi, Chouaia B, Ricci I, Favia G, Alma A, Sacchi L, Bourtzis K, Mandrioli M, Cherif A, Bandi C, Daffonchio D (2010) Acetic acid bacteria, newly emerging symbionts of insects. Applied and Environmental Microbiology 76(21):69636970

Dalecky A, Gaume L, Schatz B, McKey D, Kjellberg F (2005) Facultative polygyny in the plant-ant Petalomyrmex phylax (Hymenoptera: Formicinae): sociogenetic and ecological determinants of queen number. Biological Journal of the Linnean Society 86:133-151

Davis N, O’Dowd D, Green P Mac Nally R (2008) Effects of an alien ant invasion on abundance, behaviour, and reproductive success of endemic island birds. Conservation Biology 22(5):1165-1176.

Davis N, O’Dowd D, Mac Nally R, Green P (2009) Invasive ants disrupt frugivory by endemic island birds. Biology Letters 6:85-88 


\section{References}

Dean P, Gadsden J, Richards E, Edwards J, Charnley A, Reynolds S (2002) Modulation by eicosanoid biosynthesis inhibitors of immune responses by the insect Manduca sexta to the pathogenic fungus Metarhizium anisopliae. Journal of Invertebrate Pathology 79:93-101

Dillon R, Dillon V (2004) The gut bacteria of insects: nonpathogenic interactions. Annual Review of Entomology 49:71-92

Donegan K, Lighthart B (1989) Effect of several stress factors on the susceptibility of the predatory insect, Chrysoperia carnea (Neuroptera: Chrysopidae), to the fungal pathogen Beauveria bassiana. Journal of Insect Pathology 54:79-84

Drescher J, Bluthgen N, Feldhaar H (2007) Population structure and intraspecific aggression in the invasive ant species Anoplolepis gracilipes in Malaysian Borneo. Molecular Ecology 16:1453-1465

Drescher J, Bluthgen N, Schmitt T, Buhler J, Feldhaar H (2010) Societies drifting apart? Behavioural, genetic and chemical differentiation between supercolonies in the yellow crazy ant Anoplolepis gracilipes. PLoS ONE 5(10):1-8

Drescher J, Feldhaar H, Bluthgen N (2011) Interspecific aggression and resource monopolization of the invasive ant Anoplolepis gracilipes in Malaysian Borneo. Biotropica 43(1):93-99

Drobne D, Strus J, Znidarsic N, Zidar P (1999) Morphological description of bacterial infection of digestive glands in the terrestrial isopod Porcellio scaber (Isopoda, Crustacea). Journal of Invertebrate Pathology 73:113-119

Dunn A, Torchin M, Hatcher M, Kotanen P, Blumenthal D, Byers J, Coon C, Frankel V, Holt R, Hufbauer R, Kanarek A, Schierenbeck K, Wolfe L, Perkins S (2012) Indirect effects of parasites in invasions. Functional Ecology 26(6):1262-1274

Durmus Y, Buyukguzel E, Terzi B, Tunaz H, Stanley D, Buyukguzel K (2008) Eicosanoids mediate melanotic nodulation reactions to viral infection in larvae of the parasitic wasp, Pimpla turionellae. Journal of Insect Physiology 54:17-24

Edgar R (2010) Search and clustering orders of magnitude faster than BLAST. Bioinformatics 26(19):2460-2461 


\section{References}

Elmes G, Wardlaw J, Nielsen G, Kipyatkov V, Lopatina E, Radchenko A, Barr B (1999) Site latitude influences on respiration rate, fat content and the ability of worker ants to rear larvae: a comparison of Myrmica rubra (Hymenoptera: Formicidae) populations over their European range. European Journal of Entomology 96:117124

Errard C, Delabie J, Jourdan H, Hefetz A (2005) Intercontinental chemical variation in the invasive ant Wasmannia auropunctata (Roger) (Hymenoptera Formicidae): a key to the invasive success of a tramp ant. Naturwissenschaften 92:319-323

Espadaler X, Lebas C, Wagenknecht J, Tragust S (2011) Laboulbenia formicarum (Ascomycota, Laboulbeniales), an exotic parasitic fungus, on an exotic ant in France. Life and Environment 61(1):41-44

Espadaler X, Santamaria S (2012) Ecto- and endoparasitic fungi on ants from the Holarctic region. Psyche 2012:e168478

Evans J, Pettis J (2005) Colony-level impacts of immune responsiveness in honey bees, Apis mellifera. Evolution 59(10):2270-2274

Evans J, Schwarz R (2011) Bees brought to their knees: microbes affecting honey bee health. Trends in Microbiology 19(12):614-620

Fadrosh D, Ma B, Gajer P, Sengamalay N, Ott S, Brotman R, Ravel J (2014) An improved dual-indexing approach for multiplexed 16S rRNA gene sequencing on the Illumina MiSeq platform. Microbiome 2:6

Feldhaar H (2011) Bacterial symbionts as mediators of ecologically important traits of insect hosts. Ecological Entomology 36:533-543

Feldhaar H, Straka J, Krischke M, Berthod K, Stoll S, Mueller M, Gross R (2007) Nutritional upgrading for omnivorous carpenter ants by the endosymbiont Blochmannia. BMC Biology 5:48

Fellous S, Lazzaro B (2010) Larval food quality affects adults (but not larval) immune gene expression independent of effects on general condition. Molecular Ecology $19: 1462-1468$

Ferdig M, Spray F, Li J, Christensen B (1993) Reproductive costs associated with resistance in a mosquito-filarial worm system. American Journal of Tropical Medicine and Hygiene 49:756-762 


\section{References}

Flory S, Clay K (2013) Pathogen accumulation and long-term dynamics of plant invasions. Journal of Ecology 101:607-613

Forsgren E, Olofsson T, Vasquez A, Fries I (2009) Novel lactic acid bacteria inhibiting Paenibacillus larvae in honey bee larvae. Apidologie 41(1):99-108

Fredricks D, Relman D (1996) Sequence-based identification of microbial pathogens: a reconsideration of Koch's postulates. Clinical Microbiology Reviews 9(1):18-33

Galvez D, Chapuisat M (2014) Immune priming and pathogen resistance in ant queens. Ecology and Evolution 4(10):1761-1767

Gatschenberger H, Azzami K, Tautz J, Beier H (2013) Antibacterial immune competence of honey bees (Apis mellifera) is adapted to different life stages and environmental risks. PLoS ONE 8(6):e66415

Gerlach J (2004) Impact of the invasive crazy ant Anoplolepis gracilipes on Bird Island, Seychelles. Journal of Insect Conservation 8:15-25

Gillespie R, Reimer N (1993) The effect of alien predatory ants (Hymenoptera: Formicidae) on Hawaiian endemic spiders (Araneae: Tetragnathidae). Pacific Science 47(1):21-33

Gillespie J, Kanost M, Trenczek T (1997) Biological mediators of insect immunity. Annual Review of Entomology 42:611-643

Gonzalez-Tokman D, Gonzalez-Santoyo I, Lanz-Mendoza H, Cordoba-Aguilar A (2010) Territorial damselflies do not show immunological priming in the wild. Physiological Entomology 35:364-372

Gotoh T, Noda H, Ito S (2003) Cardinium symbionts cause cytoplasmic incompatibility in spider mites. Heredity 98:13-20

Grabherr M, Haas B, Yassour M, Levin J, Thompson D et al. (2013) Trinity: reconstructing a full-length transcriptome without a genome from RNA-Seq data. Nature Biotechnology 26(7): 644-652

Green P, O’Dowd D, Abbott K, Jeffery M, Retallick K, Mac Nally R (2011) Invasional meltdown: invader-invader mutualism facilitates a secondary invasion. Ecology 92(9):1758-1768 


\section{References}

Greenburg L, Fletcher D, Vinson S (1985) Differences in worker size and mound distribution in monogynous and polygynous colonies of the fire ant Solenopsis invicta Buren. Journal of the Kansas Entomological Society 58(1):9-18

Greenslade P (1972) Comparative ecology of four tropical ant species. Insectes Sociaux 19(3):195-212

Gruber M (2012) Genetic factors associated with variation in abundance of the invasive yellow crazy ant (Anoplolepis gracilipes). $\mathrm{PhD}$ thesis. Victoria University of Wellington, New Zealand.

Gruber M, Burne A, Abbott K, Pierce R, Lester P (2012a) Population decline but increased distribution of an invasive ant genotype on a Pacific atoll. Biological Invasions 15(3): 599-612

Gruber M, Hoffmann B, Ritchie P, Lester P (2012b) Recent behavioural and population genetic divergence of an invasive ant in a novel environment. Diversity and Distributions 18:323-333

Gruber M, Hoffmann B, Ritchie P, Lester P (2012c) Genetic diversity is positively associated with fine-scale momentary abundance of an invasive ant. Ecology and Evolution 2(9):2091-2105

Hahn D (2006) Two closely related species of desert carpenter ant differ in individuallevel allocation to fat storage. Physiological and Biochemical Zoology 79(5):847856

Haines I, Haines J (1978) Pest status of the crazy ant, Anoplolepis longipes (Jerdon) (Hymenoptera: Formicidae), in the Seychelles. Bulletin of Entomological Restoration 68:627-638

Haines I, Haines J, Cherrett J (1994) The impact and control of the Crazy ant, Anoplolepis longipes (Jerd.), in the Seychelles. In: Williams D (ed) Exotic ants: biology, impact, and control of introduced species. Westview Press, Boulder pp 206-218

He H, Chen Y, Zhang Y, Wei C (2011) Bacteria associated with gut lumen of Camponotus japonicus. Environmental Entomology 40(6): 1405-1409

Hedges L, Brownlie J, O’Neill S, Johnson K (2008) Wolbachia and virus protection in insects. Science 322:702 


\section{References}

Heinze J, Keller L (2000) Alternative reproductive strategies: a queen perspective in ants. TREE 15(12):508-512

Hill M, Holm K, Vel T, Shah N, Matyot P (2003) Impact of the introduced yellow crazy ant Anoplolepis gracilipes on Bird Island, Seychelles. Biodiversity and Conservation 12:1969-1984

Hoffmann B (2014) Quantification of supercolonial traits in the yellow crazy ant, Anoplolepis gracilipes. Journal of Insect Science 15:25

Hoffmann B (2015) Integrating biology into invasive species management is a key principle for eradication success: the case of yellow crazy ant Anoplolepis gracilipes in northern Australia. Bullet of Entomological Research 105:141-151

Hoffmann B, Andersen A, Hill G (1999) Impact of an introduced ant on native rain forest invertebrates: Pheidole megacephala in monsoonal Australia. Oecologia 120:595604

Hoffmann B, Saul W (2010) Yellow crazy ant (Anoplolepis gracilipes) invasions within undisturbed mainland Australian habitats: no support for biotic resistance hypothesis. Biological Invasions 12:3093-3108

Holldobler B, Wilson EO (1990) The Ants. Belknap Press, Cambridge

Holway D, Lach L, Suarez A, Tsutsui N, Case T (2002) The causes and consequences of ant invasions. Annual Review of Ecology, Evolution, and Systematics 33:181-233

Hu Q, Liu S, Yin F, Cai S, Zhong G, Ren S (2011) Diversity and virulence of soildwelling fungi Isaria spp. and Paecilomyces spp. against Solenopsis invicta (Hymenoptera: Formicidae). Biocontrol Science and Technology 21(2):225-234

Hu Y, Lukasik P, Moreau C, Russell J (2013) Correlates of gut community composition across an ant species (Cephalotes varians) elucidate causes and consequences of symbiotic variability. Molecular Ecology 23:1284-1300

Hughes W, Eilenberg J, Boomsma J (2002) Trade-offs in group living: transmission and disease resistence in leaf-cutting ants. Proceedings of the Royal Society B 269:1811-1819

Hughes W, Boomsma J (2004) Genetic diversity and disease resistance in leaf-cutting ant societies. Evolution 58(6):1251-1260 


\section{References}

Hunter M, Perlman S, Kelly S (2003) A bacterial symbiont in the Bacteroidetes induces cytoplasmic incompatibility in the parasitoid wasp Encarsia pergandiella. Proceedings of the Royal Society B 270:2185-2190

Ingram K, (2002) Plasticity in queen number and social structure in the invasive Argentine ant (Linepithema humile). Evolution 56(10):2008-2016

Inouye S, Uchida K, Takizawa T, Yamaguchi H, Abe S (2006) Evaluation of the effect of terpenoid quinones of Trichophyton mentagrophytes by solution and vapour contact. Journal of Infection and Chemotherapy 12:100-104

Ishak H, Plowes R, Sen R, Kellner K, Meyer E, Estrada D, Dowd S, Mueller U (2011a) Bacterial diversity in Solenopsis invicta and Solenopsis geminate ant colonies characterized by $16 \mathrm{~S}$ amplicon 454 pyrosequencing. Microbial Ecology 61:821831

Ishak H, Miller J, Sen R, Dowd S, Meyer E, Mueller U (2011b) Microbiomes of ant castes implicate new microbial roles in the fungus-growing ant Trachymyrmex septentrionalis. Scientific Reports 1:204

Jaccoud D, Hughes W, Jackson C (1999) The epizootiology of a Metarhizium infection in mini-nests of the leaf-cutting ant Atta sexdens rubropilosa. Entomologia Experimentalis et Applcata 93:51-61

Jeyaprakash A, Hoy M, Allsopp M (2003) Bacterial diversity in worker adults of Apis mellifera capensis and Apis mellifera scutellata (Insecta: Hymenoptera) assessed using 16S rRNA sequences. Journal of Invertebrate Pathology 84:96-103

Johansson H, Dhaygude K, Lindstrom S, Helantera H, Sundstrom L, Trontti (2013) A metatranscriptomic approach to the identification of microbiota associated with the ant Formica exsecta. PloS ONE 8(11):e79777

Jouvenaz D, Kimbrough J (1991) Myrmecomyces annellisae gen. nov. sp. nov. (Deuteromycotina: Hyphomycetes), an endoparasitic fungus of fire ants, Solenopsis spp. (Hymenoptera: Formicidae). Mycological Research 95(12):13951401

Kaltenpoth M (2009) Actinobacteria as mutualists: general healthcare for insects? Trends in Microbiology 17(12):529-535 


\section{References}

Kaltenpoth M, Gottler W, Herzner G, Strohm E (2005) Symbiotic bacteria protect wasp larvae from fungal infection. Current Biology 15:475-479

Kaspari M (1993) Body size and microclimate use in Neotropical granivorous ants. Oecologia 96:500-507

Keane R, Crawley M (2002) Exotic plant invasions and the enemy release hypothesis. Trends in Ecology and Evolution 17:164-170

Kellner K, Ishak H, Linksvayer T, Mueller U (2015) Bacterial community composition and diversity in an ancestral ant fungus symbiosis. FEMS Microbiology Ecology 91:fiv073

Klindworth A, Pruesse E, Schweer T, Peplies J, Quast C, Horn M, Glockner O (2013) Evaluation of general 16S ribosomal RNA gene PCR primers for classical and next-generation sequencing-based diversity studies. Nucleic Acids Research 41(1):e1

Koch H, Cisarovsky G, Schmid-Hempel P (2012) Ecological effects on gut bacterial communities in wild bumblebee colonies. Journal of Animal Ecology 81:12021210

Konrad M, Vyleta M, Theis F, Stock M, Tragust S, Klatt M, Drescher V, Marr C, Ugelvig L, Cremer S (2012) Social transfer of pathogenic fungus promotes active immunization in ant colonies. PLoS Biology 10(4):e1001300

Kostanjsek R, Strus J, Drobne D, Avgustin G (2004) 'Candidatus Rhabdochlamydia porcellionis', an intracellular bacterium from the hepatopancreas of the terrestrial isopod Porcellio scaber (Crustacea: Isopoda). International Journal of Systematic and Evolutionary Microbiology 54:543-549

Kwong W, Moran N (2013) Cultivation and characterization of the gut symbionts of honey bees and bumble bees: description of Snodgrassella alvi gen. nov., sp. nov., a member of the family Neisseriaceae of the Betaproteobacteria, and Gilliamella apicola gen. nov., sp. nov., a member of Orbaceae fam. nov., Orbales ord. nov., a sister taxon to the order 'Enterobacteriales' of the Gammaproteobacteria. International Journal of Systematic and Evolutionary Microbiology 63:2008-2018

Lacey L, Frutos R, Kaya H, Vail P (2001) Insect pathogens as biological control agents: do they have a future? Biological Control 21:230-248 


\section{References}

Lach L, Hoffmann, B (2011) Are invasive ants better plant-defense mutualists? A comparison of foliage patrolling and herbivory in sites with invasive yellow crazy ants and native weaver ants. Oikos 120:9-16

Larkin M, Blackshields G, Brown N, Chenna R, McGettigan et al. (2007) ClustalW and ClustalX version 2. Bioinformatics 23:2947-2948

Lauzon C, Bussert T, Sjogren R, Prokopy R (2003) Serratia marcescens as a bacterial pathogen of Rhagoletis pomonella flies (Diptera: Tephritidae). European Journal of Entomology 100:87-92

Lazzaro B, Sackton T, Clark A (2006) Genetic variation in Drosophila melanogaster resistance to infection: a comparison across Bacteria. Genetics 174:1539-1554

Lease H, Wolf B (2011) Lipid content of terrestrial arthropods in relation to body size, phylogeny, ontogeny and sex. Physiological Entomology 36:29-38

Lester P, Bosch P, Gruber M, Kapp E, Peng L, Brenton-Rule E, Buchanan J, Stanislawek W, Archer M, Corley J, Masciocchi M, Van Oystaeyen A, Wenseleers T (2015) No evidence of enemy release in pathogen and microbial communities of common wasps (Vespula vulgaris) in their native and introduced range. PLoS ONE 10(3):e0121358

Liberti J, Sapountzis P, Hansen L, Sørensen S, Adams R, Boomsma J (2015) Bacterial symbiont sharing in Megalomyrmex social parasites and their fungus-growing ant hosts. Molecular Ecology 24:3151-3169

Lindahl B, Nilsson R, Tedersoo L, Abarenkov K, Carlsen T, Kjoller R, Koljalg U, Pennanen T, Rosendahl S, Stenlid J, Kauserud H (2013) Fungal community analysis by high-throughput sequencing of amplified markers- a user's guide. New Phytologist 199:288-299

Liu S, Vijayendran D, Bonning B (2011) Next generation sequencing technologies for insect virus discovery. Viruses 3:1849:1869

Lockwood J, Hoopes M, Marchetti M (2009) An introduction to invasion ecology. In: Invasion ecology. Blackwell Publishing, Malden pp. 1-17

Lord J (2010) Dietary stress increases the susceptibility of Tribolium castaneum to Beauveria bassiana. Journal of Economic Entomology 103(5):1542-1546 


\section{References}

Lowe S, Browne M, Boudjelas S (2000) 100 of the world's worst invasive alien species.

Aliens 12:1-12

Lysyk T, Kalischuk-Tymensen L, Selinger L, Lancaster R, Wever L, Cheng K (1999) Rearing stable fly larvae (Diptera: Muscidae) on an egg yolk medium. Journal of Medical Entomology 36(3): 382-388

Majer J (1984) Recolonisation by ants in rehabilitated open-cut mines in Northern Australia. Reclamation and Revegetation Research 2:279-298

Martínez-Rodríguez P, Sarsa J, Peco B, Jauregui B, Rivera D, Bella J (2013)

Endosymbiont-free ants: Molecular biological evidence that neither Wolbachia, Cardinium or any other bacterial endosymbionts play a role in thelytokus parthenogenesis in the harvester ant species, Messor barbarus and M. capitatus (Hymenoptera: Formicidae). European Journal of Entomology 110(2):197-204

Martinson V, Danforth B, Minckley R, Rueppell O, Tingek S, Moran N (2011) A simple and distinctive microbiota exclusively associated with honey bees and bumble bees. Molecular Ecology 20(3):619-628

Masella A, Bartram A, Truszkowski J, Brown D, Neufeld J (2012) PANDAseq: pairedend assembler for Illumina sequences. BMC Bioinformatics 13:31

McDonald D, Price M, Goodrich J, Nawrocki E, DeSantis T, Probst A, Andersen G, Knight R, Hugenholtz P (2012) An improved Greengenes taxonomy with explicit ranks for ecological and evolutionary analyses of bacteria and archaea. ISME Journal 6(3):610-618

Mezger D, Pfeiffer M (2003) Influence of the arrival of Anoplolepis gracilipes (Hymenoptera: Formicidae) on the composition of an ant community in a clearing in Gunung Mulu National Park, Sarawak, Malaysia. Asian Myrmecology 4:89-98

Milks M, Fuxa J, Richter A (2008) Prevalence and impact of the microsporidium Thelohania solenopsae (Microsporidia) on wild populations of red imported fire ants, Solenopsis invicta, in Louisiana. Journal of Invertebrate Pathology 97:91102 


\section{References}

de Miranda J, Cordoni G, Budge G (2010) The acute bee paralysis virus-Kashmir bee virus-Israeli acute paralysis virus complex. Journal of Insect Pathology 103:S30S47

MiSeq Reference Guide (2013) 16S Metagenomic sequencing library preparation.

Preparing 16S ribosomal RNA gene amplicons for the Illumina MisSq system. NZGL, NZ Part \# 15044223 Rev. B

Mitra S, Stark M, Huson D (2011) Analysis of 16S rRNA environmental sequences using MEGAN. BMC Bioinformatics 12(Suppl 3):S17

Mullen L, Goldsworthy G (2006) Immune responses of locusts to challenge with the pathogenic fungus Metarhizium or high doses of laminarin. Journal of Insect Physiology 52:389-398

Nguyen B, Ribiere M, vanEngelsdorp D, Snoeck C, Saegerman C, Kalkstein A, Schurr F, Brostaux Y, Faucon J, Haubruge E (2011) Effects of honey bee virus prevalence, Varroa destructor load and queen condition on honey bee colony survival over the winter in Belgium. Journal of Apiculture 50(3):195-202

Nonacs P (1991) Less growth with more food: how insect-prey availability changes colony demographics in the ant, Camponotus floridanus. Journal of Insect Physiology 37(12):891-898

O’Dowd D, Green P, Lake P (2003) Invasional “meltdown” on an oceanic island. Ecology Letters 6:812-817

Oi D, Williams D (2003) Thelohania solenopsae (Microsporidia: Thelohaniidae) infection in reproductives of red imported fire ants (Hymenoptera: Formicidae) and its implication for intercolony transmission. Environmental Entomology 32(5):1171-1176

Oi D, Valles S (2009) Fire ant control with entomopathogens in the USA. In: Hajek T, Glare T, O'Callaghan M (eds) Use of microbes for control and eradication of invasive arthropods, vol 6. Springer Netherlands, Dordrecht, pp 237-257

Oi D, Valles S, Porter S (2012) The fire ant (Hymenoptera: Formicidae) pathogen, Vairimorpha invictae (Microsporidia: Burenellidae), not detected in Florida. Florida Entomologist 95(2):506-508 


\section{References}

Oi D, Porter S, Valles S (2015) A review of the biological control of fire ants (Hymenoptera: Formicidae). Myrmecological News 21:101-116

Oldroyd B (2007) What's killing American Honey bees? PLoS ONE 5(6):e168

Okuno M, Tsuji K, Sato H, Fujisaki K (2012) Plasticity of grooming behaviour against entomopathogenic fungus Metarhizium anisopliae in the ant Lasius japonicus. Journal of Ethology 30:23-27

Panteleev D, Goryacheva I, Andrianov B, Reznik N, Lazebny O, Kulikov A (2007) The endosymbiotic bacterium Wolbachia enhances the nonspecific resistance to insect pathogens and alters behaviour of Drosophila melanogaster. Russian Journal of Genetics 43(9):1066-1069

Passera, L. 1994. Characteristics of tramp ants. In: Williams D (ed) Exotic ants: biology, impact, and control of introduced species. Westview Press, Boulder pp 23-43

Paulson A, von Aderkas P, Perlman S (2014) Bacterial associates of seed-parasitic wasps (Hymenoptera: Megastigmus). BMC Microbiology 14:224

Pereira R, Williams D, Becnel J, Oi D (2003) Yellow-head disease caused by a newly discovered Mattesia sp. in populations of the red imported fire ant, Solenopsis invicta. Journal of Invertebrate Pathology 81:45-48

Perlman S, Kelly S, Hunter M (2008) Population biology of cytoplasmic incompatibility: maintenance and spread of Cardinium symbionts in a parasitic wasp. Genetics 178:1003-1011

Pham L, Dionne M, Shirasu-Hiza M, Schneider D (2007) A specific primed immune response in Drosophila is dependent on phagocytes. PLoS Pathogens 3(3):e26

Poinar G (2012) Nematode parasites and associates of ants: past and present. Psyche 2012:e192017

Porcar M, Caballero P (2000) Molecular and insecticidal characterization of a Bacillus thuringiensis strain isolated during a natural epizootic. Journal of Applied Microbiology 89:309-316

Porter S, Valles S, Oi D (2013) Host specificity and colony impacts of the fire ant pathogen, Solenopsis invicta virus 3. Journal of Invertebrate Pathology 114:1-6 


\section{References}

Priya N, Ojha A, Kajla M, Raj A, Rajagopol R (2012) Host plant induced variation in gut bacteria of Helicoverpa armigera. PLoS ONE 7(1):e30768

R Core Team (2013) R: A language and environment for statistical computing. R Foundation for Statistical Computing, Vienna (http://www.R-project.org)

Reaney L, Knell R (2010) Immune activation but not male quality affects female current reproductive investment in a dung beetle. Behavioral Ecology 21:1367-1372

Reber A, Chapuisat M (2012) No evidence for immune priming in ants exposed to a fungal pathogen. PLoS ONE 7(4):e35372

Rice W (1989) Analyzing tables of statistical tests. Evolution 43:223-225

Richards M, Packer L (1994) Trophic aspects of caste determination in Halictus ligatus, a primitively eusocial sweat bee. Behavioural Ecology and Sociobiology 34(6):385391

RNAlater Handbook (2006) Qiagen, Velno

Rokop Z, Horton M, Newton I (2015) Interactions between co-occuring lactic acid bacteria in the honey bee hive. Applied and Environmental Entomology 80(20): doi: 10.1128/AEM.01259-15 AEM.01259-15

Rolff J, Siva-Jothy M (2003) Invertebrate ecological immunology. Science 301:472-475

Roth O, Sadd B, Schmid-Hempel P, Kurtz J (2009) Strain-specific priming of resistance in the red flour beetle, Tribolium castaneum. Proceedings of the Royal Society B 276:145-151

Ruppell O, Heinze J, Holldobler B (2002) Intracolonial patterns of reproduction in the queen-size dimorphic ant Leptothorax rugatulus. Behavioral Ecology 13(2):239247

Russell J (2012) The ants (Hymenoptera: Formicidae) are unique and enigmatic hosts of prevalent Wolbachia (Alphaproteobacteria) symbionts. Myrmecological News $16: 7-23$

Russell J, Moran N (2006) Costs and benefits of symbiont infection in aphids: variation among symbionts and across temperatures. Proceedings of the Royal Society B 273(1586):603-610 


\section{References}

Russell J, Moreau C, Goldman-Huertas B, Fujiwara M, Lohman D, Pierce N (2009) Bacterial gut symbionts are tightly linked with the evolution of herbivory in ants. PNAS 106(50):21236-21241

Russell J, Funaro C, Giraldo Y, Goldman-Huertas B, Suh D, Kronauer D, Moreau C, Pierce N (2012) A veritable menagerie of heritable bacteria from ants, butterflies and beyond: broad molecular surveys and a systematic review. PLoS ONE 7(12):e51027

Russell-Smith J, Ryan PG, DuRieu R (1997) A LANDSATT MSS-derived fie history of Kakadu National Park, monsoonal northern Australia, 1980-1994: seasonal extent, frequency and patchiness. Journal of Applied Ecology 35:829-846

Ryu J, Kim S, Lee H, Bai J, Nam Y, Bae J, Lee D, Shin S, Ha E, Lee W (2008) Innate immune homeostasis by the homeobox gene caudal and commensal-gut mutualism in Drosophila. Science 319:777-782

Sakai A, Allendorf F, Holt J, Lodge D, Molofsky J, With K, Baughman S et al. (2001) The population biology of invasive species. Annual Review of Ecology, Evolution, and Systematics 32:305-332

Sandström A, Anderson M, Asp A, Bohman P, Edsman L, Engdahl F, Nyström P, Stenberg M, Hertonsson L, Vrålstad T, Granèli W (2014) Population collapses in introduced non-indigenous crayfish. Biol Invasions 16:1961-1977

Sarty M, Abbott K, Lester P (2006) Habitat complexity facilitates coexistence in a tropical ant community. Oecologia 149:465-473

Scheffer V (1951) The rise and fall of a reindeer herd. The Scientific Monthly 73(6):356362

Scheibel L, Adler A, Trager W (1979) Tetraethylthiuram disulfide (Antabuse) inhibits the human malaria parasite Plasmodium falciparum. PNAS 76(10):5303-5307

Schmid-Hempel P (1998) Parasites in Social Insects. Princeton University Press, Princeton

Schmid-Hempel P (2003) Variation in immune defence as a question of evolutionary ecology. Proceedings of the Royal Society London B 270:357-366 


\section{References}

Schmid-Hempel P, Eckhardt M, Goulson D, Heinzmann D, Lange C, Plischuk S, Escudero L, Salathe R, Scriven J, Schmid-Hempel P (2013) The invasion of southern South America by imported bumblebees and associated parasites. Journal of Animal Ecology 83:823-837

Schrempf A, Cremer S, Heinze J (2011) Social influence on age and reproduction: reduced lifespan and fecundity in multi-queen ant colonies. Journal of Evolutionary Biology 24:1455-1461

Schroeder D, Martin S (2012) Deformed wing virus. Virulence 3(7):589-591

Sébastien A, Gruber, M, Lester P (2011) Prevalence and genetic diversity of three bacterial endosymbionts (Wolbachia, Arsenophonus, and Rhizobiales) associated with the invasive yellow crazy ant (Anoplolepis gracilipes). Insectes Sociaux $59: 33-40$

Sébastien A, Lester P, Hall R, Wang J, Moore N, Gruber M (2015) Invasive ants carry novel viruses in their new range and form reservoirs for a honeybee pathogen. Biology Letters 11:20150610

Sharon G, Segal D, Ringo J, Hefetz A, Zilber-Rosenberg I, Rosenberg E (2013) Commensal bacteria play a role in mating preference of Drosophila melanogaster. PNAS 107:46:20051-20056

Secil E, Sevim A, Demirbag Z, Demir I (2012) Isolation, characterization and virulence of bacteria from Ostrinia nubilalis (Lepidoptera: Pyralidae). Biologia 67(4):767776

Sikorowski P, Lawrence A, Inglis G (1993) Effects of Serratia marcescens on rearing of the tobacco budworm (Lepidoptera: Noctuidae). American Entomologist 47(1):51-60

Simberloff D (2008) We can eliminate invasions or live with them. Successful management projects. Biological Invasions 11(1):149-157

Simberloff D, Gibbons L (2004) Now you see them, now you don't! - population crashes of established introduced species. Biological Invasions 6:161-172 


\section{References}

Simberloff D, Van Holle B (1999) Positive interactions of nonindigenous species: invasional meltdown? Biological Invasions 1:21-32

Singh R, Levitt A, Rajotte E, Holmes E, Ostiguy N, vanEngelsdorp D, Lipkin W, dePamphilis C, Toth A, Cox-Foster D (2010) RNA viruses in hymenopteran pollinators: evidence of inter-taxa virus transmission via pollen and potential impact on non-Apis hymenopteran species. PLoS ONE 5(12):e14357

Singh S, Priya N, Kumar J, Rana V, Ellango R, Joshi A, Priyadarshini G, Asokan R, Rajagopal R (2012) Diversity and phylogenetic analysis of endosymbiotic bacteria from field caught Bemisia tabaci from different locations of North India based on 16S rDNA library screening. Infection, Genetics and Evolution 12:411419

Sirvio A, Pamilo P (2010) Multiple endosymbionts in populations of the ant Formica cinerea. BMC Evolutionary Biology 10:335

Siva-Jothy M, Moret Y, Rolff J (2005) Insect immunity: an evolutionary ecology perspective. Advances in Insect Physiology 32:1-48

Srinatha H, Jalali S, Sriram S, Chakravarthy A (2015) Isolation of microbes associated with field-collected populations of the egg parasitoid, Trichogramma chilonis capable of enhancing biotic fitness. Biocontrol Science and Technology 25(7):789-802

Stanley D, Haas E, Miller J (2012) Eicosanoids: exploiting insect immunity to improve biological control programs. Insects 3:492-510

Suwabe M, Ohnishi H, Kikuchi T, Kawara K, Tsuji K (2009) Difference in seasonal activity pattern between non-native and native ants in subtropical forest of Okinawa Island, Japan. Ecological Restoration 24:637-643

Tagami Y, Doi M, Sugiyama K, Tatara A, Saito T (2006) Wolbachia-induced cytoplasmic incompatibility in Liriomyza trifoli and its possible use as a tool in insect pest control. Biological Control 38:205-209

Tamura K (2002) Evolutionary distance estimation under heterogenous substitution pattern among lineages. Molecular Biol Evol 19:1727-1736

Tamura K, Stecher G, Peterson D, Filipski A, Kumar S (2013) MEGA6: Molecular Evolutionary Genetics Analysis Version 6.0. Mol. Biol. Evol. 30:2725-2729 


\section{References}

Taylor C, Hastings A (2005) Allee effects in biological invasions. Ecology Letters 8:895908

Thomas M, Payne-Makrisa C, Suarez A, Tsutsui N, Holway D (2006) When supercolonies collide: territorial aggression in an invasive and unicolonial social insect. Molecular Ecology 15:4303-4315

Tompkins D, Dunn A, Smith M, Telfer S (2011) Wildlife diseases: from individuals to ecosystems. Journal of Animal Ecology 80:19-38

Torchin M, Lafferty K, Dobson A, McKenzie V, Kuris A (2003) Introduced species and their missing parasites. Nature 421:628-630

Tsutsui N, Suarez A (2003) The colony structure and biology of invasive ants. Conservation Biology 17(1):48-58

Tufts D, Bextine B (2009) Identification of bacterial species in the hemolymph of queen Solenopsis invicta (Hymenoptera: Formicidae). Environmental Entomology 38(5):1360-1364

Ugelvig L, Kronauer D, Schrempf A, Heinze J, Cremer S (2010) Rapid anti-pathogen response in the ant societies relies on high genetic diversity. Proceedings of the Royal Society B 277(1695):2821-2828

Ugelvig L, Cremer S (2012) Effects of social immunity and unicoloniality on hostparasite interactions in invasive insect societies. Functional Ecology 26:13001312

Valles S (2007) Ethanol preservation of fire ants allows retrospective screening for Solenopsis invicta virus-1. Florida Entomologist 90(3):577-578

Valles S (2012) Positive-strand RNA viruses infecting the red imported fire ant, Solenopsis invicta. Psyche 2012

Valles S, Strong C, Dang P, Hunter W, Pereira R, Oi D, Shapiro A, Williams D (2004) A picorna-like virus from the red imported fire ant, Solenopsis invicta: initial discovery, genome sequence, and characterization. Virology 328:151-157

Valles S, Varone L, Ramirez L, Briano J (2009) Multiplex detection of Solenopsis invicta virus -1, -2, and -3. Journal of Virological Methods 162:276-279 


\section{References}

Valles S, Oi D, Porter S (2010) Seasonal variation and the co-occurrence of four pathogens and a group of parasites among monogyne and polygyne fire ant colonies. Biological control 54:342-348

Valles S, Oi D, Yu F, Tan X, Buss E (2012) Metatranscriptomics and pyrosequencing facilitate discovery of potential viral natural enemies of the invasive Caribbean crazy ant, Nylanderia pubens. PLoS ONE 7(2):e31828

Valles S, Porter S, Choi M, Oi D (2013) Successful transmission of Solenopsis invicta virus 3 to Solenopsis invicta fire ant colonies in oil, sugar and cricket bait formulations. Journal of Invertebrate Pathology 113:198-204

Valles S, Porter S, Firth A (2014) Solenopsis invicta virus 3: pathogenesis and stage specificity. Virology 460-461:66-71

vanEngelsdorp D, Evans J, Saegerman C, Mullin C, Haubruge E, Nguyen B, Frazier M, Frazier J, Cox-Foster D, Chen Y, Underwood R, Tarpy D, Pettis J (2009) Colony collaspe disorder: a descriptive study. PLoS ONE 4(8):e6481

Vasquez C, Stouthamer R, Jeong G, Morse J (2011) Discovery of a CI-inducing Wolbachia and its associated fitness costs in the biological control agent Aphytis melinus DeBach (Hymenoptera: Aphelinidae). Biological Control 58:192-198

Vasquez A, Forsgren E, Fries I, Paxton R, Flaberg E, Szekely L, Olofsson T (2012) Symbionts as major modulators of insect health: lactic acid bacteria and honeybees. PLoS ONE 7(3):e33188

Vilcinskas A, Stoecker K, Schmidtberg H, Rohrich C, Vogel H (2013) Invasive harlequin ladybird carries biological weapons against native competitors. Science 340:862863

Vitousek P, D’Antonio C, Loope L, Rejmanek M, Westbrooks R (1997) Introduced species: a significant component of human-caused global change. New Zealand Journal of Ecology 21(1):1-16

Vogel V, Pederson J, Giraud T, Krieger M, Keller L (2010) The worldwide expansion of the Argentine ant. Diversity and Distributions 16:170-186

Warwick R, Clarke K, Suharsono S (1990) A statistical analysis of coral community responses to the 1982-83 El Nino in the Thousand Islands, Indonesia. Coral Reefs $8: 171-179$ 


\section{References}

Wenseleers T, Ito F, Van Borm S, Huybrechts R, Volckaert F, Billen J (1998)

Widespread occurrence of the micro-organism Wolbachia in ants. Proceedings of the Royal Society B 265:1447-1452

Wenseleers T, Sundström L, Billen J (2002) Deleterious Wolbachia in the ant Formica truncorum. Proceedings of the Royal Society B 269:623-629

Wetterer J (2005) Worldwide distribution and potential spread of the long-legged ant, Anoplolepis gracilipes (Hymenoptera: Formicidae). Sociobiology 45(1):77-97

Wetterer J (2006) The vanished plague ants (Hymenoptera: Formicidae) of $19^{\text {th }}$ century Bermuda. Myrmecol Nachr 8:219-224

Wetterer J (2012) Worldwide spread of the African big-headed ant, Pheidole megacephala (Hymenoptera: Formicidae). Myrmecological News 17:51-62

Wilkinson T (1998) The elimination of intracellular microorganisms from insects: an analysis of antibiotic-treatment in the pea aphid (Acyrthosiphon pisum). Comparative Biochemistry and Physiology 119:871-881

Williams D, Oi D, Knue G (1998) Infection of red imported fire ant (Hymenoptera: Formicidae) colonies with the entomopathogen Thelohania solenopsae (Microsporidia: Thelohaniidae). Journal of Economic Entomology 92(4):830-836

Xu P, Liu Y, Graham R, Wilson K, Wu K (2014) Densovirus is a mutualistic symbiont of a global crop pest (Helicoverpa armigera) and protects against a baculovirus and Bt biopesticide. PLoS Pathogens 10(10):e1004490

Yang C, Yu Y, Valles S, Oi D, Chen Y, Shoemaker D, Wu W, Shih C (2010) Loss of microbial (pathogen) infections associated with recent invasions of the red imported fire ant Solenopsis invicta. Biological Invasions 12:3307-3318

Young G, Bellis G, Brown G (2001) The crazy ant, Anoplolepis gracilipes (Smith) (Hymenoptera: Formicidae) in east Arnhem Land, Australia. Journal of Australian Entomology 28(3):97-104

Yoshiyama M, Wu M, Sugimura Y, Takaya N, Kimoto-Nira H, Suzuki C (2012) Inhibition of Paenibacillus larvae by lactic acid bacteria isolated from fermented materials. Journal of Invertebrate Pathology 112(2013):62-67

Zchori-Fein E, Perlman S (2004) Distribution of the bacterial symbiont Cardinium in arthropods. Molecular Ecology 13:2009-2016 


\section{Appendices}

\section{Plaster nestbox construction instructions}

View from side

1. Place Perspex frame on clean, flat surface.

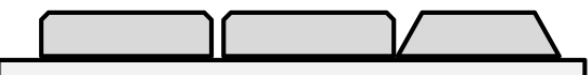

View from top
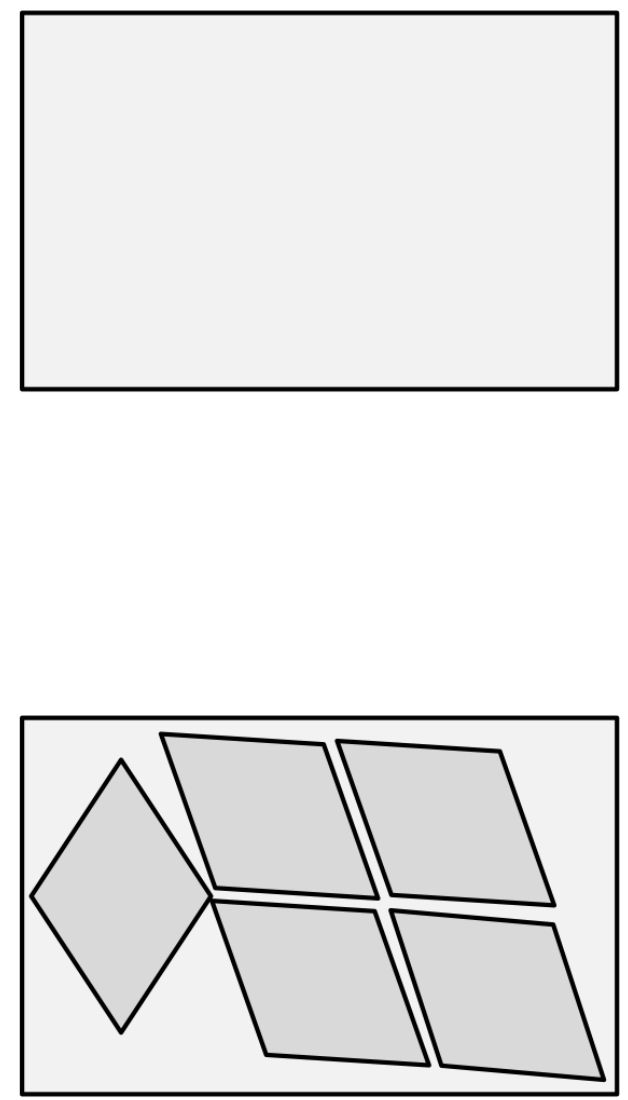

2. Place weigh boats on Perspex frame. Use tape to stick weigh boats to frame, don't let tape reach the edge. 


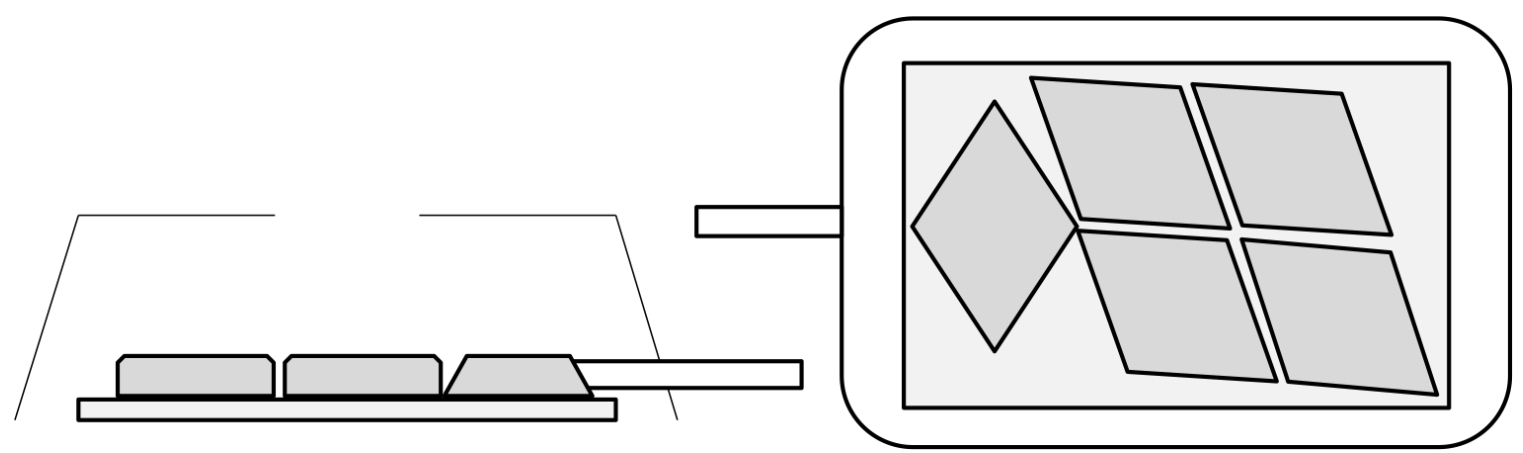

3. Drill hole in front of the plastic container that will be used as the nest box. Place plastic container upside down over Perspex. Cut a hole in bottom of plastic container (will add plaster through this). Put plugged tube (plug to prevent plaster from entering) in hole so it is touching the front-most weigh boat, this will be the nest entrance.

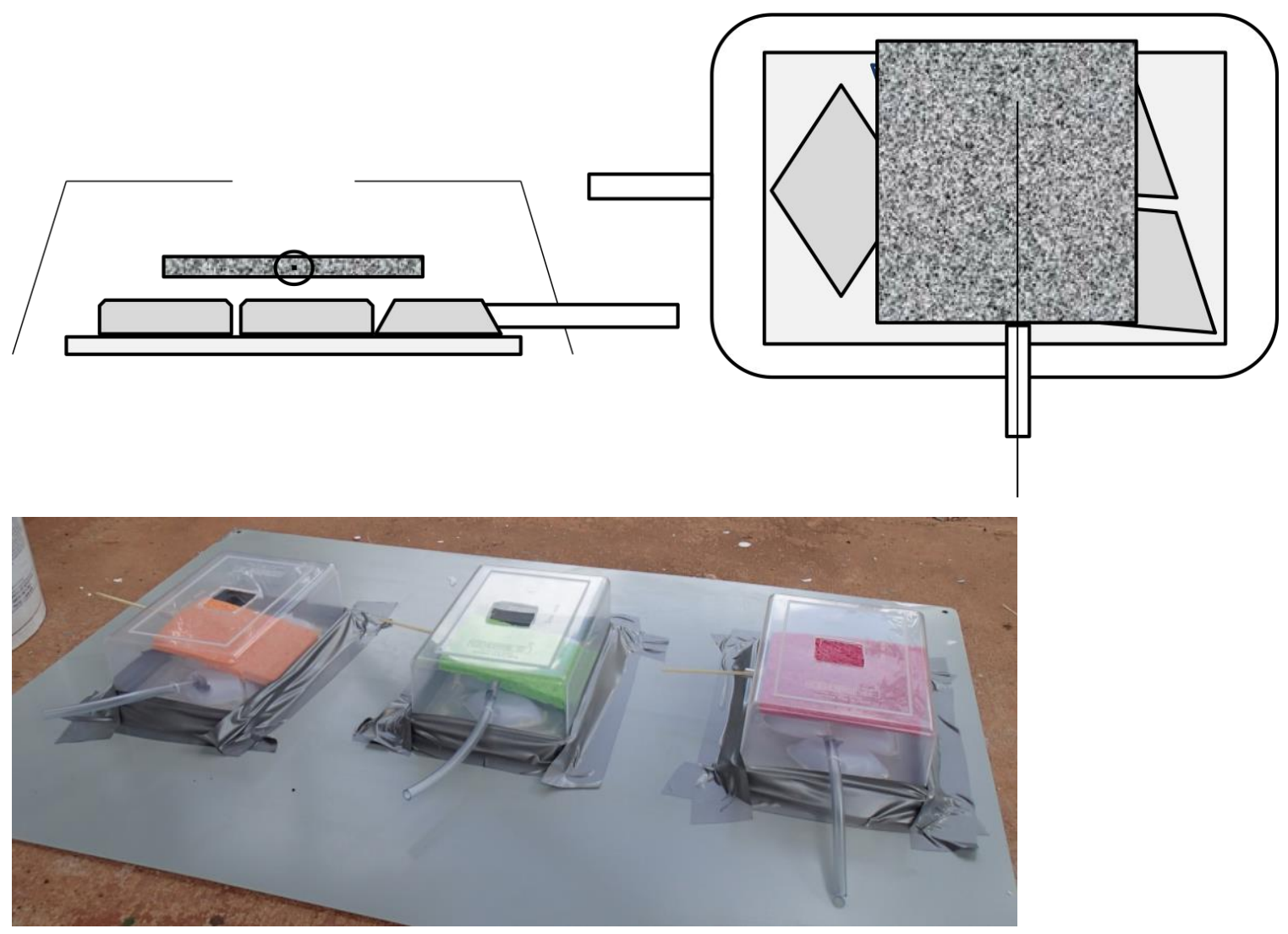

4. Drill a second hole in side of plastic container, put a piece of tube in it. Thread a wire or wooden skewer through the tube and spike a sponge on it. Make sure the tube is 
touching the sponge. This will allow water to be injected into the sponge, keeping the nest humid. Duct tape the edges of the plastic container firmly to your working surface to prevent plaster from leaking out.

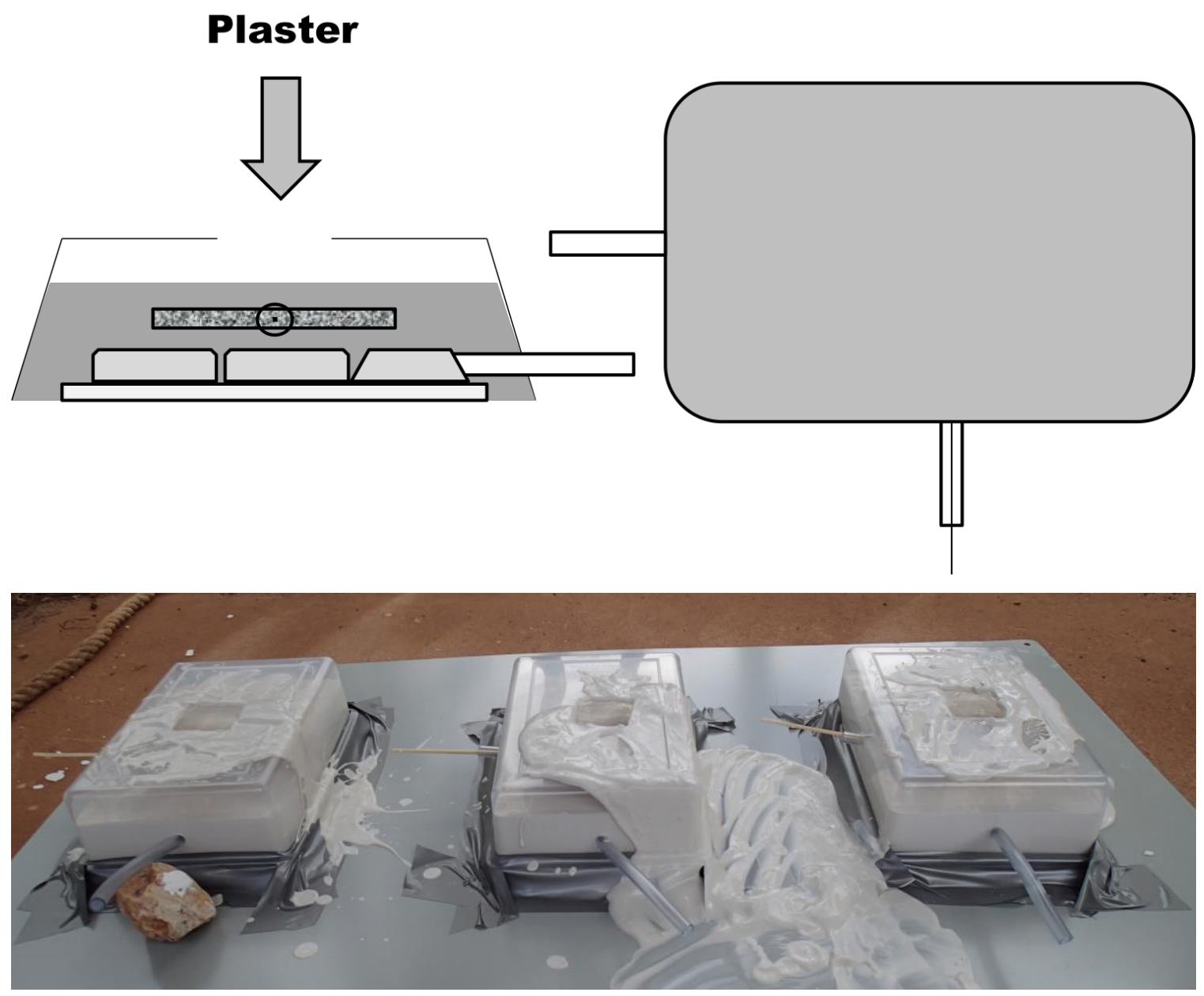

5. Add plaster until sponge is completely covered. Allow to sit until firm BUT NOT COMPLETELY DRY. 

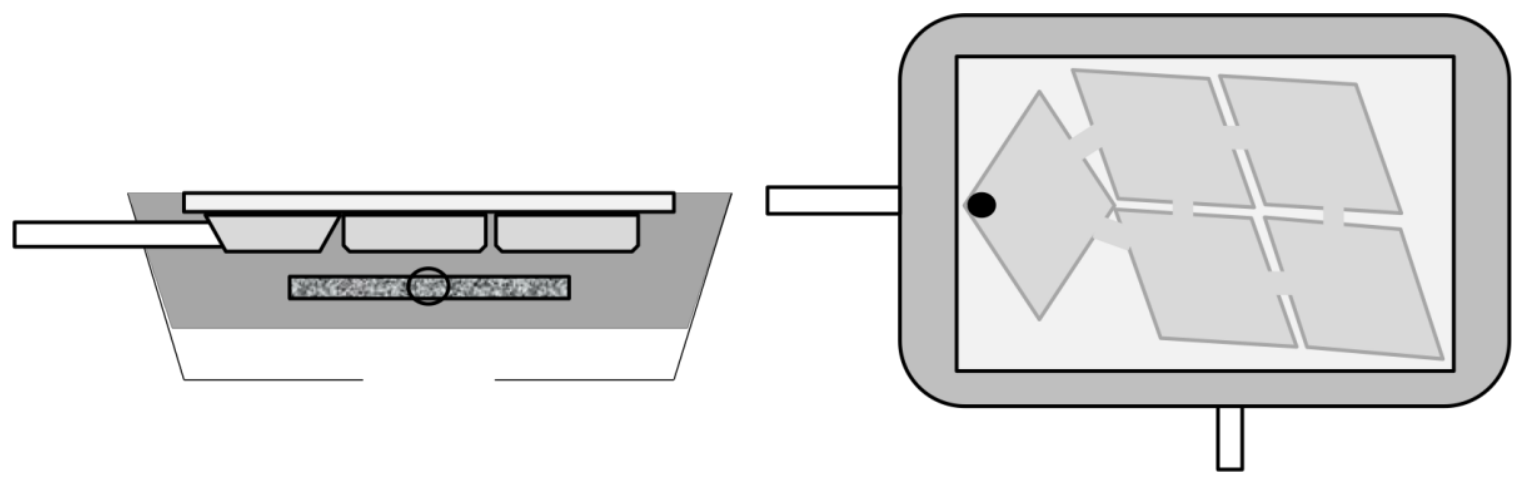

6. Flip plastic container over. Remove Perspex and weigh boats, unplug entrance tube, cut corridors between the chambers with a knife, remove wire or wooden skewer from sponge. Replace Perspex.
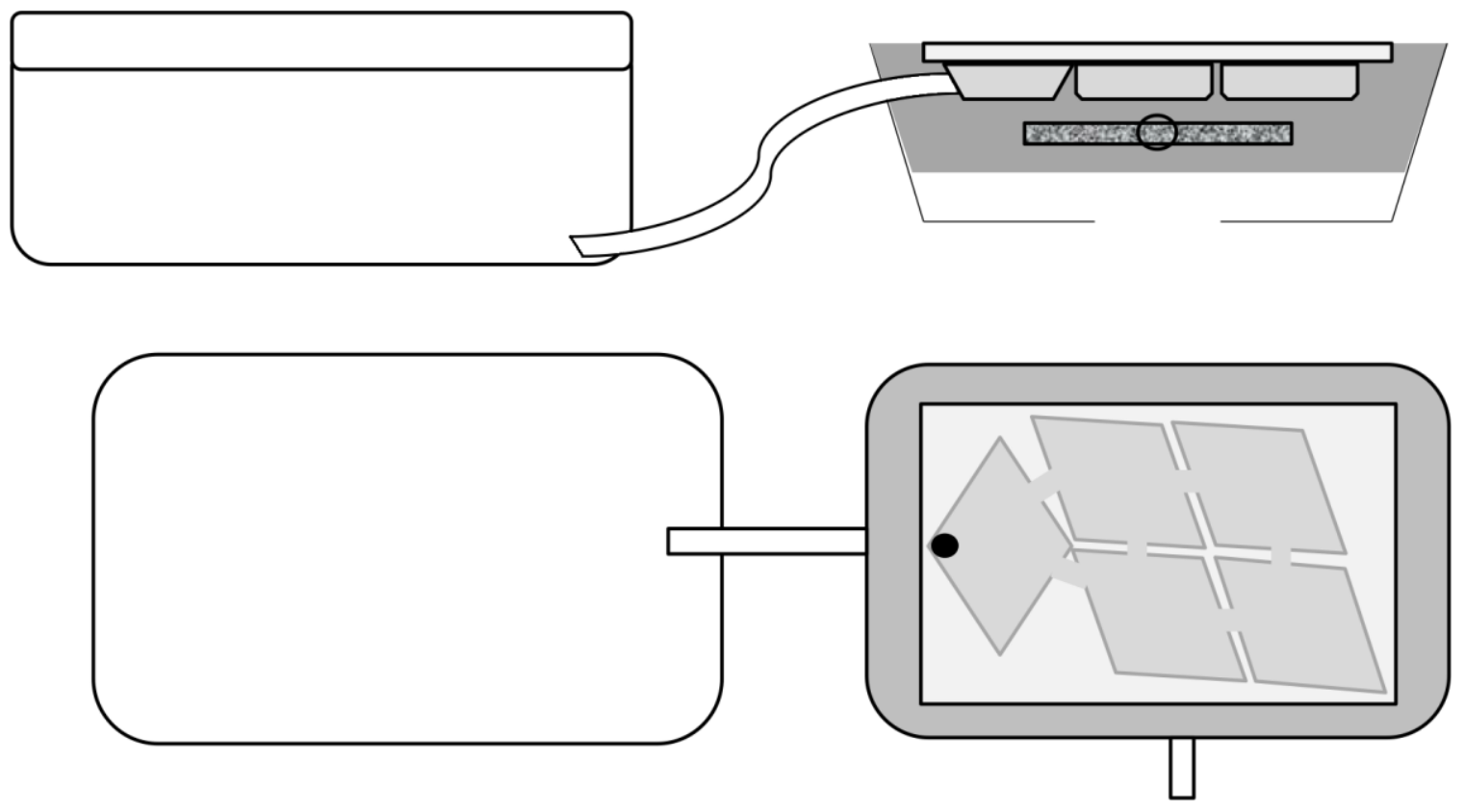

7. Drill a hole close to the bottom of a second container and attach nest entrance tube (if the tube is not resting on the bottom of the second container the ants will not find the entrance). Coat the sides of this container with Fluon, place a mesh sheet over the top and cut a hole in the lid. This will be the foraging arena. 


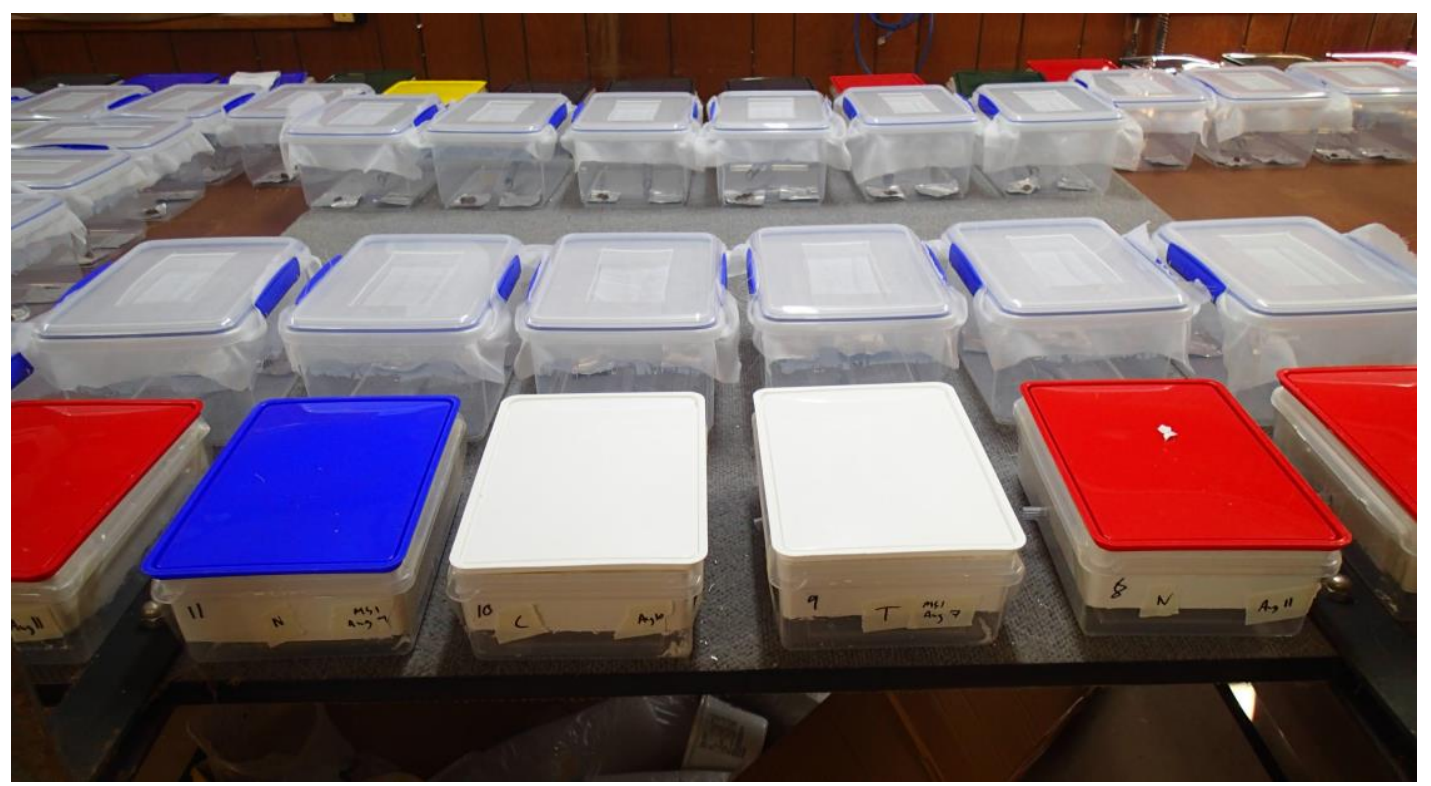

Note: I used the opaque plastic lid of the Tupperware container that became the nest box as a cover for the nest area (see in above photo). However, in retrospect I would instead use red cellophane, as this would allow observation of the nest, without disturbing the ants. 
Appendices

\section{Local ant community data}

I investigated if there is any preliminary evidence that resident ant community structure is affected by the differing abundances of $A$. gracilipes.

\section{Methods}

A. gracilipes and local ant community abundance

I also measured abundance of A. gracilipes and local ant species at all six sites using pitfall traps. Traps were placed at each site on August $19^{\text {th }} 2013$, and July $24^{\text {th }}$ and $25^{\text {th }}$ 2014 and left for 48 hours. There were four plots in each site, separated by at least $10 \mathrm{~m}$. Plots were placed in areas where crazy ants were seen to be present. Within each plot five pitfall traps were placed one metre apart and arranged in a cross shape. A mixture of 1:1 ethylene glycol and water was used as a preservative, and each trap was filled 2/3 full. Pitfall traps were $5.5 \mathrm{~cm}$ high and $4.5 \mathrm{~cm}$ across. After collection A. gracilipes were removed and counted. All other ant species were removed, stored in $70 \%$ ethanol and taken to the CSIRO Tropical Ecosystems Research Laboratory where they were identified to species and ant functional group (Andersen 1995). Ant functional groups are a global classification based on ant community dynamics in relation to environmental stress and disturbance (for a description of the different functional groups see Andersen 1995, 1997). This classification system is commonly used in studies of Australian ant communities (Andersen and Majer 2004; Hoffmann et al. 1999). The ant community was examined because A. gracilipes usually only affect other ant species when their densities are high (Gruber et al. 2012b; Sarty et al. 2006). Thus impact on the ant community can be thought of as another measurement of A. gracilipes abundance. In 2014, each site also had a paired uninvaded site within 35-100 m, each of which had three plots with five pitfall traps each.

Pitfall traps were pooled for each plot. A univariate general linear model was used to compare A. gracilipes abundance between sites and years. Anoplolepis gracilipes abundance was log transformed to meet assumptions of normality before analysis. I used a permutational analysis of variance (PERMANOVA) with 9999 permutations to test for 
Appendices

differences in ant community composition with population type, site and year as fixed factors. The resemblance matrix was derived using the Bray-Curtis similarity index (Clarke 1993). All community data was square root transformed prior to analysis to decrease the influence of very abundant species. Differences between samples were visualized for the Bray-Curtis analysis using a principal coordinate analysis plot (PCoA). The PERMANOVA and PCoAs were run in Primer-E v 6.1.13 \& PERMANOVA + v 1.0.3 (Clarke and Gorley 2006).

Poisson generalized linear model with a log-link function to examine which functional groups were affected by population type, site and year. The best fitting model using Akaike information criterion (AIC) values included population type, site and year as factors. $P$-values were corrected for multiple testing by a Bonferroni's correction (Rice 1989). Both the univariate general linear model, and the generalized linear model were run in the program IBM SPSS Statistics v 22.0.0.0.

\section{Results}

\section{Local ant community structure}

Sixty-four ant species other than A. gracilipes were found across all six study sites, 3472 individuals in total. Four ant species occurred at every invaded site: Monomorium sp. 24 laeve gp., Nylanderia sp. 4 vaga gp., Opisthopsis haddoni and Pheidole sp. 3 variabilis gp. More individuals of other ant species were caught in 2014 (1049 vs 1343), and more species were also found in this year (33 vs 42). All three independent variables, population type (Pseudo $\left.F_{1,65}=3.913, p<0.001\right)$, site $\left(\right.$ seudo $\left.F_{3,65}=2.103, p=0.040\right)$ and year (Pseudo $F_{1,65}=2.287, p=0.001$ ) had a significant effect on ant community structure. The combined PCO1 and PCO2 axes accounted for $34.2 \%$ of the total variation in the PCOA (Figure S.1). The most common functional group found, by an order of magnitude (1382 workers), was generalized Myrmicinae, which accounted for $40 \%$ of all ants collected. The next highest group was dominant Dolichoderinae (712 workers) (Table S.1). Dominant Dolichoderinae was significantly negatively affected by A. gracilipes abundance $(\mathrm{z}=-10.030, p<0.001)$, with the majority found in declined sites $(72 \%)$ and uninvaded sites (27\%). A single individual was collected in the declining site, M1, and 
none were found in expanding sites. Site and year also significantly affect Dominant Dolichoderinae abundance ( $\mathrm{z}=14.402, p<0.001 ; \mathrm{z}=13.412, p<0.001)$ with more found in 2014 (115 vs 406). Generalized Myrmicinae were significantly positively affected by population type $(\mathrm{z}=4.286, p<0.001)$, as well as site $(\mathrm{z}=-23.701, p<0.001)$ and year $(\mathrm{z}=\mathrm{-}$ $3.245, p<0.001)$. No other functional groups were significantly affected by A. gracilipes abundance, site or year (Figure S.2, Table S.1). 
Appendices
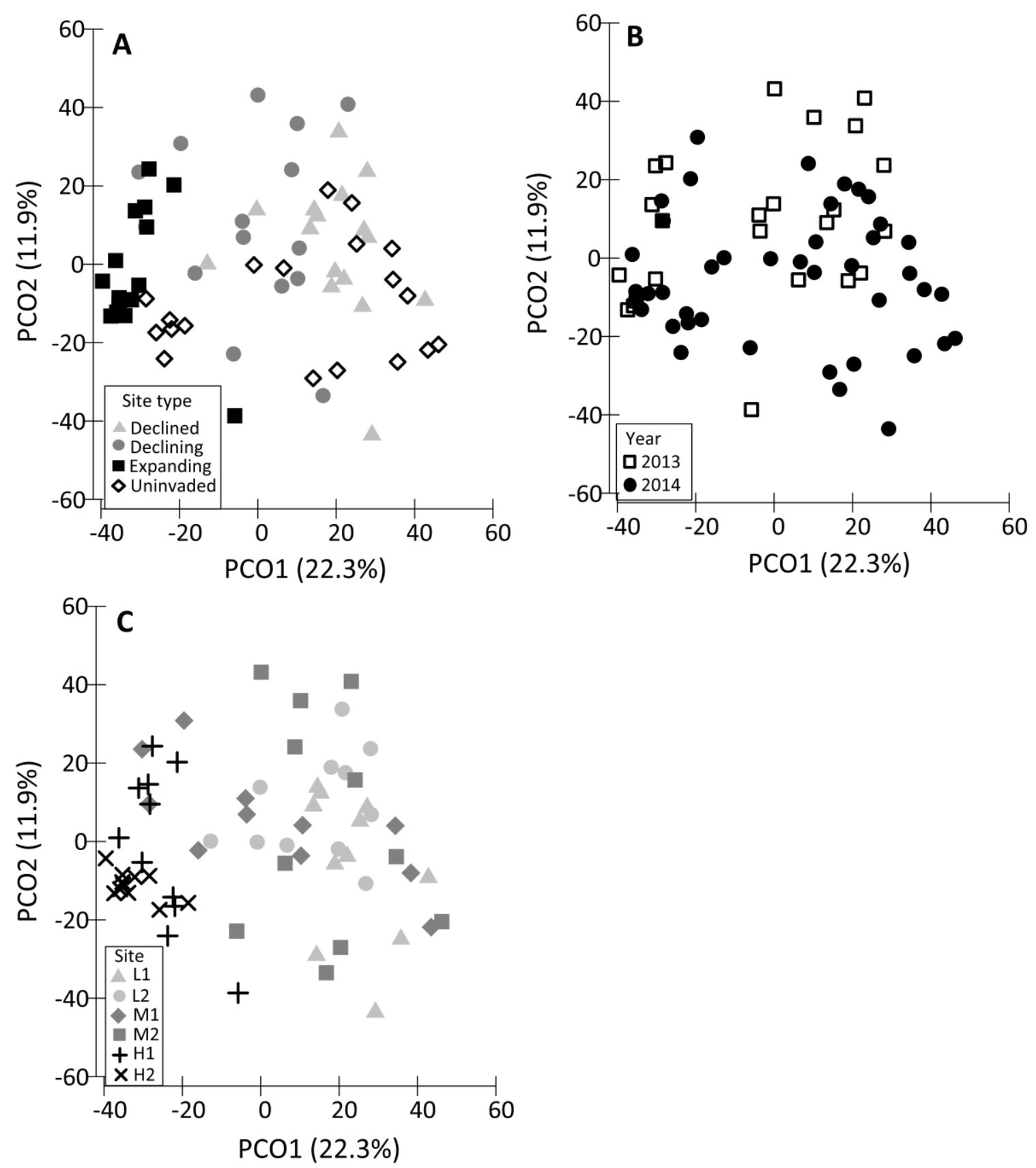

Figure S.1. PCoA based on Bray-Curtis distance values computed for local ant communities between A) population type, B) year and C) site. The first and second $\mathrm{PCoA}$ axes are shown, and the percent of Bray-Curtis distance variation explained by each axis is listed next to the axis labels. 
Table S.1. Results of generalized linear model of functional group abundance as a function of population type, site and year. The final column shows the total number of workers caught in pitfall traps, pooled across all sites for each functional group. The Dominant Dolichoderine were significantly

negatively affected by population type, and the generalized Myrmicinae were positively affected. A negative $B$ indicates a negative association between A. gracilipes abundance (using population type as a surrogate for $A$. gracilipes abundance) and functional group abundance, and a positive $B$ value a positive association.

\begin{tabular}{|c|c|c|c|c|c|c|c|c|c|c|}
\hline & \multicolumn{3}{|c|}{ Population type } & \multicolumn{3}{|c|}{ Site } & \multicolumn{3}{|c|}{ Year } & \\
\hline & $\beta$ & $\mathrm{SE}$ & $p$ & $\beta$ & $\mathrm{SE}$ & $p$ & $\beta$ & $\mathrm{SE}$ & $p$ & $\begin{array}{c}\# \\
\text { individuals }\end{array}$ \\
\hline Cryptic & 0.287 & 0.179 & 0.109 & -0.162 & 0.080 & 0.044 & -0.760 & 0.301 & 0.012 & 55 \\
\hline Dominant Dolichoderinae & -0.366 & 0.036 & $<0.001$ & 0.358 & 0.025 & $<0.001$ & 1.395 & 0.104 & $<0.001$ & 712 \\
\hline Generalized Myrmicinae & 0.156 & 0.037 & $<0.001$ & -0.430 & 0.018 & $<0.001$ & -0.175 & 0.054 & 0.001 & 1382 \\
\hline Hot climate specialist & 0.001 & 0.129 & 0.996 & 0.444 & 0.104 & $<0.001$ & 18.350 & 13.510 & 0.989 & 33 \\
\hline Opportunist & -0.080 & 0.051 & 0.117 & -0.018 & 0.026 & 0.497 & 0.199 & 0.104 & 0.055 & 469 \\
\hline Subordinate Camponotini & -0.238 & 0.141 & 0.091 & 0.114 & 0.072 & 0.116 & -0.139 & 0.256 & 0.586 & 69 \\
\hline
\end{tabular}



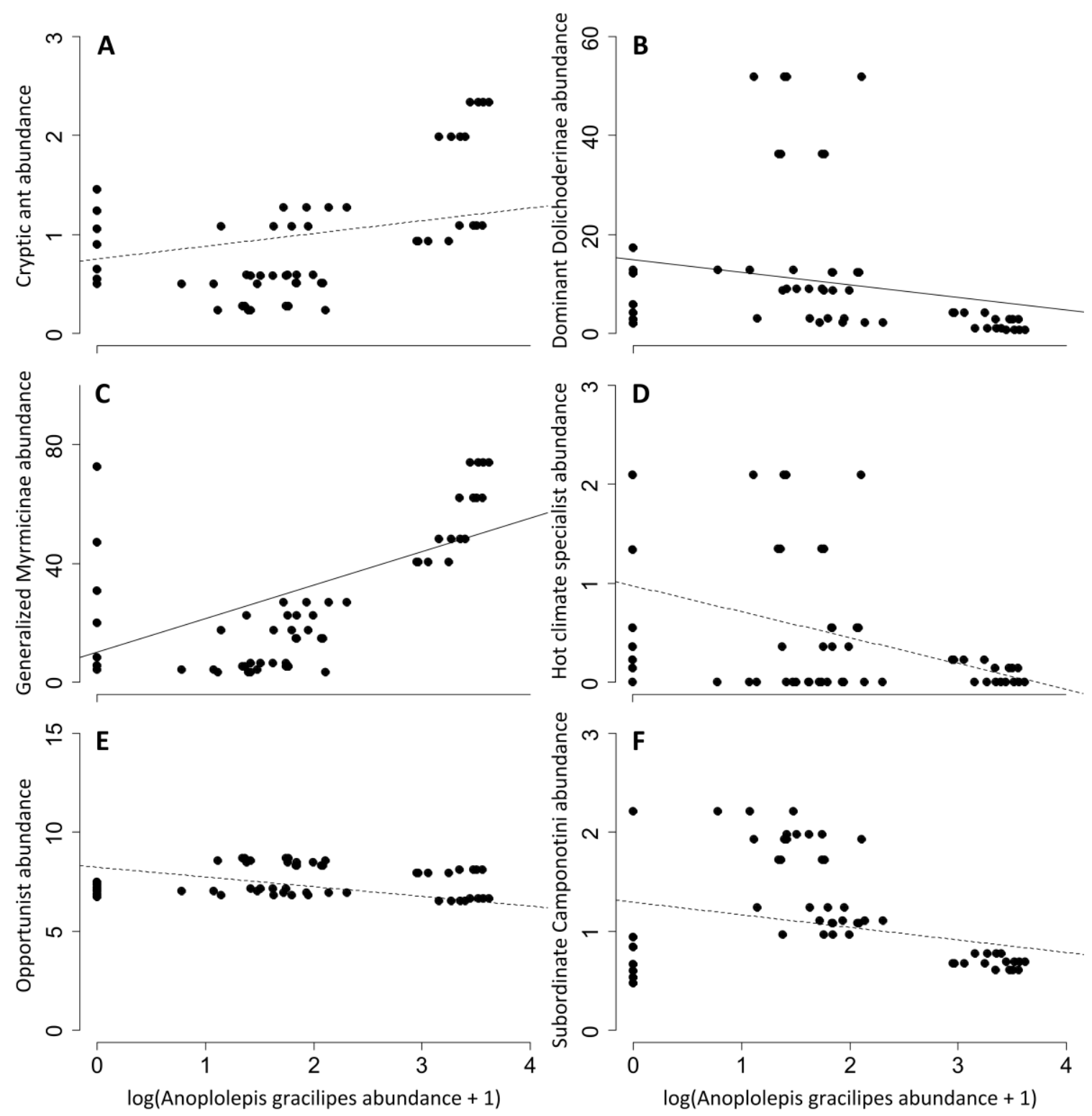

Figure S.2. Relationship between $A$. gracilipes abundance (total number of ants per plot) and the abundance of resident ant species by functional group (total number of ants in each functional group per plot). For ease of visual interpretation $A$. gracilipes abundance was used as a surrogate for population type and a line of best fit from the model was plotted on each graph. Solid lines indicate a significant relationship between functional group abundance and population type (generalized linear model) and dashed lines indicate a non-significant relationship. 


\title{
Here today, gone tomorrow: declines and local extinctions of invasive ant populations in the absence of intervention
}

\author{
M. Cooling • B. D. Hoffmann
}

Received: 21 April 2015/Accepted: 18 August 2015

(C) Springer International Publishing Switzerland 2015

\begin{abstract}
Invasive species are known to exhibit boom and bust cycles. We report population declines of one of the world's most serious ant invaders, Anoplolepis gracilipes (Smith) (yellow crazy ant) in Arnhem Land, Australia. Anoplolepis gracilipes populations are known to fluctuate, both spatially and temporally, but this is the first instance of quantitative monitoring of spatial declines of entire populations. We present before and after survey data on seven populations that have either declined substantially or disappeared completely without human intervention. Sites ranged in size from 1.8 to 15 ha. Although the mechanistic cause of these declines remains unknown, A. gracilipes populations in Arnhem Land represent a unique opportunity to investigate mechanisms by which a globally significant invader declines, which could have important implications for invasive species management worldwide.
\end{abstract}

Keywords Anoplolepis gracilipes · Population collapse $\cdot$ Invasive species $\cdot$ Survey

M. Cooling ( $\square)$

School of Biological Sciences, Victoria University of Wellington, PO Box 600, Wellington 6140, New Zealand e-mail: Meghan.Cooling@vuw.ac.nz

B. D. Hoffmann

CSIRO Land and Water Flagship, Tropical Ecosystems Research Centre, PMB 44, Winnellie, NT 0822, Australia

\section{Introduction}

Population declines of an exotic species following an initial population "explosion" are a well recognized, but rarely investigated, syndrome of invasions (Simberloff and Gibbons 2004; Gruber et al. 2012a; Sandström et al. 2014). In most instances, the mechanisms driving the declines are unclear (Cooling et al. 2012; Sandström et al. 2014). Similarly, data quantifying the declines as they occur are extremely rare because they most often happen quickly and unexpectedly, and because interest in invasions is reduced after a decline has taken place, which results in a publication bias (Simberloff and Gibbons 2004).

The yellow crazy ant, Anoplolepis gracilipes (Smith), is considered one of the world's most widespread, ecologically and economically damaging invasive ant species (Holway et al. 2002), and like many other invasive ant species it can reach extraordinarily high population densities and substantially modify ecosystems (O'Dowd et al. 2003). Populations of this ant are also known to fluctuate strongly, both spatially and temporally (Haines et al. 1994; Abbott 2005; Gruber et al. 2012a, b). Anoplolepis gracilipes was first detected in northeast Arnhem Land in Australia's Northern Territory in 1982 (Majer 1984), though it had probably been established for several decades prior (Young et al. 2001). The ant is patchily distributed throughout 25,000 ha, inhabiting mostly undisturbed savanna woodland, where it forms spatially discrete 
populations probably as a result of accidental dispersal by people (Hoffmann and Saul 2010; Fig. 1).

Some populations of A. gracilipes were found to decline or disappear, in the absence of intervention, during delimiting surveys, that were part of management operations against this ant that have been ongoing in northeast Arnhem Land since 2004. The declines occurred either between the time that they were found and then accurately delimited, between multiple delimitations when treatments were delayed, or while they were being observed for other experimental work (Hoffmann 2014, 2015). Here we detail large-scale reductions in the spatial extent of four populations of this highly invasive species, including one population (site $\mathrm{G}$ ) that we monitored for 3 years. We also present data on three populations that were recorded as present, but disappeared before they were spatially delimited.

\section{Methods}

We monitored and quantified the change in spatial extent of four populations and recorded the collapse of

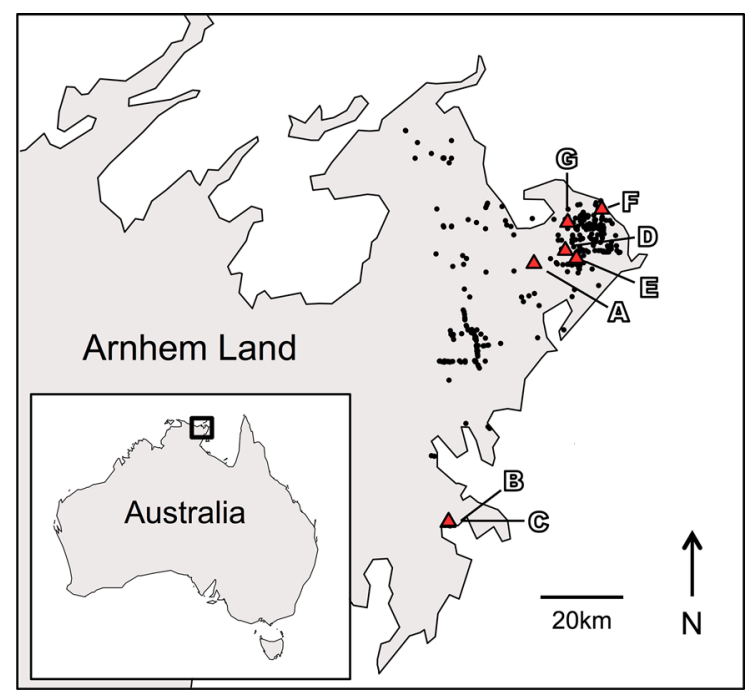

Fig. 1 Inset of Australia and map of Arnhem Land showing locations where A. gracilipes has been detected since 2003 (black circles), and the locations of the populations detailed here (triangles). Sites $B$ and $C$ appear as one site on this map because they are $<500 \mathrm{~m}$ apart. Note that most of these detections (black circles) represent spatially discrete populations, and most have not been resurveyed since their initial detection, so it is unknown how many others have undergone spatial collapse since their detection three others (Fig. 1). Unfortunately ideal baseline data was not obtained for most populations due to this work not being anticipated when they were first found or mapped. Four populations were mapped using the standard visual assessments used by the eradication program (detailed below), but GPS data were not collected at sites $\mathrm{A}$ and $\mathrm{F}$ for each visual assessment, rather only the boundary of each population was recorded as a polygon, thereby giving only an area, not an indication of $A$. gracilipes continuity through the area. However, pre-decline nest density at site A was known from prior research (Hoffmann 2015). Three populations (B, C, D) were not mapped prior to their decline and so their baseline data are only a single GPS point indicating that they existed, and thus their original extents are unknown.

Mapping and subsequent re-surveys of populations were conducted by visual assessments of the presence/ absence of A. gracilipes workers. Assessments were conducted between 0600 and 0930 and 1530 and 1830 , when temperatures do not greatly hinder A. gracilipes activity (15-30 ${ }^{\circ} \mathrm{C}$; Hoffmann 2015). Assessments were conducted by teams of people walking in parallel, commencing in any direction from an $A$. gracilipes detection point. Assessments were conducted haphazardly, approximately one per every $2 \mathrm{~m}$. Early work conducted prior to 2007 did not collect point-level GPS data, rather only the boundary of populations was recorded as a polygon. When pointlevel GPS data were collected, A. gracilipes was recorded as present or absent. The boundary of the population was deemed to have been determined when no detections had been made for at least $100 \mathrm{~m}$ in all directions from the peripheral detections. The accuracy of visual assessments in determining A. gracilipes presence/absence was verified in a previous pilot study, where visual assessments accurately detected the full extent of multiple small and isolated clusters of nests previously delineated using attractive food lures (data not presented). Visual assessments are the standard technique used by the management program for detection and mapping A. gracilipes populations. This visual method did not attempt to detect nests, as this would be an impossible task to complete accurately at the scale of multiple hectares. Therefore data presented here focus on population distribution, not abundance.

In subsequent assessments to quantify decline, the entire area of small populations $(<9 \mathrm{ha}$; populations 
A-E) was re-surveyed, but for the two larger populations ( $\mathrm{F}$ and $\mathrm{G})$ only two areas of 2.3 and 8.6 ha respectively that originally had a high density of detections were re-surveyed. Finally, to assess if the populations had merely shifted their distribution to a new area, we also conducted a search up to $400 \mathrm{~m}$ in all directions around the original distribution of population $\mathrm{G}$, and for three other populations (A, B, C) searches in some peripheral locations also extended well past the $100 \mathrm{~m}$ search limit.

\section{Results}

Of the seven populations, five (sites A, B, C, D, E) appear to have disappeared completely from when they were first found or mapped to when they were resurveyed (Table 1; Figs. 2, 3). These populations ranged in size from single point detections with unknown extent to 3.6 ha. The populations at sites $\mathrm{F}$ and $\mathrm{G}$, which had the largest original infestations covering 15 and 8.6 ha respectively, declined substantially. Average nest density at site F was known to be one nest per $6.3 \mathrm{~m}^{2}$ in 2006 (Hoffmann 2015), which declined to only a single nest being found throughout 2.3 ha in 2012 and no other detections being made throughout a greater area in other informal searches (data not presented). No A. gracilipes were found in the areas searched on the eastern half and far western side of site G in 2012, and there was a clear continual decline in detections, including their spatial distribution, throughout the permanent re-survey zone throughout all years (Fig. 4). No detections were made up to $400 \mathrm{~m}$ surrounding site $\mathrm{G}$ in 2012, or at sites A-C where searches sometimes exceeded far more than $100 \mathrm{~m}$ past a detection point, making it unlikely that the populations had just moved to a new location.

\section{Discussion}

Populations of A. gracilipes have previously been reported to fluctuate (Haines et al. 1994; Abbott 2005; Gruber et al. 2012a) but their decline over several years has rarely been monitored. We quantified the spatial decline of four A. gracilipes populations, and documented the extinction of three others. On the Seychelles, very abundant local populations of $A$. gracilipes declined and disappeared over extensive areas within 5 years (Haines et al. 1994). A supercolony on Christmas Island was observed to decline rapidly in abundance over an 18 month period, to the point that red land crabs, which are completely excluded by high-densities of $A$. gracilipes, were able to recolonize the area (Abbott 2005; Abbott et al. 2014). Though uncommon, other established and widespread invasive species have been known to collapse or decline suddenly (Simberloff and Gibbons 2004; Sandström et al. 2014). For example, invasive giant African land snail populations on islands periodically crash, apparently due to a bacterial pathogen (Simberloff and Gibbons 2004). Introduced deer are well known for initial population explosions followed by catastrophic collapse, caused by overexploitation of resources (Simberloff and Gibbons 2004). The highly invasive signal crayfish has been known to suffer unexplained population declines, Sandström et al. (2014) found that $41 \%$ of surveyed signal crayfish populations in Swedish lakes had collapsed. This sudden disappearance of populations has also been observed in several species of invasive ants (Wetterer 2006, 2012). Pheidole megacephala populations have been observed to go through boom and bust phases throughout their introduced range (Wetterer 2012) and local populations of Linepithema humile in New Zealand periodically collapse (Cooling et al. 2012). Mechanisms such as pathogens and overexploitation of resources may not cause the disappearance of a population, but simply reduce the population to low enough levels that it becomes vulnerable to Allee effects or stochastic processes (Taylor and Hastings 2005).

Invasive species are thought to be vulnerable to population decline due to low genetic diversity resulting in inbreeding depression and the inability to adapt to local environments (Vogel et al. 2010). A recent study investigating population genetic structure showed that all A. gracilipes populations in Arnhem Land are likely to be descended from the introduction of a single population (Gruber et al. 2012a).

Due to the nature of the surveys done, we do not know when A. gracilipes became established in our study sites, nor in most cases how long it took populations to collapse. However, we do know that populations at sites B and C disappeared completely in under 2 years, so swift declines are possible. Declines of smaller infestations such as observed at site E may be explained by stochastic events that all small 
Table 1 Details of initial surveys and reassessments of seven A. gracilipes populations conducted between 2003 and 2014

\begin{tabular}{|c|c|c|c|c|c|}
\hline Site & Year & Mapping method & Area surveyed (ha) & Presence points & Absence points \\
\hline \multirow[t]{2}{*}{$\mathrm{F}$} & 2006 & Boundary mapped ${ }^{1}$ & 14.97 & $\mathrm{n} / \mathrm{a}$ & $\mathrm{n} / \mathrm{a}$ \\
\hline & 2012 & Point-level GPS data ${ }^{2}$ & 2.3 & 1 & 700 \\
\hline \multirow[t]{4}{*}{$\mathrm{G}^{\mathrm{a}}$} & 2007 & Point-level GPS data & 8.62 & 154 & 6192 \\
\hline & 2012 & Point-level GPS data & 8.62 & 17 & $3317^{\mathrm{b}}$ \\
\hline & 2013 & Point-level GPS data & 8.62 & 35 & 4102 \\
\hline & 2014 & Point-level GPS data & 8.62 & 14 & 3380 \\
\hline \multirow[t]{2}{*}{ A } & 2003 & Boundary mapped & 3.64 & $\mathrm{n} / \mathrm{a}$ & $\mathrm{n} / \mathrm{a}$ \\
\hline & 2013 & Point-level GPS data & 10.29 & 0 & 3980 \\
\hline \multirow[t]{2}{*}{$\mathrm{E}$} & 2008 & Point-level GPS data & 6.53 & 16 & 5072 \\
\hline & 2013 & Point-level GPS data & 3.47 & 0 & 1586 \\
\hline \multirow[t]{3}{*}{ B } & 2003 & Presence detected ${ }^{3}$ & Not delimited & $\mathrm{n} / \mathrm{a}$ & $\mathrm{n} / \mathrm{a}$ \\
\hline & 2005 & Visual assessment ${ }^{4}$ & Not delimited & $\mathrm{n} / \mathrm{a}$ & $\mathrm{n} / \mathrm{a}$ \\
\hline & 2009 & Point-level GPS data & 1.80 & 0 & 156 \\
\hline \multirow[t]{3}{*}{$\mathrm{C}$} & 2003 & Presence detected & Not delimited & $\mathrm{n} / \mathrm{a}$ & $\mathrm{n} / \mathrm{a}$ \\
\hline & 2005 & Visual assessment & Not delimited & $\mathrm{n} / \mathrm{a}$ & $\mathrm{n} / \mathrm{a}$ \\
\hline & 2009 & Point-level GPS data & 2.06 & 0 & 261 \\
\hline \multirow[t]{2}{*}{$\mathrm{D}$} & 2004 & Presence detected & Not delimited & $\mathrm{n} / \mathrm{a}$ & $\mathrm{n} / \mathrm{a}$ \\
\hline & 2008 & Point-level GPS data & 2.3 & 0 & 1461 \\
\hline
\end{tabular}

Sites ordered from declining to extinct A. gracilipes

Mapping methodologies are: ${ }^{1}$ no point level GPS data were recorded of A. gracilipes presence/absence, only the boundary of the population was determined; ${ }^{2}$ point level GPS data recorded of $A$. gracilipes presence/absence throughout the population; ${ }^{3}$ rapid visual reassessment of $A$. gracilipes presence/absence only, no GPS data recorded; ${ }^{4}$ single GPS detection point only collected to record the location of a broad and unmapped A. gracilipes population

a The area and number of presence/absence points for all 4 years, refers to the re-surveyed area delimited by the polygon in Fig. 4

b Approximately half of the absence points were inadvertently lost and are not reported here

populations are vulnerable to, but collapses of larger infestations such as observed at sites $A$ and $G$ are less easily explained. There are several hypotheses to explain these results and patterns, which include fire, pesticides, migration, resource overexploitation and pathogens or parasites. Bush fires are commonplace in the savanna woodland where these declines occurred, with up to half or more of some regions being burnt each year (Russell-Smith et al. 1997) and most sites in this study burning at least every 2 years (B. Hoffmann, personal observation). Considering the high frequency of burning, it seems very unlikely that $A$. gracilipes would have been able to persist in this region for over 30 years (and probably much longer) if populations could not tolerate fire. These populations have not been treated with poison baits, nor do they appear to have moved. Though individual nests may move up to several meters, it is extremely unlikely for an entire population covering multiple hectares and consisting of hundreds of individual nests to move hundreds of meters away as one and we found no evidence for this. Overexploitation of resources is also an unconvincing argument in this case. Like many other invasive ant species, A. gracilipes populations are largely driven by carbohydrates (Holway et al. 2002; O'Dowd et al. 2003) and the savanna woodland in Arnhem Land consists predominantly of Acacia, which has carbohydrate-producing extra-floral nectaries (Lach and Hoffmann 2011). Previous studies in this region have found no association between Acacia or invertebrate abundances in high density vs low density A. gracilipes populations (Hoffmann and Saul 2010; Gruber et al. 2012b). Five arthropod nest symbionts and one ecto-parasitic mite have been found in association with A. gracilipes in Arnhem 


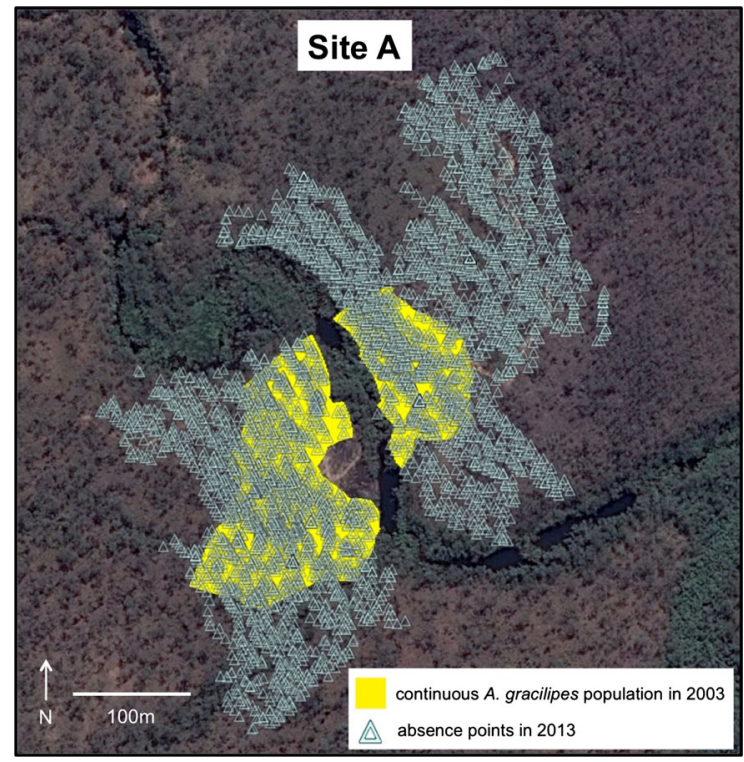

Fig. 2 Site $A$ showing the distribution of a continuous $A$. gracilipes population surveyed in 2003 (polygons), and absence points recorded when the site was resurveyed in 2013 (triangles). No A. gracilipes were observed in the 2013 sampling. Note that the central data gap is an inaccessible flooded creek and bare rock face

Land (Hoffmann 2015), but they are unlikely to have such an important influence as they have been rarely encountered.

Pathogens are a final factor that may cause localized extinctions, and work is currently being undertaken to determine what role, if any, pathogens may play in these declines. Invasive species can carry their own microorganisms and pathogens into their new environment (Oi and Valles 2009), or pick up novel ones in their introduced range (Espadaler et al. 2011). For example, it is now well known that Solenopsis invicta brought several pathogens with it to North America from its native range in South America, and many more have been found by surveying its native range (Oi and Valles 2009). Some of these pathogens, such as Thelohania solenopsae, are now being used as biocontrol agents against $S$. invicta (Oi and Valles 2009). As the native range of $A$. gracilipes is unknown, we are unable to survey for potential co-evolved pathogens, but we do know that A. gracilipes harbours potentially pathogenic fauna throughout its range (Gruber et al. in press). It remains unclear, however, exactly which associated fauna is pathogenic or not, and what is from the native range or has been transmitted to the ant within the exotic range. Unexplained population declines such as these are key research arenas because the declines may indicate unhealthy populations and the presence of pathogens (Valles et al. 2012). Declining A. gracilipes populations in Arnhem Land represent a unique opportunity to investigate mechanisms by which a globally significant invader declines. Identifying the drivers and mechanisms behind such declines could have
Fig. 3 Site $E$ showing the A. gracilipes population as mapped in 2008 and 2013. The white polygon indicates the same area on both maps

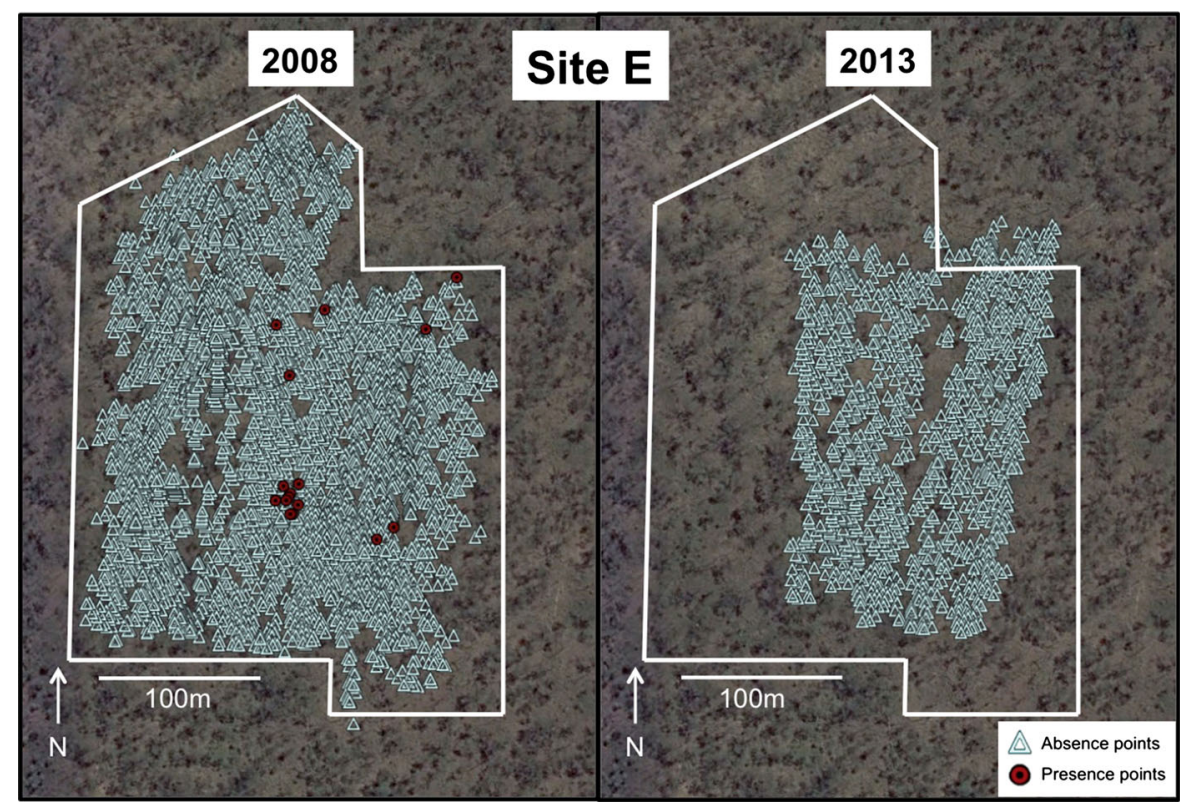


Fig. 4 Site $G$ showing the A. gracilipes population as mapped in 2007, 2012, 2013 and 2014. The white polygon indicates the same area on all maps. The black rectangle on the 2012 map indicates where GPS data of A. gracilipes absence points were lost

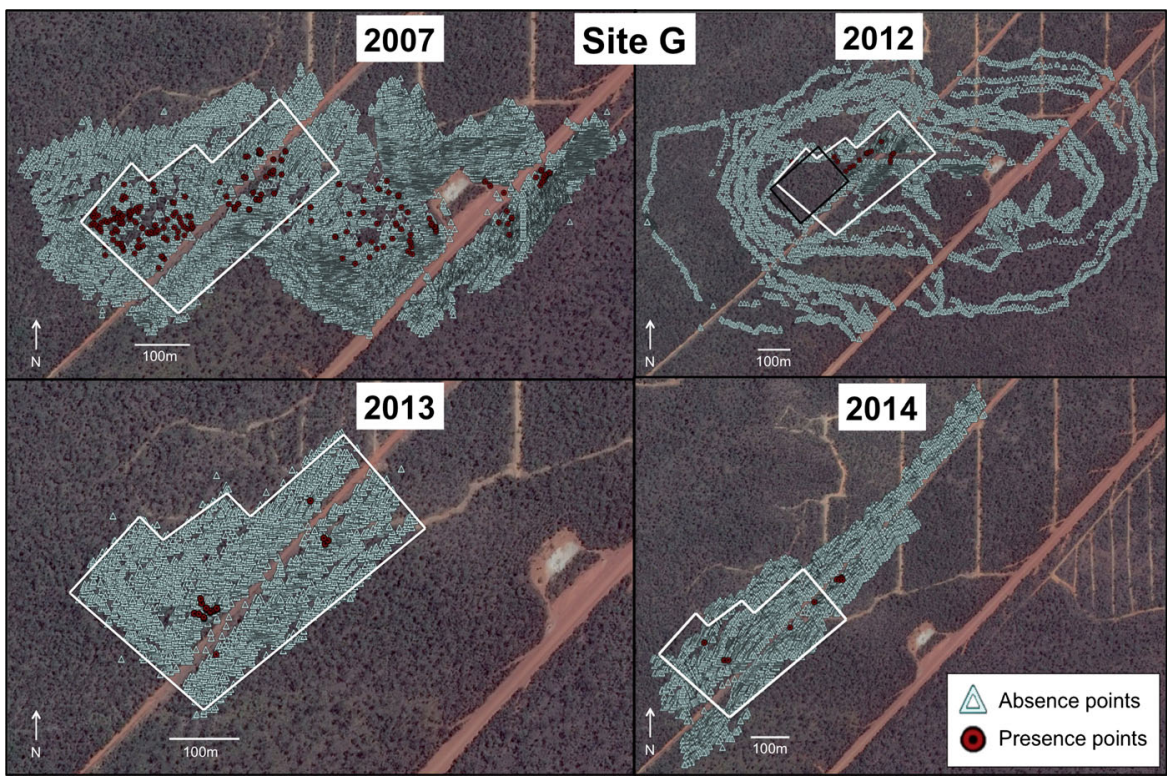

important applications for invasive species management worldwide.

Acknowledgments We thank the many people that provided technical assistance, especially Daryl Lacey, Jon Edgar, Balupalu Yunupingu, Arian Pearson, Tony Schultz and the many people involved with Conservation Volunteers Australia. Thanks to Dhimurru Aboriginal Corporation and the traditional landowners of northeast Arnhem Land for access to the region, and the staff of Rio Tinto for access to the mining leases and accommodation. We thank Pete Green and an anonymous reviewer for their valuable comments.

\section{References}

Abbott K (2005) Supercolonies of the invasive yellow crazy ant, Anoplolepis gracilipes, on an oceanic island: forager activity patterns, density and biomass. Insectes Soc 52:266-273

Abbott K, Green P, O'Dowd D (2014) Seasonal shifts in macronutrient preferences in supercolonies of the invasive yellow crazy ant Anoplolepis gracilipes (Smith, 1857) (Hymenoptera: Formicidae) on Christmas Island, Indian Ocean. Aust Entomol 53(3):337-346

Cooling M, Hartley S, Sim D, Lester P (2012) The widespread collapse of an invasive species: Argentine ants (Linepithema humile) in New Zealand. Biol Lett 8(3):430-433

Espadaler X, Lebas C, Wagenknecht J, Tragust S (2011) Laboulbenia formicarum (Ascomycota, Laboulbeniales), an exotic parasitic fungus, on an exotic ant in France. Vie et Milieu 61(1):41-44

Gruber M, Burne A, Abbott K, Pierce R, Lester P (2012a) Population decline but increased distribution of an invasive ant genotype on a Pacific atoll. Biol Invasions 15(3):599-612

Gruber M, Hoffmann B, Ritchie P, Lester P (2012b) Genetic diversity is positively associated with fine-scale momentary abundance of an invasive ant. Ecol Evol 2(9):2091-2105

Gruber M, Friedlander A, Buckley K, Jack C, Hoffmann B, Ritchie P, Lester P (in press) Among-population diversity in microbial communities of the invasive yellow crazy ant Anoplolepis gracilipes. PLoS One

Haines I, Haines J, Cherrett J (1994) The impact and control of the Crazy ant, Anoplolepis longipes (Jerd.), in the Seychelles. In: Williams D (ed) Exotic ants: biology, impact, and control of introduced species. Westview Press, Boulder, pp 206-218

Hoffmann B (2014) Quantification of supercolonial traits in the yellow crazy ant, Anoplolepis gracilipes. J Insect Sci 15:25

Hoffmann B (2015) Integrating biology into invasive species management is a key principle for eradication success: the case of yellow crazy ant Anoplolepis gracilipes in northern Australia. Bull Entomol Res 105:141-151

Hoffmann B, Saul W (2010) Yellow crazy ant (Anoplolepis gracilipes) invasions within undisturbed mainland Australian habitats: no support for biotic resistance hypothesis. Biol Invasions 12:3093-3108

Holway D, Lach L, Suarez A, Tsutsui N, Case T (2002) The causes and consequences of ant invasions. Annu Rev Ecol Evol Syst 33:181-233

Lach L, Hoffmann B (2011) Are invasive ants better plant-defense mutualists? A comparison of foliage patrolling and herbivory in sites with invasive yellow crazy ants and native weaver ants. Oikos 120:9-16

Majer J (1984) Recolonisation by ants in rehabilitated open-cut mines in Northern Australia. Reclam Reveg Res 2:279-298

O’Dowd D, Green P, Lake P (2003) Invasional "meltdown" on an oceanic island. Ecol Lett 6:812-817 
Oi D, Valles S (2009) Fire ant control with entomopathogens in the USA. In: Hajek T, Glare T, O'Callaghan M (eds) Use of microbes for control and eradication of invasive arthropods, vol 6. Springer Netherlands, Dordrecht, pp 237-257

Russell-Smith J, Ryan PG, DuRieu R (1997) A LANDSATT MSS-derived fie history of Kakadu National Park, monsoonal northern Australia, 1980-1994: seasonal extent, frequency and patchiness. J Appl Ecol 35:829-846

Sandström A, Anderson M, Asp A, Bohman P, Edsman L, Engdahl F, Nyström P, Stenberg M, Hertonsson L, Vrålstad T, Granèli W (2014) Population collapses in introduced non-indigenous crayfish. Biol Invasions 16:1961-1977

Simberloff D, Gibbons L (2004) Now you see them, now you don't! - population crashes of established introduced species. Biol Invasions 6:161-172

Taylor C, Hastings A (2005) Allee effects in biological invasions. Ecol Lett 8:895-908
Valles S, Oi D, Yu F, Tan X, Buss E (2012) Metatranscriptomics and pyrosequencing facilitate discovery of potential viral natural enemies of the invasive Caribbean crazy ant, $\mathrm{Ny}$ landeria pubens. PloS one 7(2): 31828

Vogel V, Pederson J, Giraud T, Krieger M, Keller L (2010) The worldwide expansion of the Argentine ant. Divers Distrib 16:170-186

Wetterer JK (2006) The vanished plague ants (Hymenoptera: Formicidae) of $19^{\text {th }}$ century Bermuda. Myrmecol Nachr $8: 219-224$

Wetterer JK (2012) Worldwide spread of the African bigheaded ant, Pheidole megacephala (Hymenoptera: Formicidae). Myrmecol News 17:51-62

Young G, Bellis G, Brown G (2001) The crazy ant, Anoplolepis gracilipes (Smith) (Hymenoptera: Formicidae) in east Arnhem Land, Australia. Aust Entomol 28(3):97-104 